Final Report

FWHA/IN/JTRP-2006/36

\title{
FACTORS IN DEBRIS ACCUMULATION AT BRIDGE PIERS
}

\author{
By \\ Dennis A. Lyn \\ Professor of Civil Engineering \\ Thomas J. Cooper \\ Hydraulics Laboratory Coordinator \\ Charles A. Condon \\ Graduate Research Assistant \\ and \\ Lu Gan \\ Graduate Research Assistant \\ School of Civil Engineering \\ Purdue University \\ Joint Transportation Research Program \\ Project No: C-36-62P \\ File No: 9-8-16 \\ SPR-2959 \\ Conducted in Cooperation with the \\ Indiana Department of Transportation \\ and the U.S. Department of Transportation \\ Federal Highway Administration
}

The contents of this report reflect the views of the authors, who are responsible for the facts and the accuracy of the data presented herein. The contents do not necessarily reflect the official views or policies of the Indiana Department of Transportation or the Federal Highway Administration at the time of publication. The report does not constitute a standard, specification, or regulation.

Purdue University

West Lafayette, IN 47907

August 2007 


\section{TECHNICAL Summary}

INDOT Research

Technology Transfer and Project Implementation Information

\section{Factors in Debris Accumulation at Bridge Piers}

\section{Introduction}

Debris accumulation at bridge piers has been a significant problem at a number of bridge sites in Indiana, increasing risks of upstream flooding, scour, and stream instability. The current study aimed at identifying factors contributing to debris accumulation in order to formulate guidelines for the design of new bridges that would minimize their occurrence or impact. Three related approaches were taken: i) a systematic study of the available underwater bridge inspections reports, ii) a program of periodic visits and visual examination of bridge sites that were thought to be prone to debris accumulation, and iii) continued video monitoring of three bridge sites, and analysis of video images recorded during debris-transporting events.

\section{Findings}

Heavy debris accumulation was observed at $\approx 20 \%$ of these sites, with the heaviest accumulations being concentrated in southwestern Indiana. The great majority occurred as single-pier accumulations. In most cases, the spatial pattern of accumulation was quite repeatable, with the same pier being observed to suffer accumulation again and again, indicating that the accumulation process is not random, and is likely determined by specific local factors. The location of the thalweg at the crossing section was not particularly strongly correlated with the location of the heaviest accumulation. On the other hand, piers quite close to the banks at low stage were observed to have little or no accumulations. Smaller island or peninsula features immediately upstream of piers and lateral channel expansions are moderately associated with accumulations.

At larger bridge crossings with longer (> 100-ft) pier-to-pier spans, recurrence intervals for very heavy accumulations were longer than the study period of 18 months; in contrast, for shorter ( $<70$-ft) pier-to-pier spans, heavy accumulations could occur every year. Debris transport tends to be heaviest during the initial, e.g., first $12-18$ hours, rising part of the hydrograph. For long-duration events, with a large time-to-peak, the heaviest transport (and even accumulation) could occur well before the flow peak, such that relatively light or even negligible transport occurred near the flow peak or during the receding part of the hydrograph. Several observations of destabilization of accumulations were made, indicating that such events may be more frequent than might be otherwise thought. These could also explain the often observed short bursts of intense debris transport activity, termed clusters. The cylindrical pile debris deflectors were ineffective as debris countermeasures, and may have exacerbated the problem. There was insufficient information to evaluate thoroughly the performance of the commercial DebrisFree device.

\section{Implementation}

The main aim of the project was the development of guidelines that might help in the design of bridges so as to avoid or at least

minimize debris accumulations. The following summarizes the important points: 
- Pier-to-pier spans should certainly exceed Diehl's design log length $(\approx 80$ $\mathrm{ft}$ ), say should be greater than $100-\mathrm{ft}$, if practical.

- Unnecessary widening of the channel at the bridge crossing should be avoided.

- The following aspects of pier placement within the stream should be seriously considered:

- At locations without pronounced bar or island formation, piers should be placed close to the banks, say within 15-ft of the banks at low stage. The pier should be placed closer to the bank if otherwise it would be located in deep water at low stage.
- At locations without pronounced bar or island formation, if piers must be placed away from the banks, then one pier should be placed close to the outer bank (as in the previous item), and the others pier should be placed as far as practicable away from the outer bank, and towards the inner bank.

- In the presence of a bar or island or upstream confluence, more detailed studies may be required for specific recommendations. As a more tentative recommendation, localized high points (islands or peninsulas) as well as the region of the bar adjacent to the 'main' channel should be avoided.

\section{Contacts}

For more information:

Dennis A. Lyn

Principal Investigator

School of Civil Engineering

550 Stadium Mall Drive

Purdue University

West Lafayette, IN 47907-2051

Phone: (765) 494-9615

Fax: (765) 496-1988

E-mail: lyn@ecn.purdue.edu

\section{Indiana Department of Transportation}

Division of Research

1205 Montgomery Street

P.O. Box 2279

West Lafayette, IN 47906

Phone: (765) 463-1521

Fax: (765) 497-1665

\section{Purdue University}

Joint Transportation Research Program

School of Civil Engineering

West Lafayette, IN 47907-1284

Phone: (765) 494-9310

Fax: (765) 496-7996

E:mail: jtrp@ecn.purdue.edu 
TECHNICAL REPORT STANDARD TITLE PAGE

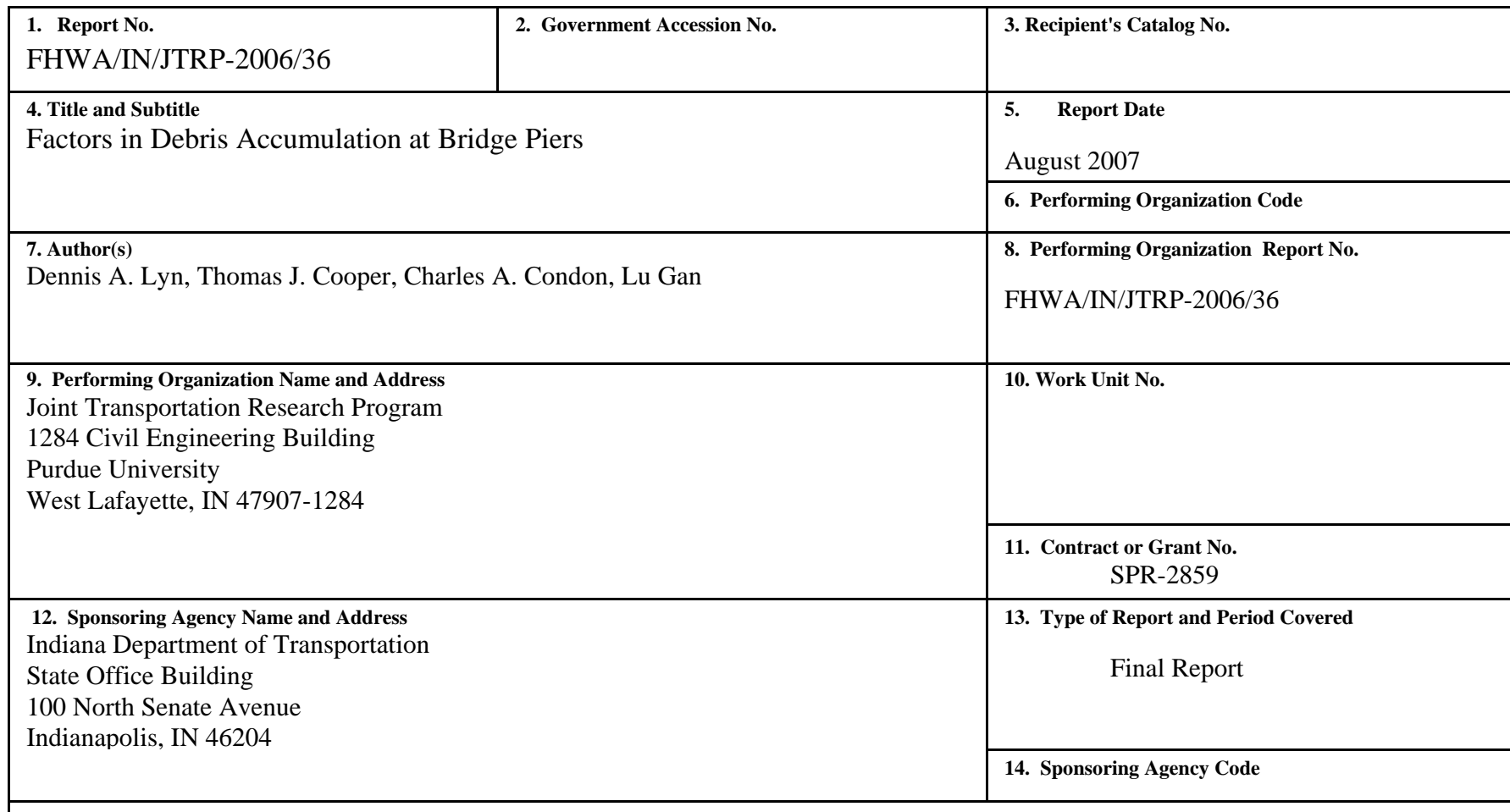

15. Supplementary Notes

Prepared in cooperation with the Indiana Department of Transportation and Federal Highway Administration.

\section{Abstract}

Debris accumulation at bridge piers has been a significant problem at a number of bridge sites in Indiana, increasing risks of upstream flooding, scour, and stream instability. The current study aimed at identifying factors contributing to debris accumulation in order to formulate guidelines for the design of new bridges that would minimize their occurrence or impact. Three related approaches were taken: i) a systematic study of the available underwater bridge inspections reports, ii) a program of periodic visits and visual examination of bridge sites that were thought to be prone to debris accumulation, and iii) continued video monitoring of three bridge sites, and analysis of video images recorded during debris-transporting events. The available underwater bridge inspection reports spanned a period of 10 years and covered 370 structures. Heavy debris accumulation was observed at $\approx 20 \%$ of these sites, with the heaviest accumulations being concentrated in southwestern Indiana. Almost all of the sites in south-central and southern Indiana experienced at least moderate debris accumulation at one time. Sites with estimated volume of debris accumulation greater than 1000 cubic yards ('mega' sites), sites where heavy debris accumulation was observed during more than one inspection ('chronic' sites), and sites with at most minor debris accumulation during more than one inspection ('lite' sites) were examined in greater detail with regards to their crosssectional geometry and the placement of the piers, and the specific location of debris accumulation. A program of periodic site inspections was undertaken that eventually covered 22 sites, including 4 'mega' sites and 6 'chronic' sites. The sites were visited at intervals of $3-4$ months over a 16-month period, and visually examined with regards to the occurrence and location of any debris accumulation, and other features, such as the presence of upstream bridges, that might be related to debris accumulation. These observations were combined with cross-section information from underwater bridge inspection reports to corroborate or refine the conclusions drawn from the broader study of underwater bridge inspection reports. Issues that could not be resolved from the bridge inspection reports, such as the behavior over time of debris accumulation, and the relationship to hydrologic events, were of particular interest in the periodic-site inspections. Although some sites suffered what might be classed as 'heavy' accumulation during the study period, no 'mega' accumulation occurred at any site, suggesting that average recurrence intervals for such events are more than 16 months, at least for larger rivers. Finally, video monitoring of debris-transporting events was conducted at three sites including one 'mega' site. This yielded the most detailed information regarding aspects that were visible above the water surface. This included including the variation of debris 'discharge' and amount of debris accumulated with time, typical debris trajectories, and even direct evidence of disaggregation of already accumulated debris. At two of the sites, extensive debris accumulations, possibly approaching 'mega' class at one site, were recorded. In contrast, little debris accumulation was noted at the third site in spite of quite heavy debris transport during at least one large flow event. For larger, longer-duration flow events, debris transport seemed to be concentrated towards the earlier rising part, such as the first 12 - 18 hours, of the event. Little correlation between the lateral location within the stream where debris transport is high and the thalweg in the immediate vicinity of the bridge crossing was found. On the basis of the observations made during the study, recommended practices are suggested for designing bridges with the aim of minimizing debris accumulation.

\begin{tabular}{|l|l}
\hline 17. Key Words & 18. Distribution Statement
\end{tabular}

bridges, hydraulics, piers, debris, scour

No restrictions. This document is available to the public through the National Technical Information Service, Springfield, VA 22161

\begin{tabular}{|c|c|c|c|}
\hline $\begin{array}{c}\text { 19. Security Classif. (of this report) } \\
\text { Unclassified }\end{array}$ & $\begin{array}{c}\text { 20. Security Classif. (of this page) } \\
\text { Unclassified }\end{array}$ & 21. No. of Pages & 104 \\
\hline
\end{tabular}




\section{TABLE OF CONTENTS}

1. INTRODUCTION AND REVIEW ................................................................................ 5

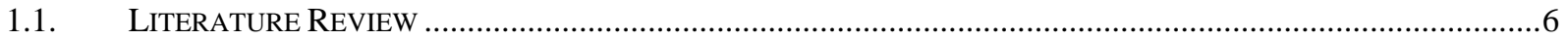

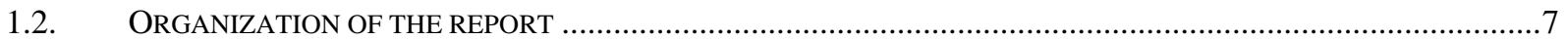

\section{CHARACTERISTICS OF DEBRIS ACCUMULATION REPORTED IN} UNDERWATER BRIDGE INSPECTION REPORTS......................................................... 8

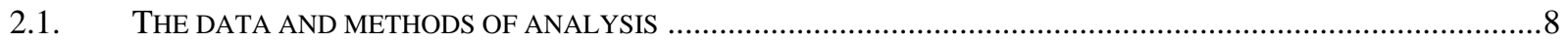

2.2. WHERE DO (OR DO NOT) HEAVY DEBRIS ACCUMULATIONS OCCUR? .......................................................10

Where do (or do not) heavy debris accumulations occur at the same time, and related issues? .......................14

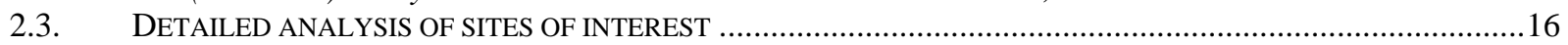

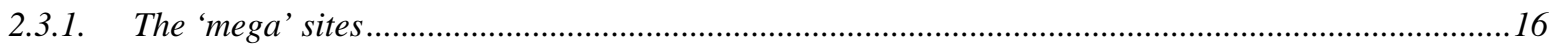

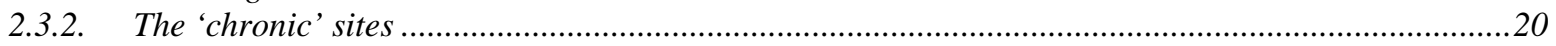

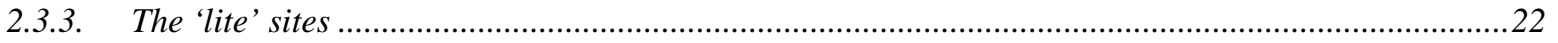

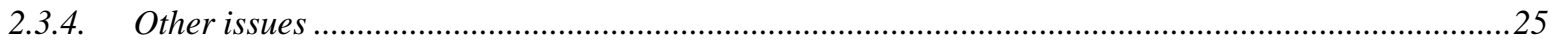

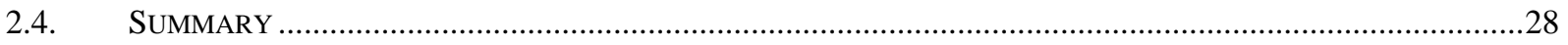

3. OBSERVATIONS FROM PERIODIC SITE VISITS ...................................................... 29

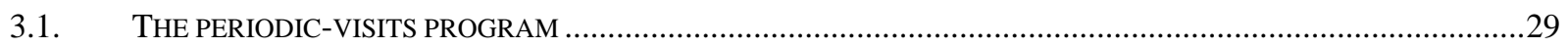

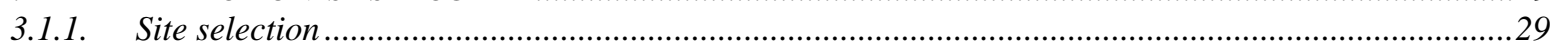

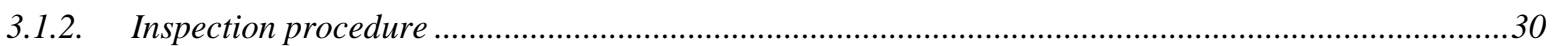

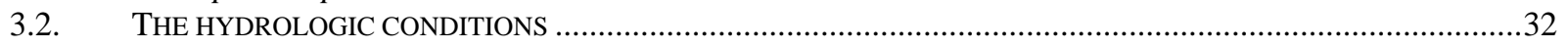

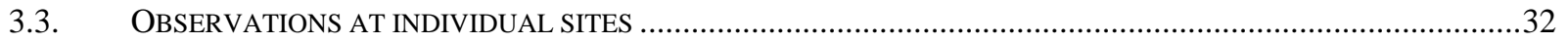

3.3.1. US50 - Wabash River near Vincennes ………............................................................................32

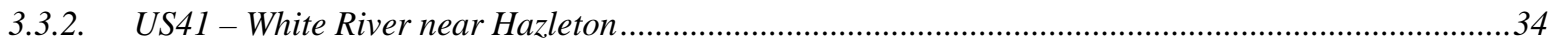

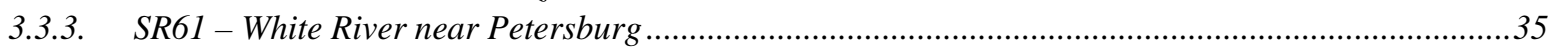

3.3.4. $\quad$ SR57 - E. Fork White River near Petersburg ………...........................................................................35

3.3.5. SR257 - E. Fork White River near Otwell/Iva .................................................................................36

3.3.6. US231(45) - E. Fork White River near Haysville...............................................................................37

3.3.7. SR164 - Patoka River near Jasper ………….................................................................................38

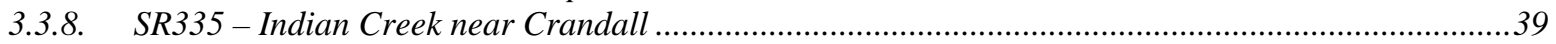

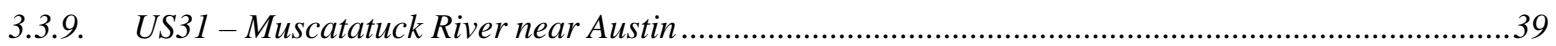

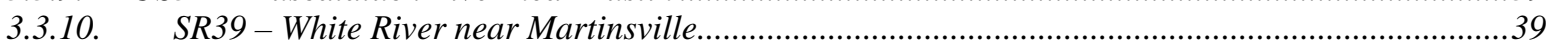

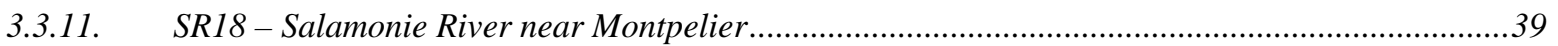

3.3.12. SR18WB - Mississinewa near Marion ………..............................................................................40

3.3.13. I469(24) - St. Mary's River near Fort Wayne ……….....................................................................41

3.3.14. US27 (Southbound) - St. Mary's River in Fort Wayne ...............................................................42

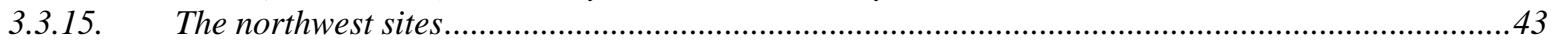

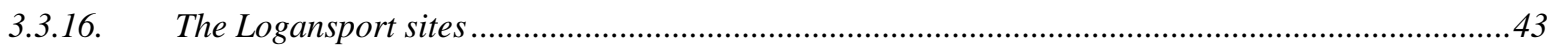

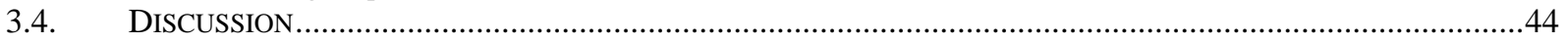

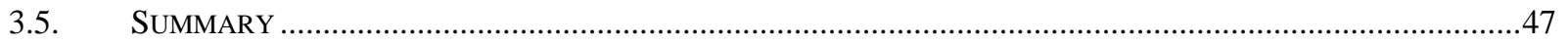

4. VIDEO MONITORING OF SELECTED BRIDGE SITES ...................................... 48

4.1. THE SR59 - EEL RIVER (SOUTH CROSSING) NEAR BRUNSWICK...........................................................48

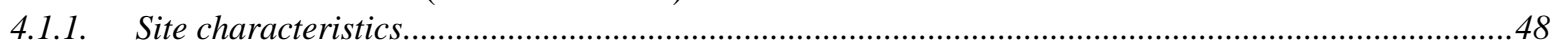

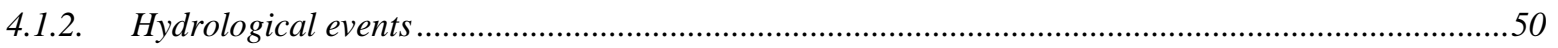

4.1.3. The video monitoring system .........................................................................................................

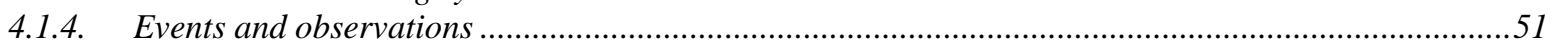

4.2. THE SR63 - VERMILLION RIVER (SOUTHBOUND) NEAR CAYUGA ……........................................................

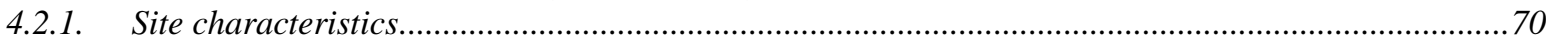

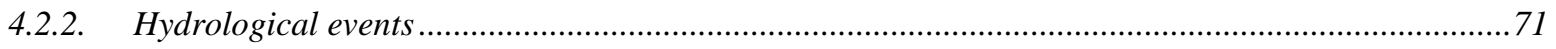

4.2.3. The video monitoring system ......................................................................................................72

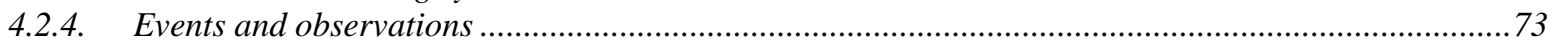




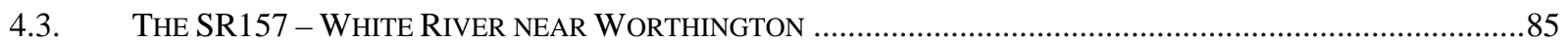

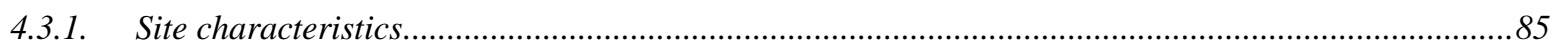

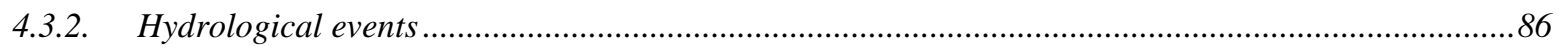

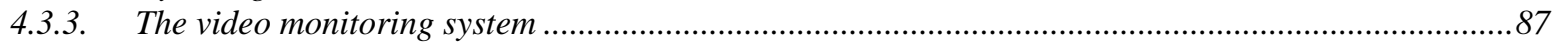

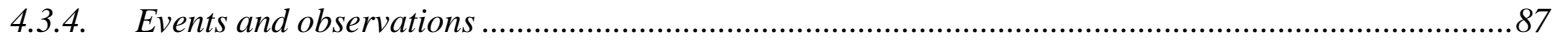

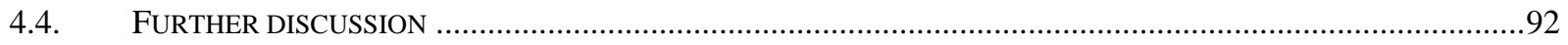

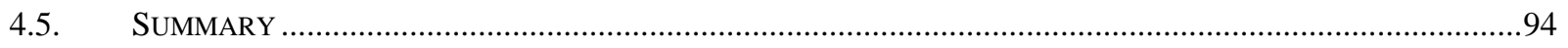

5. SUMMARY AND RECOMMENDATIONS FOR IMPLEMENTATIONS...................96

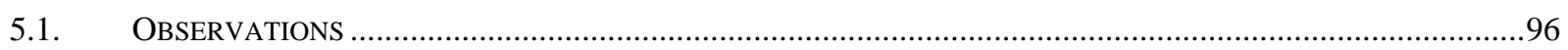

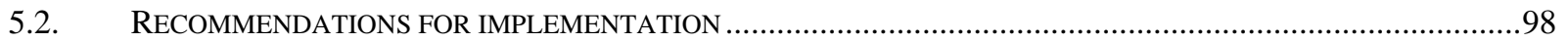

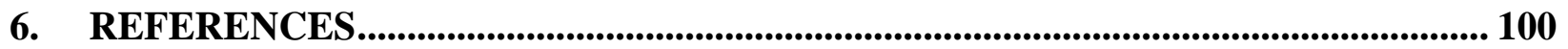




\section{Introduction and Review}

Large woody debris in river systems may cause problems at bridge sites. Early work by Brice et al. (1978) and Chang and Shen (1979), specifically on implications of large woody debris for bridge hydraulics and scour, have been updated by the more recent study of Diehl (1997) and Bradley et al. (2005; hereafter referred to as HEC-9). The problems caused or exacerbated by debris accumulation (DA) at a bridge site are varied. Due to an effective decrease in the bridge opening caused by the presence of DA, the potential for upstream flooding may be substantially increased. Both contraction and local scour around piers or abutments may also be aggravated, and bridge failures have been at least partially attributed to the presence of DA (see examples in HEC-9, Chap. 2).

At several bridge sites in the state of Indiana, DA has been a recurring problem, requiring almost annual expenditure for removal, and prompting the installation of specific DA countermeasures (e.g., Fig. 1.1). Both Diehl (1997) and HEC-9 contain references to Indiana sites or experiences with DA. In a previous study funded by the Indiana Joint Transportation Research Program, Lyn et al. (2003) performed laboratory experiments under idealized conditions, and undertook continuous field observations at two sites through video monitoring. An acknowledged limitation of the previous study was the small sample size (two sites), which might not be representative of even those sites that are especially prone to DA. This motivated the present work, which dealt solely with field observations, but at a notably larger number of sites.

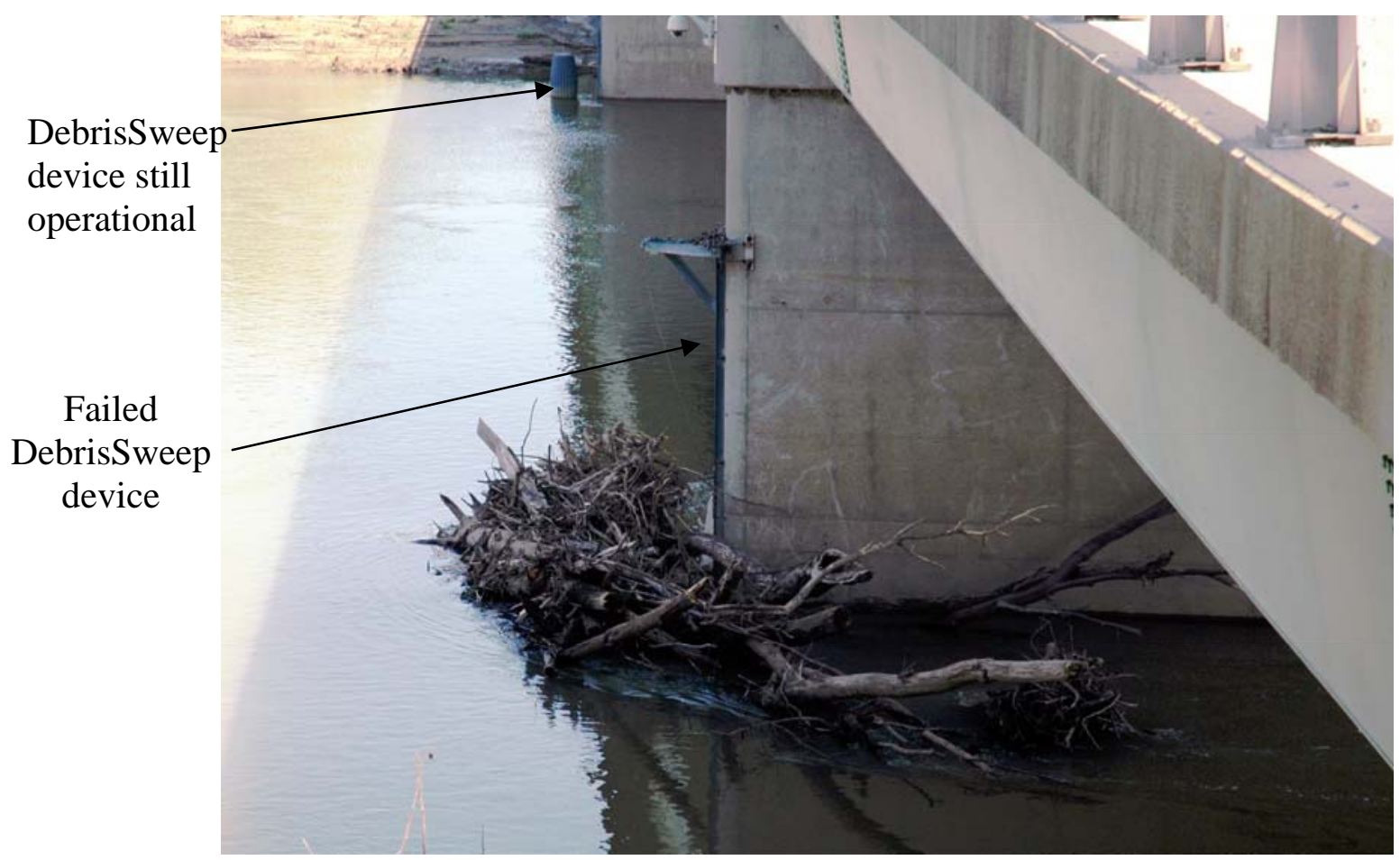

Figure 1.1: Debris accumulation at SR 157 near Worthington, where DebrisSweep devices had been installed

Like the previous work of Lyn et al. (2003), the present study was aimed at better understanding the factors contributing to, and the conditions associated with, DA, with the objective of 
providing practical guidance in avoiding potential DA problems at new bridges, and possibly mitigating such problems at existing bridges. At the start and for most of the duration of the project, the latest edition of HEC-9 had not yet been published. HEC-9, the Federal Highway Administration (FHWA) 'manual' on debris control structures, has broadly the same objective, though takes a much broader perspective, for example, dealing at length with culverts. The present work also differs from HEC-9 in its focus on original research, with collection of new data, whereas HEC-9 synthesizes current knowledge and evaluates current practices.

A three-tiered approach is used in the current study, with successive tiers decreasing in sample size, but increasing in detail. In the first tier, the results of underwater bridge inspection performed by Collins Engineers for INDOT were examined for evidence and characteristics of DA. These results covered over 300 bridge crossings, and were carried out in the period 1993 2003. At any particular site, reports were available for at most three inspections, in most cases for only two inspections, and a sizeable fraction for only one inspection. In the next tier, an attempt was made to obtain more frequent information by a program of periodic (roughly every 3 - 4 months) site visits, eventually to include more than 20 sites. During the visit, the extent to which there was any DA present was determined visually, and notable features, such as extent and location, of any accumulation were recorded. The last tier consists of a continuation of the video monitoring/recording that was started in the previous study (Lyn et al., 2003). This was performed at three sites. The equipment at the SR59 south crossing of the Eel River near Brunswick and at the SR63 crossing of the Vermillion River near Cayuga was already installed during the previous study though results were only available at that time for the Eel River site. A new site, the SR157 crossing of the White River near Worthington was added. The continuous video monitoring provided the most detailed information regarding debris transport and accumulation, but only at the three stations, which were not necessarily representative of Indiana conditions. The three-tiered approach was aimed at providing a stronger statistical basis for recommendations by securing a broad representative sample of bridge sites, while retaining the very detailed information available at only a few sites.

\subsection{Literature Review}

The major original work on the topic of DA at bridge crossings remains the work of Diehl (1997). It included analysis of data from over 2500 reported DA, and field investigations of over 100 DA. The concept of a design log length was introduced and was defined as the length 'above which logs are insufficiently abundant ... to produce drift accumulations equal to their length'. This length would provide a criterion for determining the length of a bridge span, or an estimate of the potential size of a DA. Diehl suggested that further research is needed in five main areas:

1. “compilation of existing data from maintenance engineers, bridge files, and damage reports to identify drift-laden rivers and drift-prone bridges,

2. detailed three-dimensional measurements of drift accumulations and associate scour in flood conditions,

3. definition of channel types in which drift delivery is low even in floods,

4. refinement of maximum sturdy-log length estimates to reflect regional conditions, and

5. identification of spans shorter than the design log length that nonetheless have low potential for drift accumulation.” 
The current study had the first issue as one of its main objectives, but, where possible, will try to shed light on the other issues.

In a previous study, Lyn et al. (2003) reported on both laboratory and field studies. In the latter, the first results from video monitoring, mainly from a single site (the Eel River site), were examined, yielding qualitative conclusions regarding the occurrence of DA, some in agreement with but some at variance with or not noted in the literature.

The major publication relating to DA since the previous study is Bradley et al. (2005) or HEC-9. As noted above, it is a synthesis work and does not present new results. In its discussion of DA at bridges, and particularly the issues relevant to the current work, it relies heavily on Diehl (1997) as well as the earlier Diehl and Bryant (1993). It attempts to give guidance in dealing with DA, but carefully states in chapter 3 on estimating debris quantities, "caution and familiarity with the regional characteristics of the local stream morphology and debris loading characteristics should be used when applying this information." This emphasizes the need for the current project.

\subsection{Organization of the report}

The three-tiered approach taken in the study is reflected in the organization of the report. Chapter 2 describes with the use and analysis of underwater bridge inspection reports for information relating to DA. The results of the analysis influenced to some extent the choice of the bridge sites included in the sample for the periodic site visits, the subject of discussion of Chapter 3. The continuous video monitoring at the three sites will be taken up in Chapter 4 . Chapter 5 summarizes the findings of the study, and includes recommendations for implementation. 


\section{Characteristics of debris accumulation reported in under- water bridge inspection reports}

Underwater bridge inspections are mandated to be performed regularly for bridges satisfying certain criteria. At INDOT (according to Bill Dittrich, INDOT Bridge Inspection Group), a list of such bridge crossings was compiled, based on the observation that at least one of the following conditions prevails all year round:

1. The water is too deep to enter around the substructure units (usually more than 3 feet deep).

2. The current is too fast to safely inspect in the water around the substructure units.

3. The water is too polluted to safely enter the water without adequate safety coverings.

4. The channel bottom material is too soft and an inspector would sink into muck and get stuck.

The list may change, with bridge crossings added or deleted depending on the judgment of the INDOT bridge inspection group.

The first two conditions also tend to characterize streams that will readily transport large woody debris. The underwater inspection reports, available in searchable electronic form on compact discs, therefore constitute a valuable, if in some respects limited, data source regarding DA in Indiana streams. In addition to the large number of bridge crossings for which data are available, a particular strength of the reports lies in the possibility of identifying cases where DA may be partially or wholly submerged. The purely visual examination performed during periodic site visits and in video monitoring is limited to what can be observed on the water surface. On the other hand, a weakness in the reports for studying DA stems from the very limited number of samples in time. Thus, if the inspection happens to be performed at a time when the crossing is relatively free of debris, then this could very well be misleading. Indeed, at one of the sites (SR63) chosen for continuous video monitoring, heavy or very heavy DA occurs almost annually, but the available inspection reports indicated that only light to moderate DA was observed. If heavy DA is observed at a site in an inspection report, it may be expected that the potential for heavy DA occurring in any given year is fairly high; if heavy DA is not observed, an equally strong statement regarding the low potential for heavy DA cannot be made.

\subsection{The data and methods of analysis}

The reports cover 370 individual structures, each with an individual National Bridge Inventory (NBI) number. The earliest reports date back to 1993, while the most recent available were completed in 2003. Of these, 145 (39\%) were inspected only once, 219 (59\%) were inspected twice, and $6(<2 \%)$ were inspected three times. In Figure 2.1, the spatial distribution of the sites (only 354 in total since some of the sites were not present in the GIS database), according to the number of inspection reports available, is shown, together with the larger rivers and watersheds. The sites are reasonably uniformly distributed, though there is some concentration in the northeast and in the southwest, and possibly some overrepresentation of smaller streams. A double bridge at a single geographical site is considered to have two distinct structures.

The report for each structure provides some bathymetric information, as two channel sections upstream, two channel sections downstream, as well as three sections at the bridges are 
sounded. From these data, a thalweg is also sometimes sketched, but, given the sparsity of the data on which it is based, how meaningful this thalweg is, may be questioned. Comparisons with previous bathymetric data also provide an indication of whether the channel is aggrading or degrading. Detailed hydrological information such as average annual discharge, bank-full width and depth, is however not given. Bridge structure information includes span lengths and whether the substructure consists of piers or bents. Some description of the banks and the bed material in the vicinity of the bridge is given, and the location and extent of DA are also indicated. In most cases, the description of the DA is qualitative, e.g., light or moderate or heavy, and it is not clear that same description (or recommendation for action with regards to debris) is applied consistently between different inspectors. In cases of heavy DA, estimates of the total volume of $\mathrm{DA}$, as the basis of the cost of removal, are also given in many cases.

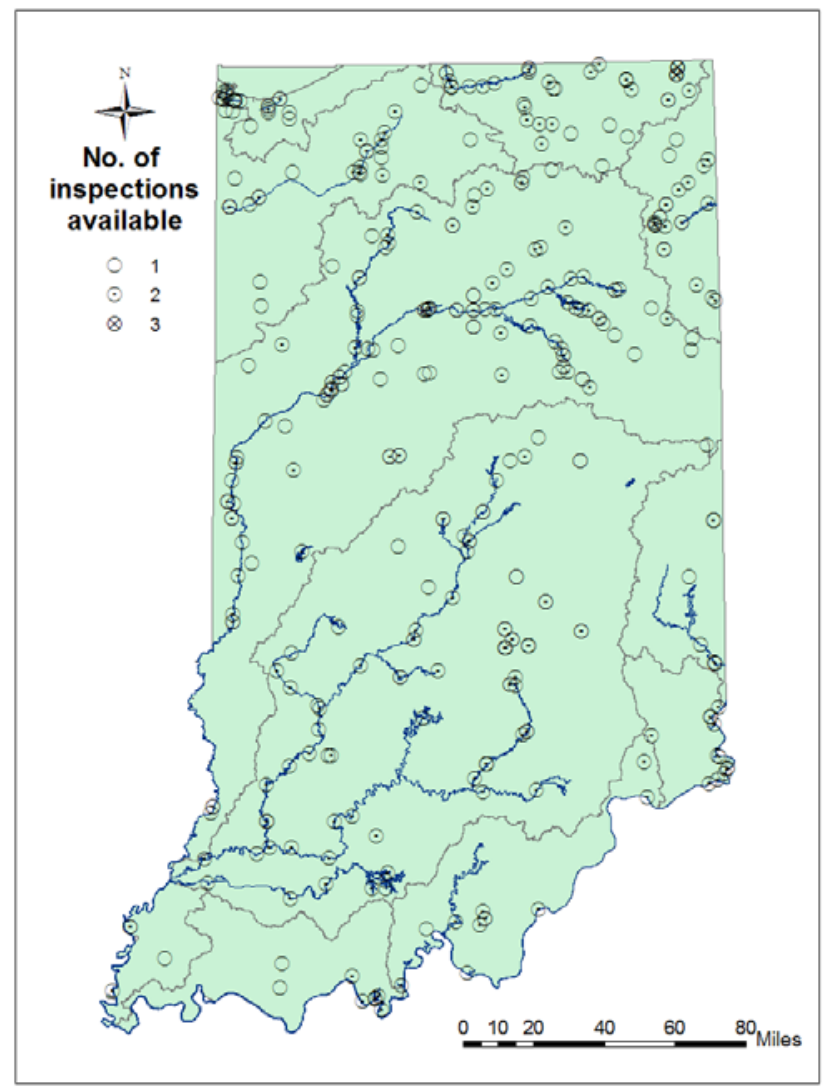

Figure 2.1 Sites with underwater inspection reports available together with larger rivers and watersheds

A Microsoft Access database was developed from information extracted from the inspection reports. It included

1. basic identification data, such as NBI number, and names of the route, the stream, and the nearest town, inspection data,

2. inspection data, such as the number of inspections and the year last inspected,

3. structure data, such as bridge span (the longest in region over stream, if not constant),

4. stream data, such as channel widths upstream and at bridge, and

5. debris accumulation data, such as degree and location of accumulation. 
In addition, the Access database was combined with GIS (geographical information systems) databases, facilitating graphical representations and spatial analyses. It is noted that information from some sites was lost because not all sites in the Access database were also present in the GIS database. Whereas a total of 370 structures are represented in the Access database, only 354 remained when this was combined with GIS database. For the purposes of this study, which focuses on those sites with heavy DA, the loss is not important because only one site with heavy DA was lost.

\subsection{Where do (or do not) heavy debris accumulations occur?}

An assessment of the factors contributing to DA might begin with the question, where have heavy DA been observed to occur in the past? Conversely, it may also be worthwhile to consider sites where minor or no accumulation has been observed. In the following, a term such as 'heavy' or 'moderate' or 'minor' generally is applied where the same or similar term is used in the inspection report. Heavy DA, so defined, was observed at a total of 74 structures, i.e., $\approx$ $20 \%$ of the total number examined, during at least one of the inspections available. In this heavy DA group, one inspection report was available for 17 structures, two reports for 56 structures, and three reports for only 1 structure. In most though not all heavy DA cases, an estimate of the volume of DA observed during the inspection was given, as the basis for a cost estimate for debris removal. Also, in most cases, the volume reported is due wholly or in large part to an accumulation at a single pier. It should be said that a definition of heavy DA solely in terms of volume may not be the most relevant in engineering practice. A volume of 50 cubic yards in a small stream with scour-critical structures may be of much greater concern than the same volume in a larger river with secure structures.

Sites (or structures) where heavy DA has been reported at least once are shown in Figure 2.2, grouped according to the estimated volume of DA in cubic yards. Those cases, 18 in number, where a volume estimate was not reported in either the sole or both inspection report(s) available, are also indicated. It is probable that the volumes associated with these are less than 100 cubic yards. Sites where a 'moderate' accumulation has been observed once are also plotted. The (statistical) distribution according to INDOT districts is also shown in Figure 2.3. Not surprisingly, the large majority of the sites are located in the two main watersheds in Indiana, the Wabash River and the White-Patoka River basins. Out of a total of seventy-two (72) sites shown in Figure 2.2, twenty-three (23) and twenty-seven (27) sites are found respectively in the Wabash River basin north of the confluence with the White River, and in the White River Patoka River basin. Relative to their size, the Western Lake Erie basin with eight and the Lower Ohio - Salt Creek basin with four also contains a significant number of sites. The White River basin seems especially prone to the largest accumulations with four of the six largest observed DA (volume > 1000 cubic yards), including the largest. In contrast, the Wabash River basin, approximately equal in area, had only one such 'mega' site; the only other 'mega' site being located in the much smaller Lower Ohio-Salt Creek basin.

It might be hypothesized that the largest DA can only develop in the downstream reaches of a river on the grounds that a sufficiently large contributing area is needed as a debris source. Most of the sites with the largest DA are indeed in the downstream reaches of the Wabash or the White Rivers, relatively far from the headwaters. It should be noted that the river GIS database from which Figure 2.2 has been developed is not complete; the headwaters of neither the Wabash nor the White Rivers appear, to say nothing of the headwaters of the Mississinewa, Salamonie, 
St. Mary's, Flatrock, and other smaller rivers. Also some of the northeastern rivers (including the Wabash) begin in Ohio, and the Wabash actually drains a part of Illinois. Large DA's have been observed towards the (Indiana) outlets of the Kankakee, Maumee, and Whitewater Rivers.

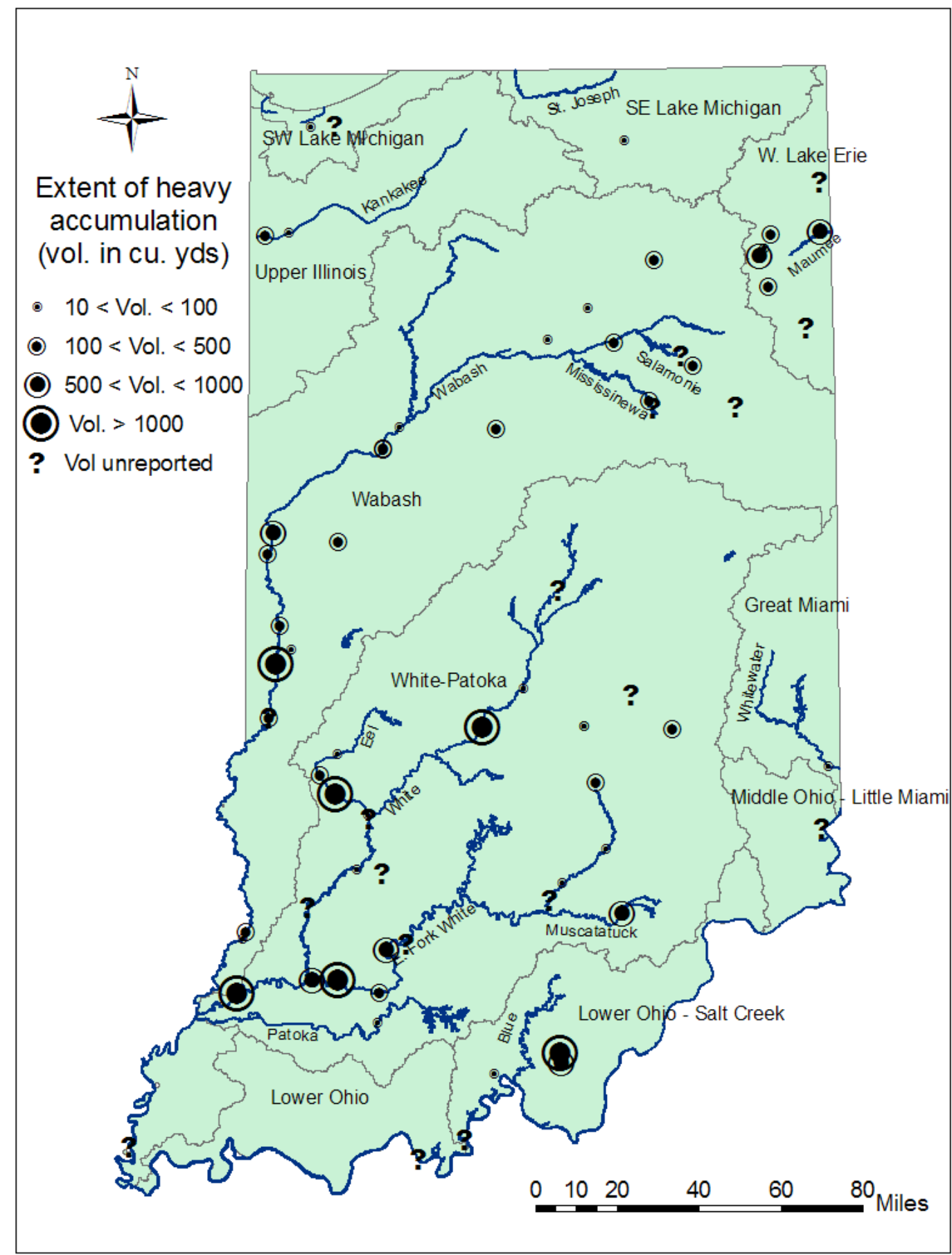

Figure 2.2: Sites where heavy accumulation was observed during at least one of the two inspection reports available (heavy accumulation sites grouped according to estimated volumes in cubic yards) 


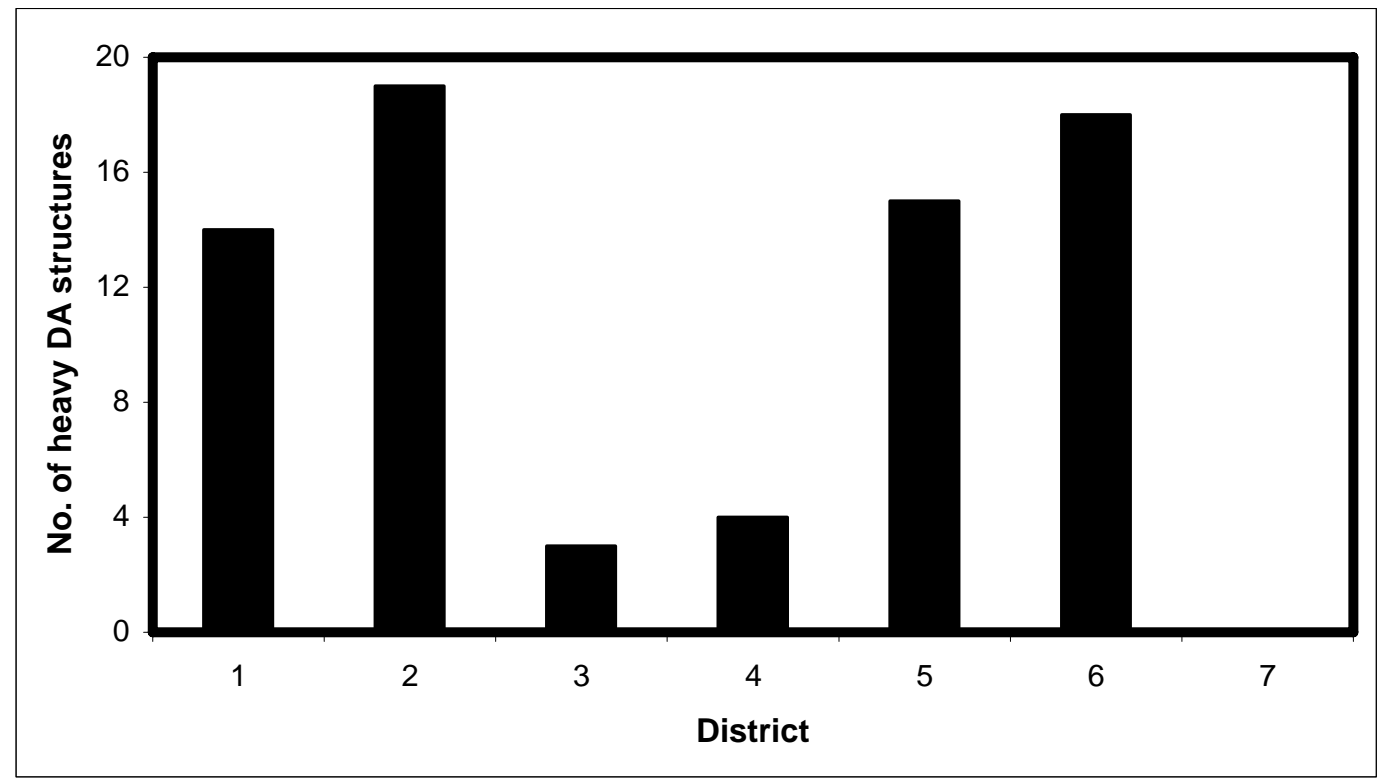

Figure 2.3: Distribution of structures with heavy DA among the INDOT districts

The data in Figure 2.2 however also suggest that a very large DA can develop within a relatively small area. One of the largest DA was reported at the SR335 - Indian Creek site, with a drainage area that is two orders of magnitude smaller than some of the other 'mega' sites, testifying to the ability of relatively small areas to mobilize large quantities of debris. Several other sites, including the nearby I64 - Indian Creek site and the US31 - Muscatatuck River site, have also produced very large if not the largest DA from relatively small areas. In addition, even with the larger rivers, two of the 'mega' sites, one on the Wabash, and the other on the White, while certainly located well downstream of the headwaters, are also well upstream of their outlets. The trend for increasing probability of the largest DA with increasing downstream distance does not amount to a general rule.

The hypothesis that large DA's occur towards the downstream end of a stream does not entirely explain the pattern of spatial distribution of large and very large DA's seen in Figure 2.2. This hypothesis would suggest that the size of DA's should generally increase in the downstream direction, and so the largest DA's would naturally be observed at sites closest to the river outlets. What is seen in Figure 2.2 is however different. Most of the 'mega' sites are followed downstream by sites where DA's have been observed to be at most very large or merely large or even only moderate. The largest volume of DA so far observed on the Wabash occurred certainly well downstream of the headwaters, but also well upstream of the outlet at the Ohio River. This Wabash mega-site is followed downstream by DA sites where however the maximum accumulations though still heavy are substantially smaller in volume. A similar pattern is also noted in the (southern and northern) Eel Rivers, the White River, and the East Fork of the White River. The limitations of sparse data from bridge inspection reports should however be kept in mind in the above discussion.

The above has focused on sites where at least moderate DA has been reported. To determine the factors contributing to DA, it may also be worthwhile to consider sites where minor or no DA was observed, since these may have attributes that help to minimize DA. The sites of interest are those for which two or more inspection reports are available, which all indicate that 


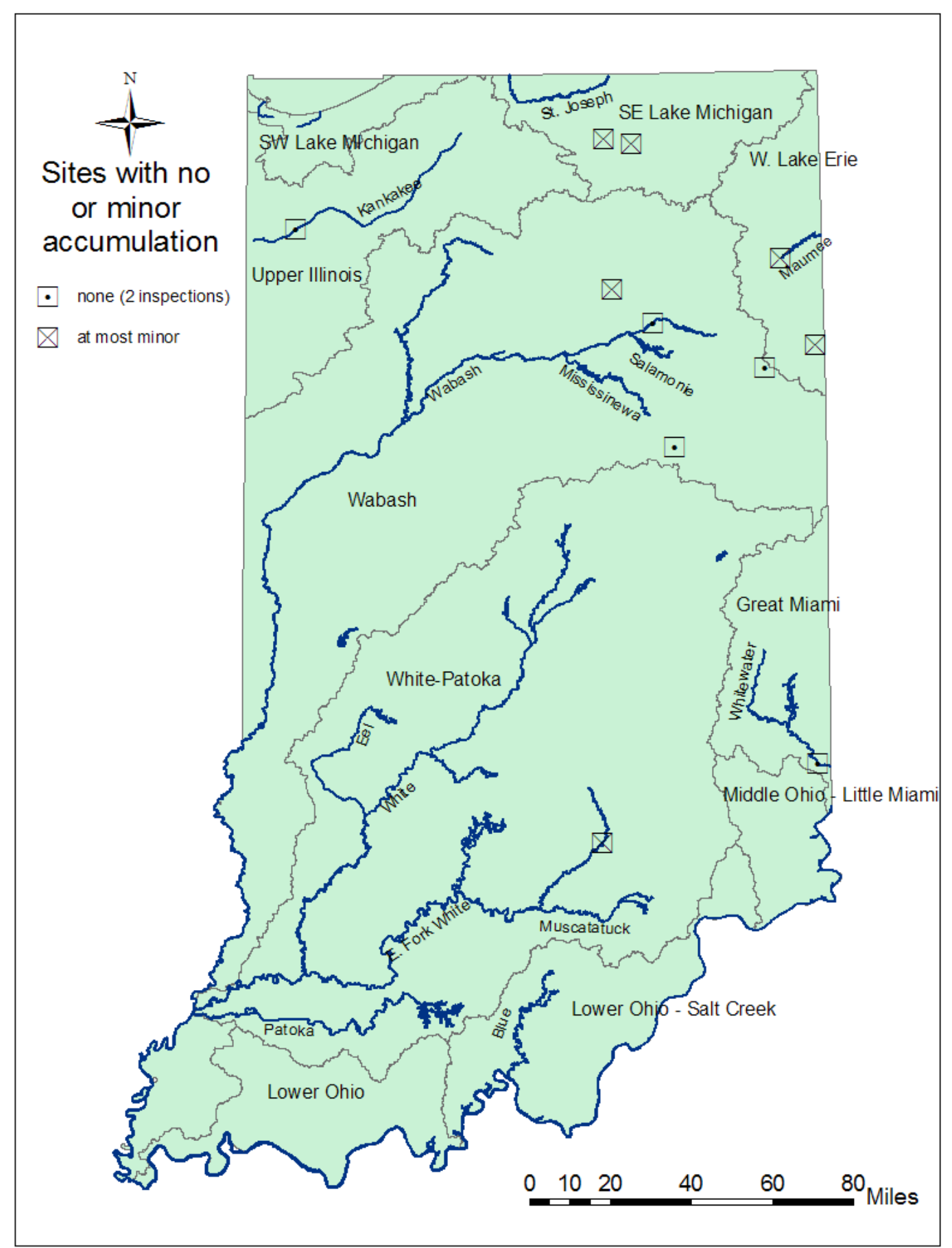

Figure 2.4: Bridge crossings with at least two inspection reports available and where either no or only minor debris accumulation was reported in all available reports

only minor or no DA was present. Further restrictions were that the sites should be distinct (not just different structures), and situated on streams that have had heavy DA reported at some point along their length. Sites just downstream of or over dams, lakes, or reservoirs, are generally free of debris, and have been excluded because they form a rather special case. With these exclusions, the remaining sites, shown in Figure 2.4, are quite few; most sites have experienced at least moderate or heavier DA, according to the available bridge reports. As might be expected from 
the discussion of sites with heavy DA, just as there is a preponderance of heavy DA sites towards southwestern Indiana, there is a preponderance of 'lite' DA sites towards northeastern (or more generally northern) Indiana. This likely reflects the northeast - southwest flow direction of the major rivers, such that the corresponding watersheds (and 'debris' sheds) drains to the southwest. The fact that minor or no DA was found on two or more inspections does not necessarily imply a site will never experience a heavy DA event. As such, in any particular case, a site identified in Figure 2.4 may simply be a statistical outlier, though the general trend of a larger proportion of 'light' DA sites in northern Indiana does likely reflect reality.

Downstream of Andrews (near Huntingdon), all crossings of the Wabash River have experienced at least moderate DA. The White River and its main tributaries are devoid of 'light' DA sites, with the interesting exception of Rockford in the upper reaches of the East Fork White River. The only other 'lite' site in Southern Indiana is found near New Trenton on the Whitewater River. Some of the 'lite' DA sites in northern Indiana are situated downstream or upstream of heavy DA sites, e.g., on the Eel, Kankakee, and the Maumee Rivers.

\section{Where do (or do not) heavy debris accumulations occur at the same time, and related issues?}

The previous section dealt primarily with the location of heavy DA sites, regardless of the time (year) that the inspection took place. Figure 2.2 (and to a lesser extent, Figure 2.4) is limited or even misleading in that the patterns seen do not occur at any one time. As a consequence, relationship between nearby sites at any given time instant cannot be determined from Figure 2.2. For example, it is not clear that the three sites on the East Fork White River just upstream of the confluence with the White River are necessarily related in having developed over the same period of time, or alternatively were observed at widely separated times. For the purposes of identifying such relationships at different sites, information at all sites at the same time should ideally be available, and all sites should at some initial time be free of all debris. What is available in the inspection reports is information at a large but still limited number of sites gathered over a span of a year (in actuality somewhat less) and it is not known whether, even for those sites that were inspected, such sites started from a common state. As such, the interpretation of the following, which is drawn from the inspection reports, must be cautious.

The four years with the largest number of available reports are 1994, 1997, 2002, and 2003. The results with regards to DA for those years, grouped according to the degree of DA observed, are plotted in Figure 2.5. As in previous figures, the sites shown are restricted to be on streams with at least one heavy DA observed, and to be not immediately downstream of a reservoir. As might be expected, there is evidence that the presence of heavy DA at neighboring sites is strongly correlated. The three sites on the East Fork of the White River just upstream of the confluence with the White River all had heavy DA in the 2002 results. Similarly, in the 1997 results, heavy DA was observed at three sites on the Wabash River at or just upstream of Terre Haute. The limitations of the data are also evident, in that some of the nearby sites were not inspected in a given year. Such a strong correlation may indicate the relatively weak role played by local features, the effects of which are overwhelmed by the debris stream. As a result, all sites in the region experience heavy DA. On the other hand, sites in the same general area will likely share common features, so that if this set of features is conducive to DA, then it should not be surprising that these sites will all experience DA. 


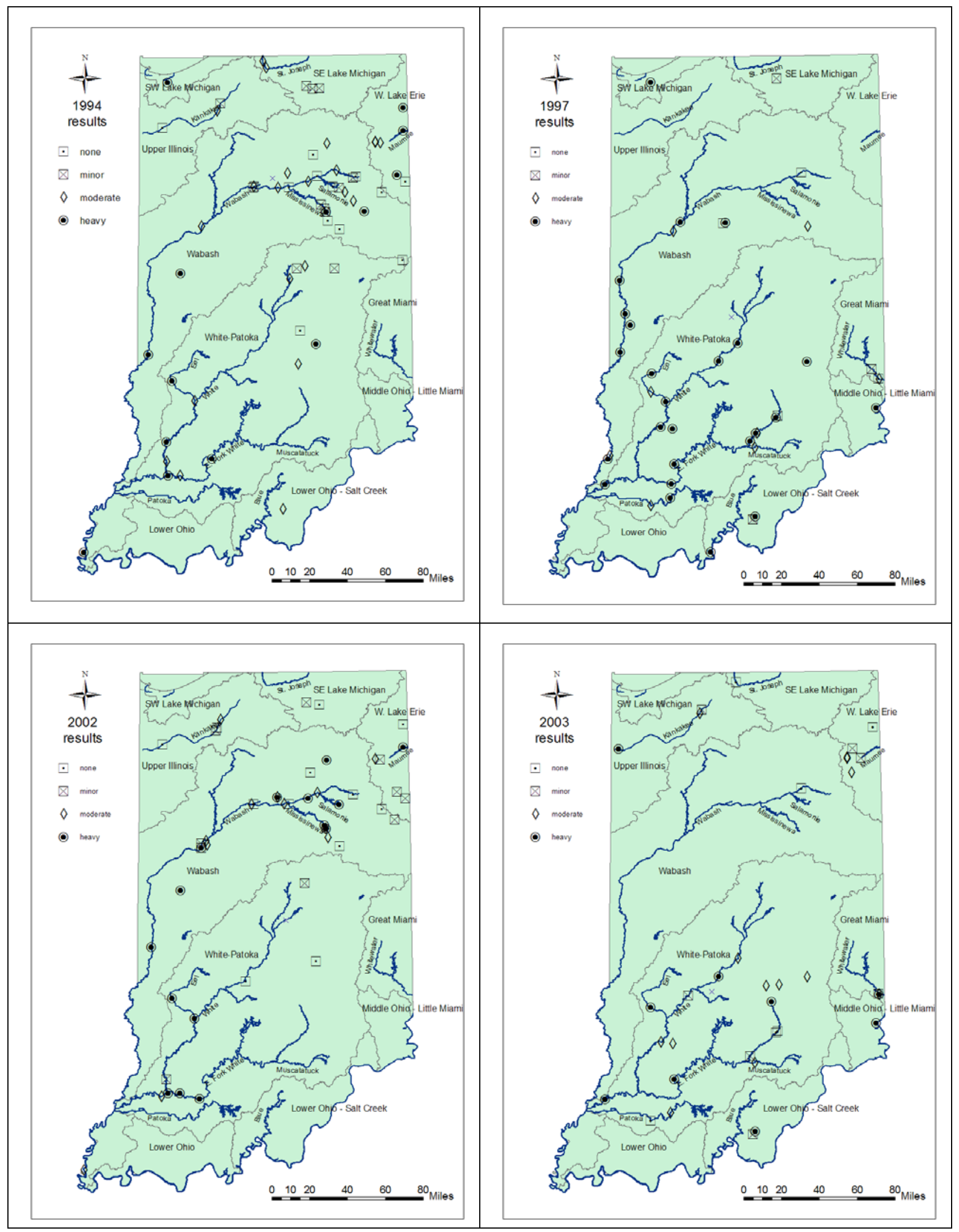

Figure 2.5: Results on DA obtained from bridge inspection reports performed in specific years 


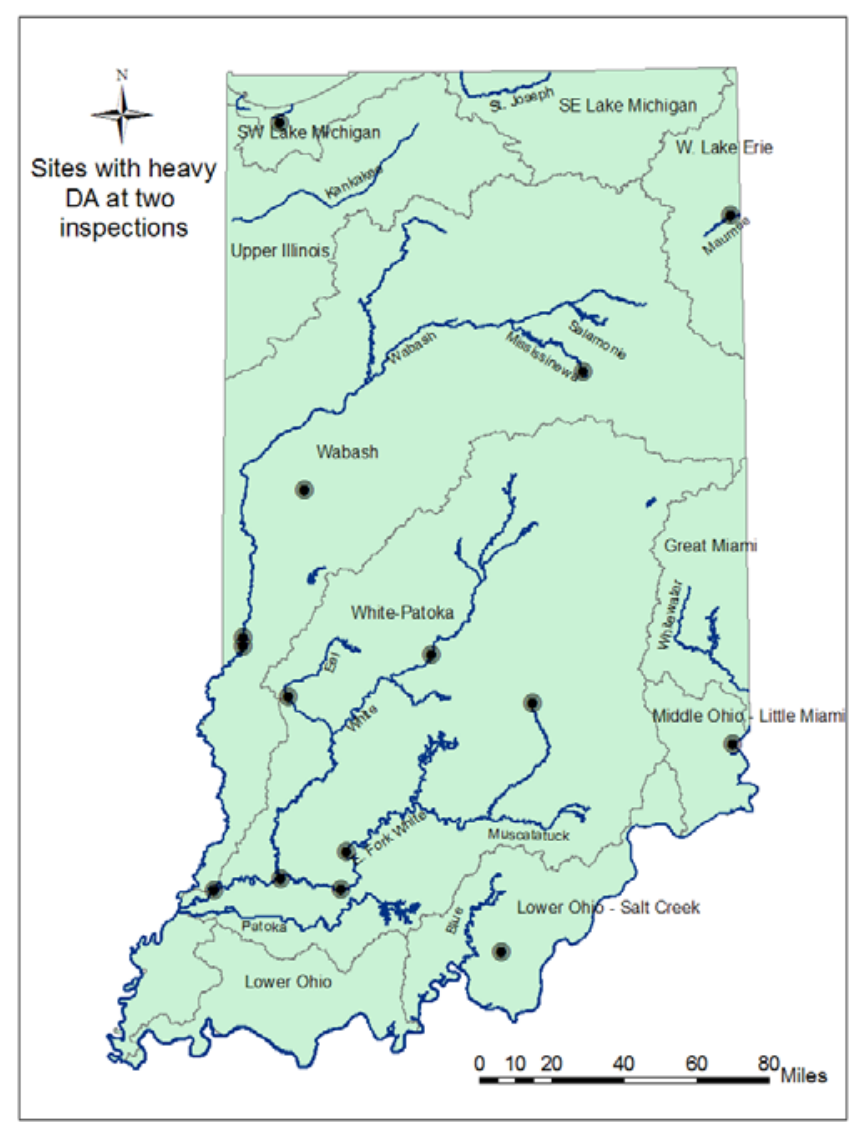

Figure 2.6: Locations of sites where the two available bridge inspection reports, typically done $\approx 6$ years apart, recorded heavy debris accumulation

\subsection{Detailed analysis of sites of interest}

The preceding sections have dealt primarily with the location of heavy DA sites, but also have identified various sites that might be worthy of more detailed examination. These include the 'mega' sites, where the largest DA (in terms of volume) have been reported, and the 'chronic' sites, where heavy DA was observed during the two inspections for which reports are available (Figure 2.6). Sites with minor or no DA are also of interest if they are situated on or near river reaches where heavy DA has been elsewhere observed. The aim of the examination would be to identify features or characteristics of the site that might be especially conducive (or from the opposite perspective, especially ) to the development of DA.

\subsubsection{The 'mega' sites}

Satellite photographs of the six 'mega' sites are shown in Figure 2.7, and the general configuration of the bridge piers relative to the bridge cross-section and the location and extent of the DA (at its maximum) from a perspective looking downstream are shown in Figure 2.8. The satellite photographs indicate a range of plan-form channel characteristics. In the vicinity of the sites, the White River, the East Fork White River, and Indian Creek exhibit significant meanders. On the other hand, the Eel River reach is relatively straight, and the Wabash River reach is somewhat intermediate. The question of scale does arise in that, on a larger scale, the Eel River would likely exhibit a higher degree of meandering. With the possible exception of the Indian 


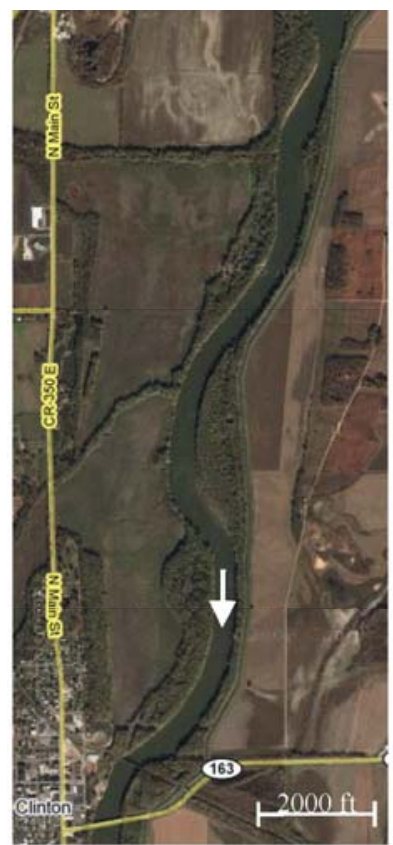

a)

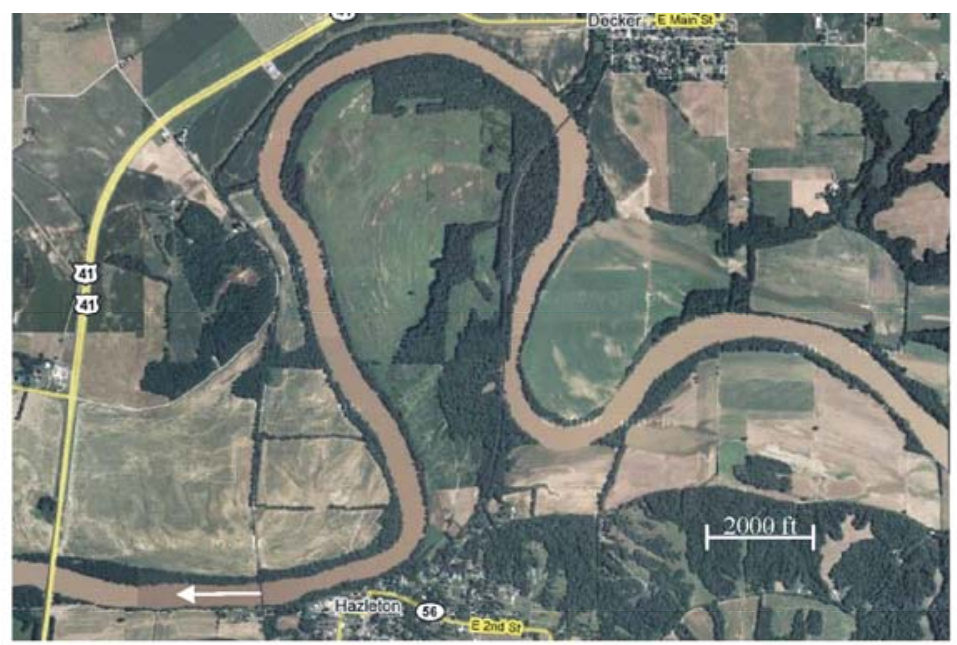

d)

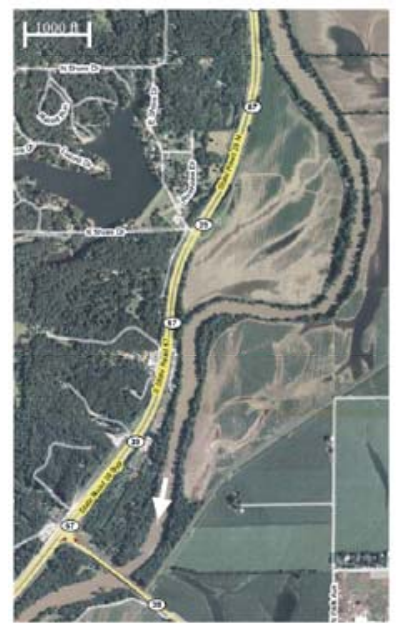

b)

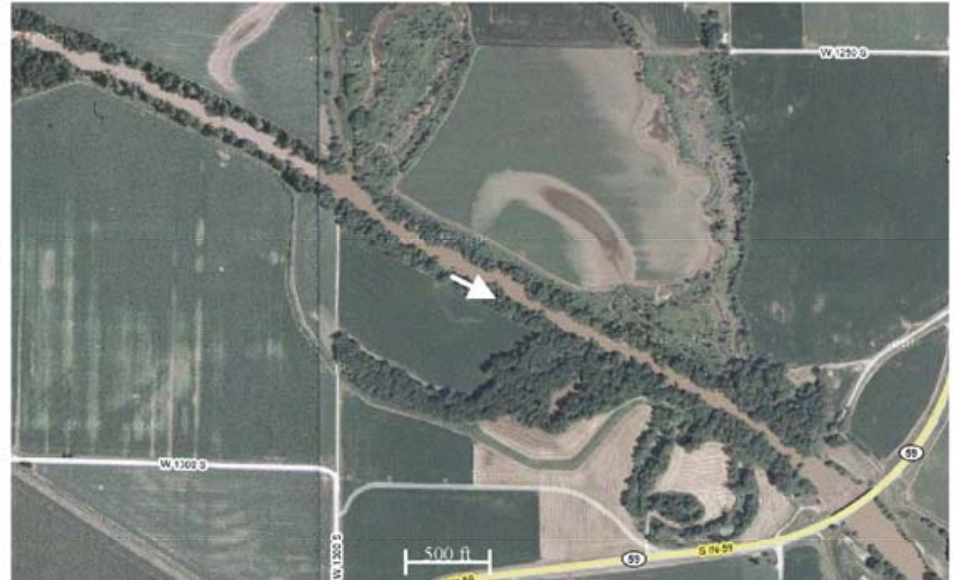

e)

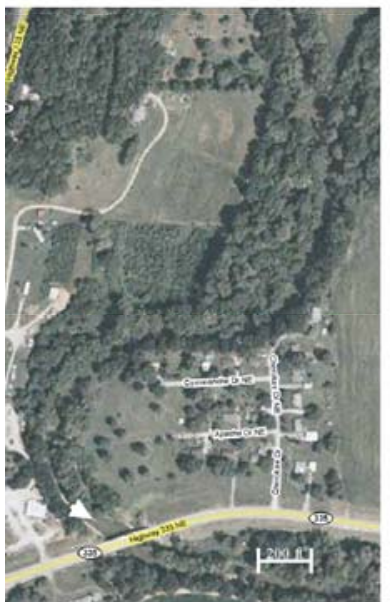

c)

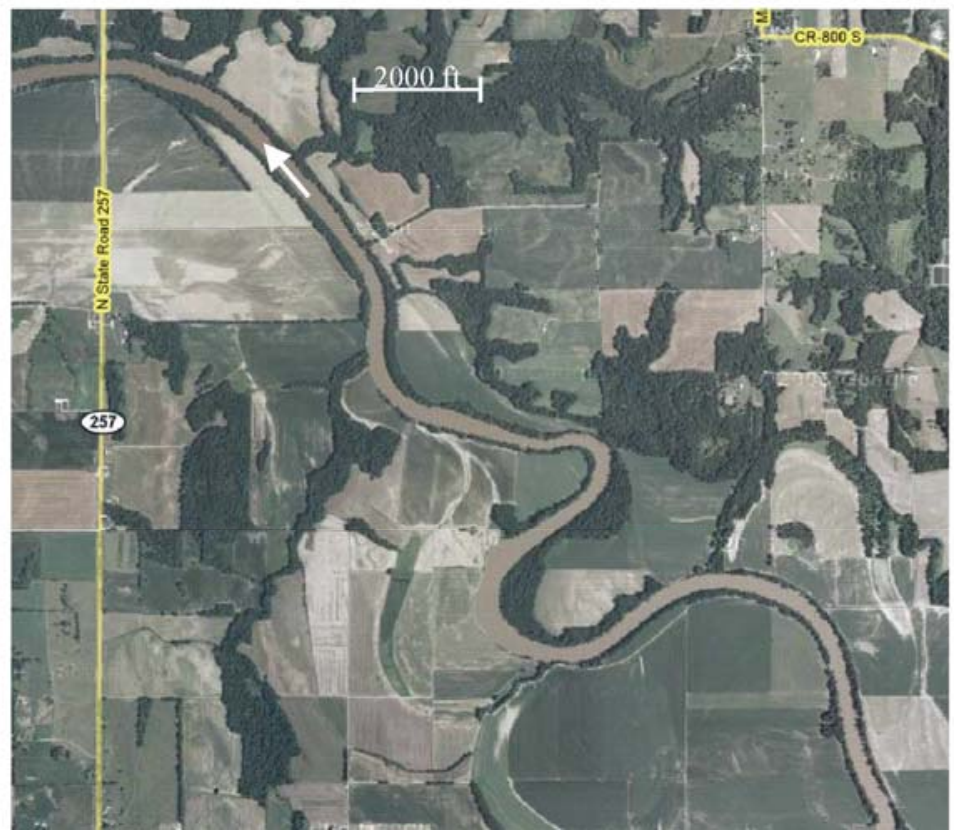

f)

Figure 2.7: Satellite photographs of the six sites with the heaviest observed debris accumulation, a) SR163-Wabash, b) SR39-White, c) SR335-Indian Creek, d) US41-White, e) SR59-Eel, and f) SR257-East Fork White (obtained from Google Maps). 
Creek site, the channels are either straight or have only a rather mild curvature at the crossings themselves, and it is uncertain to what extent more significant curvature at some distance upstream would affect flow and debris accumulation at the crossing itself. The banks of all sites seem well vegetated, though, with the possible exception of the Indian Creek site, not necessarily to any extraordinary degree. The White River, and presumably the East Fork White River also and perhaps even Indian Creek, have been characterized as having high rates of lateral migration (Diehl, 1997, citing the earlier work of Brice et al., 1978), which is consistent with the pronounced meandering seen in Figure 2.7, and would likely lead to an increased debris supply.

A feature apparent in several sites that may warrant further examination is the expansion of the channel cross-section from the reach upstream to the bridge crossing. This is particularly noticeable in Figure 2.7 at the Eel River site, but can also be seen at the Indian Creek site and the Wabash River site. Such an expansion might be expected to lead to lower velocities, assuming that the cross-sections do not change radically. These in turn may directly increase the probability of a given debris element being trapped. From the results of their laboratory experiments, Lyn et al. (2003) indicated that upstream flow velocity played an important role in determining whether debris accumulation occurred or not. A secondary effect of lower velocities might be increased sediment deposition, which may proceed so far as to form mid-stream islands or bars. At the Eel River site, such an island has formed just upstream of a pier. Diehl (1997) has also remarked that 'All of these unusually wide accumulations were at sites with potential for bar aggradation and island development.'

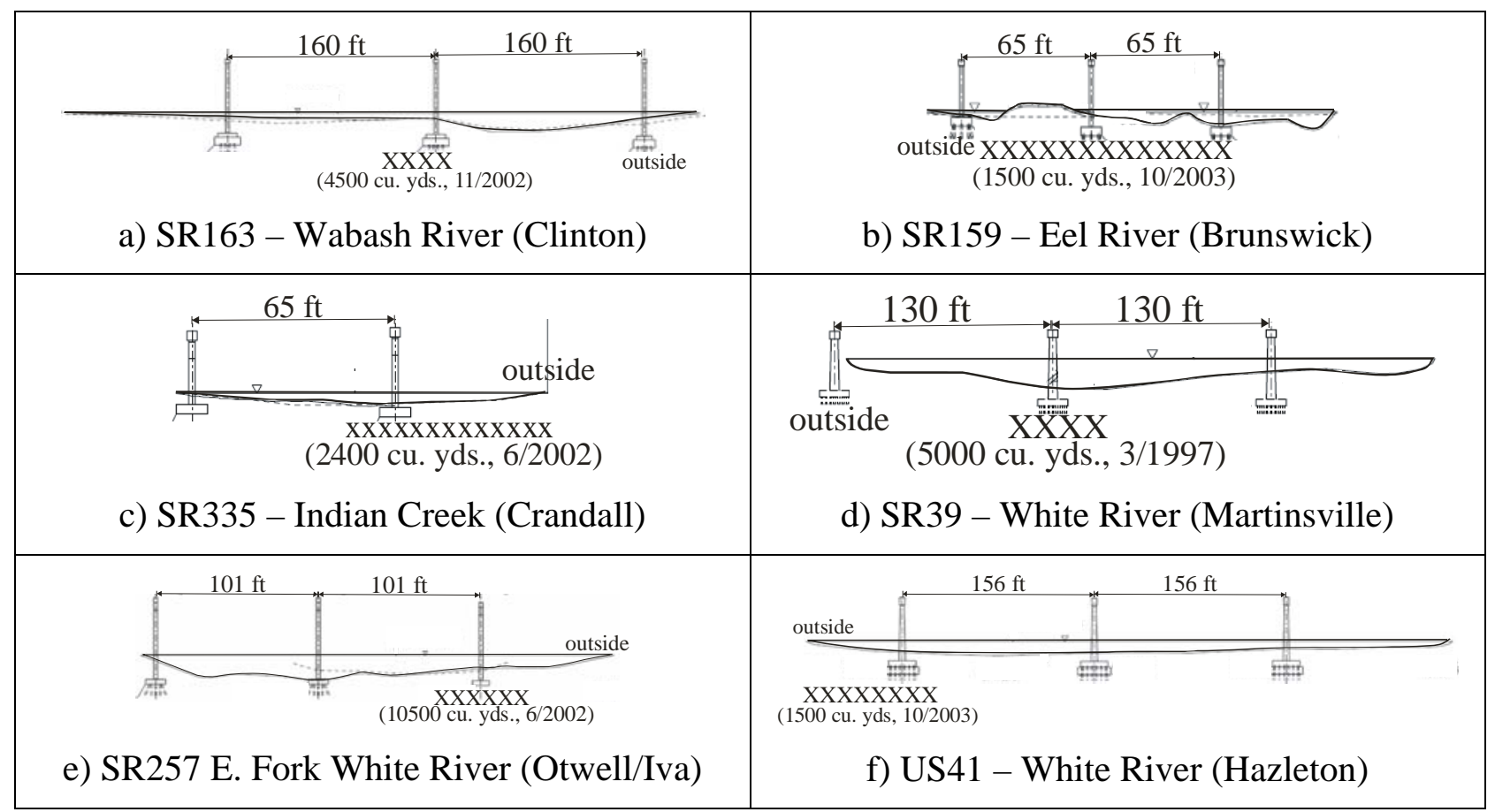

Figure 2.8: Location of piers in stream, from a view looking downstream, and the location and extent of the heaviest DA (X's indicate debris) for the 'mega' sites

The channel cross-section at the crossing, indicating the location of the piers and the lateral extent of the maximum DA, is shown in Figure 2.8 from a perspective looking downstream. In addition, the estimated volume of DA, together with the date of the inspection, is 
given in parenthesis. In general, DA was observed at other piers in addition to that shown in Figure 2.8, and in some cases, this could also be quite heavy, but the pier shown in Figure 2.8 usually had by far the largest DA. The estimated volume may however be the total at all piers. The channel bank that is on the outside of the bend is also indicated, though, in a case like the SR59 - Eel River site, the effect of the bend might be quite weak. The general shapes of the cross-sections are fairly varied. Only at the Eel River site did a noticeable island develop (see the raised ground level to the left of the middle pier). The long shallow ledge at the Wabash River site is likely part of a point bar formation, so there is some support for the Diehl's comment (already noted above) that large DA are associated with bars and islands. The other four sites do not however exhibit any especially marked feature that might be interpreted as a bar or island, even in the initial stages.

The span between piers, $L_{\mathrm{sp}}$, ranges from $65 \mathrm{ft}$ to $160 \mathrm{ft}$. This might be compared to a maximum design log length, $L_{d l}$, of about $80 \mathrm{ft}$ (or $24 \mathrm{~m}$ ), based on the maximum sturdy log length in the Eastern U. S. (Diehl, 1997; HEC-9). At four of the six sites, $L_{d l}$, is significantly exceeded. Diehl has emphasized that the 'effective' span length, $L_{\text {eff, }}$ at least as far as DA is concerned, may not be the actual span between piers, but rather the size of gap between the pier closest to a bank and that bank. The latter gap would be the narrowest opening, and so would be the most likely to trap logs. A comparison of $L_{d l}$ and $L_{\text {eff, }}$ estimated from Figure 2.8, does indicate that the two are comparable even for some of longer span bridges. Figure 2.8 may however be misleading in giving an underestimate of $L_{\text {eff. }}$ These are based on bridge inspections, which are typically performed under low- flow conditions. Under the high-flow conditions when much of the debris is actually transported, the gap between the pier closest to the bank and that bank may be substantially larger than might appear in Figure 2.8.

Whether heavy DA can occur depends not only on the debris supply, but also whether the pier is located in the path of the transported debris. Pier location within the channel will therefore play an important role in contributing to DA (Diehl, 1997). In view of the very heavy DA at these sites, the piers in Figure 2.8 might be considered examples of where not to place a pier. An interesting question is whether any practical alternative pier placement could have avoided or at least considerably reduced the accumulation. Although no definitive answer can be given based solely on the information in the bridge inspection reports, two observations suggest that better placement alternatives may in theory be possible. The first is that, though DA also occurred at other piers in the streams, this was in the large majority of cases substantially smaller. The second is that in the two available inspection reports the pier with the maximum DA was generally the same, indicating a repeatability that points to some specific feature of the pier location rather than randomness causing the DA. It should nevertheless be acknowledged that the pier placements in Figure 2.8 may not necessarily be the worst-case choices, so there may be scope for even worse choices.

The location where the maximum DA occurs varies. The thalweg, i.e., the lowest part in the section, might have been thought to be especially prominent in this regard since it is frequently stated, e.g., in HEC-9, that large woody debris tends to travel near or along the thalweg, at least in a straight channel. The evidence is rather mixed. At the SR39 - White River site, the pier with the maximum DA is located near the thalweg point, but at the SR257 - E. Fork White River site, the pier closer to the thalweg point suffered much less DA than the pier with the maximum DA. The issue is made rather more complicated by the effect of bends. At river bends, the thalweg is generally observed close to the outer bank, with the SR163 - Wabash River 
site being the clearest example. A notable exception to this rule is the SR257 - E. Fork White River site, where the thalweg point is rather far removed from the outer bank, but this site is also exceptional in that the maximum DA does not occur at a pier close to the thalweg, but rather at the pier closest to the outer bank.

From the limited evidence in Figure 2.8, the effect of the bend would seem to be dominant, in that, regardless of the location of the thalweg, the pier closest to the outer bank (and of course, in the stream) experienced the maximum DA. The need for some qualification is however clear from the case of the SR163 - Wabash River site, where the pier closest to the outer bank did experience some DA, but the maximum DA occurred at a pier, certainly closer to the outer bank than to the inner bank, but still well away from the outer bank, and even from the thalweg. It certainly cannot be excluded that the DA could have been even larger if a pier had been located nearer to the outer bank or to the thalweg. It is plausible that the largest amount of debris is carried at some distance from the bank, such that a pier very close to the bank may not be as exposed as a pier farther away from the bank. It should also be kept in mind throughout this discussion that bridge inspections are often performed under low-stage conditions, which are not representative of high-flow debris-transporting events.

The evidence in Figure 2.8 for a direct role of the bank on DA is mixed. Diehl's (1997) concept of an 'effective' span length would seem to be based on a large log spanning the gap between pier and bank, thereby generating or sustaining a large DA. In two of the cases shown in Figure 2.8, the DA does extend from the pier to the bank. This might be considered as supporting the importance of the bank's role, though there is no specific mention of a large log in the report. In at least two cases, the banks evidently do not play any role in the maximum DA, however, at the SR163 - Wabash River and at the SR39 - White River sites. Even at the SR257 - E. Fork White River site where the largest ever (in terms of estimated volume) DA was observed and where the maximum DA did occur at the pier nearest the bank, the DA did not extend to the bank, suggesting a limited if any direct role of the bank.

Due to the presence of a midstream 'island' immediately upstream of the middle pier, the SR59 - Eel River site may be somewhat of an exception to much of the above discussion. The definition of the outer bank or a unique thalweg point becomes debatable, and so any explanation of debris transport in terms of the location of the outer bank or the thalweg is open to question. Still, under high-flow debris-transporting conditions, the island would be submerged, and so any effect due to the island may only be indirect. In this regard, if an 'island' is taken to mean a local high point in the cross-section, and can be always entirely submerged, other sites could be said to exhibit 'island' features. Another 'island' related aspect is the possible positive feedback between island development and DA, wherein DA promotes further island development, which in turn may increase the likelihood of DA. A sufficiently large DA may also cause long-term changes in stream morphology, particularly in smaller channels such as the Eel River.

\subsubsection{The 'chronic' sites}

The 'mega' sites have experienced the largest DA, but heavy DA may not have been observed at a given 'mega' site during all (usually two) available inspections. Sites where heavy DA was observed at each of two inspections may be considered 'chronic' and may have features that are particularly conducive to the occurrence of heavy DA. Fifteen (15) such sites were identified, two (US41 - White River and SR39 - White River sites) of which were 'mega' sites and so already discussed, and so only 13 were studied further. The SR51(6) - Deep River bridge 


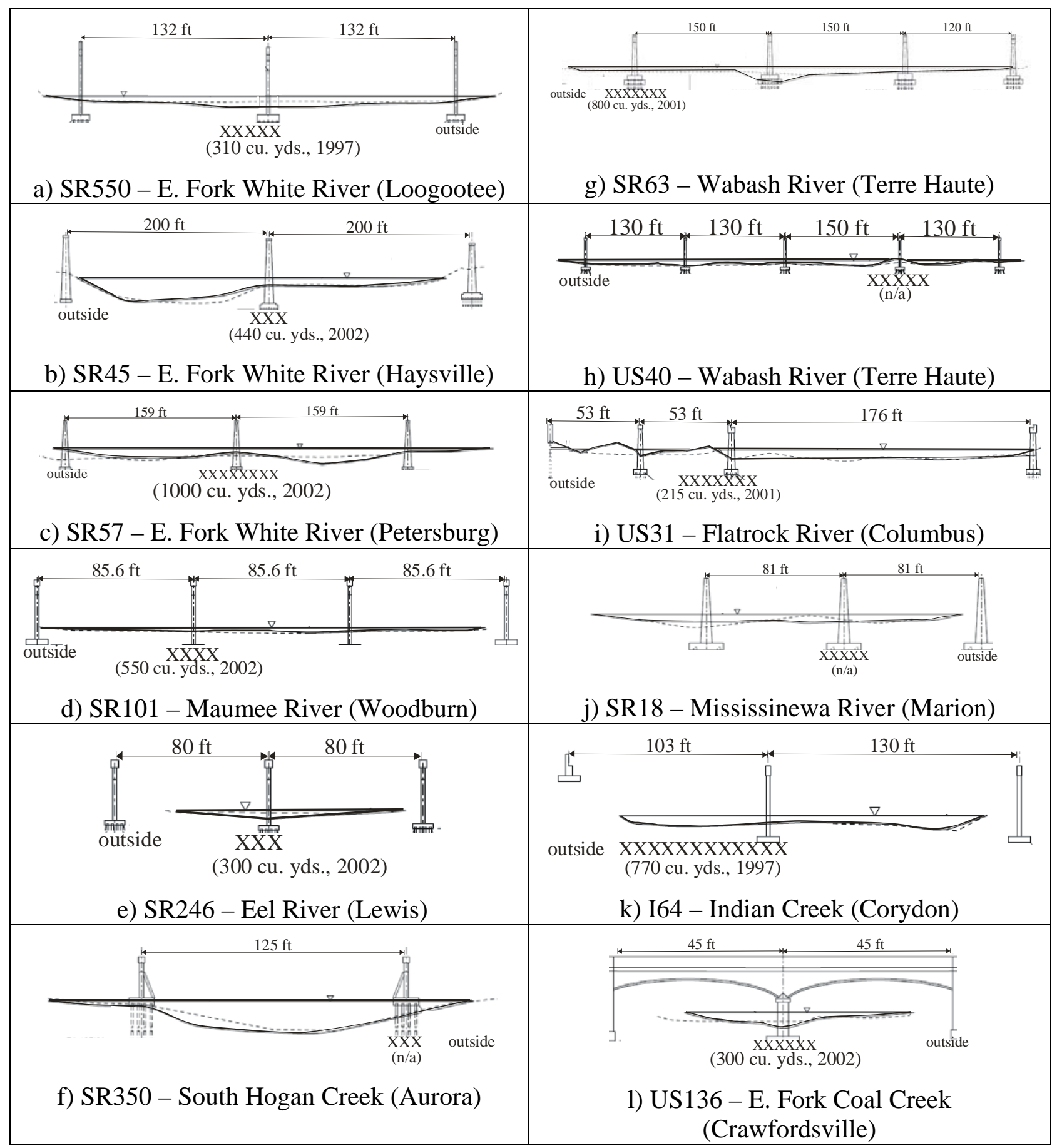

Figure 2.9: Location of piers in stream, from a view looking downstream, and the location and extent of the heaviest DA ( $X$ 's indicate debris) for the 'chronic' sites

is the only one with a bent-type substructure consisting of multiple columns, which is thought to be especially susceptible to DA. This type of substructure is relatively rare in Indiana for larger bridges over waterways, and so was not considered representative, and therefore not of interest. The remaining 12 sites are shown in Figure 2.9 in a form similar to Figure 2.8, with the location of piers in stream and the location and extent of the heaviest DA. As was the case for the 'mega' sites, the affected pier shown in Figure 2.9 had in most cases the only or by far the major 
accumulation in both inspections. The importance of this observation lies again in its indication of a high repeatability of accumulation at a specific pier, which is therefore unlikely to be entirely random. This suggests strongly that specific characteristics of the pier and site determine the occurrence of DA at that specific pier.

The span lengths between piers in Figure 2.9 are also quite large, again in many cases exceeding by far $L_{d l}(\approx 80 \mathrm{ft})$, though not necessarily $L_{\text {eff. }}$ In a number of cases, a pier is located in the vicinity of the thalweg, e.g., at the SR550 - E. Fork White River or the SR246 - Eel River sites, and the maximum DA is in fact observed there. There would nevertheless seem to be at least two cases where this relationship does not hold. At the SR63 - Wabash River site, the maximum DA occurs at the pier closest to the outer bank, whereas the thalweg, located in the immediate vicinity of a pier, may have been influenced by pier scour. At the US40 - Wabash River site, situated downstream of the SR63 - Wabash River site, the maximum DA occurs neither at the pier closest to the outer bank nor at the thalweg point, but rather curiously towards the inner bank. This may however be related to the presence of an 'island' just upstream of that pier. It may be noted that 'island'-like features are also seen at the US31 - Flatrock River, the SR57 - E. Fork White River, and the I64 - Indian Creek sites, though not as pronounced in the last two sites.

There remains a noticeable correlation between the locations of the maximum DA and the piers closer to the outer bank. Similar to what was already seen at the 'mega' sites, the piers closest to the outer bank do not necessarily experience the largest DA though they will often experience some minor or moderate DA. The SR350 - S. Hogan Creek site is interesting in this regard since the pier with the maximum DA is the closest to the outer bank, but seems to be located quite close, $\approx 30 \mathrm{ft}$, to the bank. This might be contrasted to the SR550 - E. Fork White River with a pier $\approx 40 \mathrm{ft}$ or the US40 - Wabash River site with a pier $\approx 35 \mathrm{ft}$ from the outside bank. A distinctive feature of the SR350 - S. Hogan Creek site, possibly contributing to the greater susceptibility of that pier to heavy DA, is the relatively deep flow in spite of its proximity to the bank.

The importance of the bank seems much less pronounced than might have been the case at the 'mega' sites in Figure 2.8, with the only case of the bank seeming to play any major role being at the I64 - Indian Creek site. This may be related to the DA in these cases not being as extensive as at the 'mega' sites. As such, even if the DA occurs at the pier closest to the bank, e.g., at the SR63 - Wabash River or the SR350 - South Hogan Creek sites, the DA is not large

enough to extend to the bank. On the other hand, that a heavy DA can be sustained without the bank playing any essential role throws some doubt on its importance at the 'mega' sites. Alternatively, the bank may play only a limited role in sustaining only the largest DA. If the bank does not play a significant role, then the concept of an 'effective' span length becomes less useful or needs to be substantially modified to be meaningful.

\subsubsection{The 'lite' sites}

In Figure 2.4, several 'lite' sites were shown that have had only minor or no DA observed at two inspections, but which were situated on streams that had experienced heavy DA at some point along its length. Of particular interest for the present purposes are those 'lite' sites that are adjacent or quite close to 'heavy' sites, with inspections also performed within a short time period. In such cases, it could be reasonably assumed that the 'lite' sites were exposed to similar debris 'traffic' as the nearby 'heavy' sites, but, for some site-specific reasons, did not experience 
the DA that the 'heavy' sites did. Several 'lite' sites are shown in Figure 2.10 on the left, with the corresponding 'heavy' site on the right; also indicated is the distance from the 'heavy' site, and the relative position, whether upstream or downstream. The only other sites with no DA reported in Figure 2.4 were those on the Mississinewa near Fowlerton and on the Wabash near Vera Cruz. The former had no pier in the stream during the inspections, and there was no 'heavy' site near the latter. In all cases shown, the 'lite' and the 'heavy' sites were within 5 miles of each other; in two cases, one on the Kankakee and the other on the Wabash, the inspections were separated in time by more than 1 year. The latter cases require more caution in interpretation. One case of great interest, not in Figure 2.4 because it experienced moderate DA, is the SR61 - White River (Petersburg) site, located downstream of the SR57 - E. Fork White River site which is almost a 'mega' site, and also upstream of a true 'mega' site (Hazleton). Where the outside of the bend may be ill-defined, this designation has been omitted in Figure 2.10. Satellite photographs of sites, with both 'lite' and 'heavy' bridges together, are shown in Figure 2.11, from which any stream curvature may be inferred.

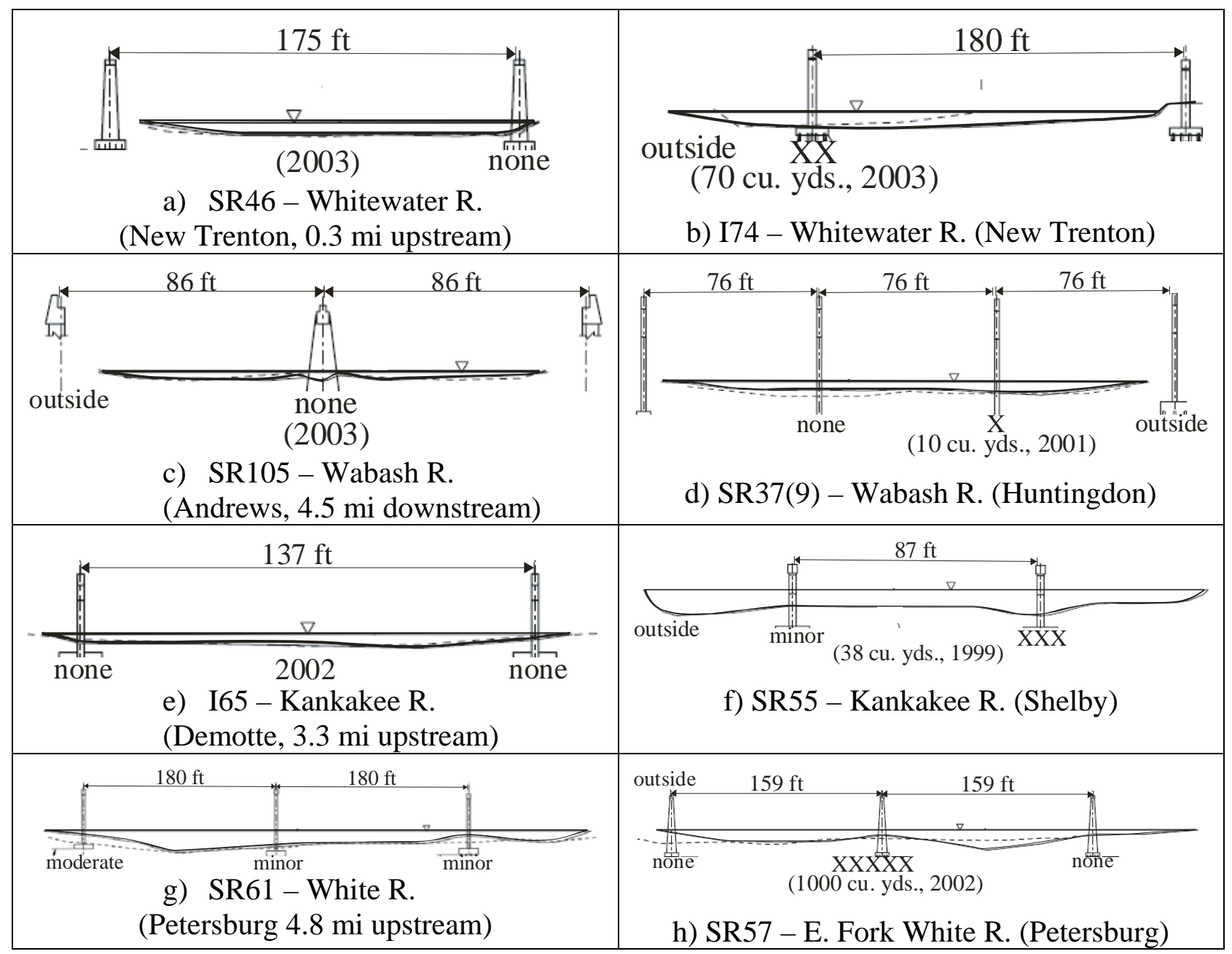

Figure 2.10: Cross-sections of bridge sites with no or minor DA (on the left, a, c, e, and g) and of nearby bridge sites with heavy DA (on the right, b, d, f, h) 


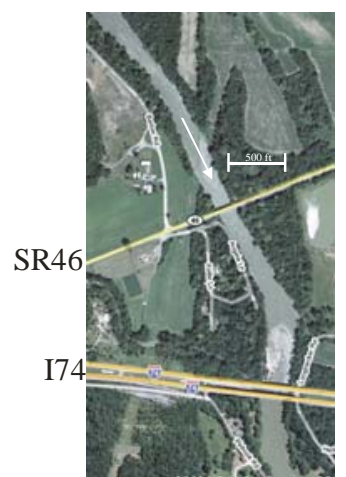

a)

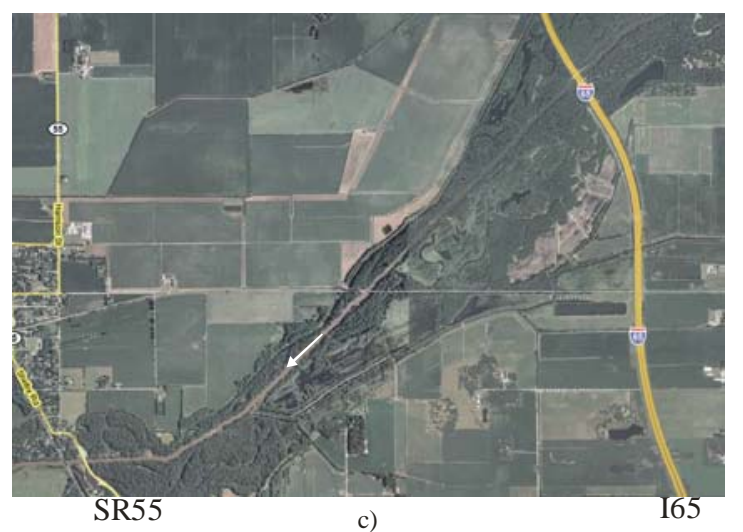

c)

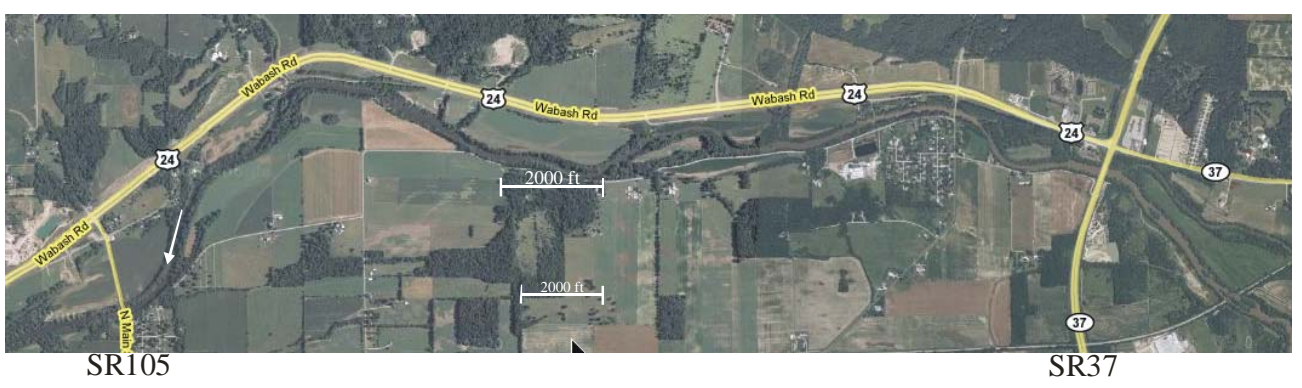

b)

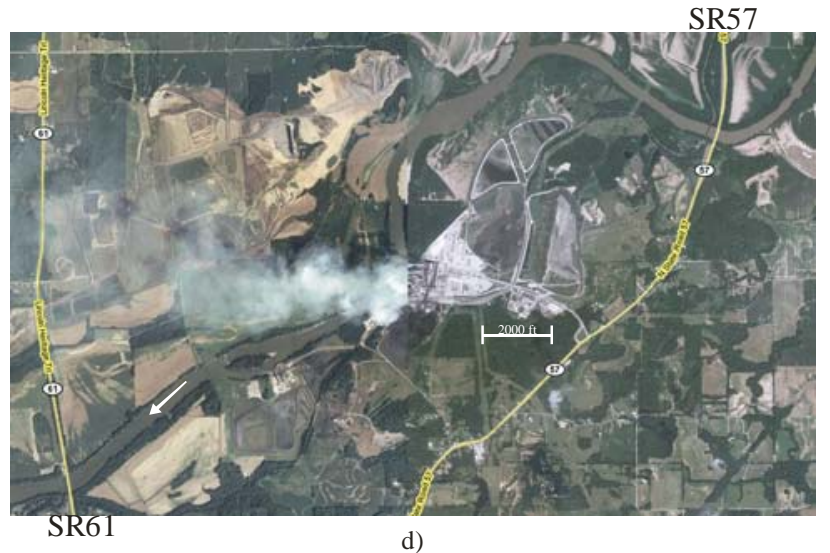

d)

Figure 2.11: Aerial photos (using GoogleMaps) of paired ('lite'+heavy) sites, a) Whitewater R. sites, b) Wabash R. sites, c) Kankakee R. sites, and d) White R. - E. Fork White R. sites

At both New Trenton sites, the span lengths are comparable. At the 'lite' upstream site, the single in-stream pier is very close to the right bank, and, from what has been previously seen, it is not surprising that no DA occurred at that pier. In comparison, at the corresponding 'heavy' site, the pier with DA is closer to, but still some distance away from, the outer bank, and also seems to be in the neighborhood of the thalweg. A possibly important point is the substantially larger channel width at the 'heavy' site. Also a side stream enters the Whitewater R.at the I74 crossing, though on the other side (right-hand side looking downstream), and may contribute to some drift.

The 'heavy' Wabash River site also conforms to expectations, with the pier with DA being again situated towards, but some distance away from, the outer bank, in the vicinity of the thalweg. On the other hand, the 'lite' downstream site is interesting in having a pier in midstream, with nearby local high points in the streambed that could be construed as 'island'-like. Some amount of DA might have been expected at the 'lite' site. The difference in the time of inspection should be noted, but at both sites, the reports for two inspections were very similar, namely, no DA at Andrews and moderate-to-heavy DA at Huntingdon. The midstream pier at Andrews is somewhat unusual in its stone masonry and its larger width, the latter of which may have helped to minimize trapping of debris. Again, the larger channel width at the 'heavy' site may be pointed out.

The Kankakee River is a highly engineered stream with unnaturally straight reaches and changes in alignment rather than bends. Both the 'lite' upstream site near Demotte and the 'heavy' downstream site near Shelby are on straight reaches, somewhat downstream of a change 
in alignment. The two in-stream piers at the 'lite' site are located close to the two banks, and so would not be expected to trap much debris. Though on a straight reach, the cross-section exhibits a slight indication of the effect of the upstream 'bend' or change in alignment (the thalweg is located towards the right). The 'heavy' downstream site has a bridge with a notably smaller span length. The effect of the upstream 'bend' is also more marked. Contrary to what might be expected, the pier with the maximum DA is located towards the inner bank, whereas the pier closer to the outer bank suffered only minor DA. The different time of inspection should be pointed out (unfortunately, there was only one inspection report available for the Shelby site; the only other inspection at Demotte in 1994 gave the same report as far as DA was concerned).

Three sites immediately upstream of the 'lite' site at Petersburg, within 50 miles, are 'chronic' sites. Within this distance, there are also two 'mega' sites, one downstream and one upstream, the latter at which the largest ever DA was reported. Thus, in spite of the fact that there was only one inspection report available, the SR61 - White River site was of interest because it experienced relatively little DA during a time period when very heavy DA was observed at nearby sites. Both the 'lite' and the 'heavy' sites had three piers in-stream, with bridges that had comparable span lengths. In the original inspection report, all three piers at the SR61 site were reported to have 'light' accumulation, though the pier closest to the outer bank clearly had more than the others. In contrast, the upstream 'heavy' site had no DA at the pier closest to the outer bank, but rather had very heavy DA at the midstream pier, located on top of an 'island'-like feature. A likely contributing factor to the situation at the SR61 site is the confluence of the White River and the E. Fork White River about 3.6 miles upstream, or about 1.2 miles downstream of the 'heavy' site (see the top right of Figure 2.11d). Besides possibly contributing its own debris load, the White River inflow most likely disrupts the flow patterns determining the debris transport in the E. Fork White River, on which the 'heavy' site is located.

\subsubsection{Other issues}

Two other general issues were examined on the basis of the available inspection reports. The first concerns the effect of a channel expansion on the likelihood of DA at a site. This has already been commented on with regards to specific sites, where a tendency was noted for DA to occur where the channel width at a bridge crossing was markedly larger than that at an upstream section. In the bridge inspection reports, cross-sectional information is usually given at the bridge (actually three sections at the bridge), at two upstream, and at two downstream sections. In most cases, the farthest upstream section is located 200-ft upstream of the bridge, though for some of the largest channels, a section 600-ft upstream was taken, and for some of the smallest channels, a section of $50-\mathrm{ft}$ upstream was taken. In terms of channel width, this implies an upstream section that is one to two channel widths upstream of the bridge. This is relatively short, and it is not expected that the expanded flow will have fully adjusted at the bridge section. It should also be pointed out that the sections taken are parallel to the bridge crossing, and so are not necessarily the same as the cross-section more typically used in hydraulic analysis, namely a cross-section perpendicular to the flow.

In the following, the width refers to the top width of flow (parallel to the bridge) as estimated from the figures given in the inspection bridge reports. This depends on the flow and hence on the time of inspection. As noted before, the flow during inspection is not representative of debris-transporting events. The main statistic to be examined is however a ratio of the width of the farthest upstream section to the width of section at the bridge centerline, and, provided, the water surface is below the bank-full elevation, the ratio should be less sensitive to the flow 
conditions. Over a longer term, e.g., between inspections, stream cross-sections may change due to erosion or deposition, and this may also change to some extent channel widths, which may again depend on when the inspection was done. In the following, the ratio of widths was determined, for the sites where 'heavy' DA was observed, from the inspection report produced when the largest DA was observed, and otherwise from the most recent inspection report.

Table 2.1: Statistical results for ratio of channel 'width' at bridge section to 'upstream channel width'

\begin{tabular}{|l|c|c|c|c|c|c|}
\hline \multicolumn{1}{|c|}{ Sample } & $\begin{array}{c}\text { No. in } \\
\text { sample }\end{array}$ & Mean & $\begin{array}{c}90 \% \text { conf. } \\
\text { interval }\end{array}$ & Median & $\begin{array}{c}\text { Max. } \\
\text { value in } \\
\text { sample }\end{array}$ & $\begin{array}{c}\text { Min. } \\
\text { value in } \\
\text { sample }\end{array}$ \\
\hline 'mega' sites & 6 & 1.36 & 0.22 & 1.10 & 1.85 & 1.04 \\
\hline 'chronic' sites & 15 & 1.25 & 0.19 & 1.04 & 2.5 & 0.94 \\
\hline 'lite' sites & 11 & 0.95 & 0.06 & 0.96 & 1.1 & 0.73 \\
\hline All sites' & 152 & 1.14 & 0.05 & 1.02 & 3.3 & 0.55 \\
All heavy ${ }^{2}$ sites & 66 & 1.22 & 0.09 & 1.05 & 3.3 & 0.70 \\
\hline All moderate ${ }^{3}$ sites & 35 & 1.12 & 0.10 & 1.04 & 2.6 & 0.72 \\
\hline
\end{tabular}

${ }^{1}$ This refers to all sites on streams with at least one heavy DA sites somewhere along its length, excluding sites in the immediate vicinity of a reservoir.

${ }^{2}$ This refers to all sites with at least once observation of heavy DA.

${ }^{3}$ This refers to all sites with two reports, at least one of which is moderate, and neither of which is more than moderate.

The statistical results for the width-ratios are given in Table 2.1. These do lend some support to a positive correlation between a flow expansion (width-ratio $>1$ ) and the occurrence of heavy DA at a site. The highest average width-ratio is found for the 'mega' sites, though the sample size is small. In spite of the rather narrow range, the $90 \%$ confidence interval is large due to the small number of such sites. The 'chronic' sites, which include two 'mega' sites, also had a high average width-ratio. In contrast, the 'lite' sites had the smallest average width-ratio $(<1)$, with a quite small range and hence small 90\% confidence interval. Although these results do suggest a statistically significant difference between the 'lite' and the 'mega' or 'chronic' sites, a qualification must be made. As discussed previously, most of the 'lite' sites are located in northern Indiana, while all of the 'mega' sites and most of the 'chronic' sites are located in southern Indiana, and this spatial difference makes difficult drawing any definitive conclusions from a direct comparison. It is also noted that of the 66 'heavy' sites, 26 or $40 \%$ are characterized by width-ratios $\geq 1.2$. Because only 44 sites have width-ratios $\geq 1.2$, the probability of a site known to have a width-ratio $\geq 1.2$ of its also having a heavy DA event can be estimated at 59\%. A similar estimate for the probability of a site known to have a width-ratio $\leq 1$ of its also having a heavy DA event is found to be $35 \%$.

The other issue examined on the basis of the inspection reports is the effect of islands in the stream. This has been noted before by Diehl (1997) as being associated with heavy DA, and was specifically investigated in a laboratory channel by Lyn et al. (2003). In general, an 'island' feature could be defined as any local high point on the channel bed, whether submerged or not. This would be overly broad and so not particularly useful. A somewhat restrictive though more 
convenient definition was taken in the following, namely, an island is taken to be an identifiable feature within the channel with its top unsubmerged. These were generally surrounded by water, unless next to a pier; 'peninsula'-like features around a pier with water on both sides of a pier were however also included. As pointed out earlier, this is somewhat arbitrary in that such a feature would become submerged during a high-flow debris-transporting event. Further, in the previous discussion of specific sites, it was observed that piers located on local high points that are submerged at the time of inspection may be associated with heavy DA. On the other hand, if a feature is sufficiently prominent that it is visually observed during a bridge inspection, then it might be expected to be most likely to have a direct effect on DA.

Consistent with much of this chapter, only those sites on streams where heavy DA was observed at least once along its length were considered. At 21 of these sites were islands as defined above identified. An island was thought however to be able to contribute directly to DA only if it were located in the immediate vicinity of pier. As such, only those sites with islands within a radius of one design $\log$ length $(\approx 80 \mathrm{ft})$ of a pier were included in the analysis. Of the 16 sites satisfying this criterion, 8, i.e., $50 \%$, experienced heavy DA at least once. Moreover, the pier with the maximum DA was in each case the pier at or closest to the island. These two observations suggest strongly that islands can contribute to DA. It might be asked whether the effect of an island is independent of the effect of a flow expansion, since one might expect that a flow expansion could lead to deposition and hence the development of an island. It was found that 5 of the 8 sites with islands that experienced heavy DA were characterized by width-ratios within $5 \%$ of unity. This would suggest that the effect of islands is independent of but somewhat weaker than the effect of flow expansion. A width-ratio $\geq 1.2$ or the presence of islands in the immediate vicinity of a pier therefore accounts for almost $50 \%$ of 'heavy' sites. Alternatively, the probability of a site having a 'heavy' DA event if it is known to have a width-ratio $\geq 1.2$ or the presence of islands in the immediate vicinity of a pier is estimated as $57 \%$.

The effect of flow expansion has been explained in terms of lower overall velocities in the stream that makes trapping of moving debris more likely. The role of islands seems rather more complicated. Because much of the vegetative debris is transported on the surface, the velocity at the water surface is important for DA. Because of the shallower depths at islands (and other features such as point bars), the surface velocity is expected to be lower in these regions, such as to make debris being transported in these regions more easily trapped. In addition, the bridge inspection results show that, in all cases of heavy DA, the DA extends to the channel bed, which seems to play a stabilizing role, as previously suggested by Lyn et al. (2003). In a sense, the 'effective' span length may therefore be determined not by the span between piers nor by the gap between pier and bank, but rather by the smallest water depth. This would presumably be found at or near an island feature. In view of these two effects, it might be wondered why the correlation between the presence of an island feature and the occurrence of a 'heavy' DA event is not stronger. These effects promoting DA may however be mitigated by a third effect, acting against DA at island features. It has been noted that debris tends to be transported in the faster moving flow regions, e.g., near the thalweg. Larger island features that begin farther upstream may sufficiently change flow patterns such that much of the debris may be directed away from the pier, which as a consequence may still experience some DA but not as much as would have been the case in the absence of the large island feature. 


\subsection{Summary}

Underwater bridge inspection reports have been examined for observations related to DA at bridge piers. Database and GIS tools were applied to characterize the extent and spatial distribution of DA in Indiana, and to identify local factors, such as cross-sectional geometry and pier placement, that might contribute to DA. It was found that the heaviest DA has historically occurred in southern Indiana, particularly in the White-River - Patoka River basin, presumably because the largest rivers drain towards the southwest. A closer study of cases with the heaviest DA, of sites where heavy DA repeatedly occurs, and of sites that experience little DA compared to nearby sites experiencing heavy DA revealed some general trends that might be useful in deciding on pier placement with the aim of minimizing the probability of heavy DA, including:

- Most bridges that require underwater bridge inspections suffer at least moderate DA. The heaviest DA in Indiana tend to be observed in the southwest, or in the downstream reaches of a stream.

- Single-pier DA characterized most of the heavy DA observed, with DA typically extending to the bottom.

- DA is of less concern in the immediate vicinity of reservoirs and lakes.

- Piers quite close to the banks at low-stage conditions seem less susceptible to DA than piers farther into the stream.

- DA tends to occur more often towards the outside of a bend.

- The location of the thalweg at or near the bridge crossing does not seem to be a good predictor of the location of the heaviest DA.

- There is some moderate statistical evidence that channel expansion at the bridge crossing and to a lesser extent the presence of island or peninsula features immediately upstream of a pier are associated with heavy DA. 


\section{Observations from periodic site visits}

As far as DA is concerned, the information taken from bridge inspection reports is flawed due to the long time interval, in most cases 5 or 6 years, between inspections, and the availability of only a single report for almost $40 \%$ of sites. As such, a number of important questions cannot be resolved. Over what time period do heavy DA develop, e.g., in a single high-flow event, or over several high-flow events during a single year, or even possibly over several years? Are the heavy DA occurrences relatively rare, or are they more or less annual events? Does the answer depend on the site? Are there preferred paths, such as along the thalweg, for debris transport? As discussed in the previous chapter, this has implications for the optimal placement of piers for the minimization of DA. Answers to such questions require more frequent inspections, ideally even continuous monitoring. Since continuous monitoring is practically only feasible for a handful of sites, an intermediate solution based on periodic (about three or four times per year) site visits was devised. This chapter describes the periodic-visits program, and the results that came from it.

\subsection{The periodic-visits program}

\subsubsection{Site selection}

The program of periodic site visits was originally motivated, not to fill the gaps in the information from the bridge inspection reports, but rather to fill the gap in the results from the continuing-monitoring program, which was restricted to only three sites. A larger sample was desired in order to draw reasonably reliable statistical conclusions, which was difficult to justify from the very detailed information from only three sites. The number and selection of the individual sites to be visited were therefore an important part of the study. At the beginning of the study, the authors were unaware of the availability of the bridge inspection reports in a convenient electronic format, and so these could not be used as a guide in the initial decision as to the sites to be included in the sample.

The initial selection of sites was based on the results of a questionnaire sent out via email to the members of the INDOT bridge inspection group in each of the INDOT districts. Bridges in the district were to be ranked on a scale of 1 to 3 according to the perceived severity of DA problems, with 1 representing sites with severe problems (requiring attention every year), 2 sites with serious problems (requiring attention every few years), and 3 sites with minor problems (noticeable debris accumulation, but does not necessarily require attention). It was decided to focus attention on 'severe' sites, i.e., those rated as 1 . Those bridges with longer span lengths were of particular interest since because they would already satisfy the span-length criterion based on design log length, and so the occurrence of DA required a different explanation. This screening resulted in a list of 25 sites of interest, of which three were already subjects of study by video monitoring and so were excluded. The locations of the remaining 22 sites were then considered in order to determine a time-efficient route in conducting the inspections. It was planned to do most of the inspections over a weekend, i.e., over two days, with any remaining sites to be close to Lafayette. As might be expected from Chapter 2, there tended to be a concentration of sites towards the southwest, and towards the north. For logistical reasons, therefore, it was decided to focus on these concentrated regions. Safe access was also an issue, particularly at sites with heavy traffic, e.g., on interstate freeways such as I74 near Shelbyville where no safe 
and convenient access could be found. The US31 - Flatrock River site near Columbus was initially selected, but over much of the study period, the channel at the site has been substantially disturbed due to construction, and so will not be included in the discussion below. The 14 remaining sites chosen to be initially inspected on a periodic basis are shown in Figure 3.1 and tabulated in Table 3.1 (all except two have so far been visited 6 times). For comparison, only 7 of these sites were considered 'heavy', and only 2 considered 'chronic', according to the characterization in Chapter 2.

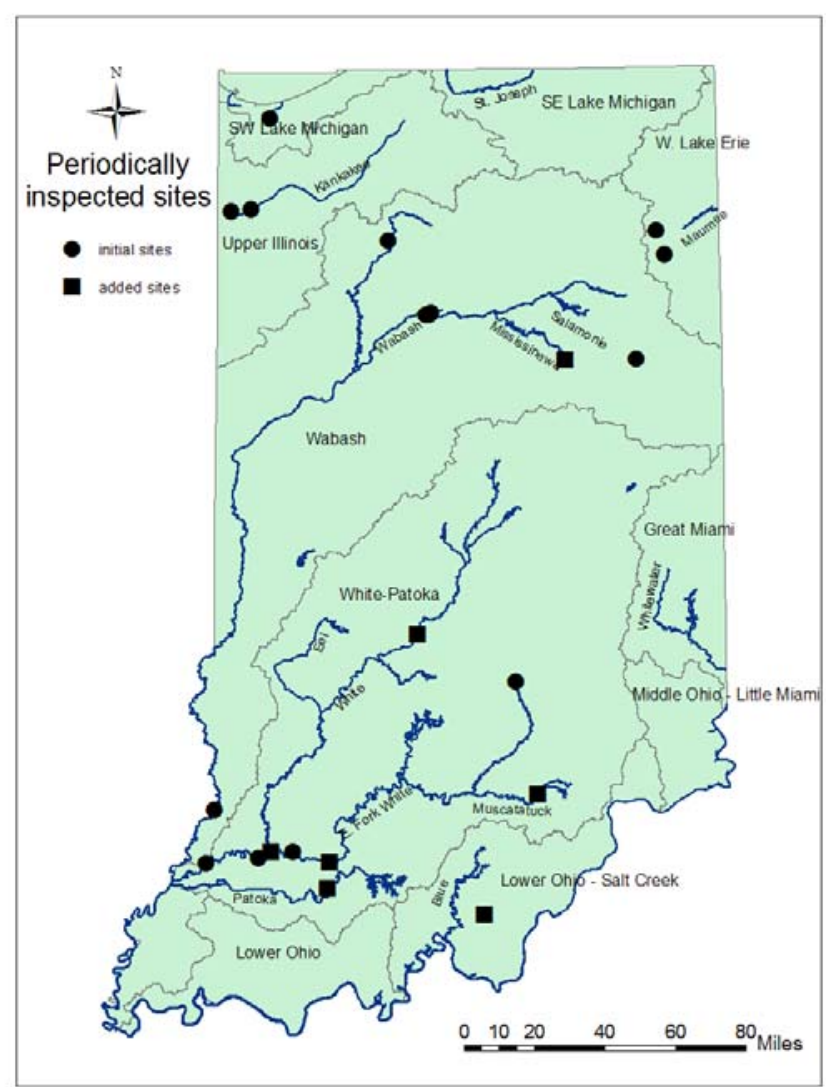

Figure 3.1: Sites at which periodic inspections were performed

After the periodic-inspection program had already started (the first set of site visits began on 12/4/2004), preliminary analysis of the bridge inspection reports indicated that there were a number of 'heavy' sites that might be of interest and would still be convenient logistically. An additional 7 sites that were considered 'heavy' in Chapter 2 were therefore included in the program of inspections. This included 2 'mega' sites (bringing the total to 4 'mega' sites; one other being included in video monitoring program, leaving the SR163 - Wabash River crossing as the only 'mega' site not covered in either program), and 4 'chronic' sites for a total of 7 (out of 15) chronic sites. This expanded program was started on 5/21/2005, and the additional sites have therefore been visited only 4 times.

\subsubsection{Inspection procedure}

The inspection consisted of a visual examination of the site from the banks or from the bridge deck, with documentation in the form of written notes and photographs. Whether a DA had occurred at the site, and if so, the extent and location, were of primary interest. A large 
limitation of such a visual examination is that only features above the water surface could be observed. The bridge reports indicate that light to moderate DA can occur at the bottom of the channel without being observed at the surface. While it is unlikely that heavy DA would not protrude through the water surface, the amount of the DA is difficult to evaluate based solely on above-water-surface data. Different levels of DA cannot be precisely classified, and so in this chapter, these are only loosely divided into minor or none, moderate, heavy, and very heavy. These groupings are expected to correspond only roughly to those in Chapter 2. Upstream (and downstream) features that might be relevant to DA were also noted. These might include nearby often abandoned upstream bridges, particularly if these showed evidence of significant DA. Depending on the ease of access to the crossing and whether there were features of interest to record, a visit might last from 15 to 30 minutes.

Table 3.1: List of sites included in the periodic site visits

\begin{tabular}{|l|c|l|}
\hline Site & No. of visits & Chapter 2 characterization \\
\hline US50 - Wabash (Vincennes) & 6 & moderate \\
\hline US41 - White (Hazleton) & 6 & heavy ('mega', 'chronic') \\
\hline SR61 - White (Petersburg) & 6 & moderate \\
\hline SR57 - E. Fork White (Petersburg) & 4 & heavy ('chronic') \\
\hline SR257 - E. Fork White (Otwell/Iva) & 5 & heavy ('mega') \\
\hline US231 - E. Fork White (Haysville) & 4 & heavy ('chronic') \\
\hline SR164 - Patoka (Jasper) & 4 & heavy \\
\hline SR335 - Indian Creek (Crandall) & 4 & heavy ('mega') \\
\hline SR39 - White (Martinsville) & 4 & heavy ('mega', 'chronic') \\
\hline US31 - Muscatatuck (Austin) & 4 & heavy \\
\hline SR18 - Mississinewa (Marion) & 4 & heavy ('chronic') \\
\hline SR18 - Salamonie (Montpelier) & 4 & heavy \\
\hline US27 - St. Mary's (Ft. Wayne) & 6 & moderate \\
\hline I469 - St. Mary's (Ft. Wayne) & 6 & heavy \\
\hline US6 - Deep (Lake Station) & 6 & heavy ('chronic') \\
\hline US41 - Kankakee (Schneider) & 6 & heavy \\
\hline SR55 - Kankakee (Shelby) & 6 & heavy \\
\hline US14 - Tippecanoe (Winamac) & 6 & moderate \\
\hline SR25 - Wabash (Logansport) & 6 & moderate \\
\hline US35 - Wabash (Logansport) & 6 & moderate \\
\hline SR25 - Eel (Logansport) & 6 & minor \\
\hline
\end{tabular}

The inspection route started at the US50 - Wabash River site, and proceeded south and west, with the first day ending at a south-central site, such as the US31 - Flatrock River site. The following day started, in the initial program, at a site either in or near Fort Wayne, and in the expanded program, at a north-central site, such as the SR18 - Mississinewa River site. The route then continued north and then west, and, if there was sufficient time (for daylight), once more west, typically ending at either the US14 - Tippecanoe River site or one of the sites in Logansport. Any remaining sites were generally visited on one or two days during the following two 
weekends. Thus, a set of site inspections was generally completed within three weekends. The six sets of visits began on 12/4/2004, 2/19/2005, 5/21/2005, 8/27/2005, 11/19/2005, 3/25/2006, roughly 3 months apart.

\subsection{The hydrologic conditions}

Flow drives DA, and the hydrologic conditions during the periodic-site-visits program are indicative of the occurrence of debris-transporting events. Daily stream discharges at several USGS stations representing various Indiana regions (from top to bottom, northeast, northwest, 2 central, southeast, and southwest) over the period from 8/2004 to 8/2006 are shown in Figure 3.2. Three of these stations (Kankakee-Shelby, St. Mary's-Fort Wayne, and White-Petersburg) are either at or in the immediate vicinity of the bridge crossing being inspected, while the other three are considered to be in the same general region as a site being inspected. Also shown in Figure 3.2 by vertical dotted lines is the first day of the site visits.

In most of Indiana (all except the southeast), the largest discharge event(s) occurred in $1 / 2005$, after the first site visit (for more than half the sites). These are likely to be two separate though related events: in the north, the peaks occur at 1/14/2005 and 1/15/2005, while in the center (and also the southeast), the peak occurs on 1/6/2005 though there are secondary peaks on $1 / 13 / 2005$ and $1 / 14 / 2005$. The southwest White River - Petersburg site is somewhat exceptional in having a broad peak on $1 / 11 / 2005$, which might simply be the integrated effects of the two events in close succession. The recurrence intervals for these large events were estimated to lie in the range $8-20$ years, with the shortest at the Kankakee station and the longest at the White River stations. For the central and southern stations, the second largest distinct (separated by more than a month) event occurred in 3/2006 with peaks at 3/12-13/2006, except at the southwest White River - Petersburg site where the peak occurred on 3/18/2006. The northern stations also had peaks at about the same time (3/13/2006 at the St. Mary's - Fort Wayne station and 3/19/2006 at the Kankakee - Shelby site), but these peaks were not necessarily the second largest distinct event. The recurrence intervals for these smaller events were generally in the range of $1-2$ years, though that at the White River - Petersburg station was estimated to be 6 7 years. If the concept of a recurrence interval for debris accumulation is useful, then the relationship between it and the recurrence interval for the stream discharge is doubtless quite complex. Experience at two of the sites involved in the video-monitoring program suggests that short-recurrence-interval flow events can cause large DA, but whether this is typical or is very site-specific needs to be investigated further.

\subsection{Observations at individual sites}

\subsubsection{US50 - Wabash River near Vincennes}

This was considered a 'heavy' DA site in Chapter 2. It was also on the initial list of sites to be periodically inspected, and so was first visited on 12/4/2004. On that day, the river stage was slightly above flood stage and rising, and moderate debris was observed at only one pier (see Figure 3.3a, pier 5 according to the bridge reports). In both the 1997 and 2001 bridge reports, moderate DA was also observed at pier 5. On the next visit, on $2 / 19 / 2005$, the river stage was again slightly above flood stage though receding. A log was still evident above the water surface, but the DA seemed to have diminished. Between these two visits, on 1/19/2005, the river had the highest discharge over the entire inspection period. During the 5/21/2005 visit, the river 


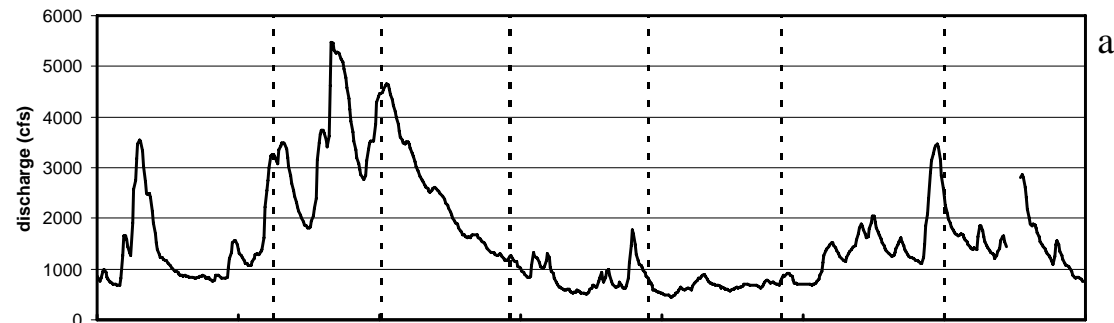

a)
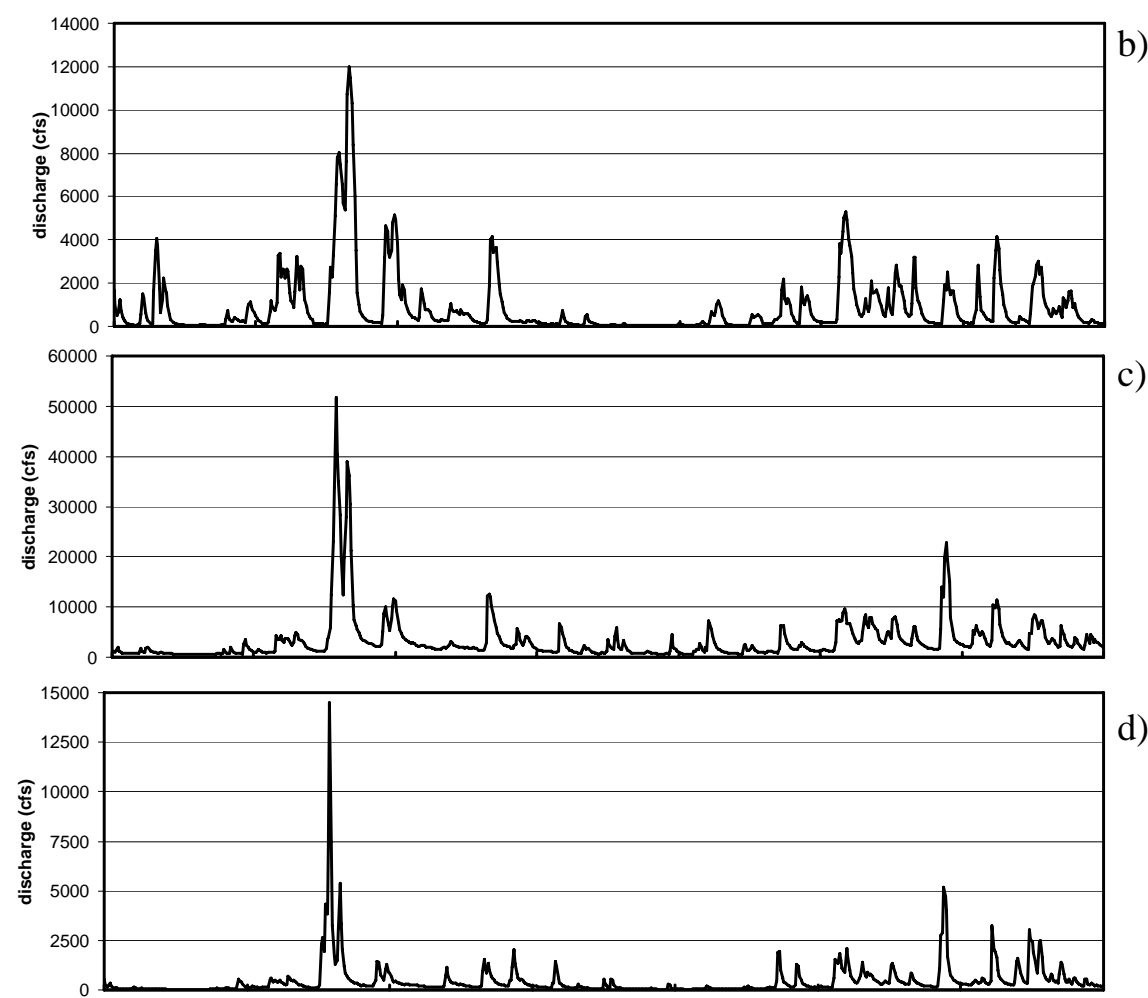

d)
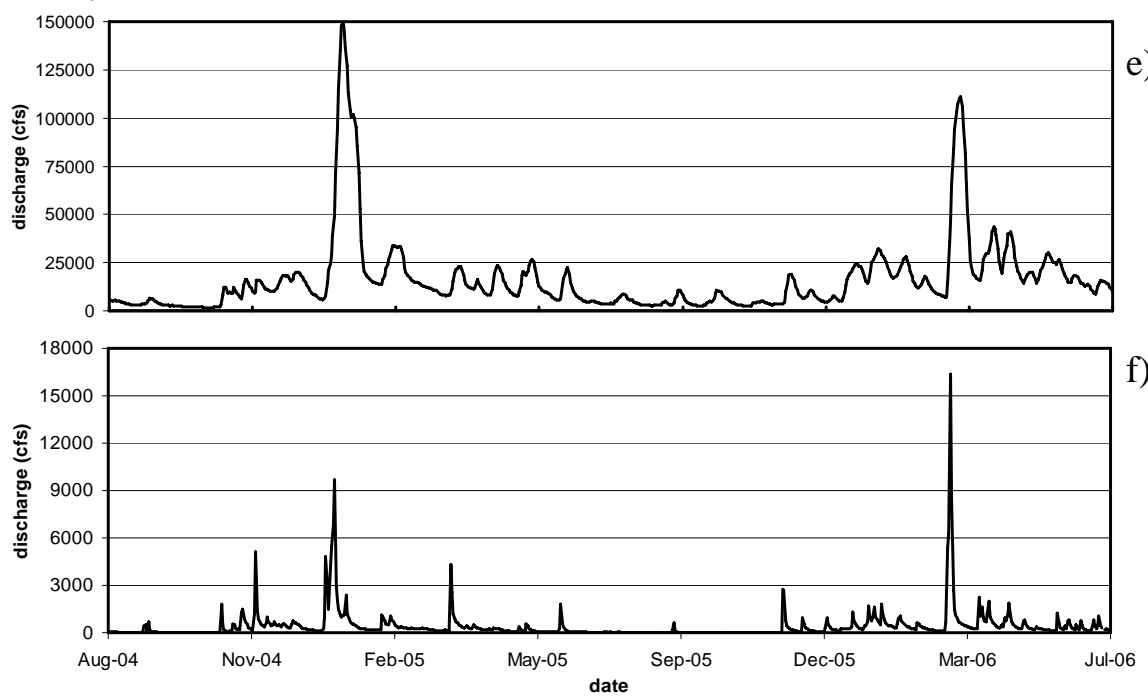

Figure 3.2: Discharge time series (source: USGS) at various stations during the program of periodic site visits, a) Kankakee (Shelby) - dotted lines indicate the first day of the site visit, b) St. Mary’s (Fort Wayne), c) White (Centerton), d) Flatrock (St. Paul), e) White (Petersburg), f) Blue (Fredericksburg) 
stage was $\approx 10 \mathrm{ft}$ lower than during the 2/19/2005 visit, and the only DA visible, apparently moderate to minor, was not on pier 5 but on the pier closer to the bank, namely pier 4 . In the 2001 bridge report, the heaviest DA was also observed at pier 4 . The river stage was still $\approx 2 \mathrm{ft}$ lower during the summer visit on 8/27/2005, and the extent of the DA became more visible, and the DA was considered moderate to heavy (Figure 3.3b). Although there were two higher-flow events between the 5/21/2005 and the 8/27/2005 visits, these were relatively small, and would not be expected to have contributed significantly to the DA. The situation did not visibly change during the subsequent visits, though the second largest flow event over the entire period did occur on 3/15/2006, less than two week before the last visit.

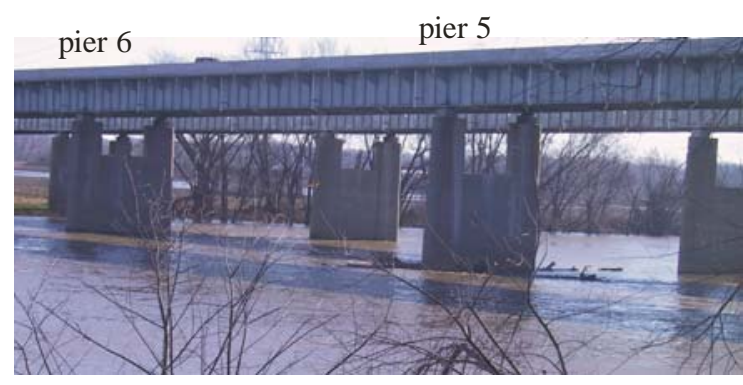

a)

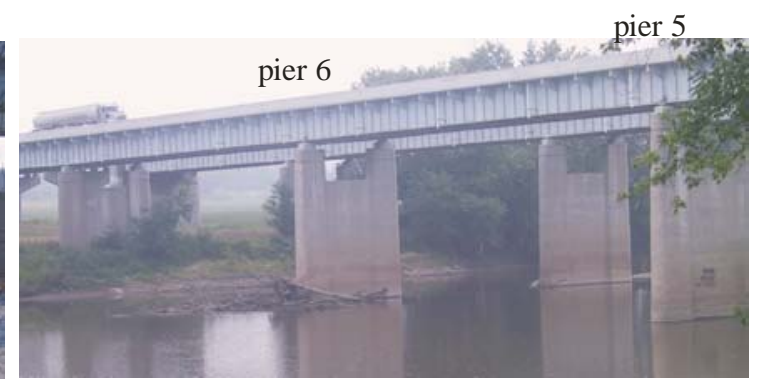

b)

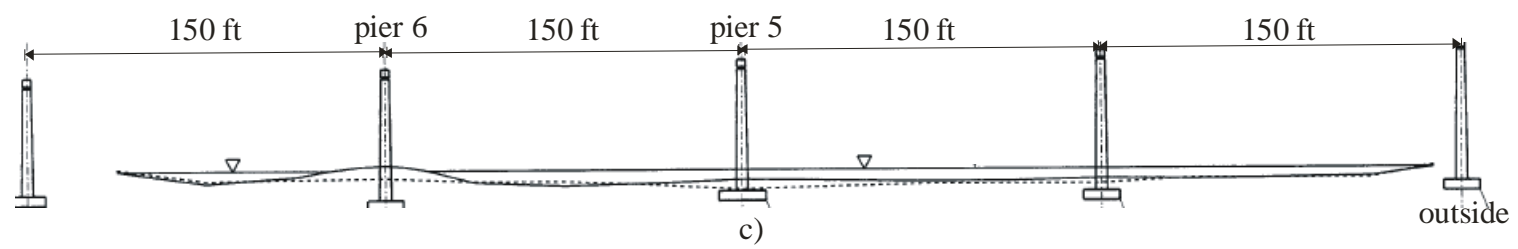

Figure 3.3: US50 - Wabash River site, a) photograph from 12/4/2004, b) photograph from 8/27/2005, and c) upstream bridge section from 2001 bridge report (all looking downstream)

The upstream bridge section, taken from the 2001 bridge report, is relatively symmetric as far as the thalweg is concerned, and does not exhibit any noticeable effect of the slight upstream bend. Most interesting however is the island feature at pier 6, where the more stable DA seemed to have formed (also somewhat unexpectedly this is towards the inner bank of the upstream bend). This island feature was not evident in any of the visits, and must have been submerged.

\subsubsection{US41 - White River near Hazleton}

In Chapter 2, this site was both a 'mega' and a 'chronic' site, and was also on the initial list of sites to be periodically visited. During the initial visit on $12 / 4 / 2005$, the river stage was relatively high, and DA was noted at the pier closest to the left bank looking downstream (Figure 3.4a). In the 2003 bridge report, the heaviest DA (1500 cu. yds.) was also observed at the same pier. On the second visit (2/19/2005), the access road to the crossing was flooded, and a close approach was not feasible. There did not however appear any substantial change with regards to DA, which also seemed to be the case in subsequent visits. During low water on the 8/27/2005 visit, however, the extent of the DA again became more evident (Figure 3.4b). The DA would likely be considered heavy but not very heavy, certainly not comparable to the 2003 DA. On the last visit (3/25/2006), a close approach was prevented again, this time by a log across the access road. If there were any changes in the DA, it was very incremental, and not notable. 
Less than mile upstream of the US41 crossing, there is an abandoned steel truss bridge (Old 41) at which there was consistently observed a DA on the pier towards the same bank as the affected pier at US41. This may play a somewhat moderating role in most years with regards to DA at US41 in that debris trapped at the upstream bridge would not be available to the downstream bridge. On the other, after this has grown to a sufficiently large size, this moderating influence may wane, such that the US41 bridge becomes increasingly exposed to greater debris supply.

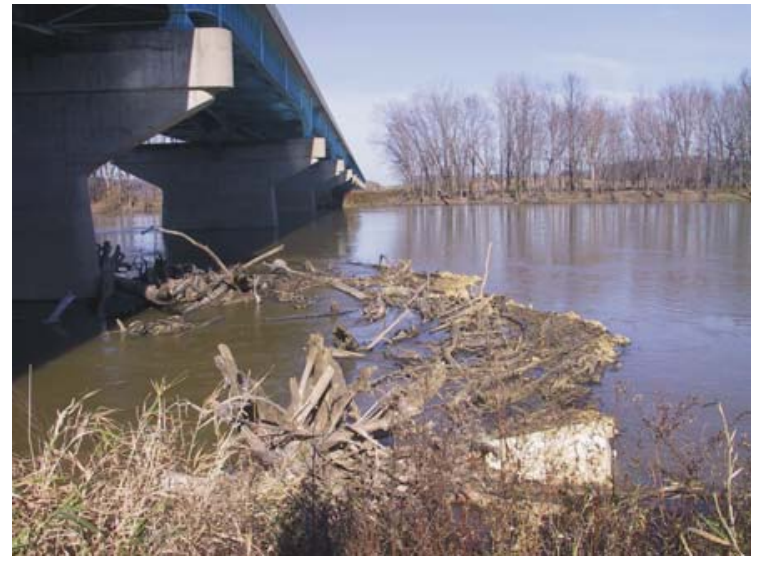

a)

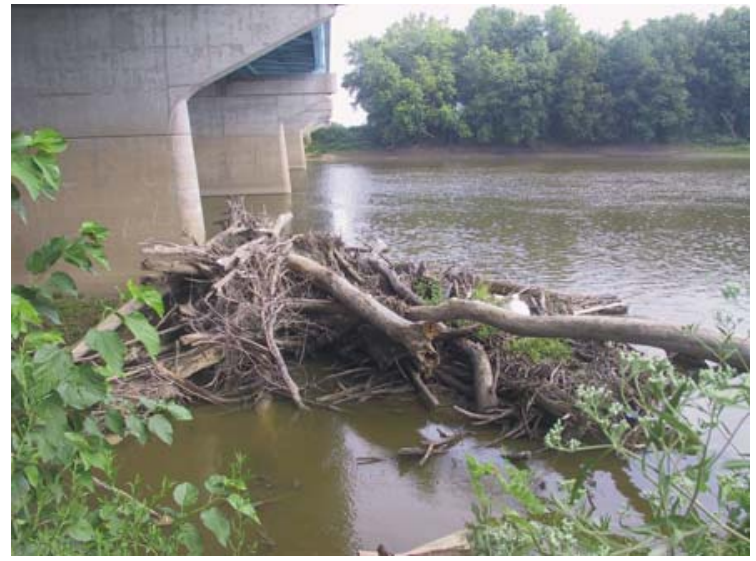

b)

Figure 3.4: US41 debris accumulation, a) on initial visit, 12/4/2004, at relatively high river stage, b) on $8 / 27 / 2005$ visit, at relatively low river stage.

\subsubsection{SR61 - White River near Petersburg}

The SR61 site is situated $\approx 25$ miles upstream of the US41 site near Hazleton, discussed in the preceding subsection, and like the Hazleton site was already discussed in Chapter 2, though as a 'lite' site rather than as a 'mega' site. Photographs from the first visit (12/4/2004) show no DA at the piers in midstream, and are unclear regarding DA on the far bank (the left looking downstream). Written notes indicate some DA visible on the far bank. Photographs from the 2/19/2005 and 8/27/2005 visits show more clearly a log on the midstream pier, and some moderate DA at the pier on the far bank. During the last visit (3/25/2006), the log at the midstream pier was no longer visible, but some minor DA was noted at the intermediate pier (in addition to that at the far pier). This pattern of DA is consistent with that in the bridge reports (see Figure 2.10g).

\subsubsection{SR57 - E. Fork White River near Petersburg}

The SR57 site is situated $\approx 1.5$ miles upstream of the confluence with the White River, and $\approx 5$ miles upsteam of the SR61 site discussed above. It was considered a 'chronic' site in Chapter 2, but was not on the initial site list, and so the first visit was performed on 5/21/2005. A DA was observed at that time (Figure 3.6a), and again seen more clearly as a heavy DA at lower river stage on 8/27/2005 (Figure 3.6b). The location of the DA, namely at the midstream pier, is consistent with bridge inspection reports. During the last visit (3/25/2006), however, written notes indicate that only light accumulation was observed (no photographic documentation was found). Interestingly, the downstream railway bridge, which had previously been clear of debris up to 11/19/2005 (Figure 3.6c), had by 3/25/2006 developed an extensive DA (Figure 


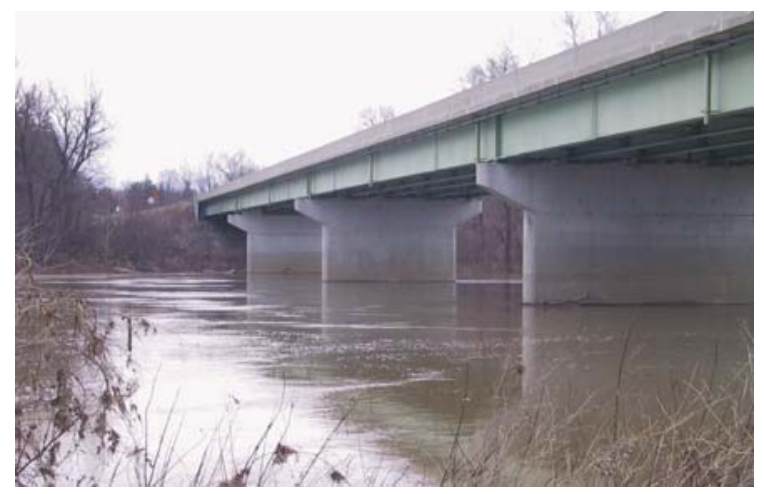

a)

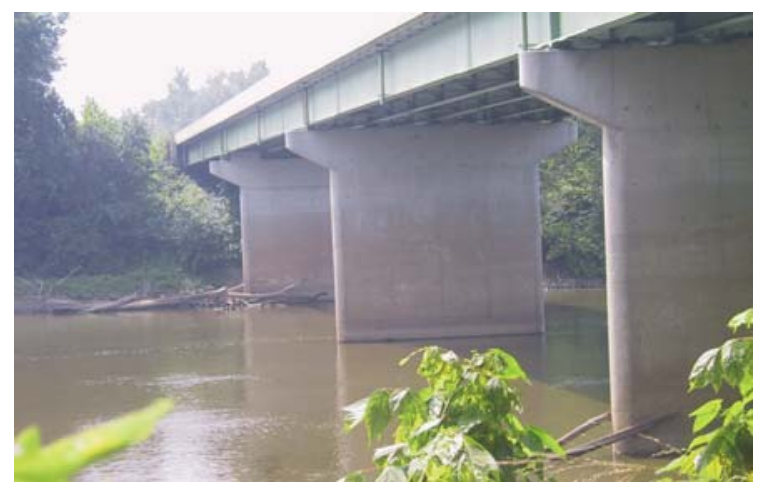

b)

Figure 3.5: SR61 site, a) from 2/19/2005, and b) from 8/27/2005.

3.6d). Although no direct evidence is available, this transfer is believed to have occurred from one pier to another mainly as a single naturally spontaneous event, in which the DA became unstable and consequently underwent a massive disaggregation, such that the debris was transported en masse and collected at the downstream pier.

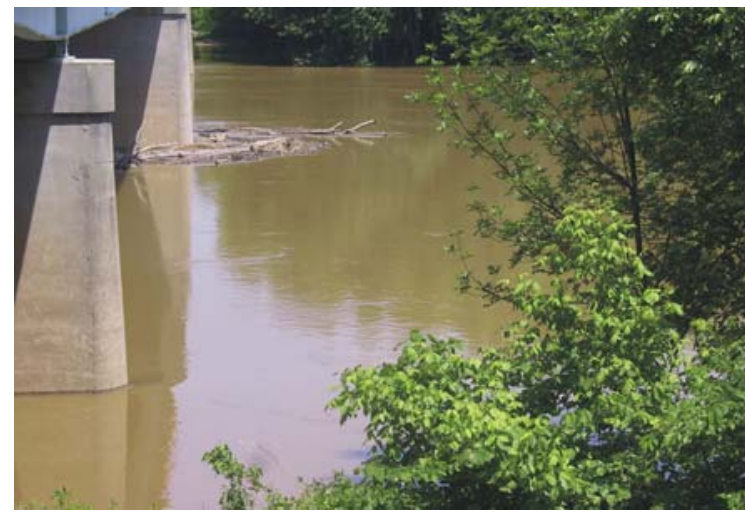

a)

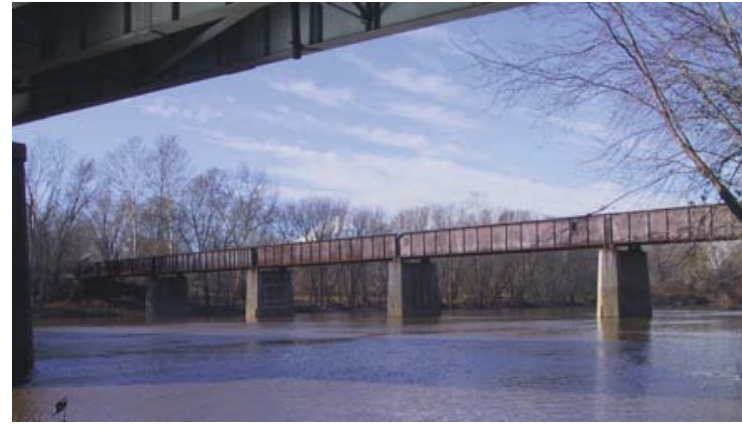

c)

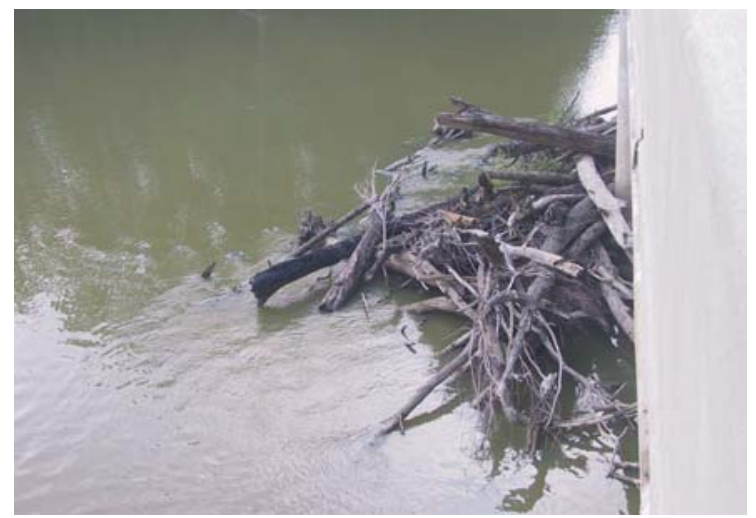

b)

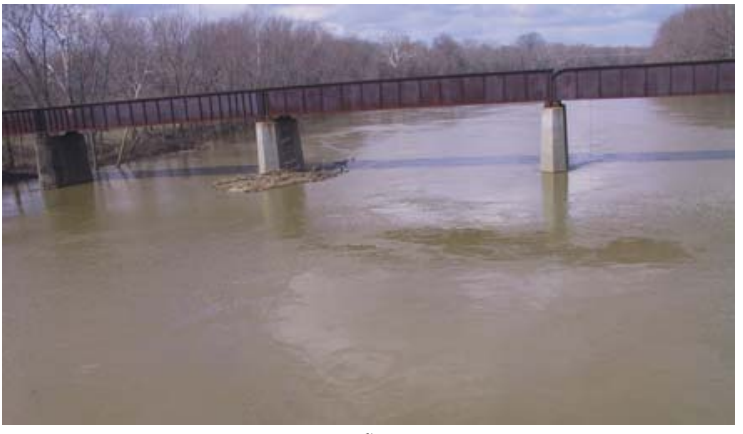

d)

Figure 3.6: SR57 site, a) from 5/21/2005, b) from 8/27/2005, c) view of downstream railway bridge on 11/19/2005, and d) view of downstream railway bridge on 3/25/2006.

\subsubsection{SR257 - E. Fork White River near Otwell/lva}

The SR257 site is $\approx 9$ miles upstream of the SR57 site. It was labeled as a 'mega' site in Chapter 2, with the largest ever estimated DA. Although it was on the initial site list, it was mistakenly overlooked during the initial set of visits, and so it was first visited on 2/19/2005. A 
heavy DA had already formed (Figure 3.7a) at the pier consistent with the bridge inspection reports. The extent is better evaluated during the low-stage visit of 8/27/2005 (Figure 3.7b), which also corresponds more closely to the bridge inspection reports. On subsequent visits, no dramatic change was evident.

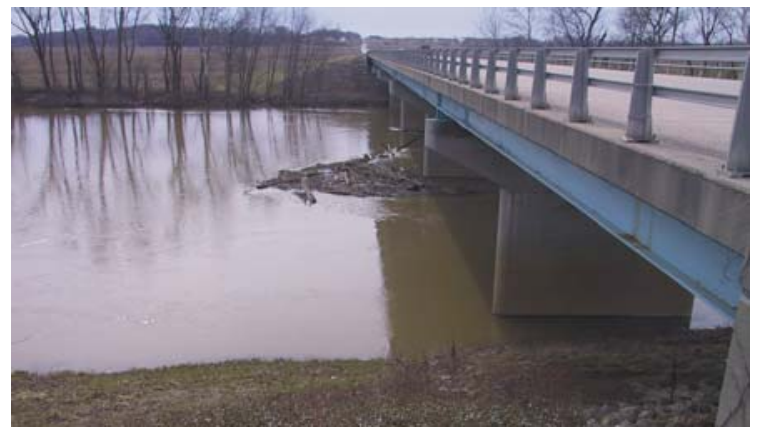

a)

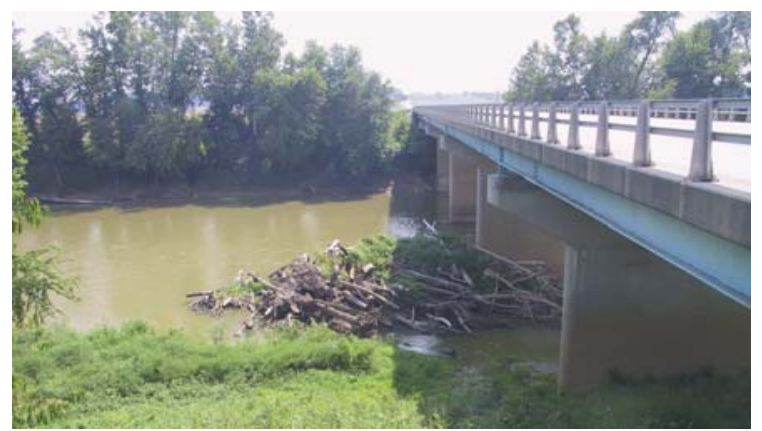

b)

Figure 3.7: Photographs at the SR257 - E. Fork White River site, a) from 2/19/2005 visit, b) from 8/27/2005 visit.

\subsubsection{US231(45) - E. Fork White River near Haysville}

The US231(45) site is $\approx 15$ miles upstream of the SR257 site. It was considered a 'chronic' site in Chapter 2, but was not on the initial site visit list, and so the first visit was undertaken on 5/21/2005. The structure is a narrow steel truss bridge, and safe access to the crossing was difficult, particularly during the summer when there was thick foliage. On the first visit, written notes indicate that there was evidence of some light to moderate DA at the midstream pier, which was seen to be moderate to heavy at the lower-stage visit on 8/27/2005. During the fall visit (11/19/2005), when the absence of foliage permitted a closer approach and better photographic documentation, the DA (Figure 3.8a) seemed to have decreased in size. Because there was no significant high-flow event, it is not clear whether this was a merely an apparent or actually a real decrease. On the other hand, there was visual evidence during the last visit on 3/25/2006 that there was an increase in the amount of DA, though the increase was not dramatic (Figure 3.8b).

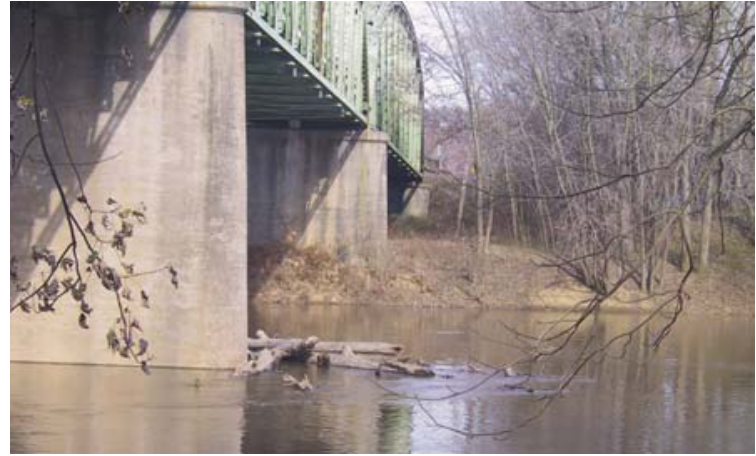

a)

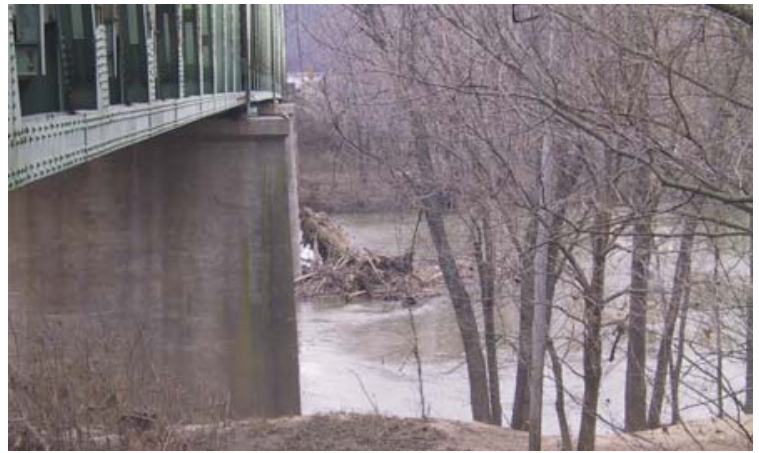

b)

Figure 3.8: Photographs from US231(45) - E. Fork White River, a) from 11/19/2005 visit, b) from 3/25/2006 visit 


\subsubsection{SR164 - Patoka River near Jasper}

The SR164 Patoka River structure is a short-span (spans are $36 \mathrm{ft}$ or shorter) bridge, and has suffered repeated DA, though it was considered only heavy but not 'chronic' in Chapter 2 . For that reason, it was at one time a test bed for a commercial debris deflection device (the same 'DebrisFree' device seen in Figure 1.1), which was however deemed to have failed, and so was subsequently removed. Likely because of its short span, it was not on the initial site list, but was reinstated because it was conveniently located just south of the US231(45) - E. Fork White River site. A dam or grade-control structure is situated just downstream of the bridge. The discharge time series at this site already exhibits the characteristics more typical of the southeast than the southwest in that the largest discharge over the study period occurred in March 2006 rather than in January 2005.

On the first visit (5/21/2005), moderate to heavy DA was noted, with debris at both piers 5 and 6 (Figure 3.9a) though close examination does not indicate that this was necessarily associated with a large log spanning two piers. In the bridge reports, DA was also observed at both piers, with perhaps a tendency for greater DA at pier 6. Part of the mounting hardware for the debris deflecting devices can still be seen at both piers in Figure 3.9a. By the next visit on $8 / 27 / 2005$, all of the debris seemed to have been deliberately cleared (Figure 3.9b), and remained clear up to the fall visit on 11/19/2005. By the last visit (3/25/2006), moderate to heavy DA had occurred again (Figure 3.9c). Unlike the earlier DA, there is some evidence that this DA may be a case of multiple-pier DA. Because of the short spans (the dam or grade-control structure may also have contributed by reducing flow velocity), this site may be especially prone to heavy DA, but its experience does demonstrate, as was already seen in Lyn et al. (2003) that recurrence intervals for heavy DA can be as short as a year.

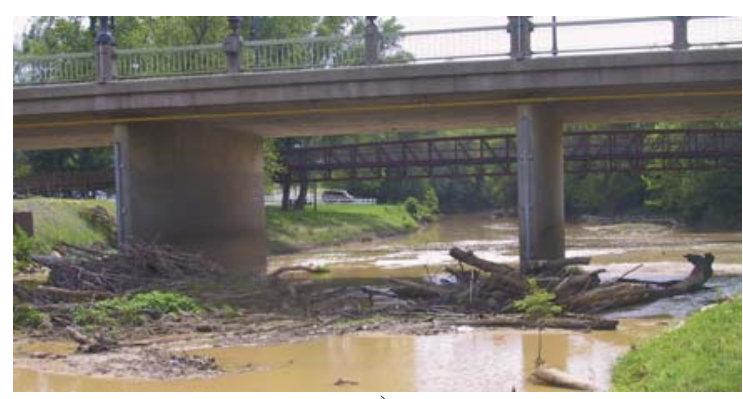

a)

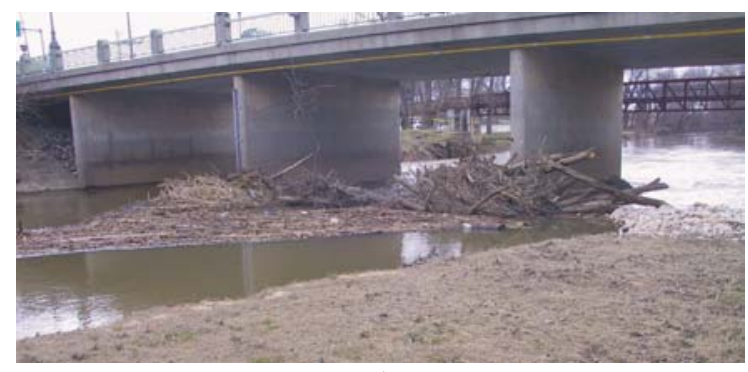

C)

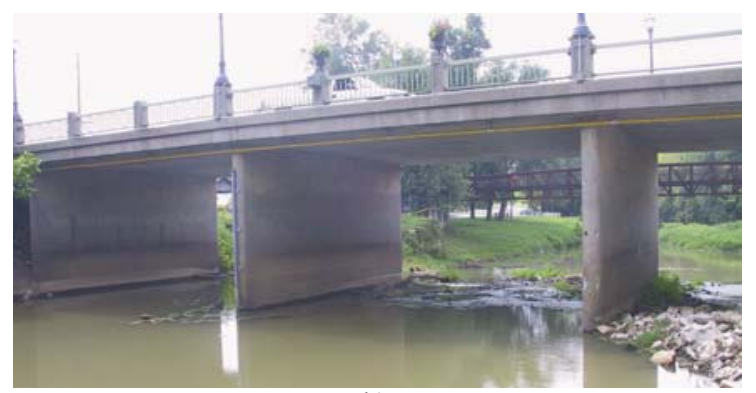

b)

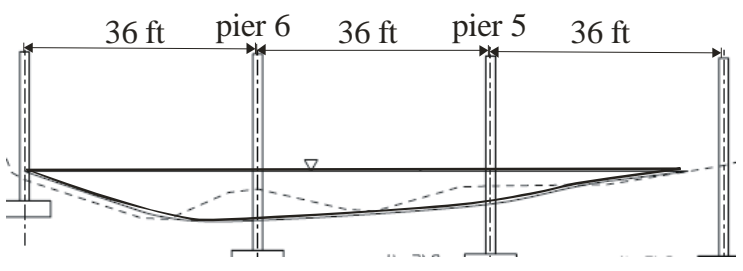

d)

Figure 3.9: Photographs from SR164 - Patoka River site, a) from 5/21/2005 visit, b) from 8/27/2005 visit, c) from 3/25/2006 visit, and d) cross-section at upstream face of bridge (looking downstream) 


\subsubsection{SR335 - Indian Creek near Crandall}

The SR335 - Indian Creek site is considered a 'mega' site in Chapter 2, but was not included in the initial site list. On the first visit (5/21/2005), a very heavy DA was observed (Figure 3.10a) essentially extending to the right bank, similar to that seen in bridge reports (see Figure 2.8c). Subsequent visits indicated some change (Figure 3.10b), but the changing water surface level mak it difficult to determine whether an overall increase or decrease in the amount of DA had occurred.

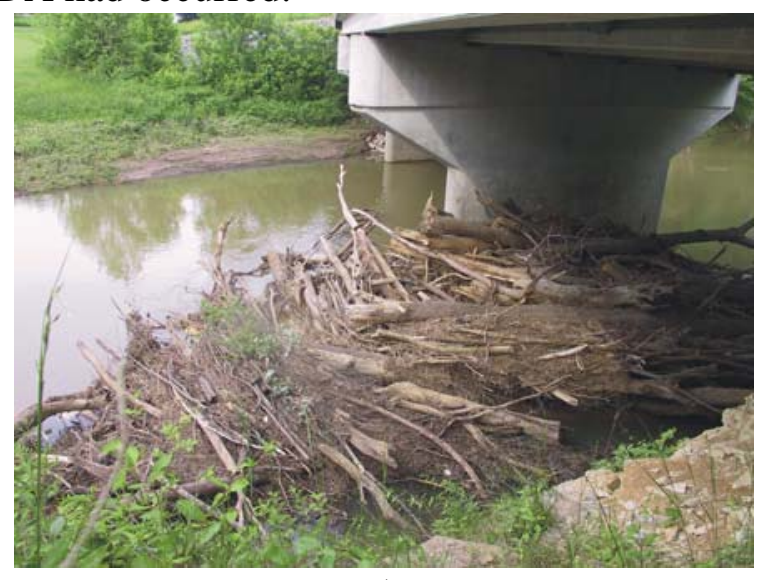

a)

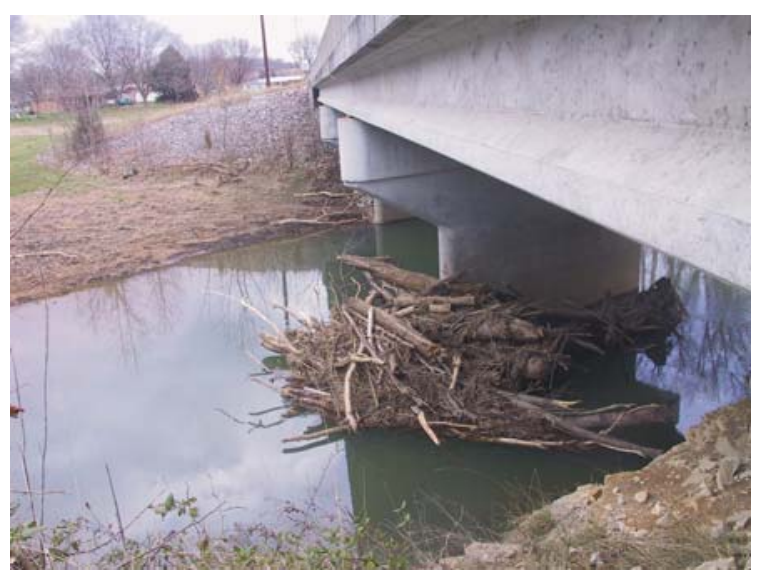

b)

Figure 3.10: Photographs of SR335 - Indian Creek site, a) from 5/21/2005 visit, b) from 3/25/2006 visit

\subsubsection{US31 - Muscatatuck River near Austin}

The US31 - Muscatatuck River site was considered 'heavy' in Chapter 2, but did not figure in the initial site list. During the summer months, close access was difficult, but written notes indicate that there was no sign of any large DA. In the fall and winter months, when photographic access was possible, there was no sign of debris at any of the piers. The 'heavy' designation in Chapter 2 was based on a large DA reported in 1997; the more recent report in 2003 reported only a minor DA.

\subsubsection{SR39 - White River near Martinsville}

The SR39 - White River site was considered both a 'mega' as well as a 'chronic' site, but was not on the initial site list. The first visit was made on 5/27/2005, and a very heavy DA was found (Figure 3.11a) at the same pier as in the bridge reports (see Figure 2.8d). Visits on 9/3/2005 and on 11/24/2005 indicated that the DA had become smaller (Figure 3.11b), though no significant high-flow event occurred during the intervening period. On the last visit on 4/8/2006, the DA had grown again (Figure 3.11c) to be very heavy.

\subsubsection{SR18 - Salamonie River near Montpelier}

The SR18 - Salamonie River site was considered a 'heavy' site in Chapter 2, and was also on the initial site list, but was only first visited on 5/22/2005, during which a moderate to heavy DA was noted (Figure 3.12a). During the summer, a number of bridges were cleared of debris, including the SR18 bridge near Montpelier. In spite of this clearing, there seemed to have developed by the 11/20/2005 visit (Figure 3.12b) another moderate DA, including the addition of a long log. The DA seemed to have decreased somewhat by the 3/26/2006 visit (Figure 3.12c), though the long log is still in evidence. 


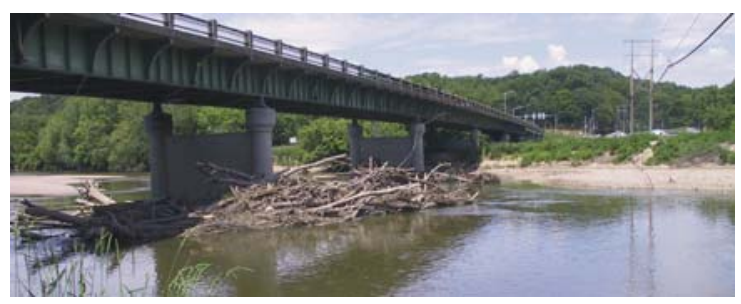

a)

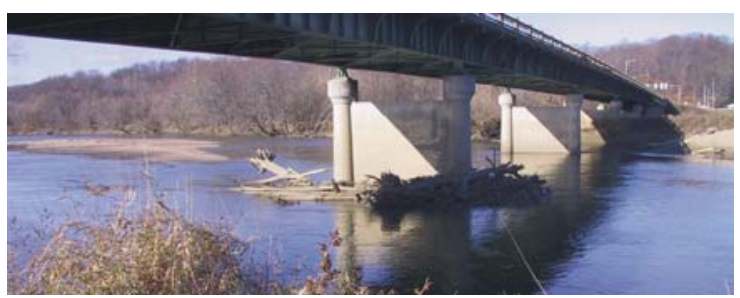

b)

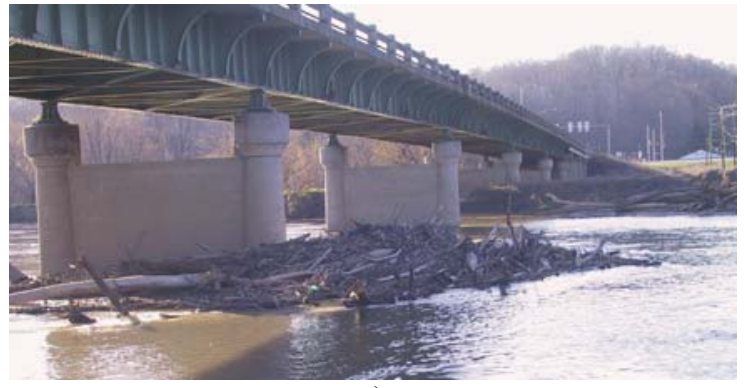

C)

Figure 3.11: Photographs of the SR39 - White River site, a) from 5/27/2005 visit, b) from 11/24/2005 visit, c) $4 / 8 / 2006$ visit.

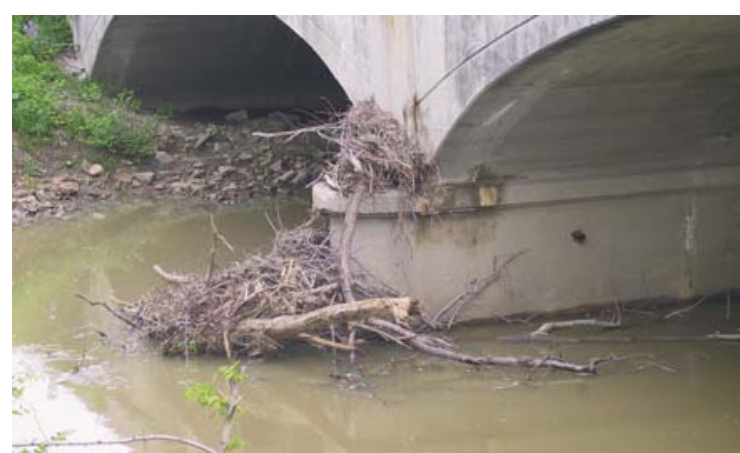

a)

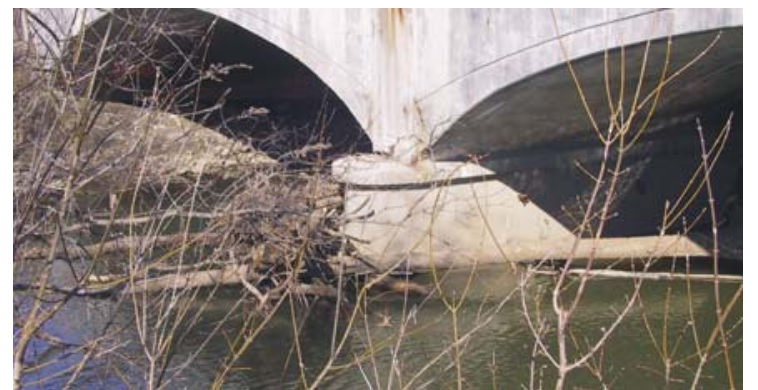

c)

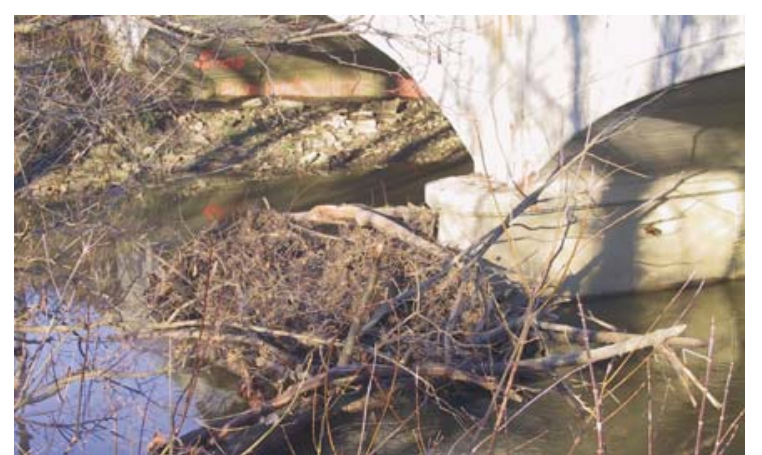

b)

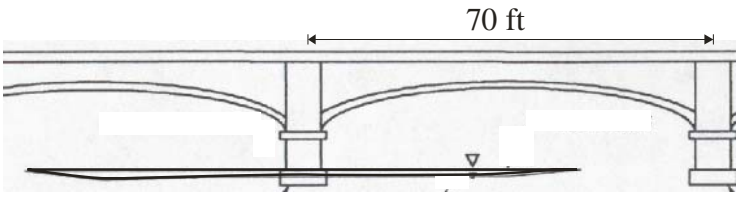

d)

Figure 3.12: Photographs of the SR18 - Salamonie River site, a) from the 5/22/2005 visit, b) from the $11 / 20 / 2005$ visit, c) from the 3/26/2006 visit, and d) cross-section just upstream of bridge looking downstream

\subsubsection{SR18WB - Mississinewa near Marion}

The SR18 (Westbound) - Mississinewa structure is $\approx 500 \mathrm{ft}$ downstream of the eastbound bridge, and $\approx 150 \mathrm{ft}$ downstream of an abandoned bridge. The westbound bridge was considered a 'chronic' site in Chapter 2, but the upstream bridge had by comparison only light accumulation in the bridge inspection reports. Neither bridge was on the initial site list. During the first visit $(5 / 22 / 2005)$, at the structure itself there was only light DA at two piers, but at the abandoned 
upstream piers, there was heavy DA (Figure 3.13a). In later visits, the isolated logs seen in earlier visits had disappeared (Figure 3.13b). This was later found to be due to debris clearing at several bridges including the SR18 westbound bridge near Marion. Written notes indicated that there was still considerable debris at the piers of the upstream abandoned bridge. The difference between the upstream and the downstream bridge as far as DA is concerned is striking. This can be attributed to the longer span of the upstream bridge (142 ft for the central span compared to $81 \mathrm{ft}$ for the central span of the downstream bridge), and possibly also the presence of the upstream abandoned bridge piers. These trap substantial amounts of debris, which if destabilized can migrate downstream as a debris cluster and in this form is more likely to be trapped at the downstream bridge.

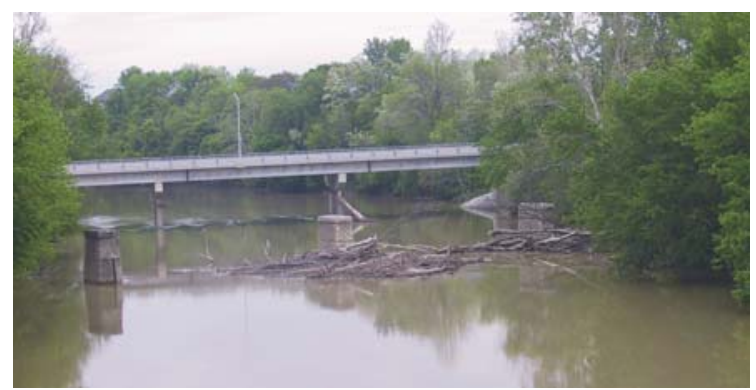

a)

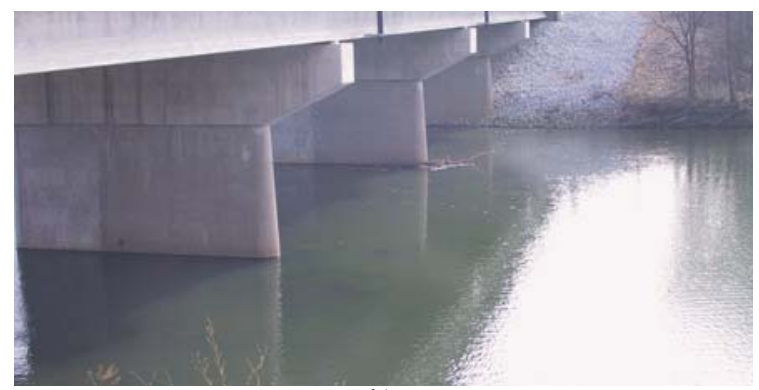

b)

Figure 3.13: Photographs from the SR18 - Mississinewa River site, a) from 5/22/2005 visit, b) from 3/26/2006 visit

\subsubsection{9(24) - St. Mary's River near Fort Wayne}

The I469(24) - St. Mary's River site was a 'heavy' site in Chapter 2, and was included in the initial site list. On the first visit (12/5/2004), a light to moderate DA was seen at the midstream pier (Figure 3.14a). A snowstorm during the second visit (2/20/2005) precluded any detailed examination, but written notes suggest that no large DA could be observed. This was

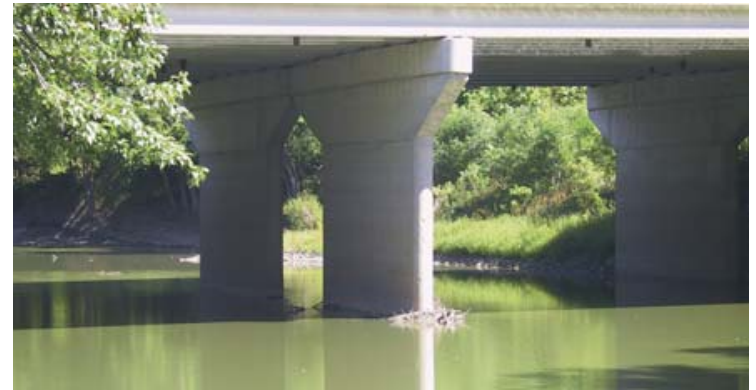

a)

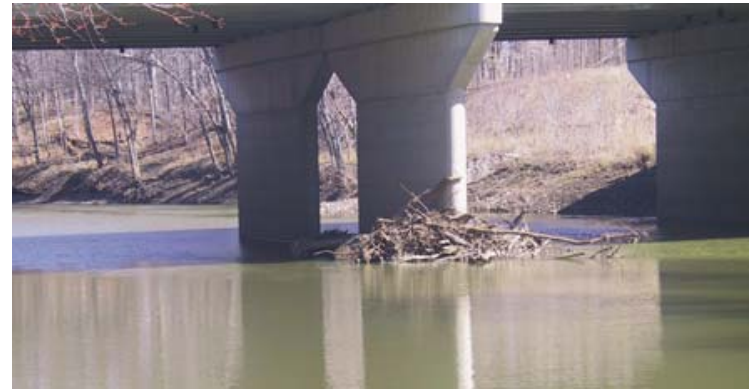

b)

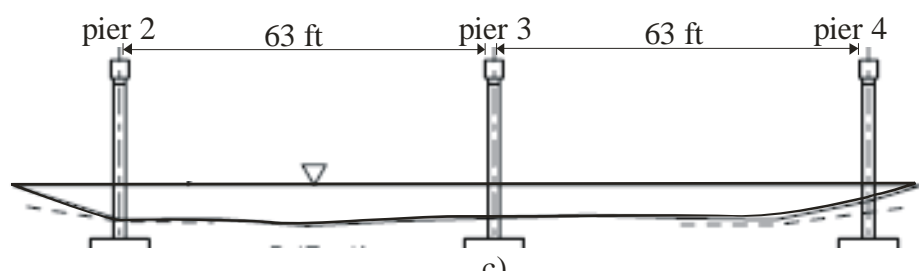

c)

Figure 3.14: Photographs from I469 - St. Mary’s River site, a) from 12/5/2004 visit, b) from 3/26/2006 visit, and c) cross-section just upstream of bridge looking downstream 
confirmed at the next visit (5/22/2005), and this situation did not change significantly until the last visit (3/26/2006) when a moderate to heavy DA was noted (Figure 3.14b). This sequence is of interest in that the largest flow event at this site occurred in January 2005, an estimated 10year event, whereas the main high flow event between 11/20/2005 and 3/26/2006 was estimated to have a recurrence interval of only $1-2$ years. A close positive relationship between the magnitude of the flow event and DA is therefore not tenable.

\subsubsection{US27 (Southbound) - St. Mary's River in Fort Wayne}

The southbound US27 - St. Mary’s River site was classed as a 'heavy' site in Chapter 2, and was included in the initial site list. On the first visit (12/5/2004), an extensive DA had already formed (Figure 3.15a), the size of which became evident on 5/22/2005 at lower stage (Figure 3.15b). The site was cleared of debris, possibly coinciding with the 8/28/2005 visit (Figure 3.15c) when the DA seemed to have been slightly reduced, but, evidently by $11 / 20 / 2005$, the DA was substantially reduced (Figure 3.15d). On the last visit (3/26/2006), a moderate to heavy DA had become re-established (Figure 3.15e). From the side view, the DA at its heaviest seemed to extend from bent 3 to bent 5 , but an upstream view shows two major accumulations at

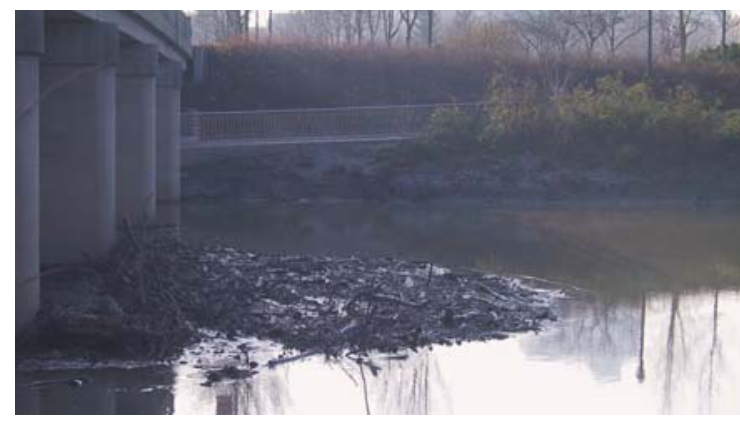

a)

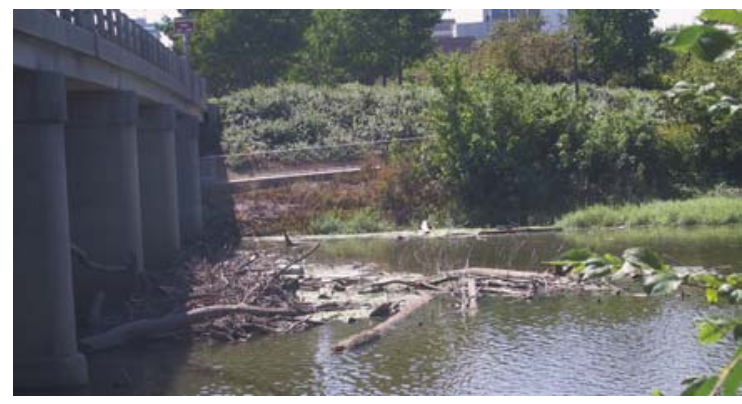

c)

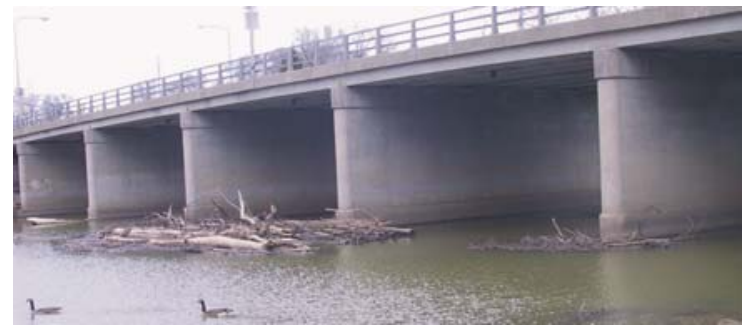

e)

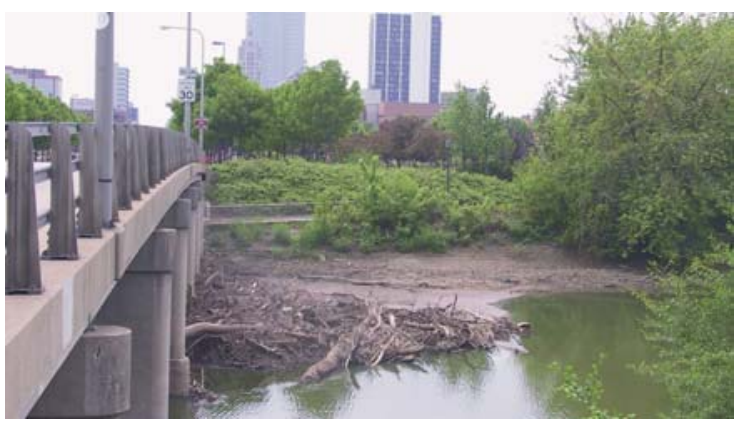

b)

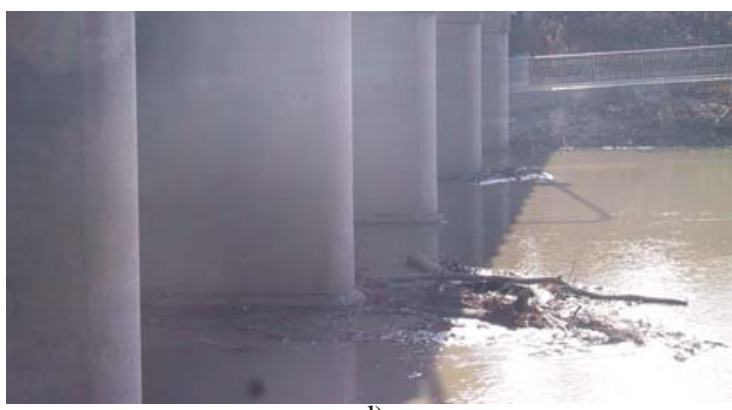

d)

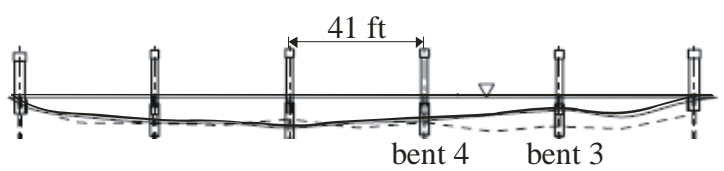

f)

Figure 3.15: Photographs from US27 - St. Mary’s River site, a) from the 12/5/2004 visit, b) from the $5 / 25 / 2005$ visit, c) from the $8 / 28 / 2005$ visit, d) from the $11 / 20 / 2005$ visit, e) from the 3/26/2006 visit, and f) cross-section just upstream of the bridge looking downstream (2003) 
bents 3 and 4 with only small if any overlap. In the 2001 bridge inspection report, when the largest DA was observed, debris extended over the entire channel at all piers, but in the more recent 2003 report, DA was mainly found at bents 3 and 4. A flow expansion (width-ratio of $\approx 1.2$ ) and short spans ( $41 \mathrm{ft}$ ) certainly contributed to the DA at this site though bents 3 and 4 are notably situated on the inside of the bend.

\subsubsection{The northwest sites}

The four sites towards the northwest, namely, US6 - Deep River near Lake Station, SR55 - Kankakee River near Shelby, US41 - Kankakee River near Schneider, and US14 - Tippecanoe River near Winamac, are discussed together because, over the course of the entire study period, little or no debris was observed at these sites. This is somewhat surprising since these include a 'chronic' site (US6) and two 'heavy' sites (SR55 and US41). At the US41 site, some debris in the form of a large log was noted at one pier during one visit (Figure 3.16b), but the most notable aspect of the site was the extensive DA at a railway bridge $\approx 200 \mathrm{ft}$ upstream (Figure 3.16c). The SR55 site had a similar feature in that minor DA was noted at one pier (Figure 3.16d), but there was extensive DA at a railway bridge $\approx 400 \mathrm{ft}$ downstream (Figure 3.16e). Because DA at railway bridges was not the focus of the study, changes over time of these large DA were not closely monitored. The presence of these extensive DA implies that debris is readily available. The lack of significant debris at the US41 site can be explained by the fact that the upstream bridge traps most of the debris, but the similar lack at the SR55 site is more difficult to explain. At neither the US6 nor the US14 site was there any debris of note (Figure 3.16a, f).

\subsubsection{The Logansport sites}

Three sites, all on the initial site list, are located in Logansport, two bridges over the Wabash River, US35 and SR25, and one bridge over the Eel River, SR25. The first is less than a mile downstream of the second, which itself is less than half a mile downstream of the third. The confluence of the Eel and the Wabash is located about 0.15 mile downstream of the third. A railway bridge crossing the Wabash also lies between SR25 and US35. Photographs at the three sites are shown in Figure 3.17 (those on the left were taken on the first visit on 12/12/2004, those on the right on the last visit on 4/1/2006). Moderate DA is seen at the SR25, initially at only a single pier (pier 4, Figure 3.17a), and was still quite large on the 11/26/2005 visit, but during the last visit, the initial DA seemed to have become noticeably smaller (Figure 3.17b). Another DA, first noticed as an isolated log on pier 5 on 5/22/2005, had already developed into moderate DA by $11 / 26 / 2005$, and remained stable to the last visit (Figure 3.17b). In the 2001 bridge report, the heaviest DA was observed at pier 3. Moderate to heavy DA is initially seen (Figure 3.17c) at piers 4 and 6 at SR24 (35), and some increase in size is noted during the last visit (Figure 3.17d). Not shown in the photographs is another smaller DA at pier 8 that was first noticed on 3/5/2005, and continued to be present to the last visit. Previous bridge reports indicated that debris was observed at these piers, but was not limited to these piers. Throughout the study period, moderate to heavy DA was observed at two piers on the railway bridge between SR25 and US35. The rather variable pattern of DA at the two bridges compared to that seen in the bridge reports may possibly be attributed to the confluence with the Eel River. Farther upstream at the SR25 bridge, the Eel River has a well-developed vegetated extensive midstream island. Minor DA was initially observed at the site(Figure 3.17e), but did not develop further, and eventually became smaller (Figure 3.17f). 


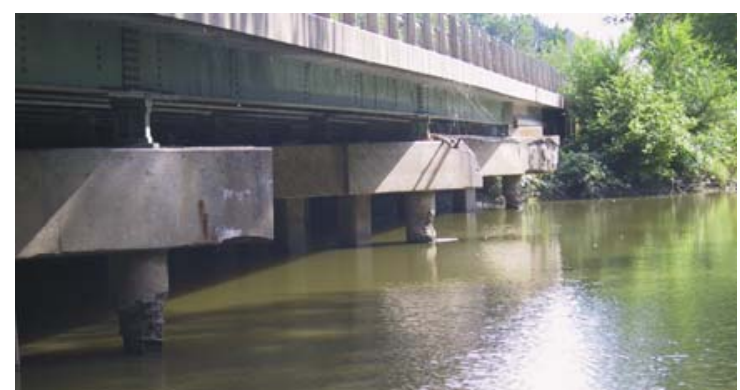

a)

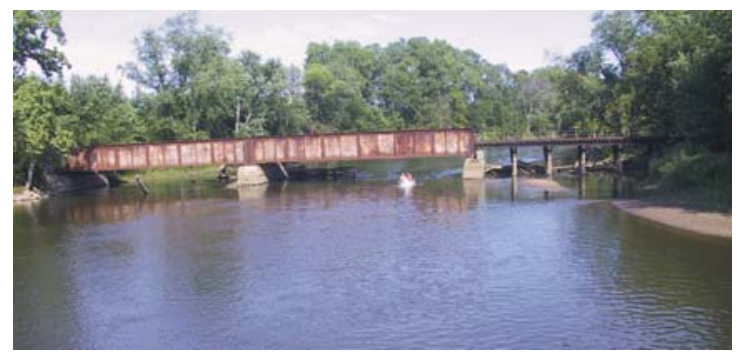

C)

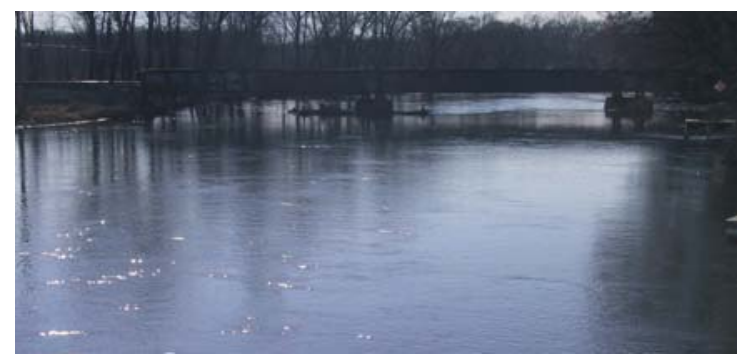

e)
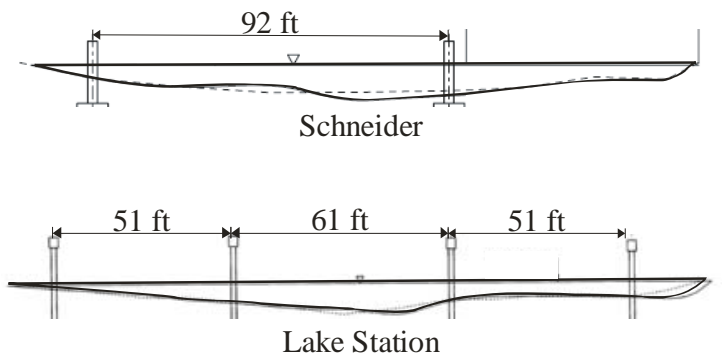

g)

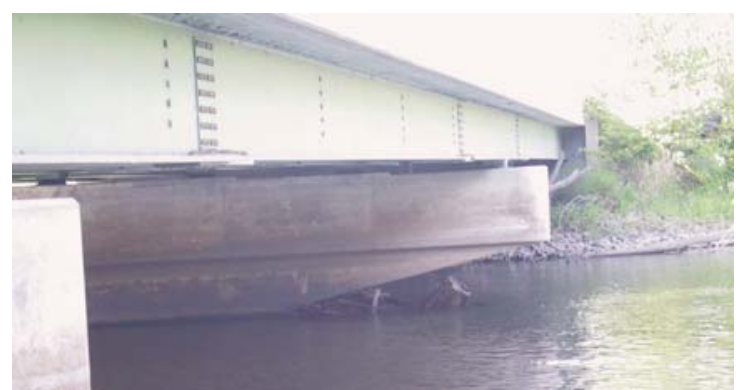

b)

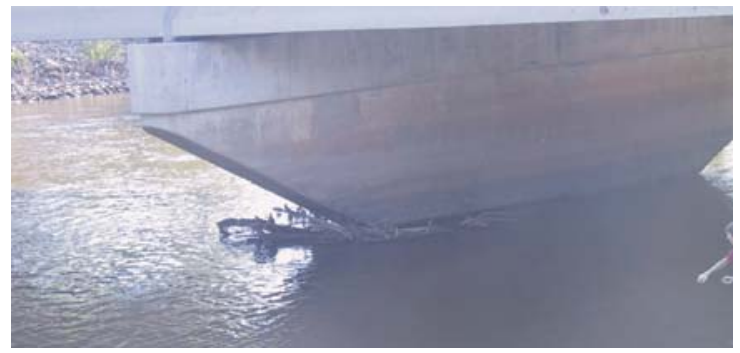

d)

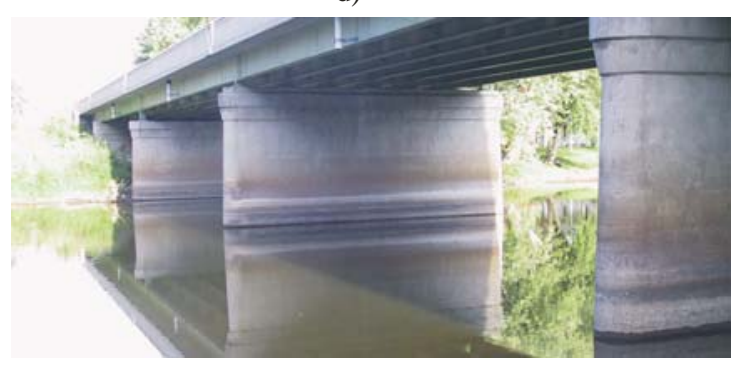

f)
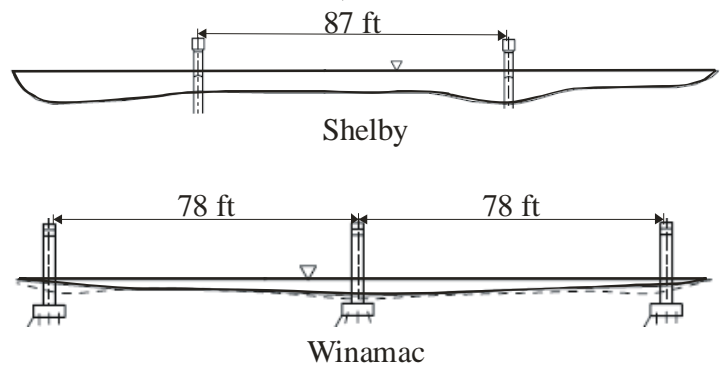

Figure 3.16: Photographs from a) US6 - Deep River site, b), c) US41 - Kankakee River site, d), e) SR55 - Kankakee River site, f) US14 - Tippecanoe River site, and g) cross-sections just upstream of bridges looking downstream. All photographs from 8/28/2005, except e), which is from $3 / 26 / 2006$.

\subsection{Discussion}

A program of periodic visits to a larger number (say $>15$ ) of sites at periods of $3-4$ months was motivated as an intermediate approach between continuous monitoring at a few $(<5)$ sites and study of bridge inspection reports for a very large number of sites that are available however only for a very limited number of times ( $1-3$ times over 12 years). A bridge inspection, conducted at an inopportune time, may give the impression of minor DA if a spontaneous disaggregation or a debris-clearing operation of a heavy DA had taken place just prior to 


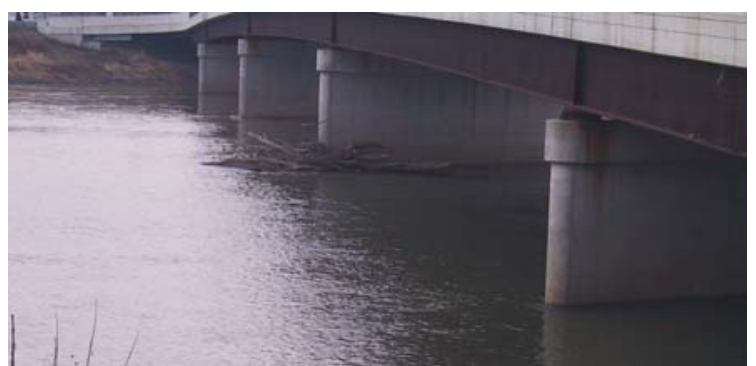

a)

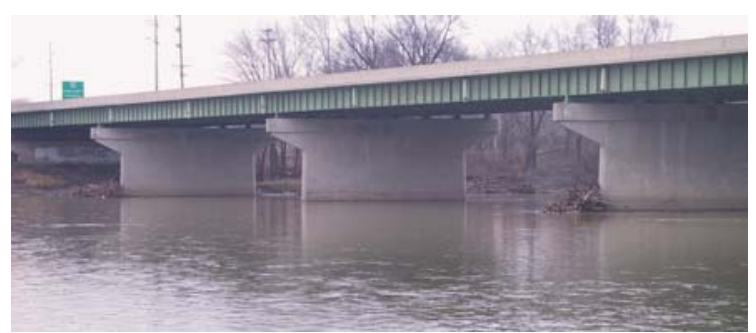

c)

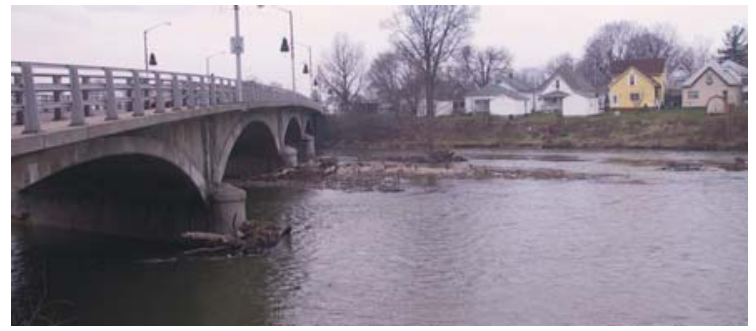

e)

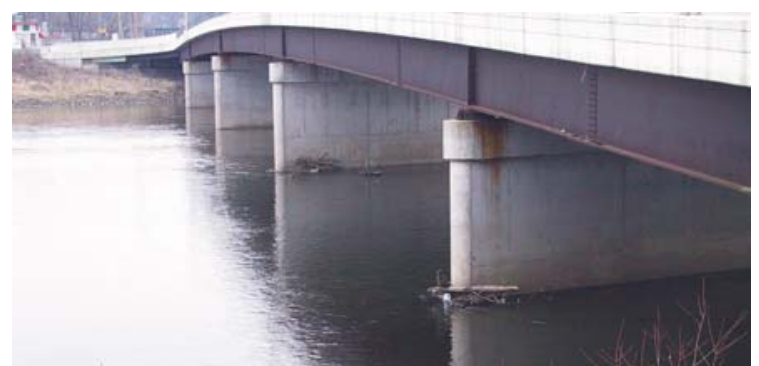

b)

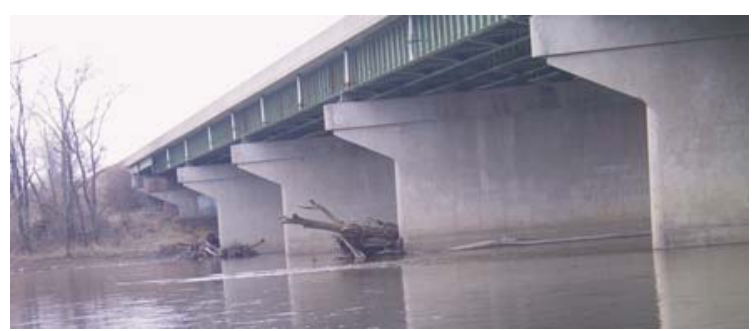

d)

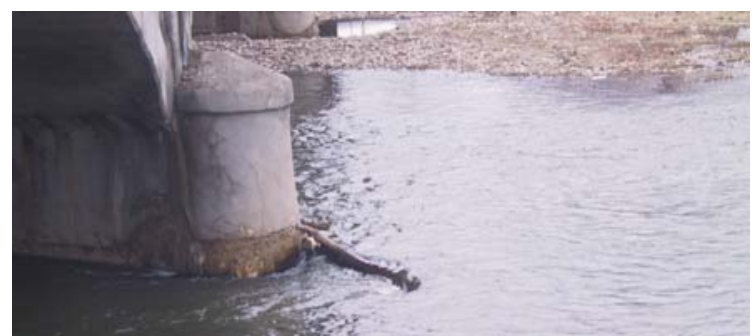

f)

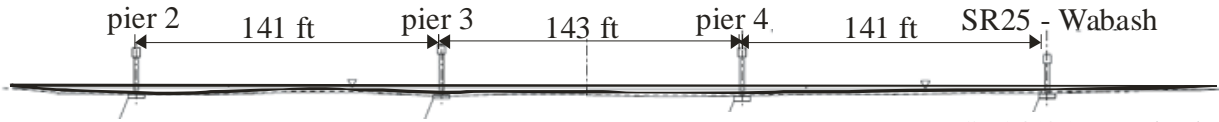

SR24(35) - Wabash

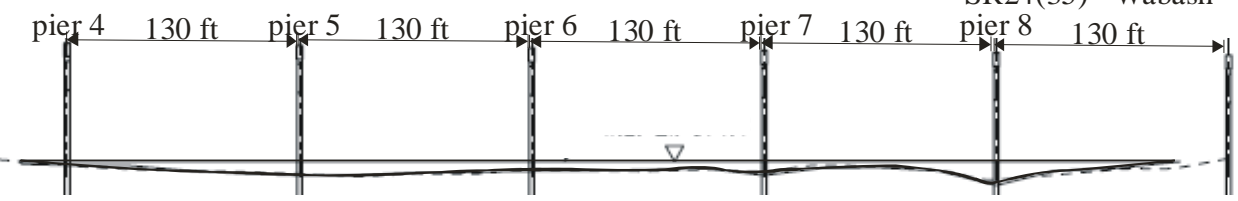

$117 \mathrm{ft}$

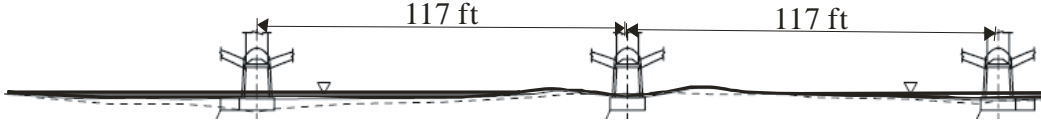

g)

Figure 3.17: Photographs of the Logansport sites, a), b) SR25 - Wabash River, c) , d), SR24(35) Wabash River, e), f) SR25 - Eel River, and g) cross-sections of the sites just upstream of the bridges. Photographs on left are from 12/12/2004, while those on the right are from 4/1/2006; cross-sections are from the latest available bridge inspection reports.

a bridge inspection. Evidence of both of these occurring was found during the current program of periodic site visits.

Of some interest is the spatial distribution of DA at a site in comparison with that seen in the bridge reports. There is a close correspondence between the two, which supports the hypothesis that the phenomenon of DA is not entirely random, i.e., DA does not occur with equal probability at each pier in the stream. Local factors strongly influence at which pier DA will 
develop to any significant extent. In some cases, an extraordinary complicating factor, such as an upstream confluence with a large stream, may however increase variability and apparent randomness, or increased DA at a pier that would otherwise not have been expected to experience large DA.

The relationship between hydrology, i.e., stream discharge, and debris accumulation has also been examined. Over the course of the study period, one large (8- - 20-year) event occurred early over most of Indiana, the southeast being the notable exception, with the next largest event being a more common $1-2$-year event. The available evidence does not support any strong correlation between the magnitude of a flow event and the likelihood of a heavy DA at any given site. The large event did not result in any dramatic initiation or development of large DA at sites that were visited about a month before and about two months after the large event. The general limitations of visual inspection at intervals of $3-4$ months must be borne in mind. In a large event at high stage, what is visible on the water surface may only be small proportion of the DA. Accumulation quickly followed by disaggregation could also occur during a time span shorter than the period between visits. On the other hand, smaller events have brought about noticeable, if not necessarily dramatic, changes in DA, e.g., at the SR39 - White River or the Fort Wayne sites. High-flow events are associated with larger depths and higher velocities at the water surface, and both of these factors might negatively affect DA.

The program of periodic site visits also gives some insight into the time development of a DA, and its recurrence interval. Over the past 16 months of the study period, it was found that, in most cases, the change if any had at all occurred was at most incremental over the visiting interval of 3-4 months. Several notable exceptions may however be highlighted. At both the SR164 - Patoka River and the US27 (southbound) - St. Mary's River sites, quite heavy DA had become established over a 4-month period from relatively minor DA beginnings. Both of these are short-span $(\approx 40 \mathrm{ft}$ ) structures that might therefore be considered most susceptible to heavy DA. This suggests that, for longer-span structures, heavy DA develop over a number of years rather than over a single season. Nevertheless, over the same 4-month interval, the SR39 White River bridge, with spans of $130 \mathrm{ft}$, did experience substantial DA, if not necessarily at the 'mega' level.

Even if a DA needs several years to achieve a very large 'mega' size, this does not imply that the growth is gradual and continuous, with some contribution from every high-flow event. A particularly interesting observation was that at the SR57 - E. Fork White River site, where, over a single visiting period, a previously stable heavy DA seemed to have disengaged from a bridge pier, and 'migrated' as an entire raft to a pier at a downstream railway bridge, which previously was wholly free of debris. This suggests that longer periods of relative 'dormancy' may be punctuated by short periods of 'highly concentrated' debris movement and quite possibly a thereby increased probability of DA.

This raises the question regarding the role played by upstream structures. In the overwhelming majority of cases in bridge inspection reports where there are parallel bridges in very close proximity, say within $100 \mathrm{ft}$, the downstream bridge suffers far less from DA than the upstream bridge, presumably because it is being sheltered by the latter. For structures more than $200 \mathrm{ft}$ apart however the sheltering effect may be considerably though possibly temporarily reduced. At a number of sites, such as the SR18 (westbound) - Mississinewa River or the US41 (northbound) - Kankakee River sites, that have had a history of heavy DA, the sites themselves had comparatively minor debris but nearby upstream bridge piers were observed to have heavy 
DA. Such upstream structures may delay DA at downstream structures, contributing to the longer periods of 'dormancy' suggested above.

Most of the discussion so far has focused on accumulation, but disaggregation, where some part or even all of the debris trapped at a pier succeeds in escaping the pier, may occur more often than is usually thought. The piers may act as in-stream debris storage, whose debris may actually be more easily mobilized than debris on the floodplains or even on the banks.

\subsection{Summary}

A program of periodic site visits, eventually covering 21 sites, was undertaken in order to obtain more information regarding the development over time of DA and the relationship of DA development to hydrologic events over a broad sample of sites. The visits were made at intervals of 3-4 months over a period of 16 months, and included one fairly large flow event (recurrence interval $>8$ years) and smaller events (recurrence interval of $1-2$ years).

A strong relationship between the magnitude of a flow event and DA at a site was not found, i.e., a much larger flow event does not necessarily result in much heavier or more extensive DA. At certain sites, particularly those with shorter pier-to-pier spans, say less than the design log length, heavy DA can occur almost every year, even in the absence of any large flow event. For the majority of sites with larger pier-to-pier spans, very large ('mega') DA would seem to require several years to develop. This does not necessarily mean that growth of a DA occurs gradually with each flow event contributing a small amount, eventually attaining a 'mega' size. There is some evidence in the current study that a DA may be 'dormant' for a longer period of time ( $>1$ year), when there is little or no growth, and possibly even a decrease in size, but then grow substantially in an abrupt manner. The role of disaggregation of large DA and of upstream structures that may trap debris may be more important than has been previously thought. 


\section{Video Monitoring of selected bridge sites}

Continuous video monitoring of a bridge site may be viewed as the limiting case of the periodic-visits program when the interval between visits becomes extremely small. In this way, there is virtually no uncertainty about whether events were missed, as all events are recorded. This assumes that the system is fully operational throughout the study period, which unfortunately was not always the case in the current study, as will be discussed. The detailed observations possible during a high-flow event also make such a system invaluable compared to the relatively sparse observations possible during a periodic site visit. The main disadvantage is the cost and effort involved in installing and maintaining the system, and in examining the huge amount of video information. Video monitoring was therefore feasible only for a very limited number of sites. Two sites, those at the SR59 south crossing of the Eel River near Brunswick and the SR63 southbound crossing of the Vermillion River near Cayuga, were installed during the previous project, dealt with in Lyn et al. (2003). A new system was installed at a third site, the SR157 crossing of the White River near Worthington. With only three sites, the video monitoring program cannot claim to give a representative picture of DA at bridge crossings in Indiana, but rather to answer questions that neither the periodic visits nor the bridge inspection reports are able to address. Video monitoring and periodic visits do share the common weakness that both can only directly document phenomena occurring on the water surface; debris transport and accumulation below the water surface, and other possibly debris-related factors such as the channel bathymetry at the time of the high-flow event, are not recorded.

In the following, the characteristics of the three sites will be described, and the notable events related to DA that were recorded will be discussed. The relationship between the time development of flow and debris, debris trajectories, and the effect of debris deflector will be of primary interest.

\subsection{The SR59 - Eel River (south crossing) near Brunswick}

\subsubsection{Site characteristics}

The SR59 - Eel River site is the only one of the three sites to be discussed in this chapter that was classified as 'heavy' in Chapter 2. Based only on the 2003 inspection report, it was deemed a 'mega' site; the earlier 1997 report indicated only moderate DA at pier 4, and only minor DA at the other two piers. This illustrates the limitations of relying entirely on bridge inspection reports for characterizing DA at bridges.

A plan view of the site, taken from the 2003 bridge report, is shown in Figure 4.1. The debris field is seen to be quite extensive, and coincides roughly with an island feature immediately upstream of pier 4. The 1997 report did not show any prominent island feature, which has therefore grown to such a large extent within a short period of time. It may also be that the increased occurrence of DA at the site is related to the growth of the island. As hinted at in discussions in previous chapters, a feedback effect may be at work where DA promotes island development, which in turn increases the likelihood of DA. The DA problem at this site was of sufficient concern that, as at the other two sites chosen for video monitoring, debris deflectors were installed in an attempt to reduce the frequency and severity of DA. One of the two installed debris deflectors, basically 24-in diameter steel encased concrete piles implanted into the channel 


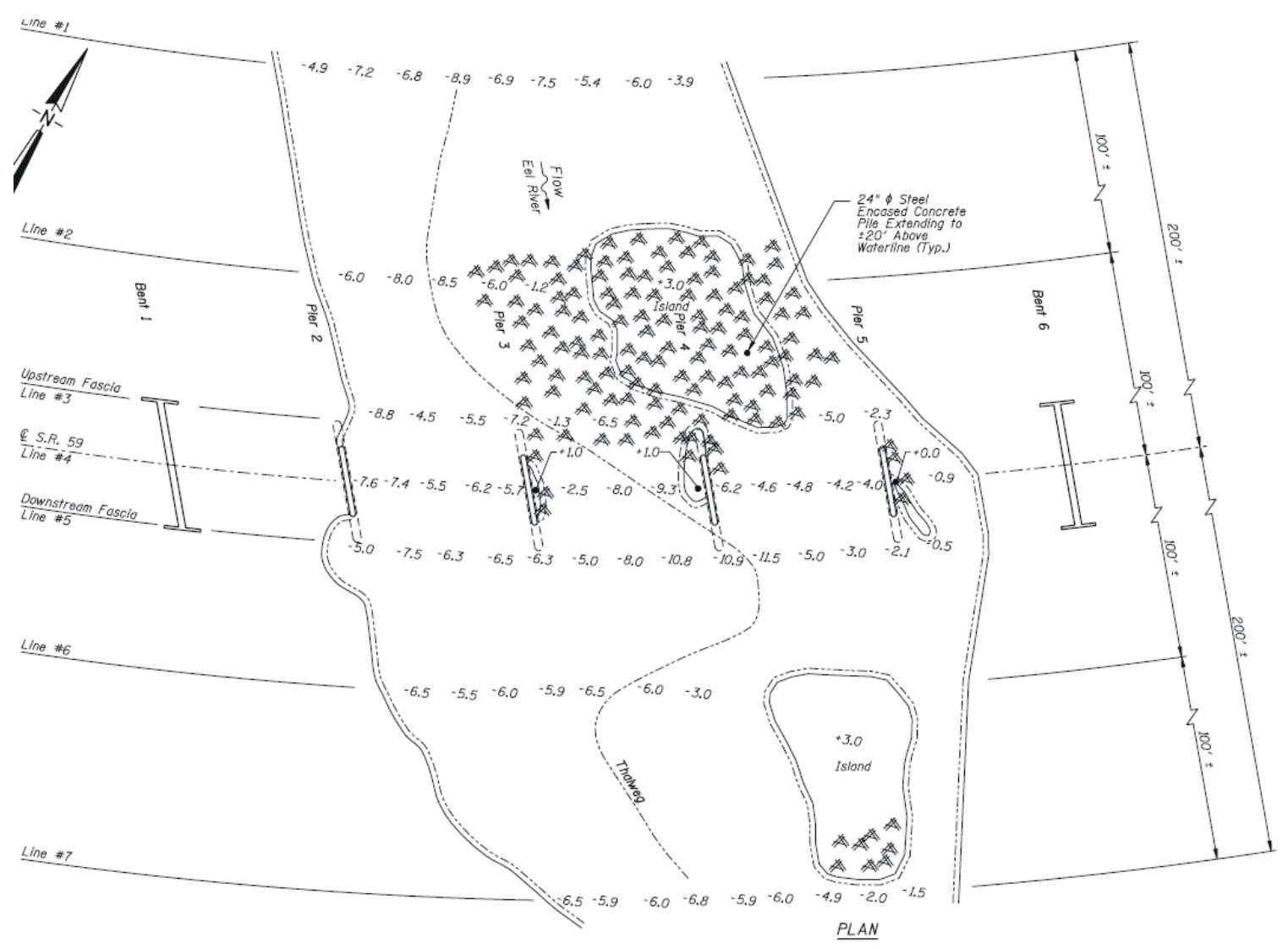

Figure 4.1: Plan view of SR59 - Eel River site (taken from 2003 bridge inspection report)
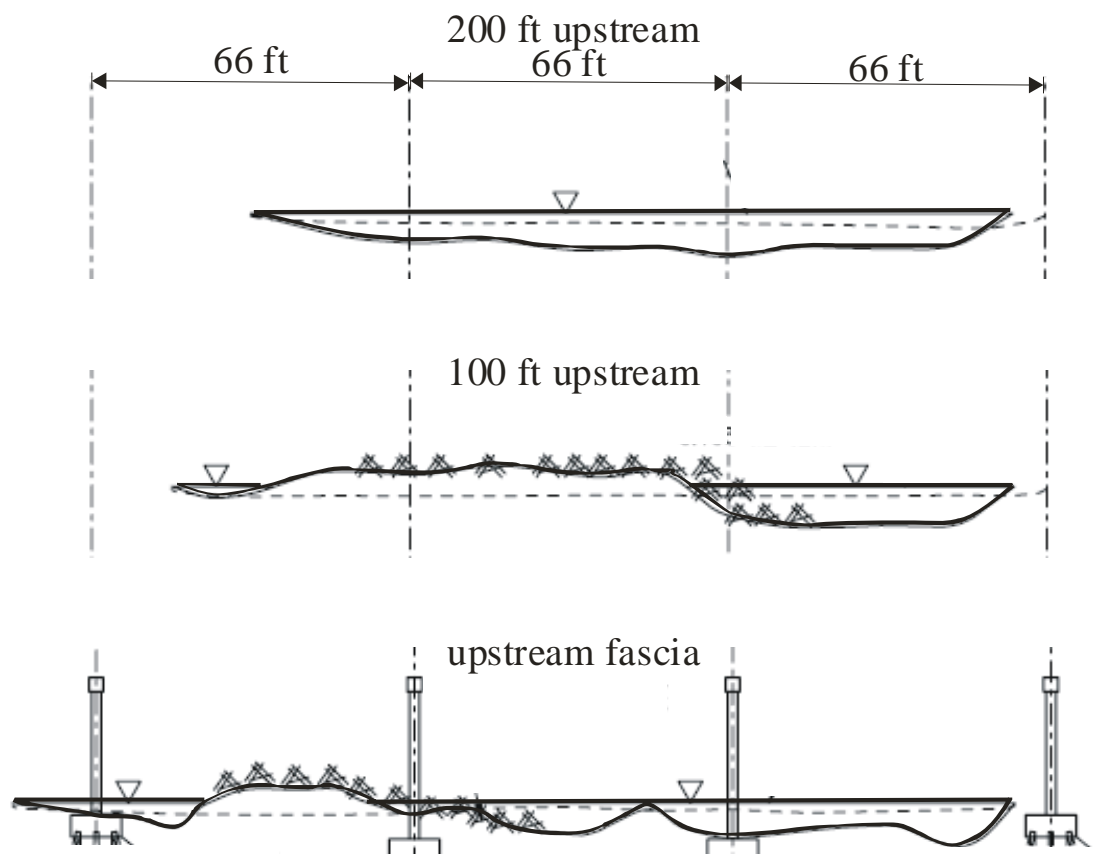

Figure 4.2: Cross-sections looking downstream at two upstream sections and at upstream bridge fascia (taken from 2003 bridge inspection report 
bed and extending $\approx 20 \mathrm{ft}$ above the bed, is shown to the right of pier 4 . Some flow expansion is noted, with a ratio of channel width at the bridge to that upstream of 1.2. As seen previously in Figure 2.7e, the Eel River in the vicinity of the bridge is relatively straight. The thalweg as sketched in the bridge inspection report is quite erratic, and it is not clear how meaningful it is as far as DA is concerned.

The cross-sections at the two upstream stations and that just upstream (fascia) of the bridge are shown in Figure 4.2. The span between piers, $66 \mathrm{ft}$, is likely less than Diehl's design log length, though it is not clear that the extensive DA is necessarily caused by a large log spanning two piers. Lyn et al. (2003) did however report finding a large log of length comparable to the pier-to-pier span. The farthest upstream cross-section is fairly regular, but is not as symmetric as might be expected for a relatively straight reach. Closer to and at the bridge crossing, the cross-sections become more complicated, with the island rising in prominence.

\subsubsection{Hydrological events}

The USGS gaging station on the Eel River nearest to the site is located $\approx 23$ miles upstream near Bowling Green. Because of the distance, the magnitudes of the hydrograph are only approximately correct for the site, and there may be a lag of up to $\approx 6$ hours in the arrival of the peaks (Lyn et al., 2003). With those qualifications, the Bowling Green data will be considered for the present purposes to apply to the site, and all reported hydrographs are based on the Bowling Green data. The video monitoring equipment at this site has been operational since 2001, and the previous report (Lyn et al. 2003) discussed observations until spring of May 2003. Herein, results beginning in 6/1/2003 will be dealt with, although the current project did not officially start until 10/1/2003. The discharge hydrograph from 6/1/2003 to 3/1/2006 is shown in Figure 4.3. Also shown is a line indicating the median annual peak discharge of $12,800 \mathrm{cfs}$, which corresponds to a 2-year event, based on 43 years of data. The largest flow event over the study period occurred on 1/6/2005 (recall in Chapter 3 that this was true of much of Indiana) with a discharge of $17,800 \mathrm{cfs}$. This was by no means a very large event, since its recurrence interval was estimated to be only $\approx 4$ years. The second largest event, on $9 / 3 / 2003$, a discharge of 13,500 cfs, had a recurrence interval of $\approx 2.2$ years, with several other smaller events.

\subsubsection{The video monitoring system}

The video monitoring equipment was installed during a previous study (Lyn et al. 2003). It consisted initially of two video cameras, one mounted on pier 4 with a view upstream, and one mounted on top of a fiberglass shed on the levee on the west bank, with a profile view, including the upstream fascia of the bridge and the two debris deflectors. Images were recorded on a digital video recording system, at a medium resolution at a rate of 1 frame every 10 seconds. During the night, the near total darkness prohibited the acquisition of any usable images, and so recording was limited to daylight hours, but was otherwise continuous. There were however periods when, owing to hardware problems, either one or both cameras or the recording system was not functioning. On 12/4/2003, the recording system was found to be malfunctioning, and so was taken out of operation, until it was repaired and reinstalled on 1/14/2004. In March 2004, it was noted that there was no vertical hold on both cameras (some signs of this were apparent in the bank camera as early as November 2003). It was decided to replace only one of the cameras, that on the bank, and this was installed on 4/8/2004. During the period from December 2003 until May 2004, little of value was recorded; as seen in Figure 4.3, a major flow event occurred during this period, peaking in 1/5/2004 at a discharge of 11,300 cfs, and so was not recorded. 


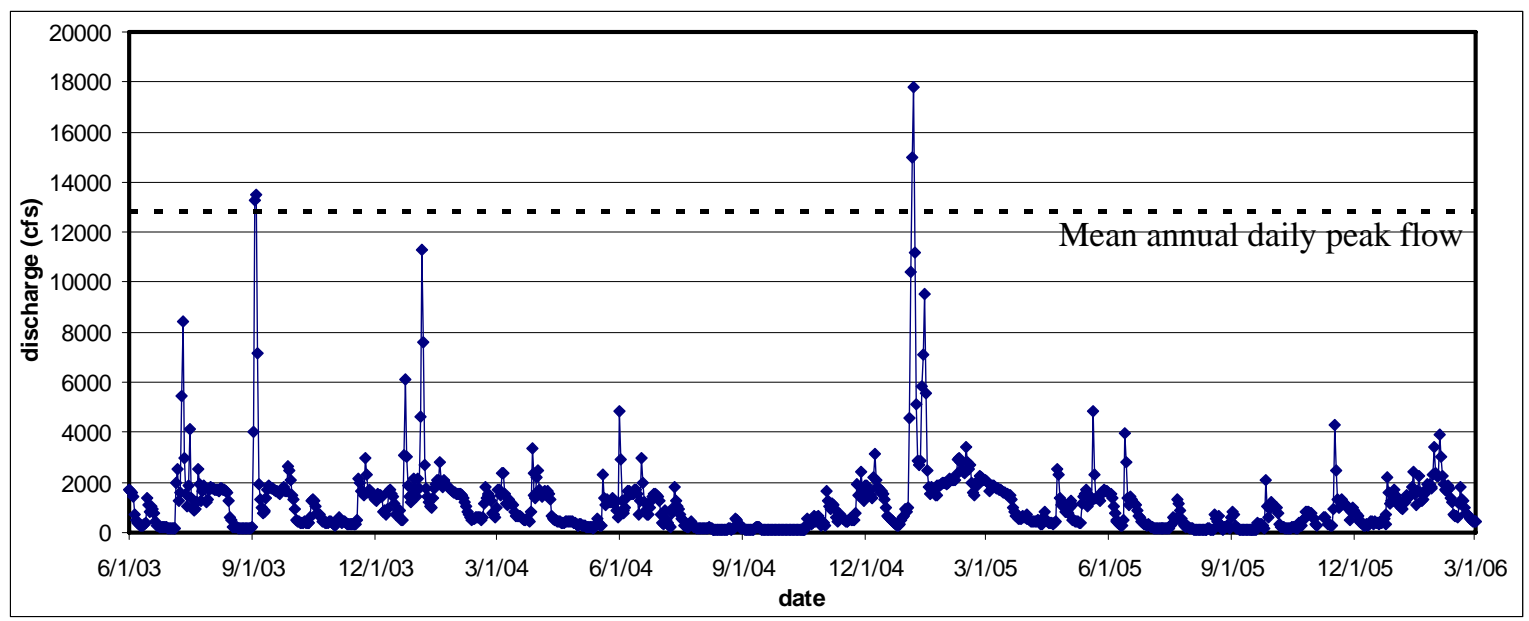

Figure 4.3: Discharge time series over study period at USGS gaging station near Bowling Green

Periodically, the recorded images were manually archived to tape or to a portable hard disk (and then, at the laboratory, eventually to tape) at the site. The large volume of data required a preliminary screening to filter out portions where essentially nothing occurred. This was based on the identification of a flow event with a sustained stage over $8 \mathrm{ft}$ (at the Bowling Green USGS gaging station). This is not a particularly stringent criterion, since events with peak discharges less than 3,000 cfs are included. If a portion of the record had been omitted, the images immediately before and after the omission are examined to determine whether significant debris accumulation may have occurred in the omitted portion. If so, then additional images can be reloaded from the archived tapes. Some minor debris transport that did not result in any noticeable accumulation may however have occurred in the omitted portion of the record and hence was not taken into account in the following discussion.

\subsubsection{Events and observations}

Event on 6/14/2003 Events will be discussed in chronological order, and the subtitle will indicate the date on which the flow event peaked. The event of 6/14/2003 was very minor, corresponding to a peak (hourly) discharge of $2150 \mathrm{cfs}$ and peak stage of $8.79 \mathrm{ft}$ (at Bowling Green), and is included merely to set the stage for discussion of later events. The site just prior to the event is shown in Figure 4.4a. Except for one large log, the site was essentially free of debris, and the prominent mid-stream island was unsubmerged. It might be thought that either no DA had recently occurred or that the site had been recently cleared. As Lyn et al. (2003) made clear however, there was heavy DA during an event in the preceding month of May, but this had spontaneously disaggregated, leaving only the large log as a relic. Towards the peak of the event (Figure 4.4b), the island is just barely submerged, but the log itself was not. No debris transport was noted during this event, and this might be taken as too small an event to mobilize debris.

Event on 7/6/2003 This event was again relatively minor, corresponding to a peak (hourly) discharge of $3630 \mathrm{cfs}$ and peak stage of $12.17 \mathrm{ft}$ (at Bowling Green). The stage and discharge time series at Bowling Green for the 9-day period starting at 7/6/2003 are shown in Figure 4.5. 


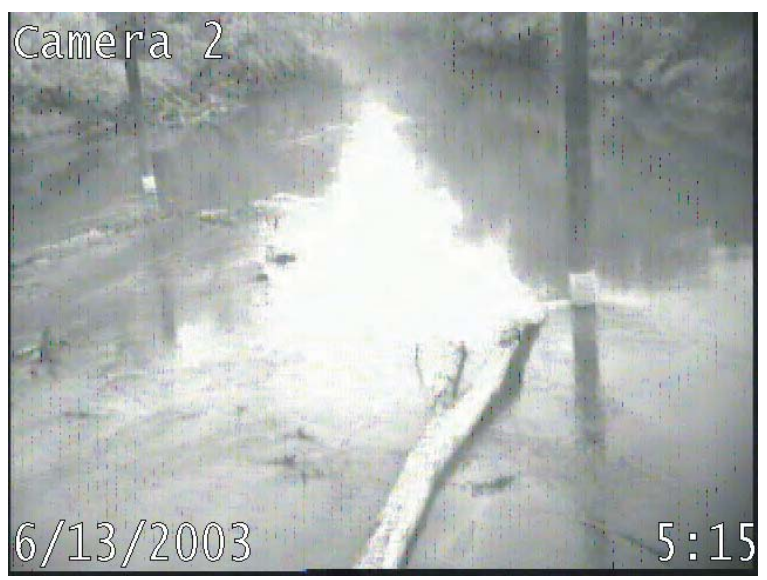

a)

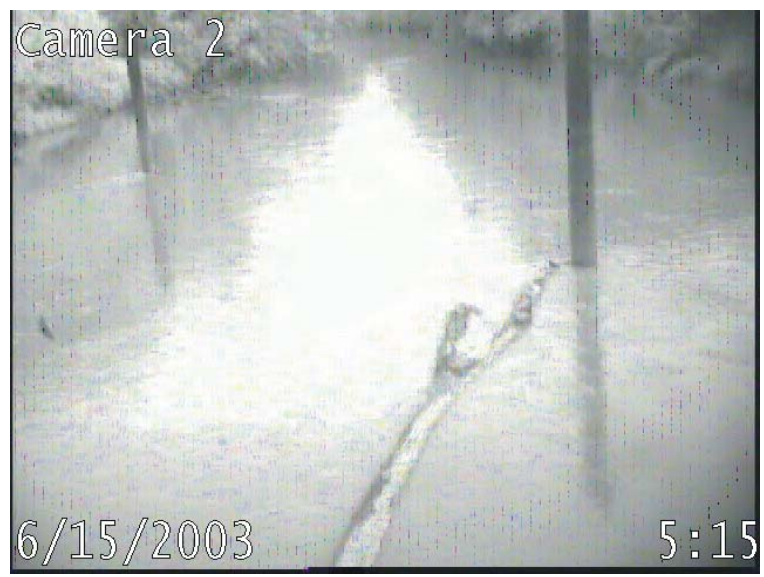

b)

Figure 4.4: Images at site before and at end of first event (date and time stamped at bottom)

Curves derived from the time series with a lag of 6 hours, which might be more representative of the SR59 site, are also shown. Unfortunately, the peak at Bowling Green occurred in the night of $7 / 6 / 2003$ at $10: 00 \mathrm{pm}$, and so most of the approach to the peak at the actual site occurred in the very early morning of $7 / 7 / 2003$, and so was not recorded. In the earliest recorded image on $7 / 7 / 2003$, the island is completely submerged, as is the large log, which was still present at the latest recorded image on the previous day at 7:43 p.m. A small branch was trapped at the closer debris deflector, which by 5:34 a.m. had been dislodged. During the entire recorded event, ending on 7/7/2003 at 7:45 pm, only two instances of transport of a large branch or log were noted, though numerous isolated instances of small twigs or branches being transported were observed.
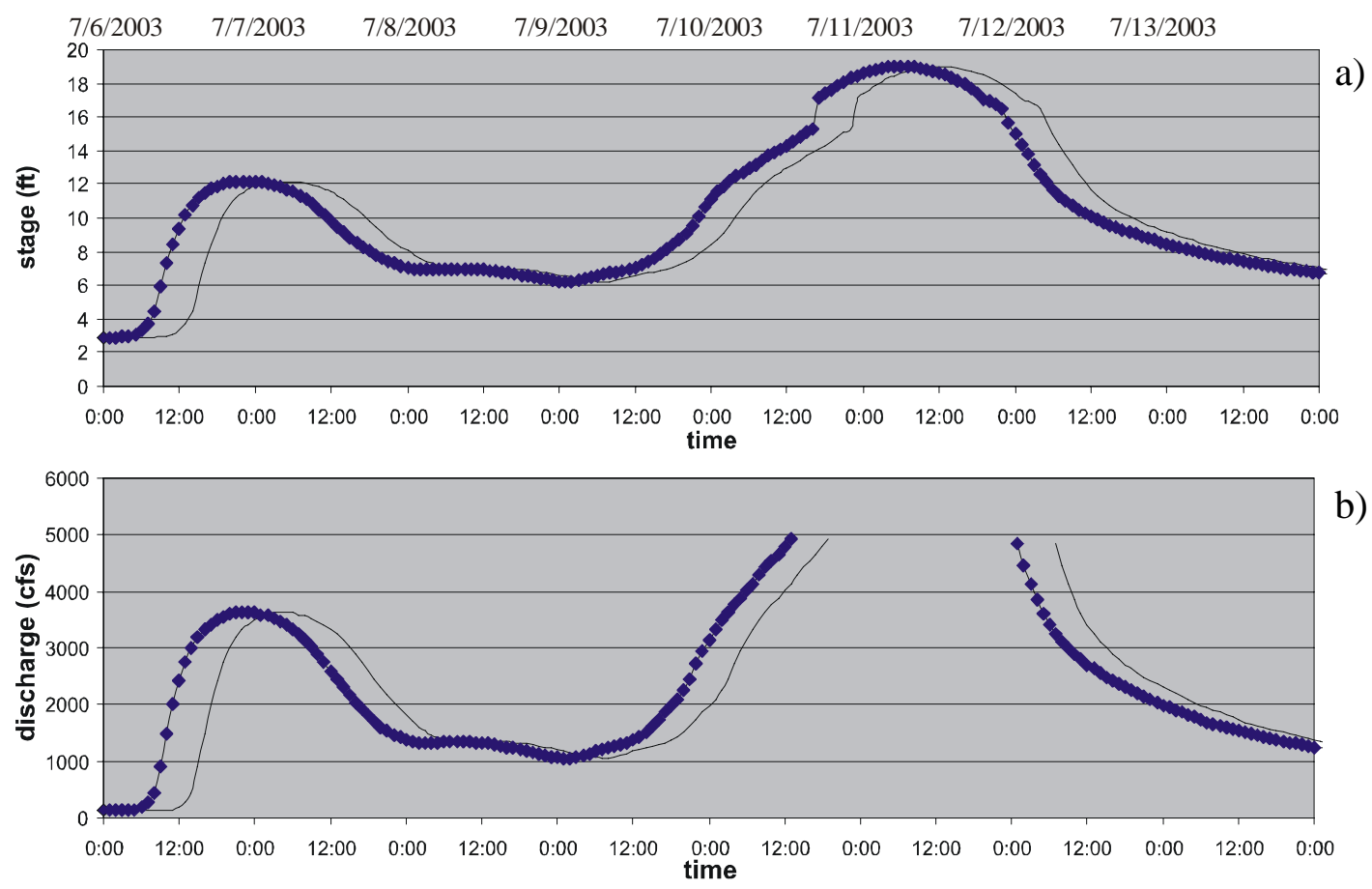

b)

Figure 4.5: a) stage, and b) discharge time series at Bowling Green in early July 2003; thin line is shifted 6 hours to the right 
The first at 6:25 a.m. involved a log estimated to be at least $30 \mathrm{ft}$ long. This was traveling with its long axis perpendicular to the flow when it was in the neighborhood of the deflectors, and was caught momentarily on the farther debris deflector, was turned, and continued downstream. Whether it was trapped at the bridge piers was not clear. The second instance involved a notably smaller, probably less than $15 \mathrm{ft}$ long, log arriving at 7:29 a.m., and being trapped at the farther deflector. This remained trapped even after the end of the recorded event.

Event on 7/11/2003 This event was fairly major (see Figure 4.4), corresponding to a peak (hourly) stage of $19.02 \mathrm{ft}$, i.e., $7 \mathrm{ft}$ higher than the preceding event, at 6:00 a.m. The site prior to the event is shown in Figure 4.6a, where the log trapped at the farther deflector is still seen. Smaller isolated debris was already noted by 5:37 a.m. on 7/10/2003, but the first large (longer than at least $10 \mathrm{ft}$ ) log, also isolated, appeared at 6:25 a.m. traveling between the deflectors, with a shorter log, soon thereafter, to the left of the deflectors going downstream. This is almost a day before the peak stage at Bowling Green. The stage and discharge at Bowling Green at a 6-hour lagged time are in the range $11-12 \mathrm{ft}$ and 3000 - $3600 \mathrm{cfs}$, consistent with the values for the preceding event, and suggesting that large logs begin to be mobilized at these values. The first debris 'cluster', i.e., a sequence of large debris elements (not necessarily all logs) in close succession, arrived at $\approx 6: 45$ a.m (Figure $4.6 \mathrm{~b}$ ). Thereafter there was only light transport of isolated small branches until $\approx 7: 23$ a.m., when another cluster arrived (Figure 4.6c). There was intense activity for 5-8 minutes, which abated somewhat afterwards. For the next two hours, there was moderate debris transport activity, mostly smaller branches, but including isolated larger logs, punctuated by very brief clusters. Much of this came to be trapped at pier 4, and possibly also pier 5. By 9:36 am (Figure 4.6d), when one of the largest log arrived, the DA at pier 4 can be seen at the bottom of the recorded images. Again only light to moderate activity resumed after this until another extended burst of debris cluster beginning at $\approx 10: 09$ a.m., such that by 10:19 a.m. much of the region between the pier and the deflector is covered by debris (Figure 4.6e). Debris activity was relatively light for the next three hours, and no significant accumulation was noted. After 1:20 p.m., activity increased to moderate, with brief cluster activity at 3:15 p.m., 3:58 p.m., 4:57 p.m., 5:34 p.m., so that by 5:50 p.m., the DA had grown substantially upstream (Figure 4.6f). Thus, in a space of less than 12 hours, what was likely a 'mega' class DA had developed. This is also 12 hours before the peak in the hydrograph of a 1year event at the Bowling Green station that is 25 miles upstream of the site.

Because the debris 'front' has moved so far upstream, beyond even the farther debris deflector, it became difficult, after 5:50 p.m. to identify debris clusters. The upstream growth of the DA was however incremental rather than dramatic, suggesting that clusters, if any came, were quite rare. By the following morning, at 5:15 a.m. (Figure 4.6g), the change in the extent of the DA from the situation at 5:50 p.m. the previous day is noticeable, but it seems clear, in spite of distortions due to perspective, that the large bulk of the DA occurred during the first 12 hours of the event, and only a substantially smaller fraction occurred during the second 12 hours. It is again recalled that the peak in the hydrograph at Bowling Green occurred at 6:00 a.m. In the ensuing hours, when the hydrograph peaked at the site and began to recede, very little if any growth can be discerned, e .g., at 3:00 p.m. That little debris transport occurred during this time is also supported by the images recorded by the bank-side camera (not shown).

The spatial distribution of the debris transport and accumulation merits discussion. The great majority of the larger debris elements was observed to follow a trajectory, between the two deflectors and closer to the eastern deflector (Figures 4.6b, c, and d). Some debris may be seen 
passing east of the closer debris deflector (Figures $4.6 \mathrm{~b}$ and c), and rarer still, some pass fairly close to the bank (Figure 4.6c). In contrast, except for the two instances in the preceding event of 7/6/2003, very little transport of larger debris elements was noted on the side of stream where the farther debris deflector is situated.

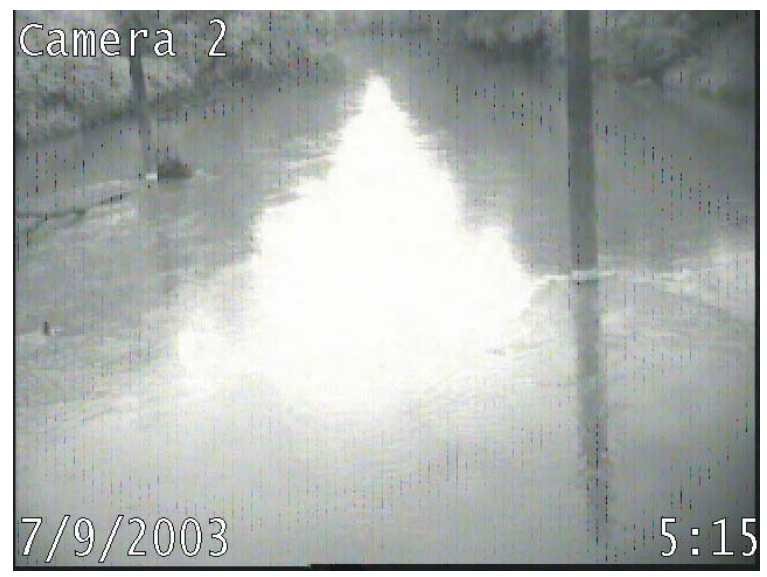

a)

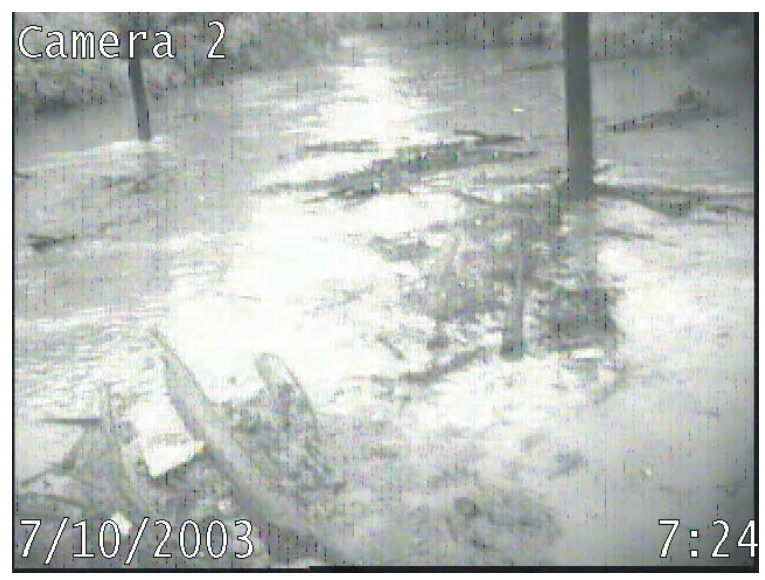

c)

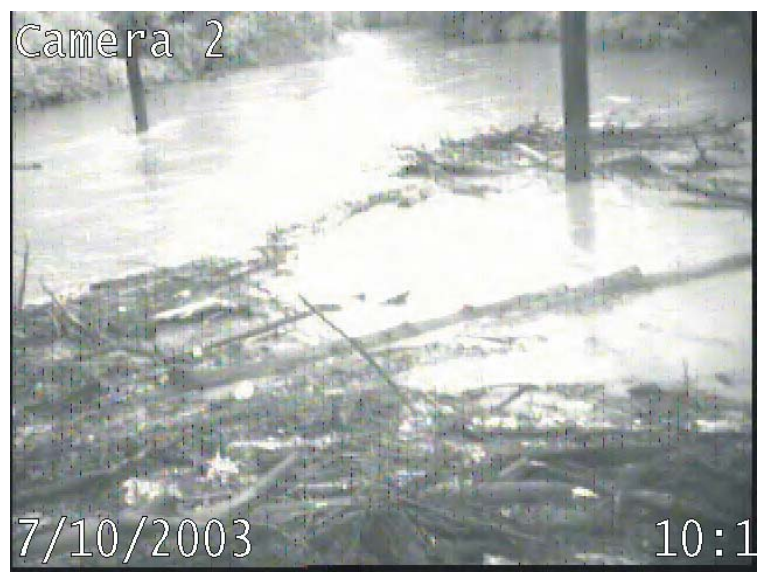

e)

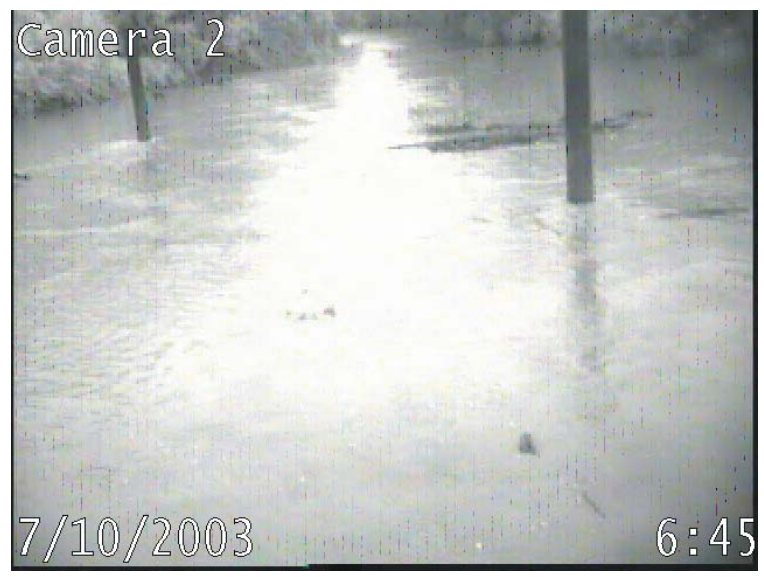

b)

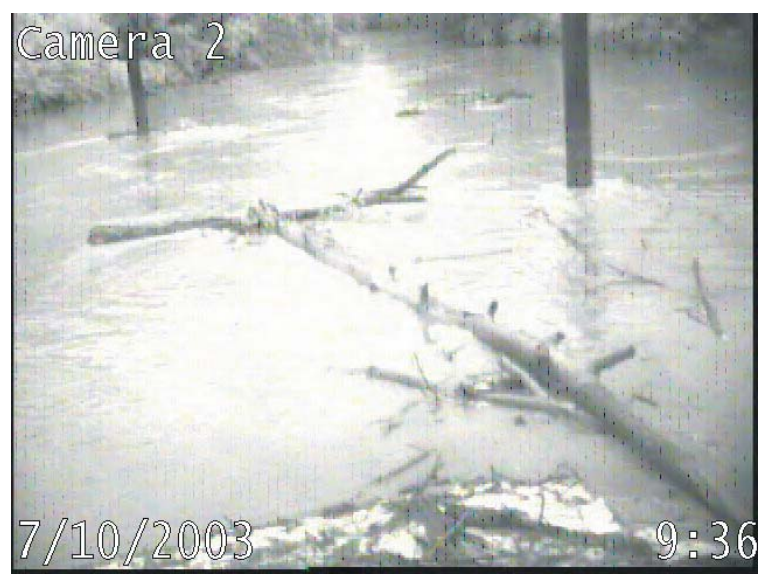

d)

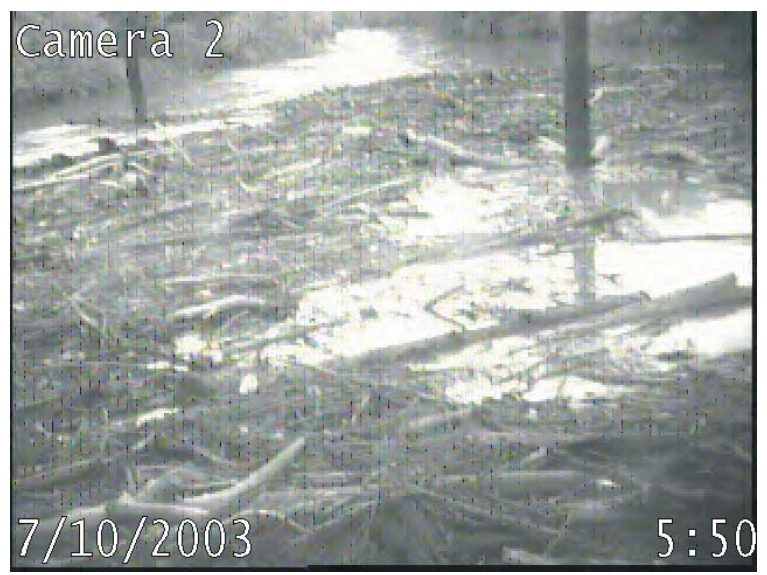

f)

Figure 4.6: Images from the site during the 7/11/2003 event 


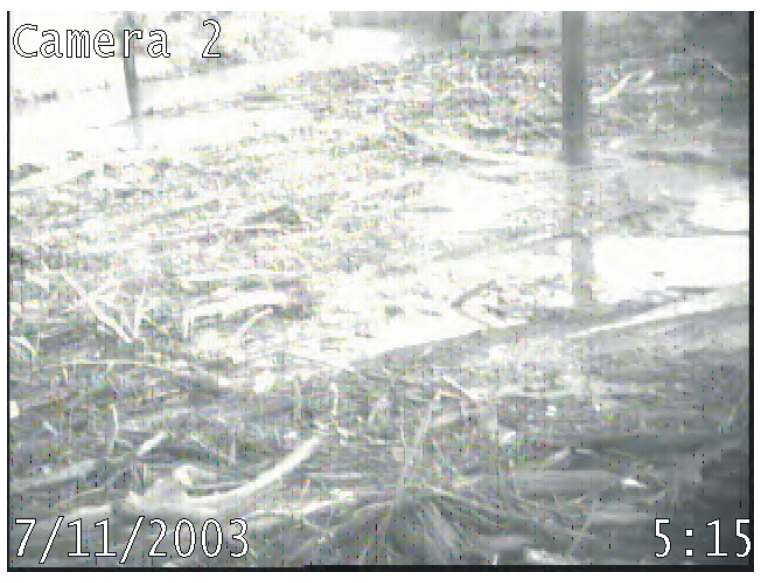

g)

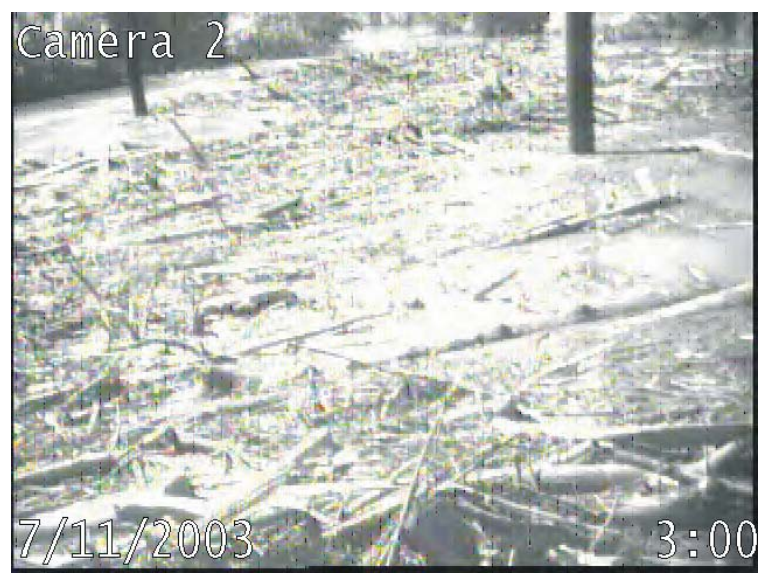

h)

Figure 4.6: Images from the site during the 7/11/2003 event (contd.)

Inspection of Figures 4.1 and 4.2 indicate however that the thalweg is generally found on the west side of the stream, even at the section that is 200-ft upstream of the bridge. The observation that debris tends to travel near the thalweg in a straight reach is clearly an oversimplification. The debris trajectory, in this case, is likely more related to the channel expansion, and possibly to the slight curvature of the stream. This is more clearly seen in Figure 2.7e, which gives a more global view of the stream than does Figure 4.5. As seen in Figure 4.6, the island feature is completely submerged during the entire event, and it seems to have little noticeable effect on debris trajectory, which is the primary factor in determining the spatial distribution of the DA within the stream.

As has been noted above, little upstream debris transport was noted during the receding portion of the flow hydrograph. A striking occurrence was however observed, starting at $\approx 4: 10$ p.m., an image (Figure 4.7a) of which was not much different from that of Figure 4.6h. The upstream portion of the DA was subject to an instability, such that within five minutes what had been the upstream nose of the DA was spontaneously redistributed over the channel (Figure 4.7b). This quite massive change may be more clearly seen in the corresponding images from the bank-side camera. This instability is reminiscent of that reported in Lyn et al. (2003), when the entire DA, rather smaller than that shown in Figure 4.6h, disaggregated, leaving behind only light accumulation, such as the isolated log shown in Figure 4.4. Some displacement within the DA closer to the bridge is also observed, but the central part of the DA was sufficiently stable to withstand the large abrupt changes in the upstream portion. This occurrence illustrates again the need for caution in making inferences about debris transport from isolated visits such as were discussed in the two previous chapters. The DA seen in Figures 4.7b and c is more uniformly distributed across the channel that had been the case prior to the instability, and could mistakenly be interpreted as supporting a model in which debris trajectories are fairly uniformly distributed over the channel.

Event on 9/2/2003 This event was substantially larger than the previous event, with an over $50 \%$ higher mean daily discharge, and a 1.5-ft higher peak hourly stage (at Bowling Green) reached at 9:00 pm (Figure 4.8). Images recorded just prior to the event show that some temporary debris clearing measures had been undertaken after the July events (Figure 4.9). The DA was noticeably less extensive than seen in Figure 4.7 and two large logs were moved to the bank. Notable debris transport was already seen on 9/1/2003 starting after $\approx 9: 30$ a.m. This is not only 
substantially before (almost 36 hours) the peak at Bowling Green, but corresponds to a stage of only $8 \mathrm{ft}$ and a discharge of only $2000 \mathrm{cfs}$ at Bowling Green, significantly smaller than what was seen in preceding events. The rising part of the hydrograph is however fairly steep, and the relationship between the hydrographs at the site and at Bowling Green is uncertain. Debris clusters, or at least briefer periods of more intense debris transport activity, were also noted. A somewhat greater tendency was noted for debris trajectories to veer away from the existing DA to the more open area (to the west). As a result, debris was more frequently seen traveling to the west of the farther deflector. This may indicate greater consolidation of the DA nearer the bridge, perhaps extending to the channel bottom, thereby offering greater flow resistance in the region of the existing DA, and thus affecting upstream flow and debris trajectory.

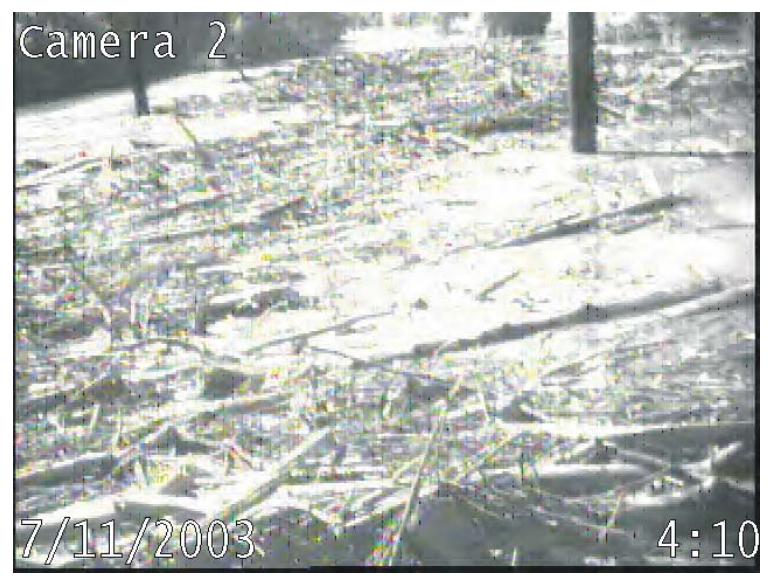

a)

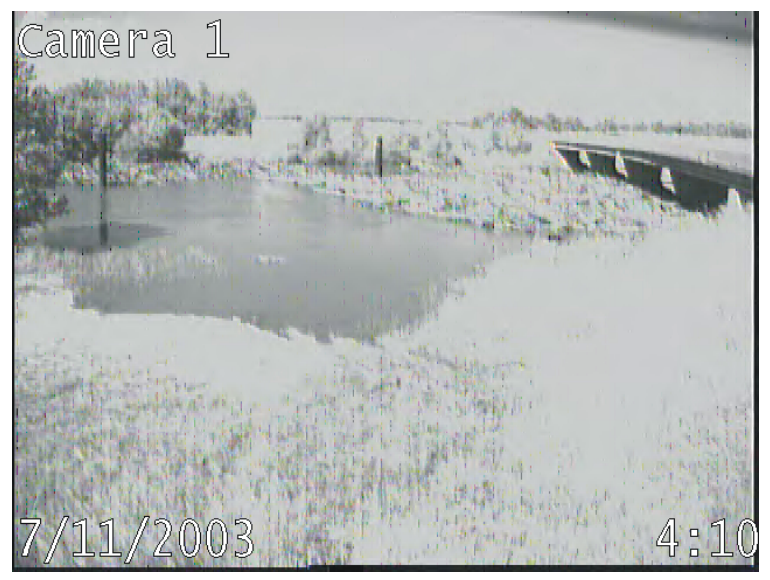

c)

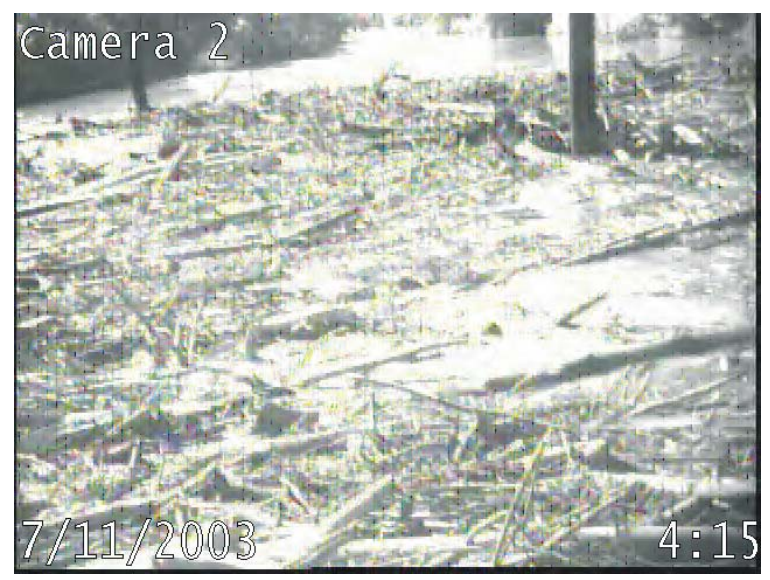

b)

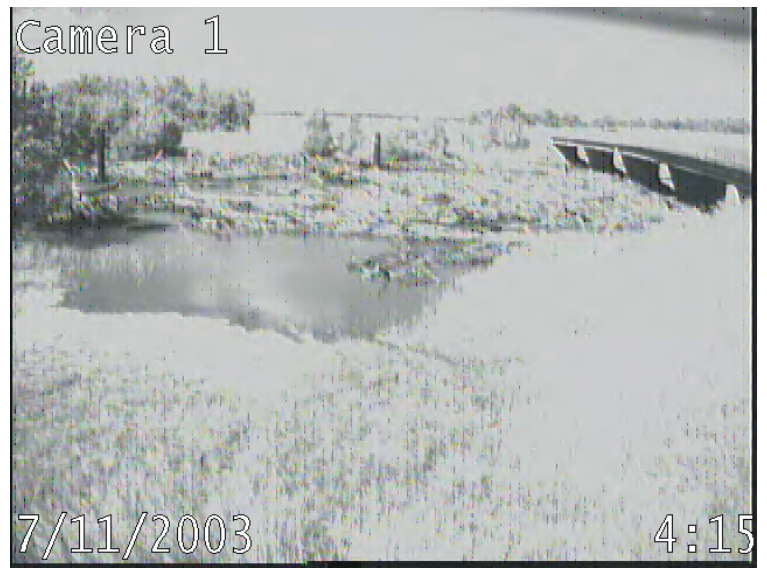

d)

Figure 4.7: Images before and after spontaneous massive redistribution of debris, a), b) from piermounted camera, c), d) from bank-side camera

Movement and instability were again noted within parts of the DA. By 11:55 a.m., the lower left portion had drifted downstream (Figure 4.10a), and by 3:30 p.m., the upstream portion, which seemed to be hanging on to the farther deflector, also became unstable, and was transported downstream (Figure 4.10b). Images from the bank-side camera suggest but do not show definitively that the transported debris, or at least the bulk of it, was not trapped again at 

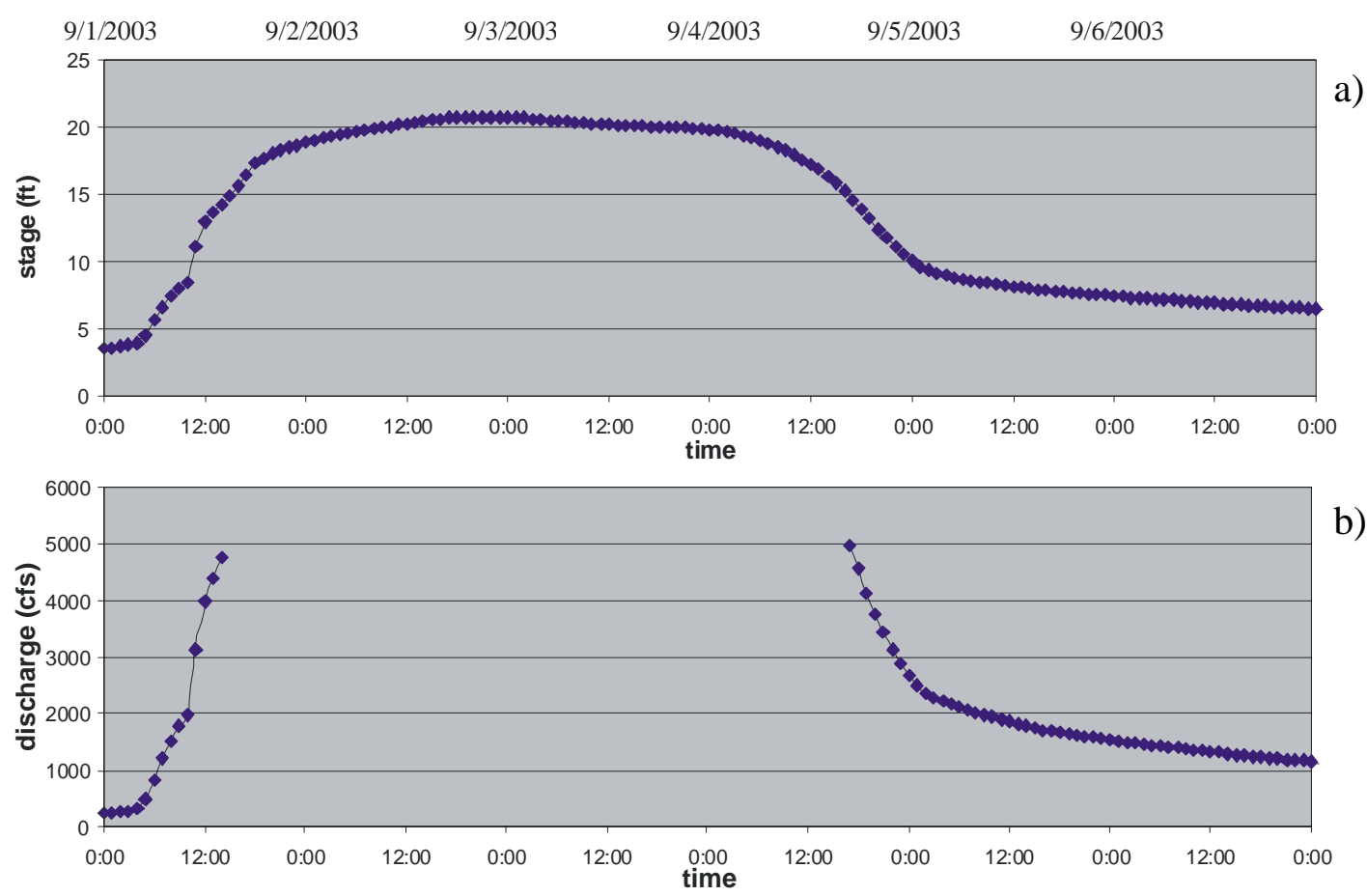

b)

Figure 4.8: a) stage, and b) discharge time series at Bowling Green in early July 2003; thin line is shifted 6 hours to the right

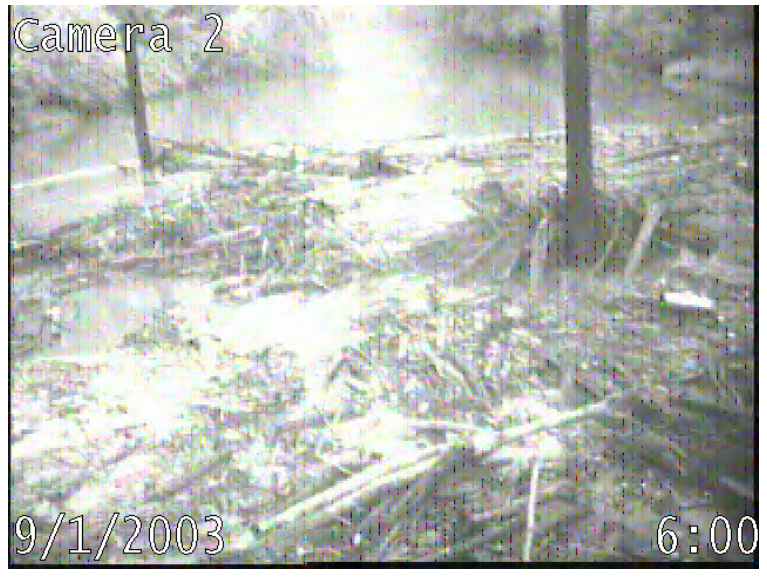

a)

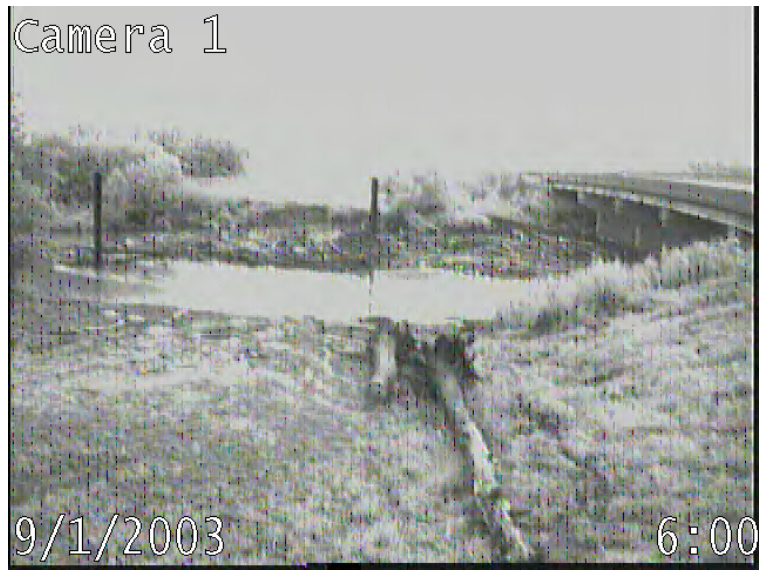

b)

Figure 4.9: Images just prior to 9/2/2003 event, a) from pier-mounted camera, and b) from bankmounted camera.

the bridge. Towards the end of the recording of that day, at 7:31 p.m., the DA re-developed, primarily on the west side (Figure 4.10c). This contrasts with the pattern of the preceding event, in which the DA developed primarily on the eastern side. This development continued during the night, such that by early morning, 6:00 a.m., a very heavy, if not necessarily 'mega'-class, DA, had again formed (Figure 4.10d). The spatial distribution differs somewhat from that seen in the previous event (e.g., Figure 4.6h). The larger part of the DA is found towards the left (west) rather than to the right. This is consistent with the already mentioned greater tendency of debris to veer towards that direction and the pattern of development leading to Figure 4.10c.

The time of Figure 4.10d is still some 15 hours before the peak of the hydrograph at 


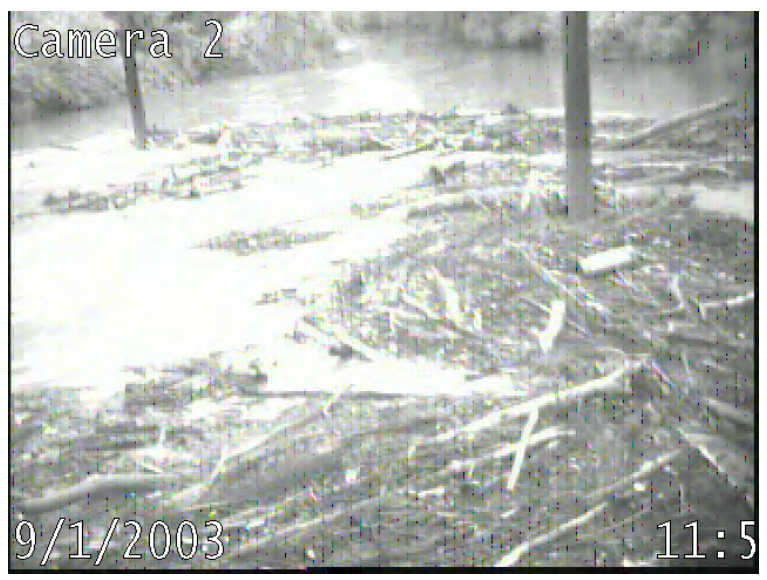

a)

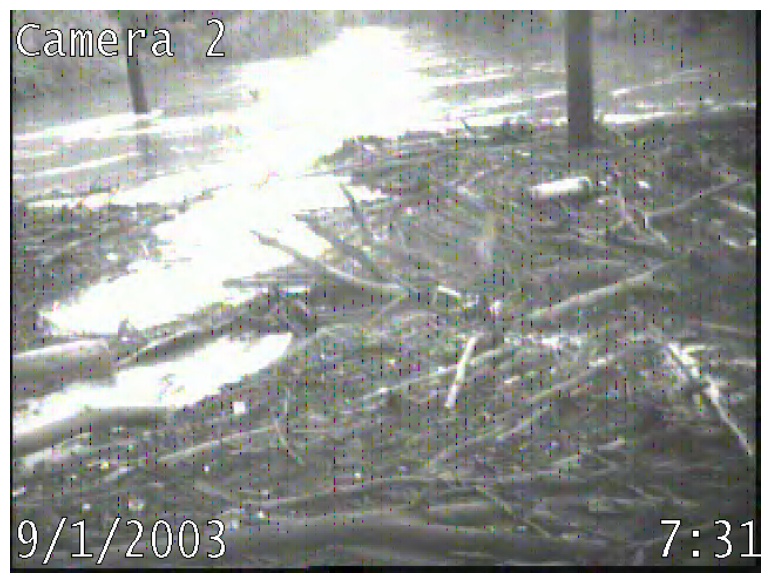

c)

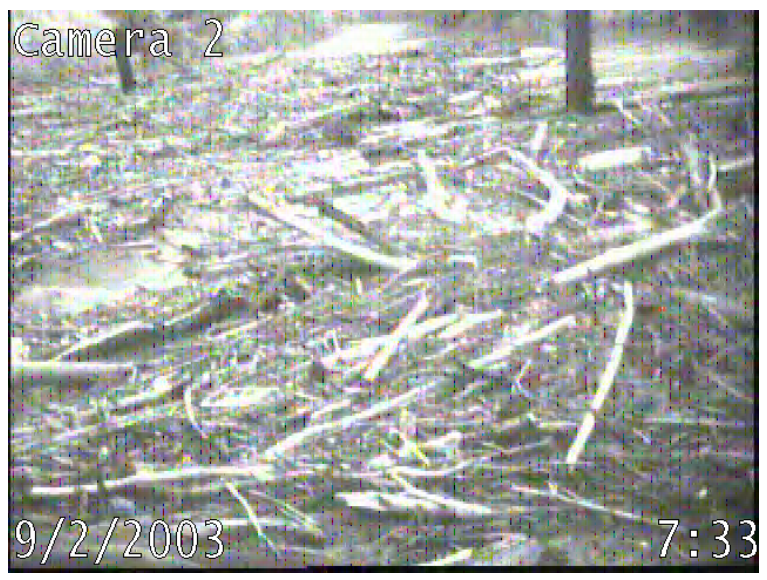

e)

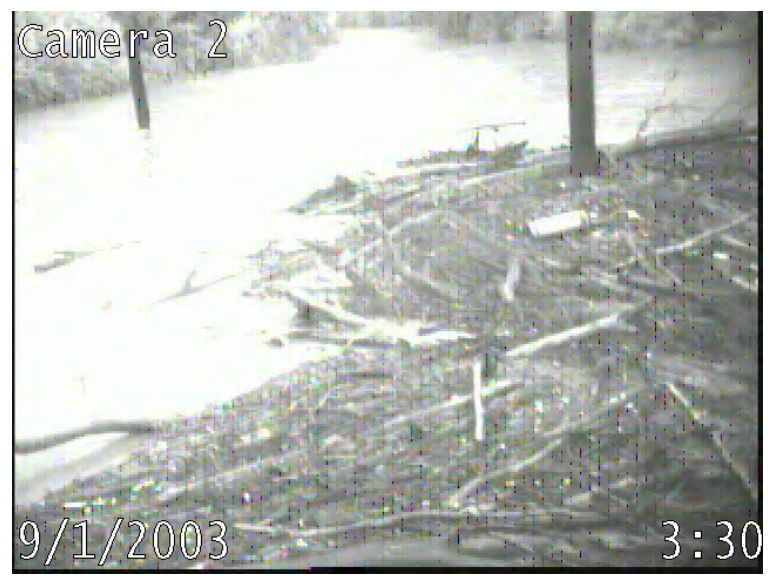

b)

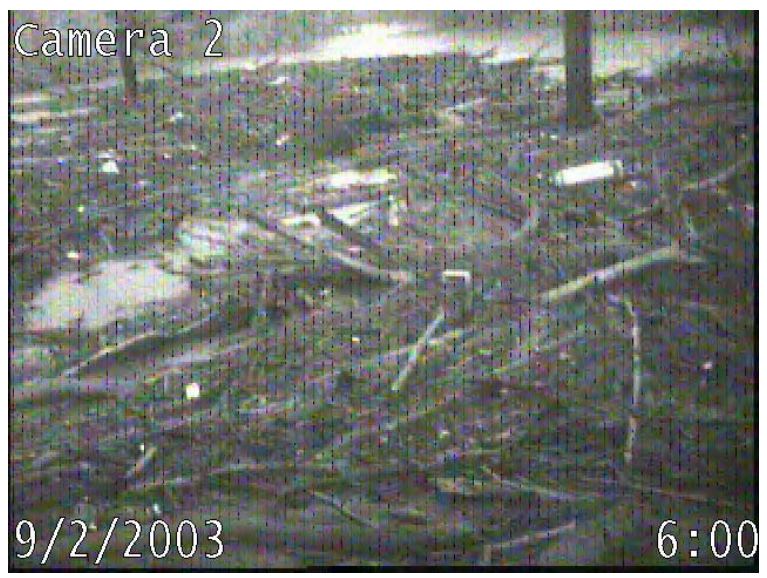

d)

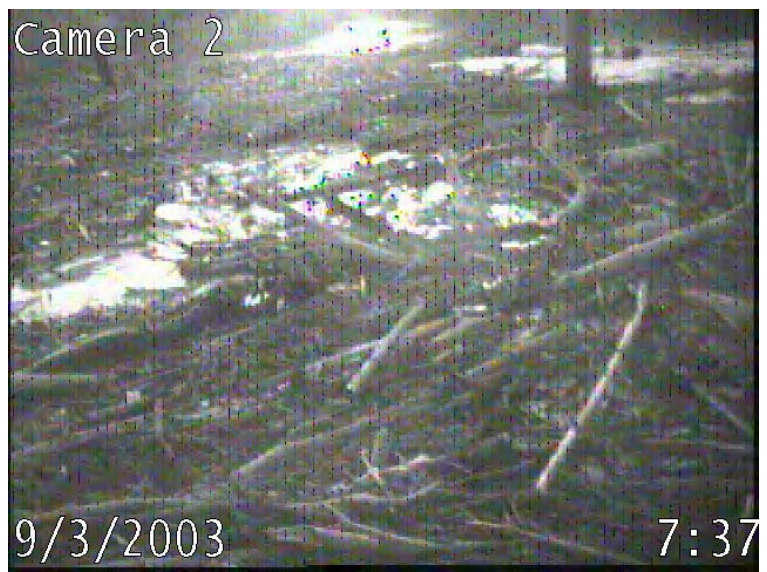

f)

Figure 4.10: Images of 9/2/2003 event (time and date stamped at lower edge).

Bowling Green (the stage at 6:00 a.m. is 1-ft below the peak stage). Because of the extent of the DA which occupied most of the image view, as well as the lighting conditions, images from the pier-mounted camera for most of the day were not useful for determining debris transport. The bank-mounted camera, with a view of only the east side of the channel, recorded only sporadic debris transport of only isolated small branches, and it was not clear whether the debris 
originated upstream or had broken off from the main DA. Nevertheless, an image from the piermounted camera recorded towards the end of the day (Figure 4.10e) does show some accumulation during the day, but as was seen in the preceding event, the bulk of the DA was formed during the first 12 - 18 hours of the event, and only a much smaller fraction was added thereafter.

A noteworthy aspect of the images in Figure 4.10 is the change in orientation (or tilt) with respect to the vertical of the farther debris deflector from Figure 4.10a to Figure 4.10f. This signaled the impending collapse of that deflector, which unfortunately occurred during the night and so was not captured on camera. The deflector still seen in Figure 4.11a on the evening of 9/3/2003 is absent in Figure 4.11b taken in the early morning of 9/4/2003. Because that deflector was instrumental in trapping debris traveling through that region of the channel, its collapse led to an instability of the DA, the result of which was a massive redistribution of the debris (and probably also some debris transported downstream). By the time of Figure 4.11, the stage at Bowling Green had already crested over 20 - 30 hours ago, so the stage, though possibly still high, at the site should have been receding between Figures 4.11a and b. A comparison of the water levels in Figure 4.11 reveals however that the stage had risen significantly, which was no doubt due to the blockage almost of the entire channel resulting from the redistribution of the DA. Although the stage did not rise further during this event, INDOT personnel apparently deemed the situation too risky, and intervened the next morning on 9/5/2003 to clear the debris.

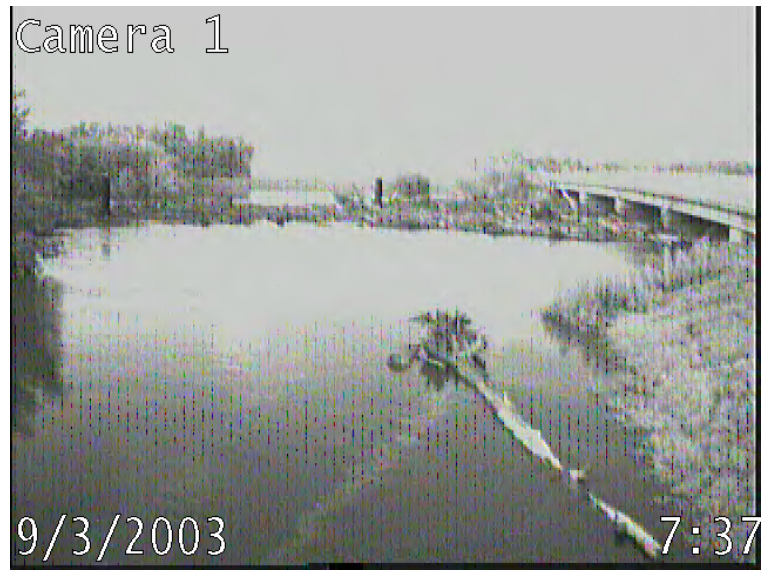

a)

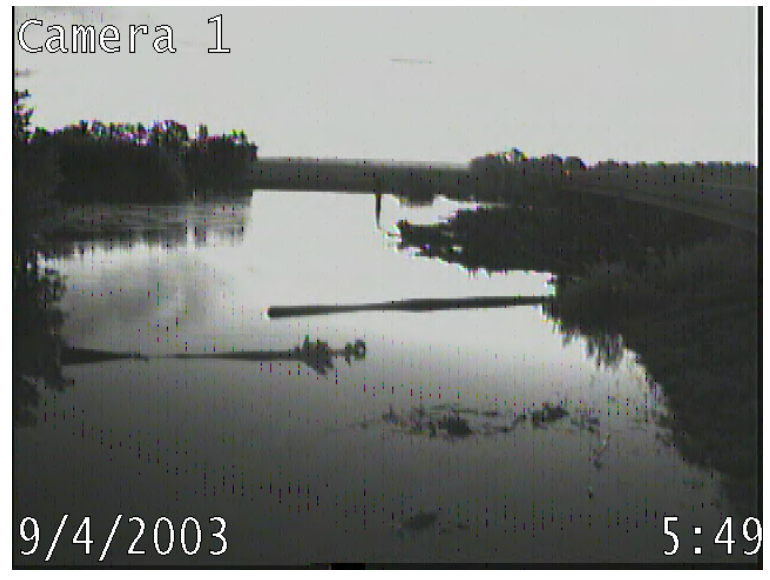

b)

Figure 4.11: Comparison of images taken with the bank-mounted camera from the evening of $9 / 3 / 2003$ and from the morning of $9 / 4 / 2003$

Events after 9/6/2003 and before 2005 Two other small events were recorded in 2003 after 9/6/2003. The first peaked on 9/27/2003, at a stage of $10.56 \mathrm{ft}$ and a discharge of $2910 \mathrm{cfs}$, and the second peaked on 11/24/2003, at a stage of $11.8 \mathrm{ft}$ and a discharge of $3460 \mathrm{cfs}$. Very little or no debris transport was observed during both of these events. The small magnitudes and short durations of these events likely played a role in the minimal debris transport, but the two very large events in the preceding five months may also have depleted much of the easily mobilized debris. From 12/2003 to 5/30/2004, no video was recorded due to camera and video recorder failure or malfunction. During this period, a large flow event, comparable in magnitude to that on $9 / 2 / 2003$, occurred on $1 / 5 / 2004$, with smaller events (Figure 4.3) before and after. The video system became operational again on 5/31/2004, but due to budget constraints, only the bank-side camera was replaced. With only a single camera, it was decided to focus more closely on the 
region near the piers and at the same time include the remaining debris deflector. This resulted in a smaller field of view than was previously the case, and no direct information of the upstream flow would be available.
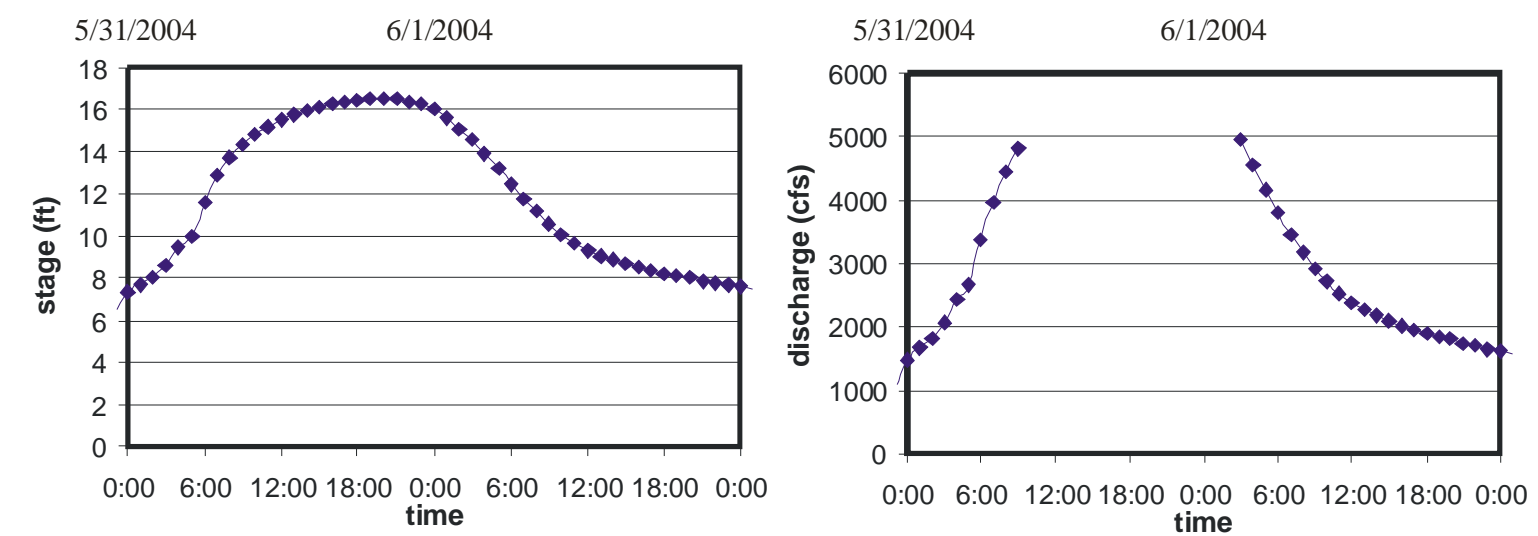

Figure 4.12: Stage and discharge hydrographs for event of 5/31/2004.

The largest flow event recorded in 2004 started on 5/31/2004, the day the system was again operating. The hydrographs of this event, peaking at $16.5 \mathrm{ft}$ at 8:00 p.m., is shown in Figure 4.12. At the beginning of the record, at 5:15 a.m., some DA is already seen trapped at the debris deflector, but the piers show no sign of any extensive DA (Figure 4.13a). Because the flow event has only just started, the DA observed is likely the result of previous events. In view of the magnitude of the event on 1/5/2004, it is somewhat surprising that a heavier DA was not observed. Already before 6:00 a.m., debris transport was noted. Large clusters were later often seen (Figures 4.13b and c), though well before the peak of the hydrograph. In spite of the substantial debris transport, the DA at the pier is only moderate, and much of the debris seemed to have been transported past the bridge (Figure 4.13d). The size of the DA at the deflector is noticeably larger than that at the pier. Two minutes after Figure 4.12d was recorded, however, the DA at the deflector had disaggregated, and much of it was carried away downstream (Figure 4.13e). The lack of any evidence of DA due to the previous large event of 1/5/2004 may be explained, not by any lack of mobilizable debris, but rather by both a less effective debris trapping (the cause of which is however unknown) and possible instabilities leading to disaggregation of any DA that did develop. An image taken less than two weeks later during a much lower stage (Figure 4.13f) gives a clearer picture of the DA, including that portion that might have submerged under a higher stage. Thus, a comparison of Figures 4.13e and $\mathrm{f}$ reveals that there was submerged DA at the debris deflector, and also DA at the pier, though some of what is seen may actually be the local island feature just upstream of the pier.

Several other smaller flow events during 2004 were examined, but while some debris transport was observed, it was generally light, consisting of isolated branches and logs (though some were fairly large). Some DA occurred at the debris deflector, where some large logs became trapped, but the DA at the pier grew very little if at all.

Event of 1/6/2005 and 1/14/2005 The largest flow during the project period started on 1/3/2005, and peaked at a stage of $21.6 \mathrm{ft}$ and a discharge of 20,000 cfs at 6:00 a.m. on 1/6/2005 (Figure 4.14), and was followed soon thereafter by another smaller event with a peak stage of $19.1 \mathrm{ft}$ and a peak discharge of $9960 \mathrm{cfs}$, attained at 8:00 a.m. on 1/14/2005. At the beginning of the event, a large log was being balanced at the debris deflector, and some DA at the pier can be seen, with a 
large log extending upstream (Figure 4.15a). Already before 9:00 a.m. on 1/3/2005 (correspond ing to discharges $\approx 3500 \mathrm{cfs}$, isolated smaller debris elements are seen being transported, arriving with greater regularity after 9:30 a.m. The first significant cluster started at 11:23 a.m (Figure 4.15b). During another cluster at $\approx 12: 45$ p.m., the log at the debris deflector became

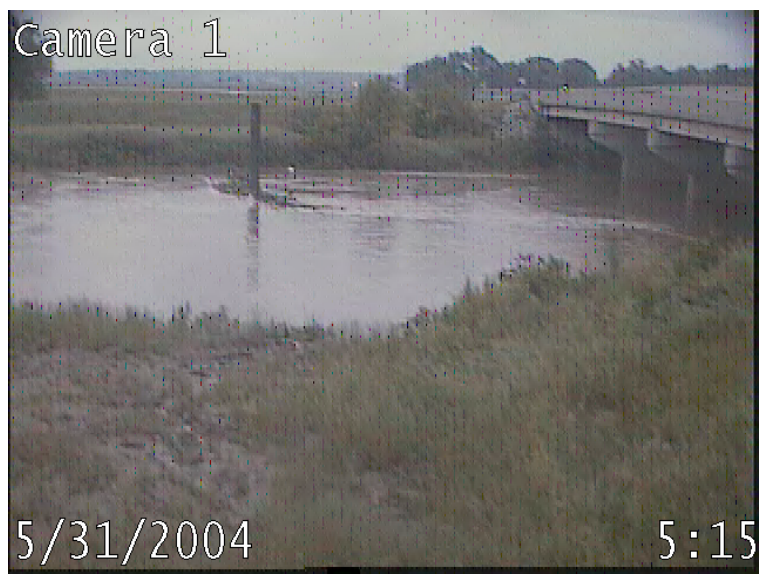

a)

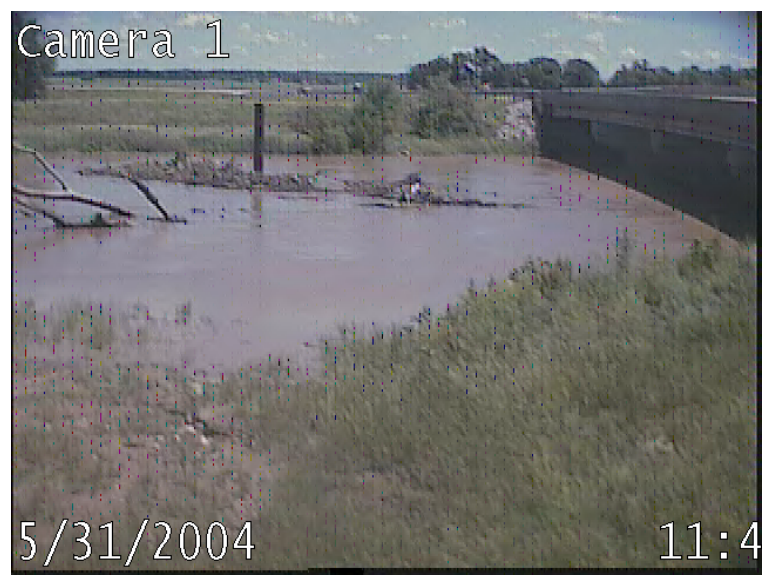

c)

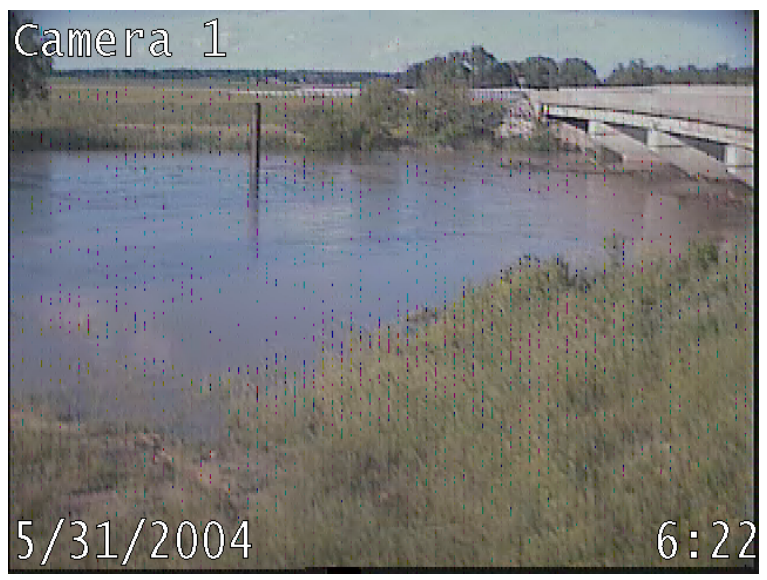

e)

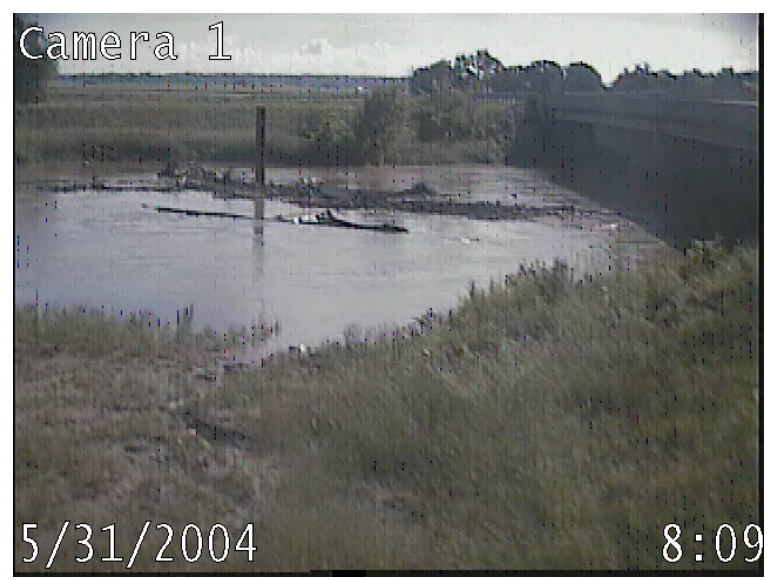

b)

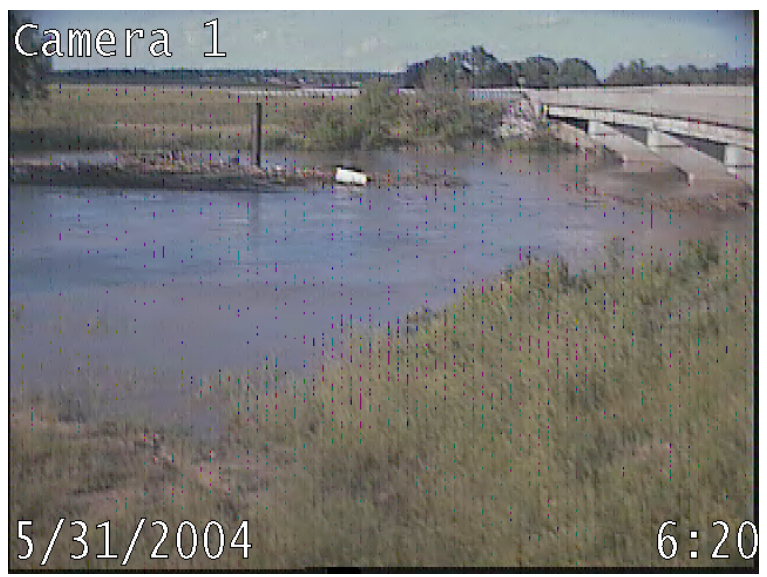

d)

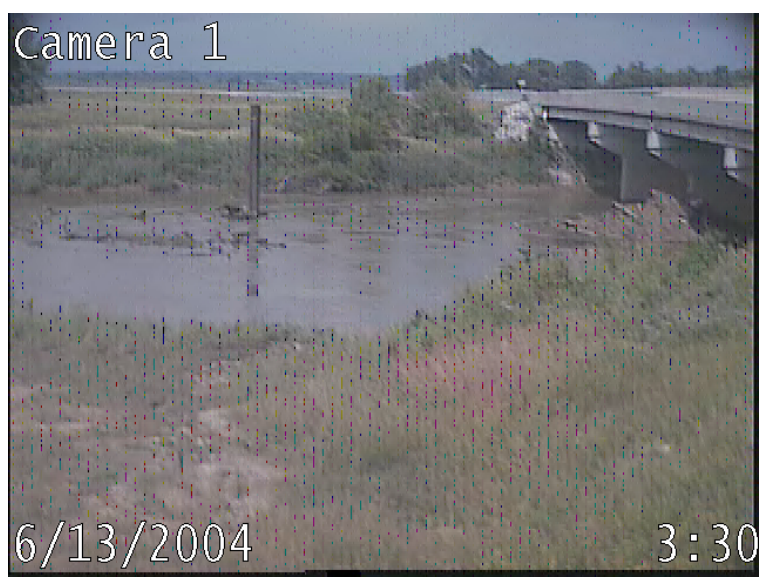

f)

Figure 4.13: Images from the 5/31/2004 event 

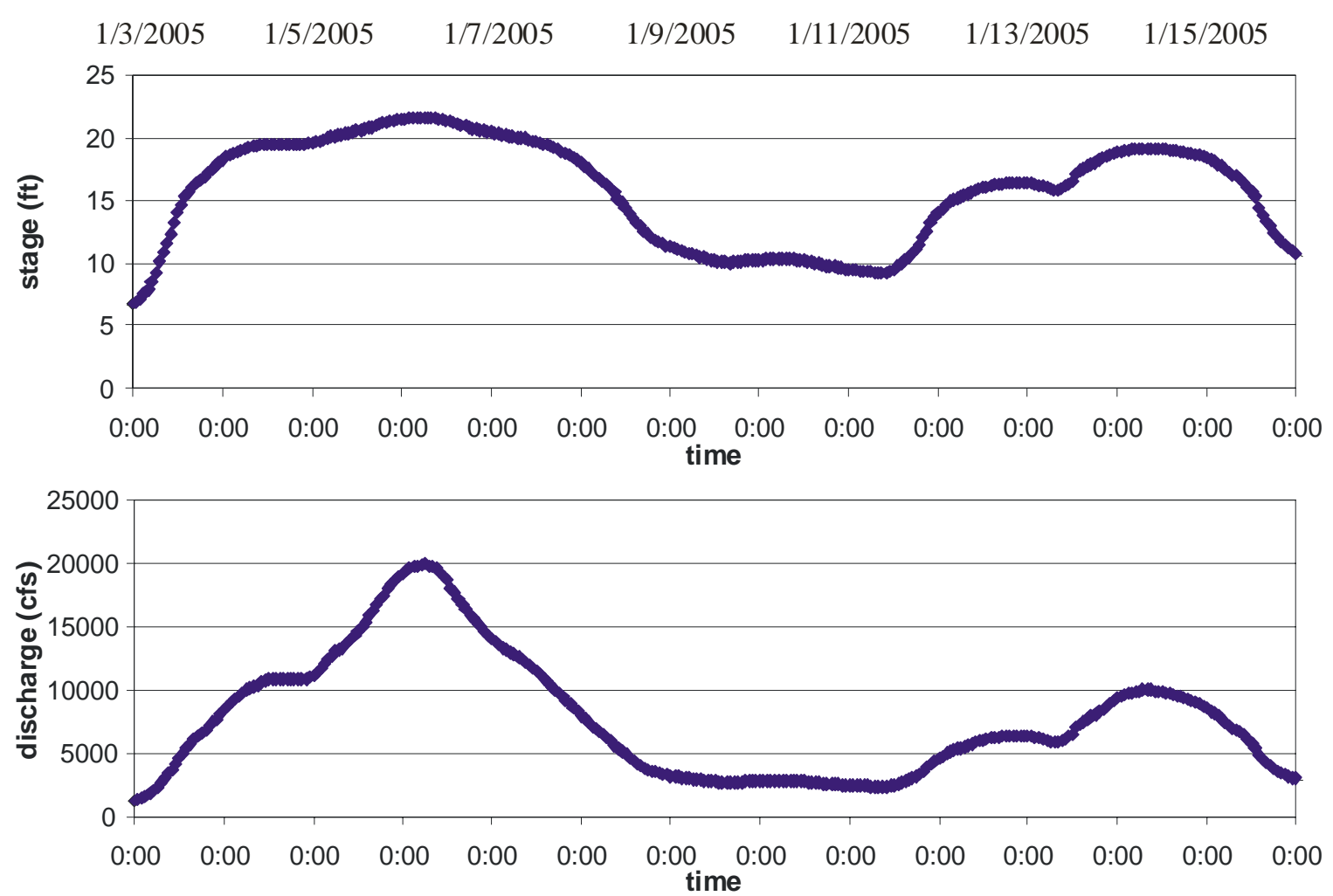

Figure 4.14: Stage and discharge hydrographs between 1/3/2005 and 1/16/2005.

disengaged (Figure 4.15c). Towards the end of the recording on that day, a moderately heavy DA has become established at the pier (Figure 4.15d). On the next morning at 8:00 a.m., still more than 40 hours before the peak, the DA had grown noticeably (Figure 4.15e). Debris transport was still noticeable, though there were no large clusters, such that ten hours later, the DA had grown but not dramatically (Figure 4.15f). The picture did not change markedly overnight, and during the day, the DA, rather than growing, shrunk somewhat due to attrition (Figure 4.15g). This trend continued until the next evening (Figure 4.15h). The tilting of the debris deflector in Figure $4.15 \mathrm{~h}$ should also be pointed out. The following morning, by which time the peak of the hydrograph has already been passed for some time, the deflector is not seen, having tilted so far as to be submerged (Figure 4.15i). As a consequence, some or all of the DA at the deflector has become part of the DA at the pier. The extent of the DA seen in Figure 4.15i is again deceptive, because only that above the high water surface is seen. At a lower stage (over 10-ft difference at Bowling Green), the full extent of the DA is better appreciated (Figure 4.15j). The still present tilted deflector may also be seen.

The subsequent flow event, the third largest during the project period, started on $1 / 11 / 2005$, but, except for isolated debris elements, little upstream debris transport was noted during the entire day. There was however another instability within the existing DA, leading to a spontaneous redistribution of the DA. At 5:36 p.m., the picture is essentially the same as that on the previous day (Figure 4.15j) with a single DA extending some distance upstream; at 5:37 p.m., the upstream part of the DA has broken in two parts (Figure 4.15k), and two minutes later, the two parts are carried to the flanks of the original DA, with some undoubtedly being carried past the bridge. (Figure 4.15l). This remained unchanged for the rest of the recorded images on that day, but the following morning, by 7:34 a.m., the DA had grown considerably (Figure 4.15m), so 
that its upstream edge extended again past the tilted debris deflector. The arrival of a cluster at the same time may also be noted in the dark blotches just upstream of the DA. Transported debris was seen regularly over the next $5-6$ hours, with several larger clusters being observed. The largest of these started to arrive at $\approx 12: 31$ p.m., by which time the DA had grown farther upstream somewhat, but there was still a large gap between the upstream end of the DA and the

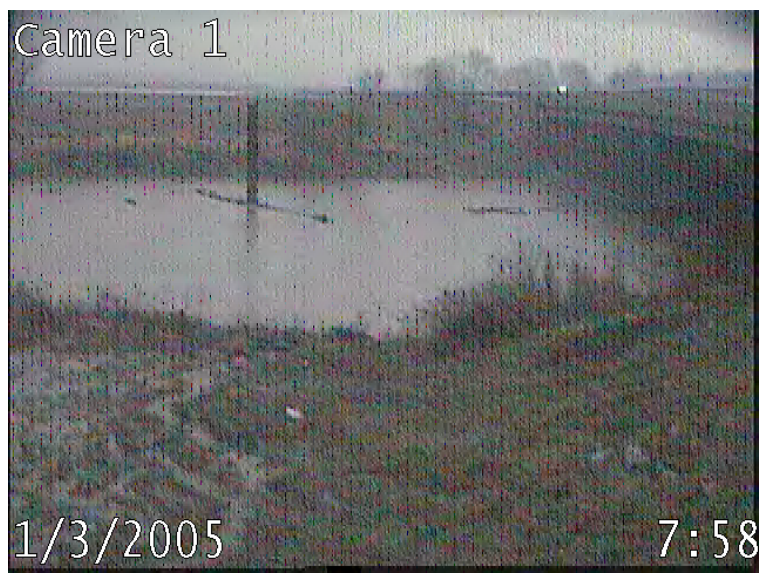

a)

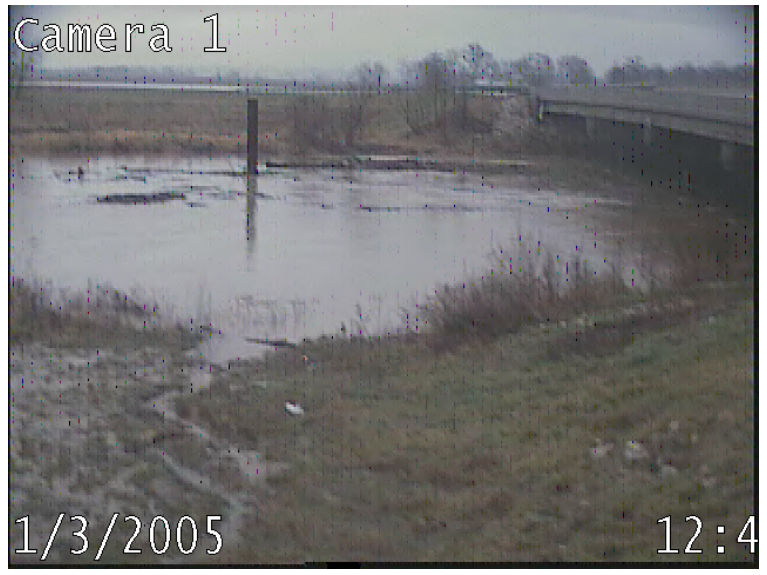

c)

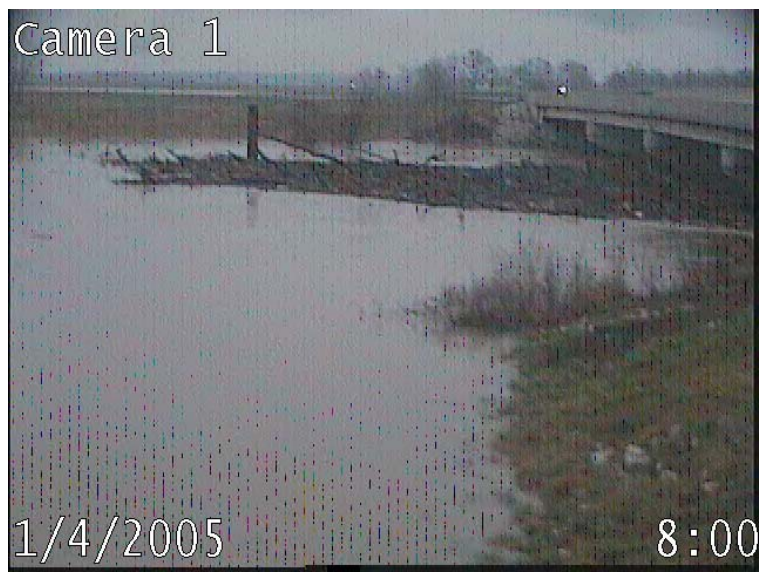

e)

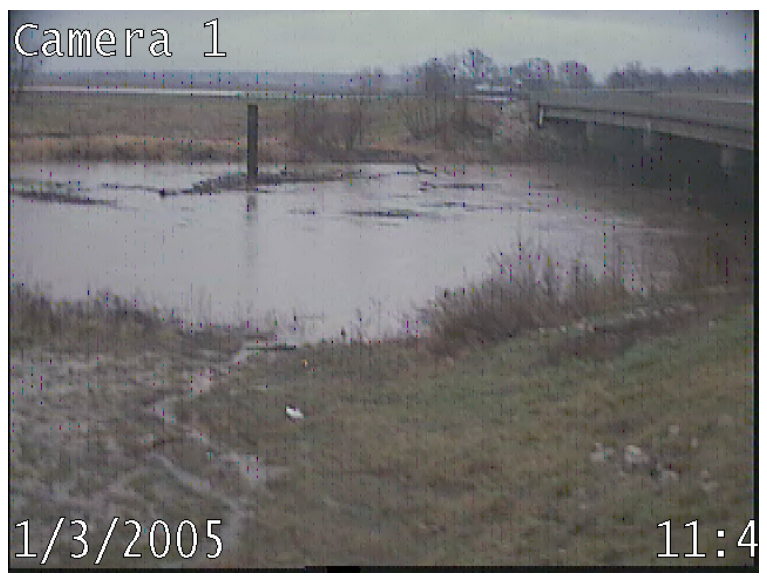

b)

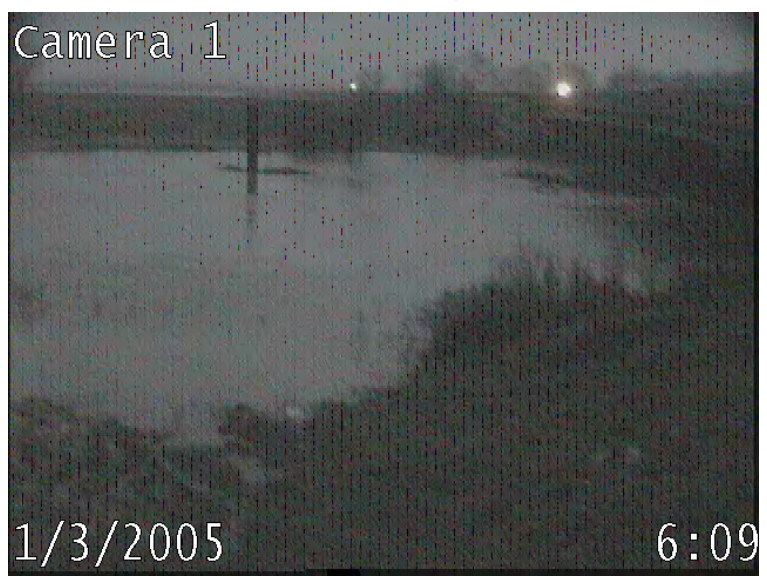

d)

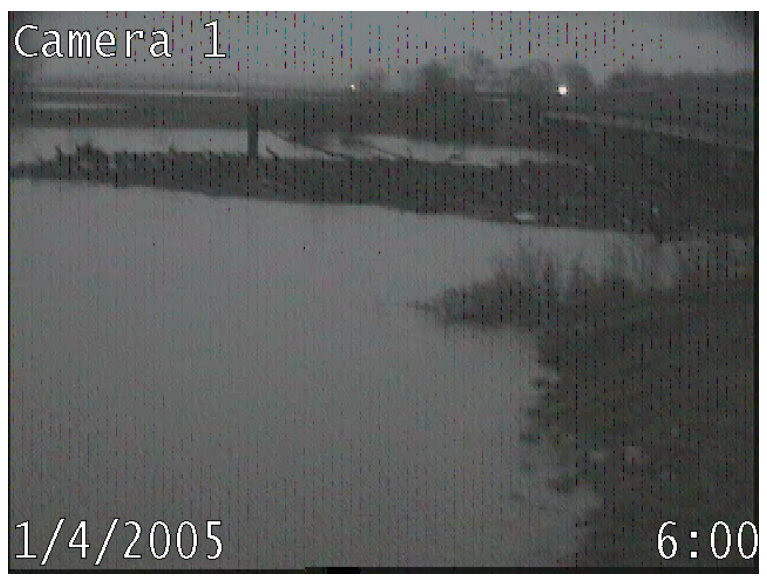

f)

Figure 4.15: Images from the events with peaks on 1/6/2005 and 1/14/2005. 


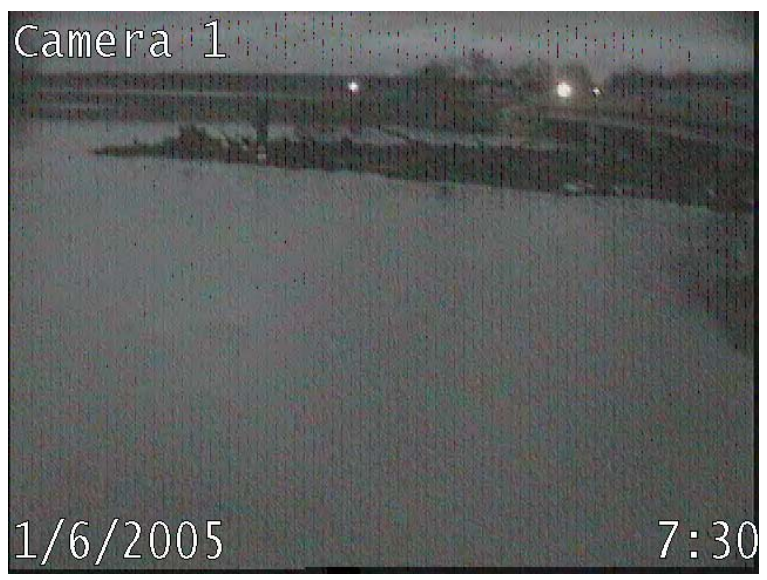

g)

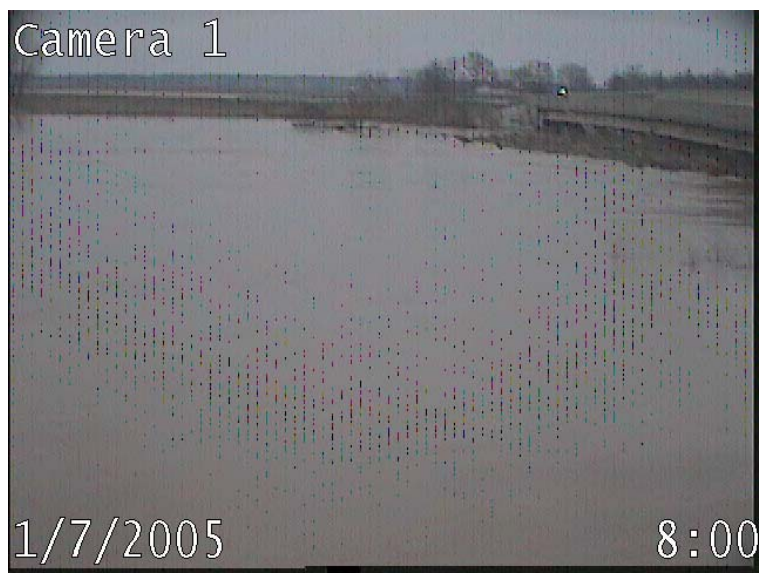

i)

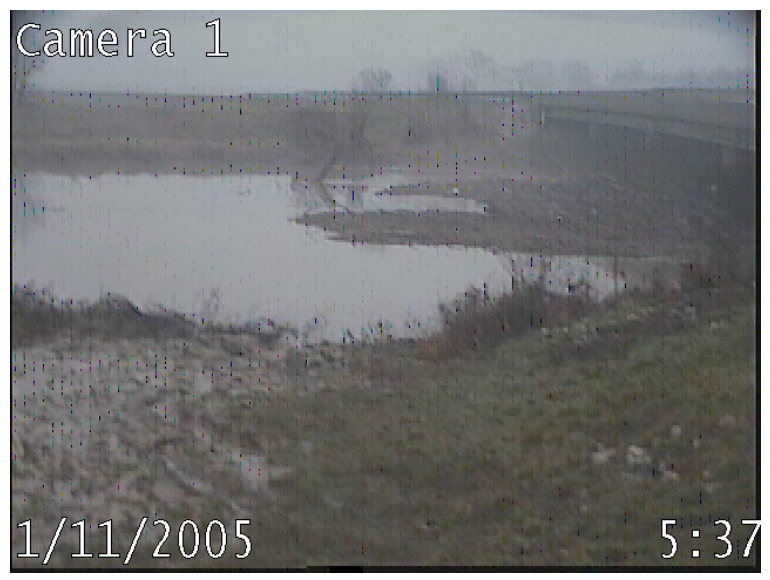

k)

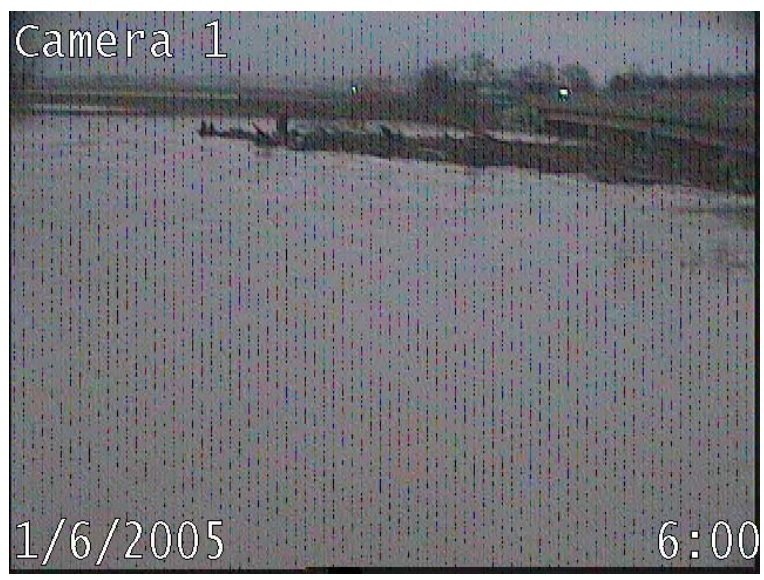

h)

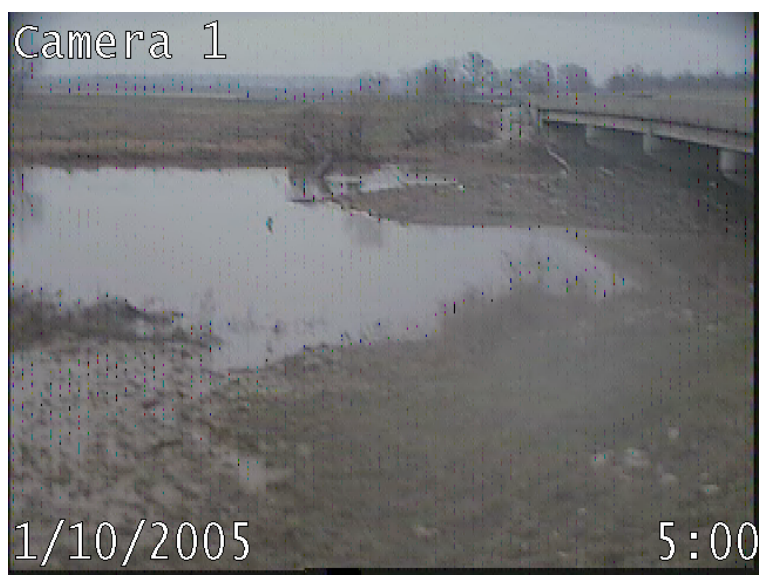

j)

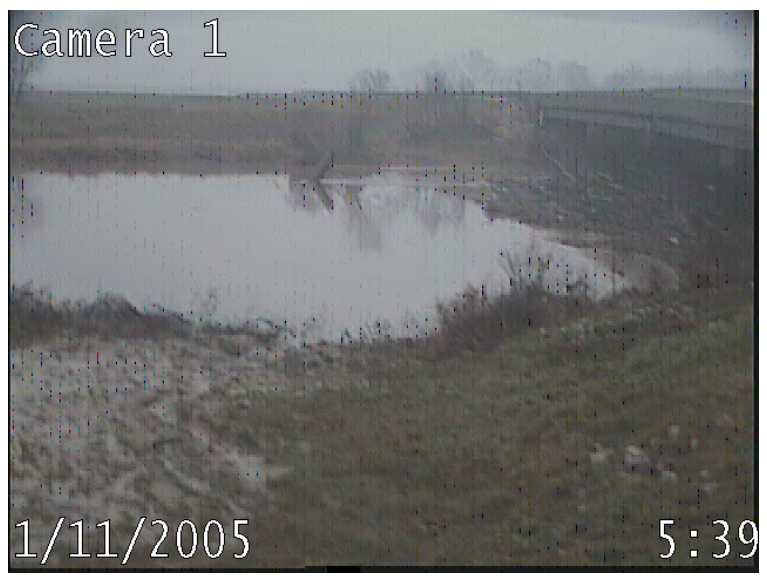

l)

Figure 4.15: Images from events with peaks on 1/6/2005 and 1/14/2005 (contd.).

leftmost extent of the image. By 1:30 p.m., the DA extended past the upstream boundary of the camera field of view (Figure 4.15n). After this, again more than 40 hours before the hydrograph peak, transport activity was apparently substantially reduced. This observation however may to some extent be misleading because the upstream end of the DA, and hence any upstream DA growth, could not be seen. Still no significant debris transport on either side of the DA was noted during the rest of the day, and the following morning at 8:00 a.m., changes were subtle 


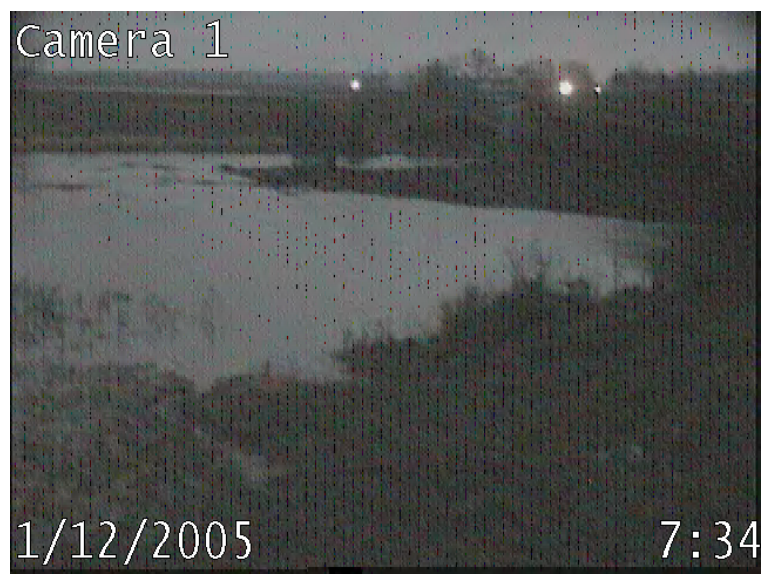

m)

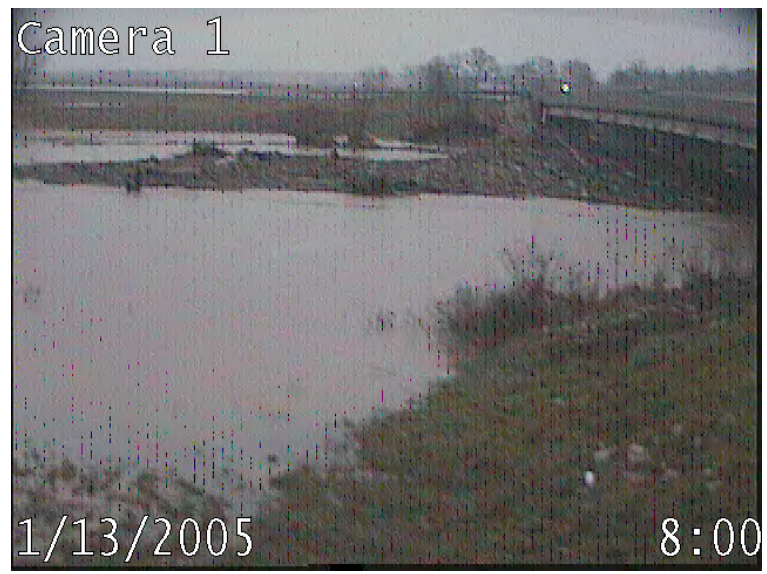

p)

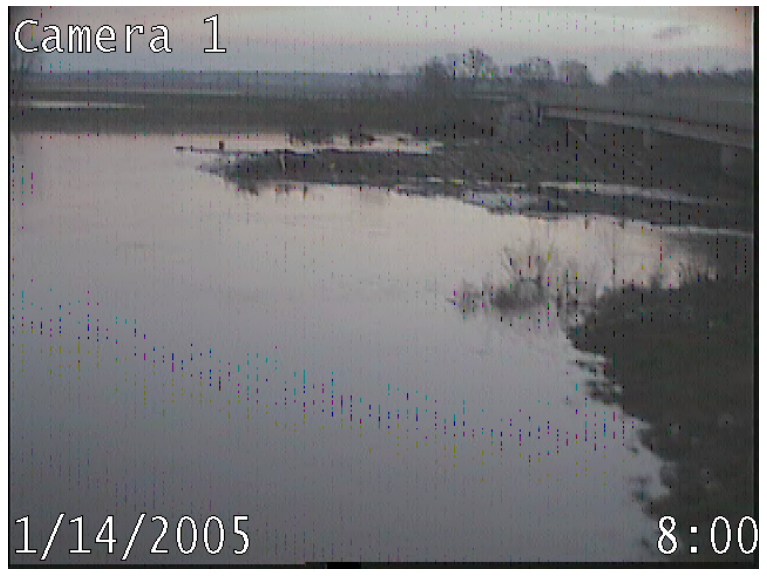

r)

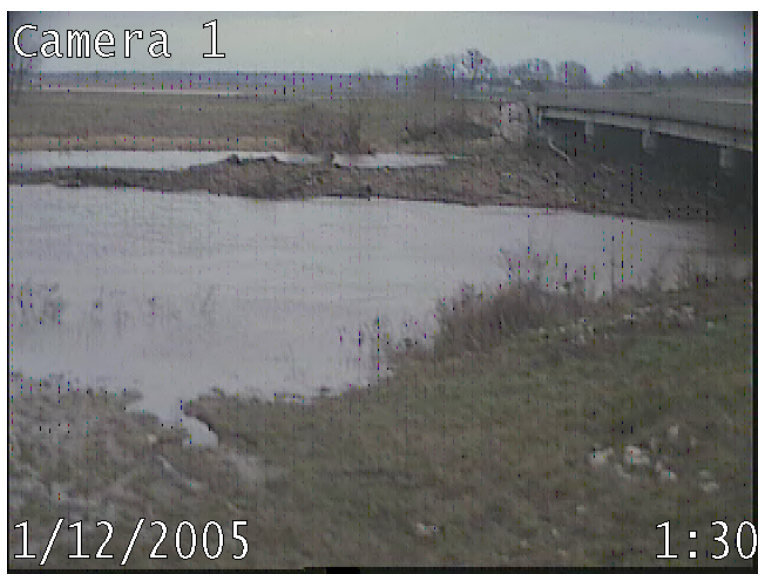

n)

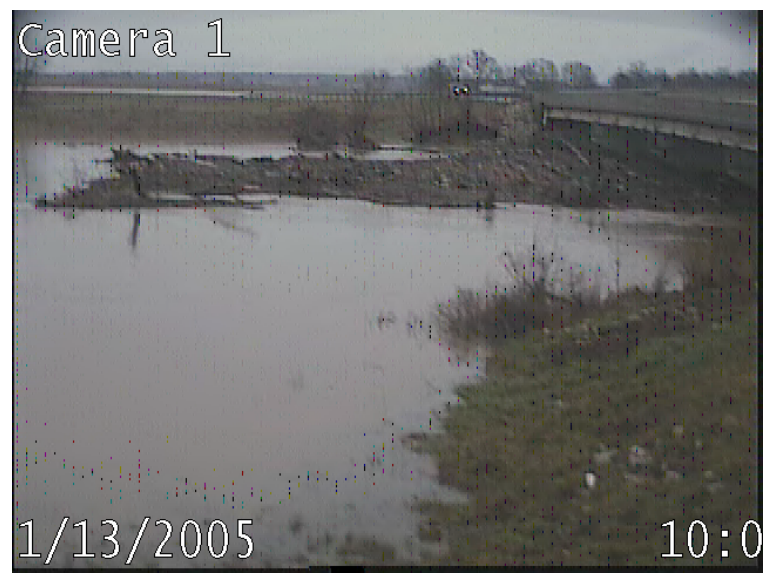

q)

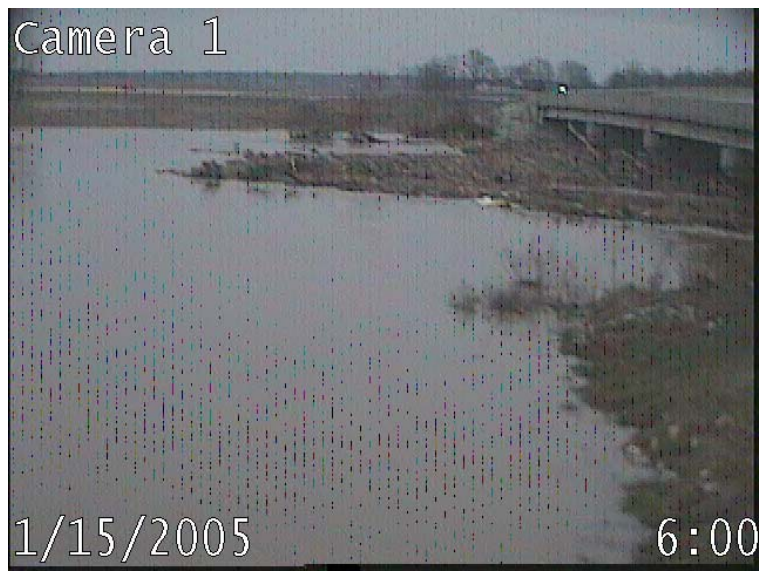

s)

Figure 4.15: Images from events with peaks on 1/6/2005 and 1/14/2005 (contd.).

rather than dramatic (Figure 4.15p). Nevertheless some sustained debris transport was observed, but some of this seemed to have resulted from 'erosion' or 'attrition' of the nose of DA. This was supported by the turning of the nose of the DA at $\approx 10: 00$ a.m. (Figure $4.15 q$ ). With the nose of the DA in view, some transport of small debris elements was observed, particularly during the morning, though the DA did not change noticeably during the rest of the day. By the next 
morning, it was evident that the nose of the DA had again broken off, with a sizeable portion being trapped at the bridge (Figure 4.15r). By this time, the hydrograph had peaked at Bowling Green, and little debris transport was noted, such that the picture remained the same towards the end of the event (Figure 4.15s).

Other events of 2005 The remainder of 2005 saw several flow events that were flagged for inspection, but these were quite minor in magnitude (Figure 4.3). An event peaked on 2/14 at 2:00 p.m., with a stage of $12.7 \mathrm{ft}$ and a discharge of $3890 \mathrm{cfs}$. What little upstream debris transport was noted during the entire event arrived primarily near the peak. There was however another case of DA instability (Figure 4.16) which may be pointed out. This occurred before the peak of the event ( $\approx 4$ hours before the peak at Bowling Green), and rather curiously, it was the middle portion of the DA that was washed downstream.

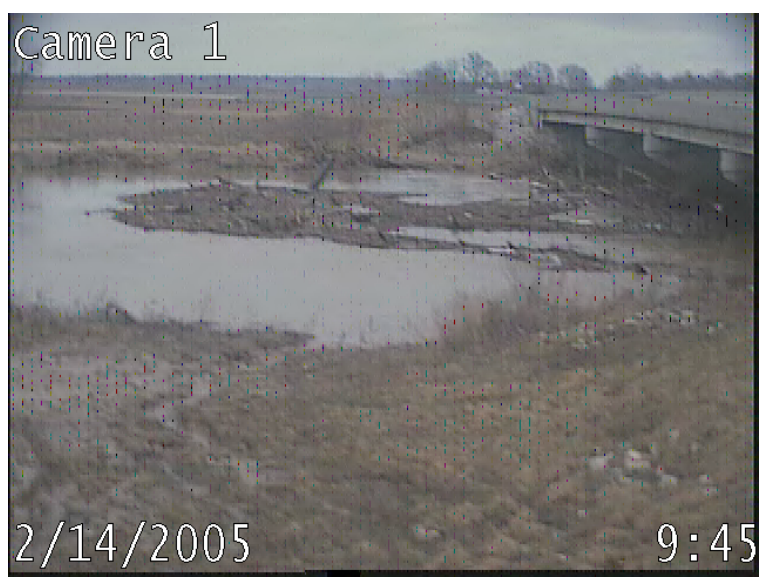

a)

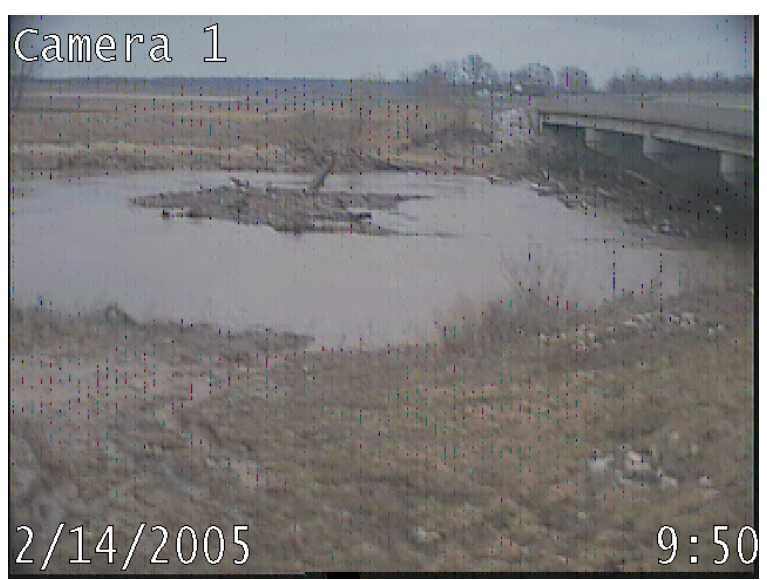

b)

Figure 4.16: DA instability incident during event of 2/14/2005, a) before, b) after.

The largest flow event in 2005, apart from those in January, started on 5/20 and peaked the same day at 2:00 p.m. with a stage of $15.5 \mathrm{ft}$ and a discharge of $5590 \mathrm{cfs}$. Transport of large debris elements was already noticeable before 6:00 a.m (Figure 4.17a). The large log on the bank is evidence of a debris clearing operation, and there seems little or no debris at the piers or at the debris deflector at the beginning of the event. Quite large debris elements were mobilized (Figure 4.17b). Clusters were also observed, even rather late in the event (Figure 4.17c), somewhat contrary to what was seen in earlier events. By the end of the day (Figure 4.17d), the DA at the pier had grown noticeably, again indicating debris-transport activity quite late in the event. Images from the following morning show some apparent increase in the extent of the DA, but this may be due to a lower stage exposing more of the DA.

The peak stage of this event is $\approx 1 \mathrm{ft}$ lower than the already discussed event from the previous year at about the same time (5/31/2004). The initial conditions at the piers were quite similar in being relatively clear of debris. The hydrographs differ somewhat in that this event had a steeper initial rise, and shorter duration of high stages. This may explain the observation of significant transport even late in the event. The hydrographs are again those at Bowling Green, and, especially for these 'flashier' events, local conditions may be influential in shaping hydrographs. Although this flow event is slightly smaller, the resulting DA is arguably larger. This might however have been the consequence of the DA instability observed during the 2004 event. 

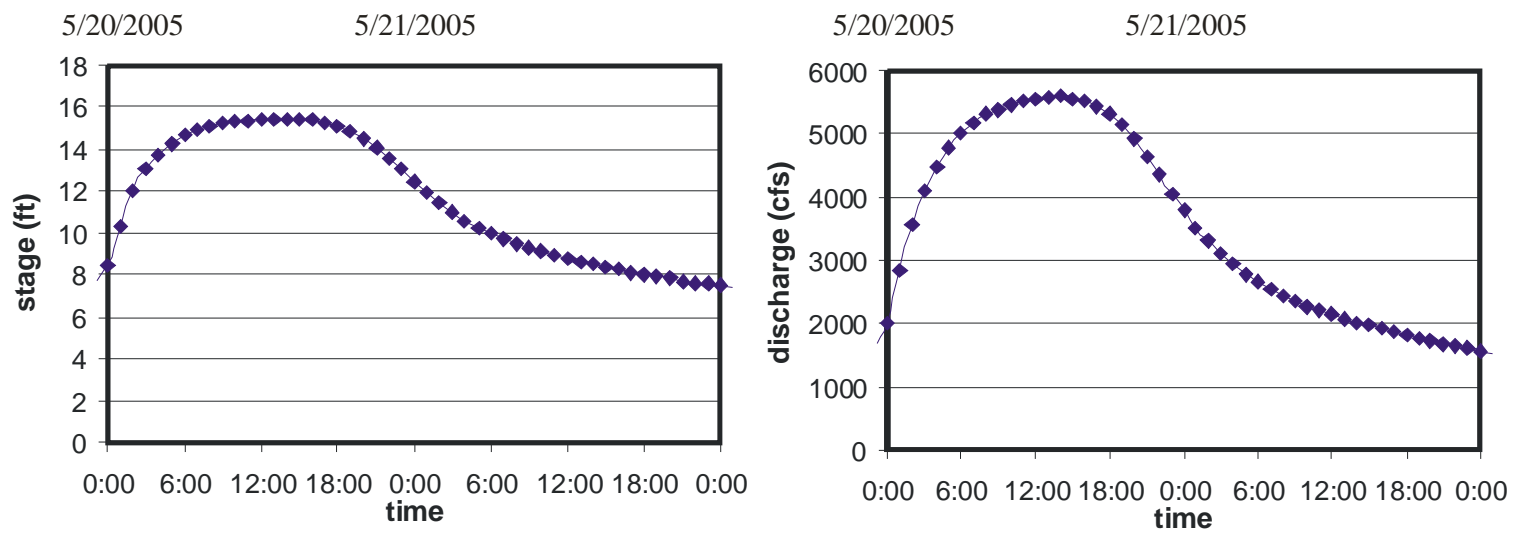

a)

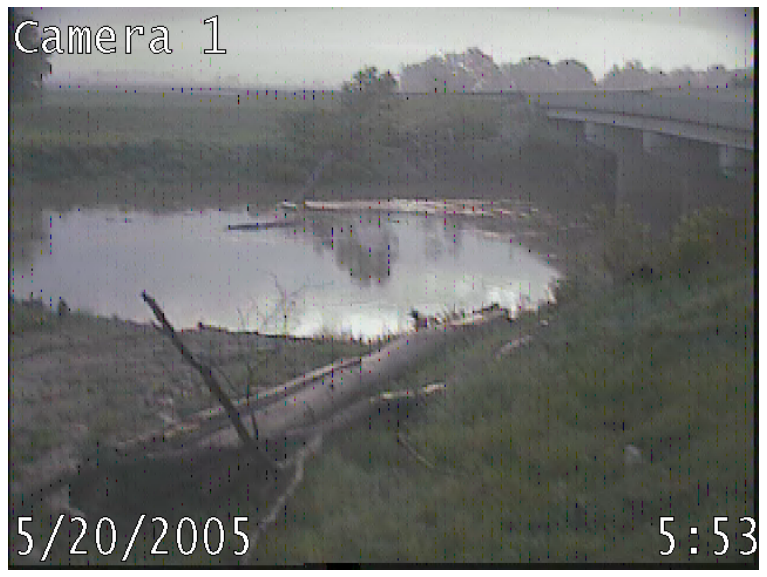

b)

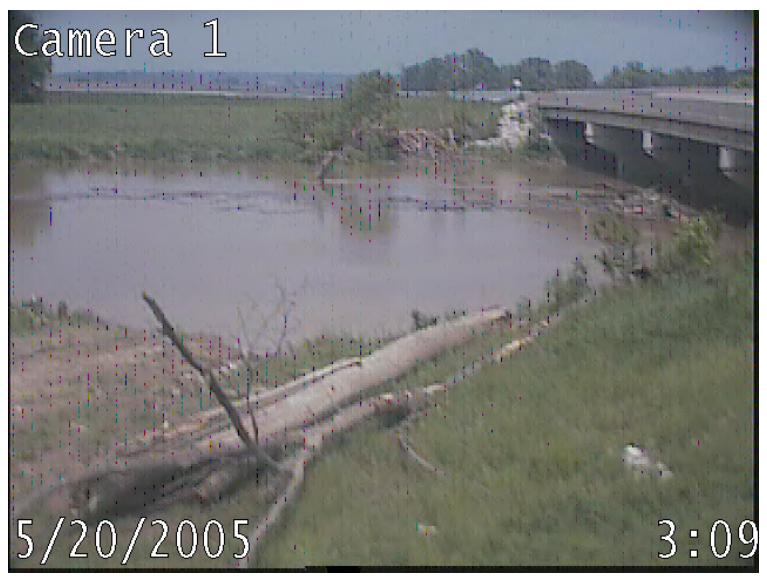

d)

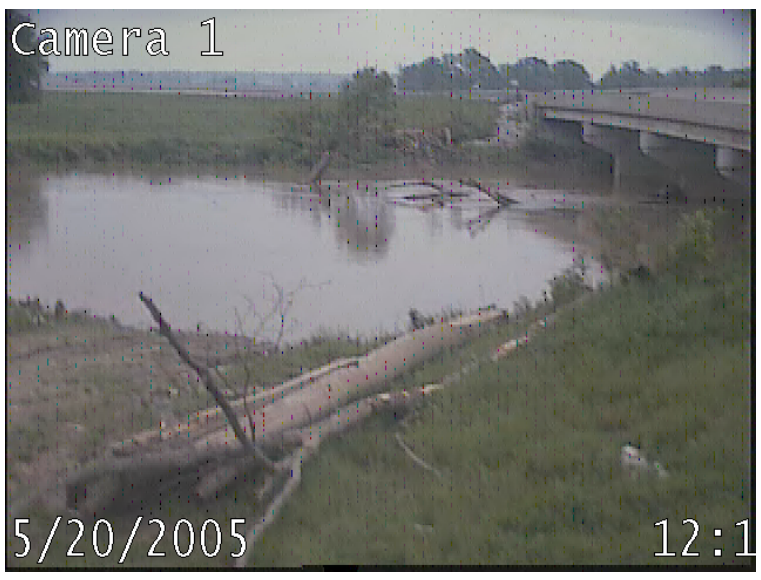

c)

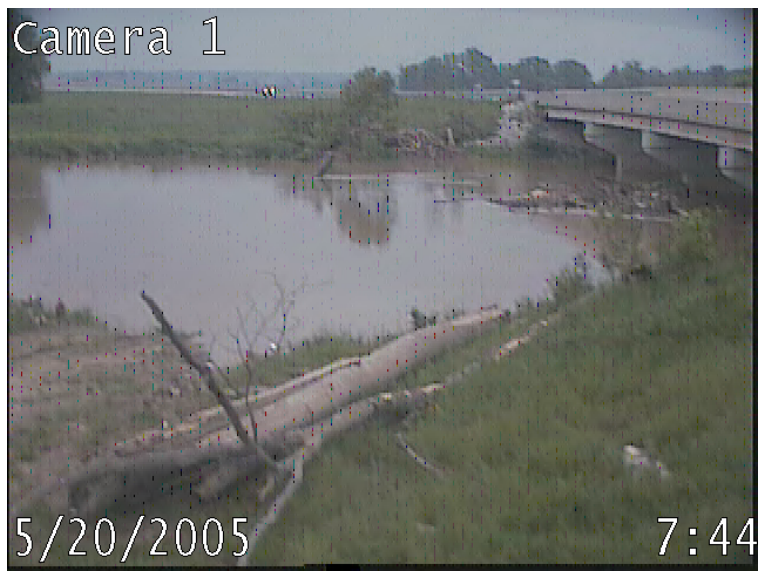

e)

Figure 4.17: a) stage and discharge hydrographs, b), c), d), e) images from event of 5/20/2005

Another flow event of slightly smaller magnitude occurred shortly thereafter on 6/13 (Figure 4.18a), peaking at noon with a stage of $14.2 \mathrm{ft}$ and a discharge of $4710 \mathrm{cfs}$. Again, debris transport was quite active in the early morning (5:24 a.m., Figure 4.18b). By 9:28 a.m., there has been substantial DA growth. This continued to a lesser degree until somewhat after 1:00 p.m. (Figure 4.18c), and was then much reduced, such that the DA growth by the end of the (recording) day was less marked (cf. Figures $4.18 \mathrm{c}$ and d). Evidently there must have been 
further debris transport overnight, as the DA did grow slightly (Figure 4.18e). The DA remained essentially the same until $\approx 11: 31$ a.m., when the upstream end became unstable, and by 11:35 a.m. (Figure 4.18g), had been washed away. The DA did not noticeably change after this.

The final flow event of 2005 of any significance occurred on 11/16, peaking at noon with a stage of $14.3 \mathrm{ft}$ and a discharge of $4770 \mathrm{cfs}$ (Figure 4.19a). The first notable debris transport
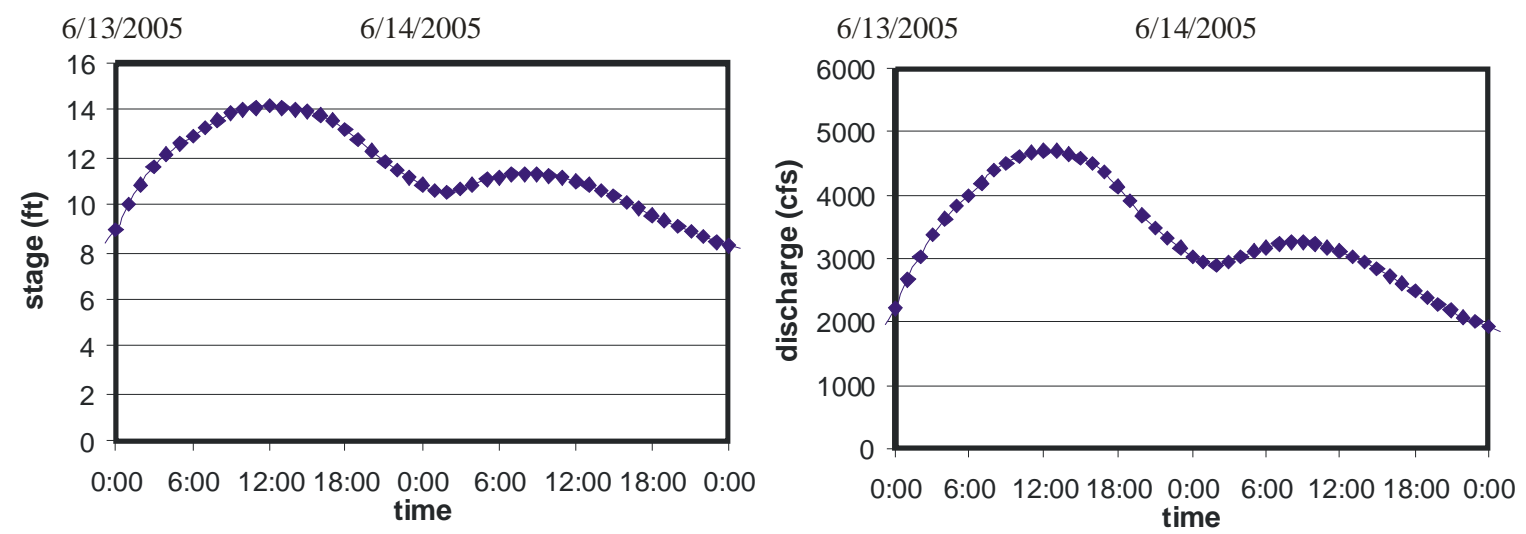

a)

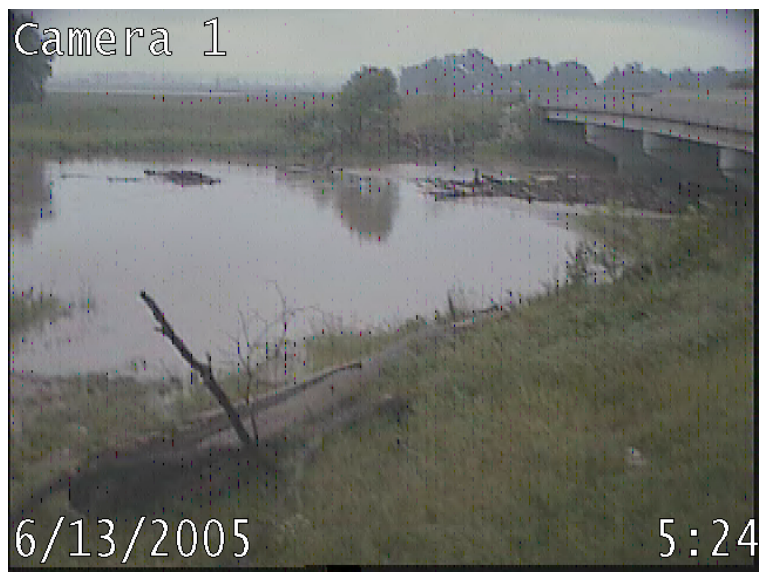

b)

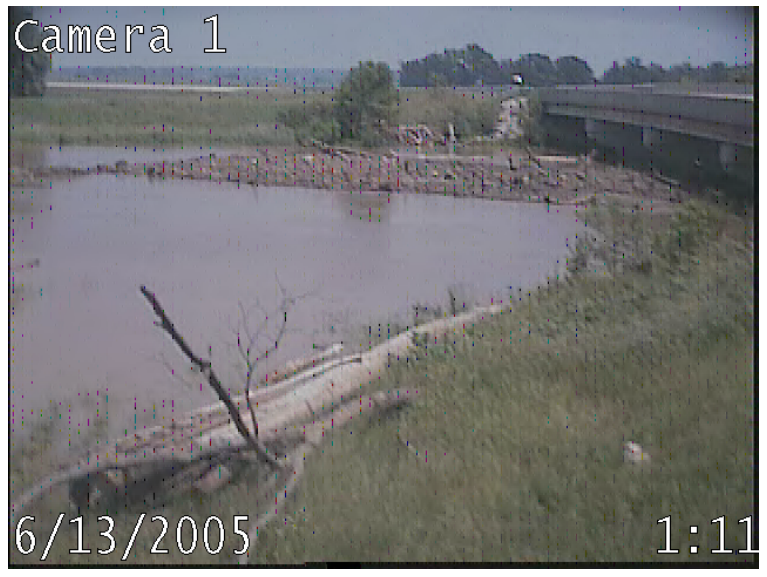

d)

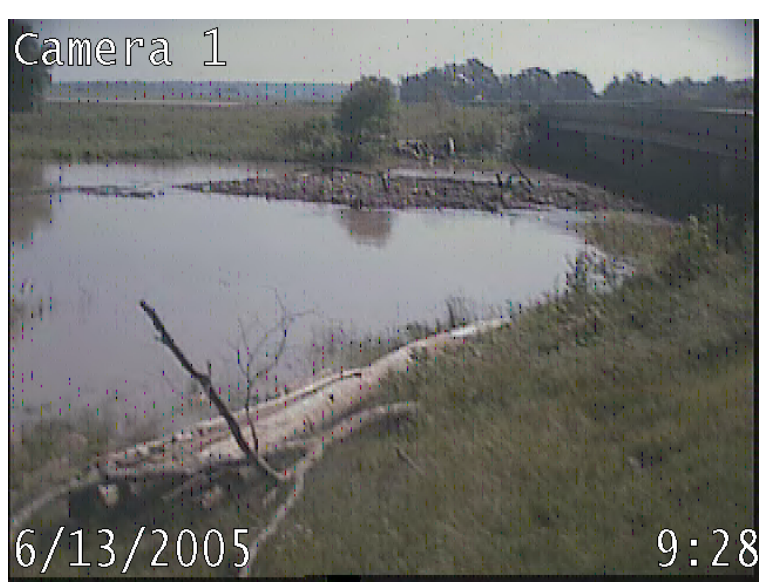

c)

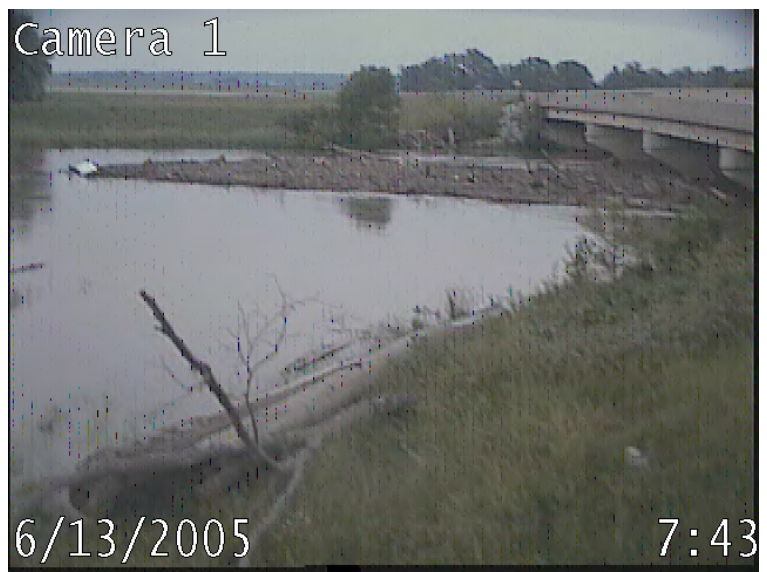

e)

Figure 4.18: a) stage and discharge hydrographs, b), c), d), e), f), g) images for event of 6/13/2005 


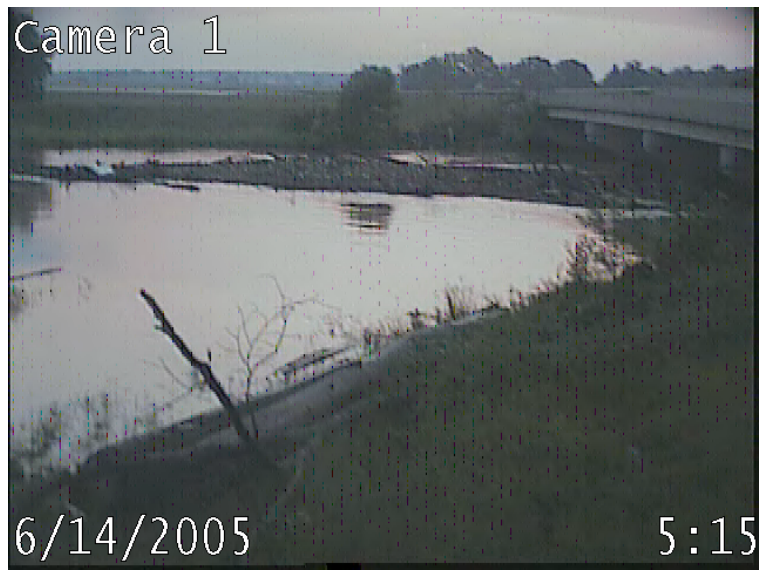

f)

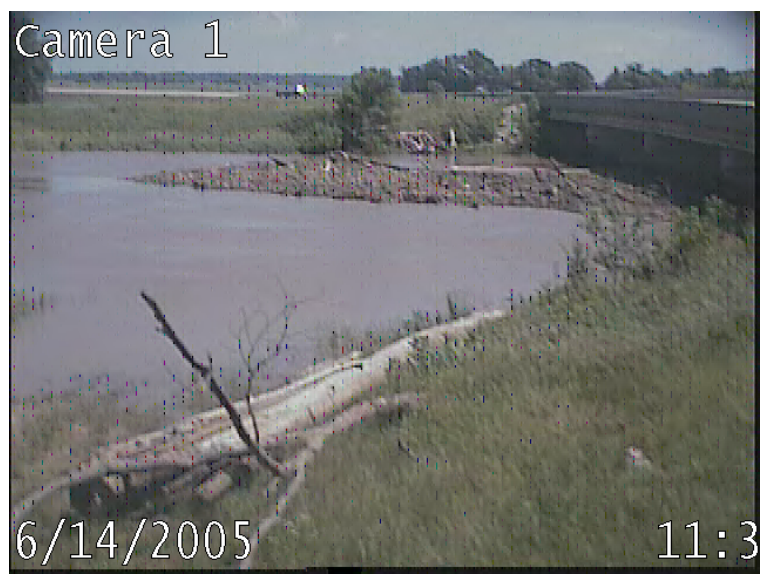

g)

Figure 4.18: a) stage and discharge hydrographs, b), c), d), e), f), g) images for event of 6/13/2005contd.

started at $\approx 7: 23$ a.m., and was actually a cluster (Figure $4.19 b$ ). It is not clear whether there was significant transport before that time because the available daylight for usable images was quite circumscribed during the fall and winter months, typically only between 7:00 a.m. and 6:00 p.m. Transport for this event seemed rather more clustered than usual. There was even a large and extended cluster, starting at $\approx 4: 51$ p.m. and ending at $\approx 5: 01$ p.m. (Figure 4.19 c), notably well past the hydrograph peak (at Bowling Green). There did not appear to be any other significant transport after this, though again this might be masked by the upstream end of the DA not appearing within the field of view of the camera. In any case, not much change in the DA was observed.

Summary of observations at the SR59 site The SR59 site is characterized by a relatively straight reach, with a flow expansion at the bridge crossing, and a distinct island feature just upstream of one of the piers. In Chapter 2, it was classified as a 'mega' site, and at the beginning of the study period had two debris deflectors installed. Several general observations may be made concerning debris transport and accumulation:

- The large bulk of the debris transport occurs within the first 12 hours of the event. If the time to the peak flow is longer than that, relatively little transport or accumulation is noted afterwards. If the time to peak is shorter, then some significant transport or accumulation might still occur after the peak, though generally transport or the rate of accumulation is reduced during the receding part of the hydrograph.

- This may explain why the magnitude or duration of a flow event may not be closely correlated with either the amount of debris transport or the resulting DA.

- It also suggests that the bulk of the DA originates within a smaller part of the entire watershed, i.e., the debris-shed is smaller than the watershed.

- Very heavy DA can result from a single event. The discharge at which the general mobilization of debris, $Q_{d}$, begins can be substantially smaller than the 2-year discharge. At this site, a ready supply of debris seems available, such that, provided $Q>Q_{d}$, for an extended period of time, say over 12 hours, a heavy accumulation is almost certain to develop. This is particularly so if there is initially some residual debris at the bridge piers that can act as a nucleus for growth. In the case of a site that is initially completely free of 
debris, e.g., due to a prior clearing operation, accumulations may be smaller because it may take longer for the initial nucleus to form.

- Instabilities of the DA may not be as rare as might be thought, and may cause substantial redistribution of debris or even entire disappearance. These seem to be more prone to occur during the latter part of the flow event, generally the receding part of the hydrograph.

- Debris tends to be transported in the central region of the stream, but does not necessarily follow the thalweg, at least not in the immediate vicinity of the bridge crossing.
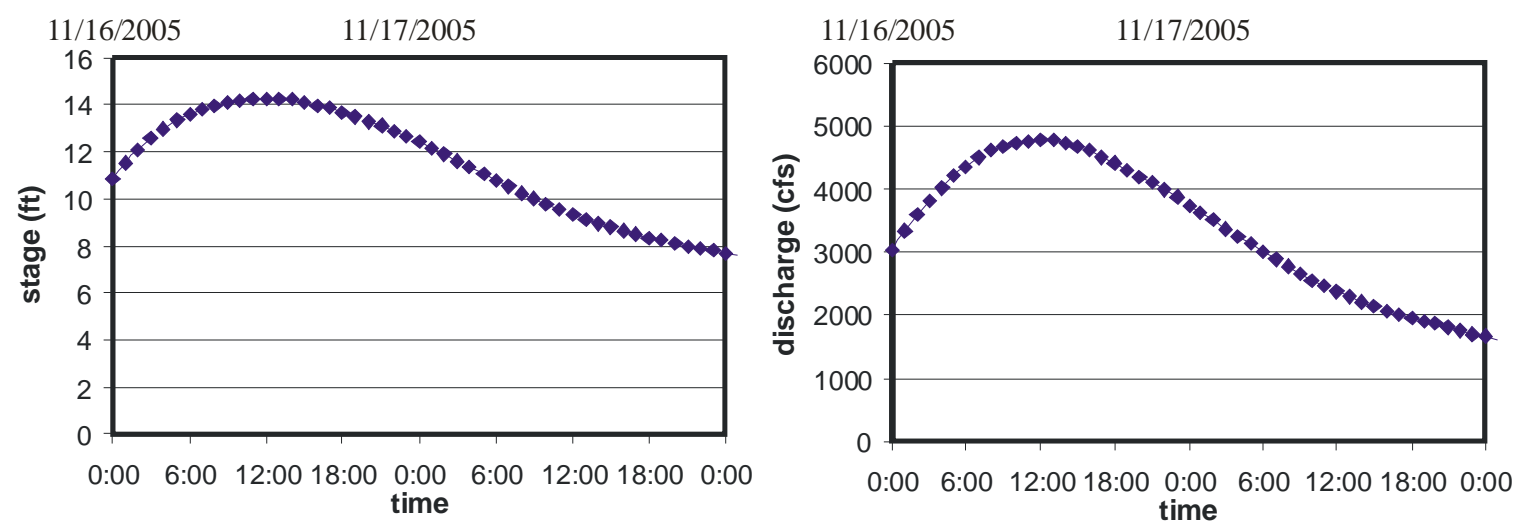

a)

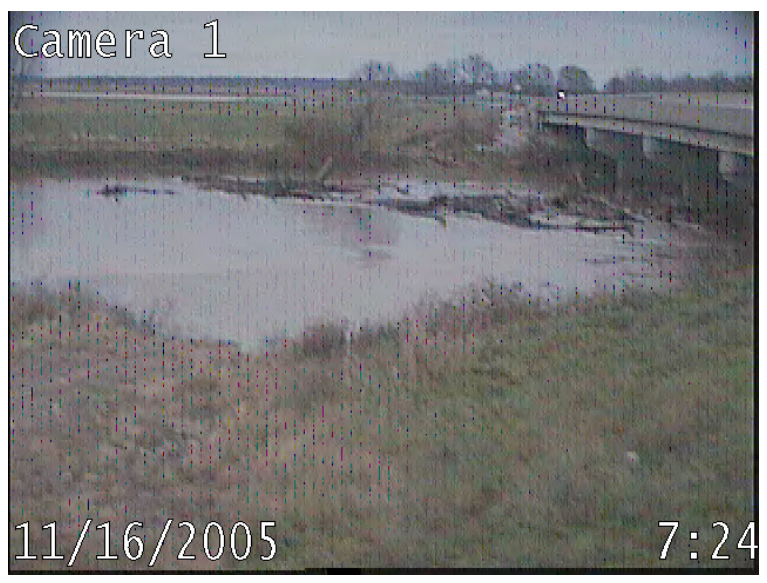

b)

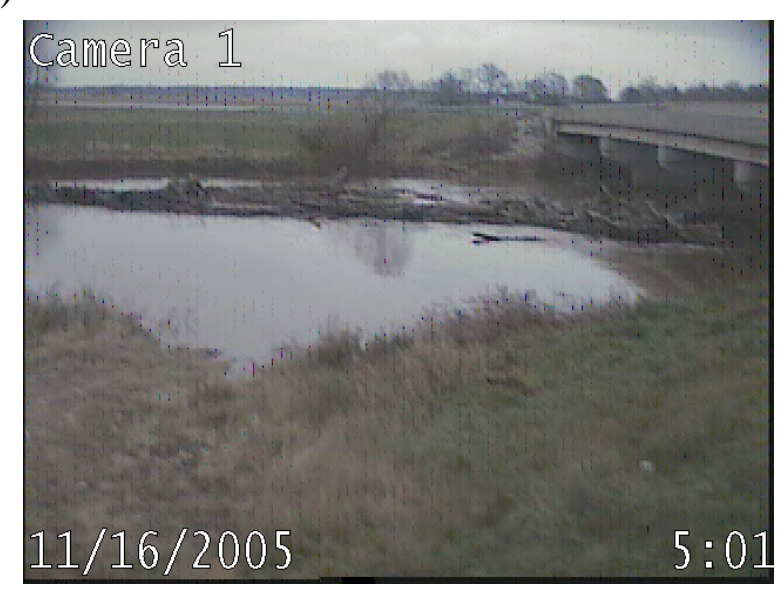

c)

Figure 4.19: a) stage and discharge hydrographs, b), c) images from event of 11/16/2005

\subsection{The SR63 - Vermillion River (southbound) near Cayuga}

\subsubsection{Site characteristics}

The SR63 - Vermillion River site provides an example of the weakness of the underwater bridge inspections for use in identifying sites suffering from heavy DA. It was twice inspected (in 1994 and 2001), and only light or moderate DA was reported. As such, it was not considered a site with heavy DA in Chapter 2. Like the SR59 site, INDOT had installed debris deflectors implying that there were serious concerns regard DA. Two photographs, one taken in 2002 and the other in 2003 (Figure 4.20), indicate that very heavy, even possibly 'mega' class, DA, may frequently occur. 


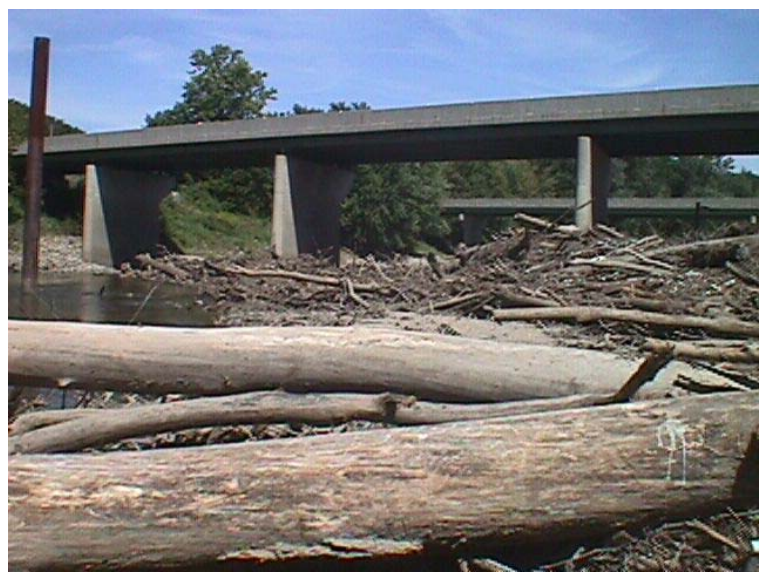

a)

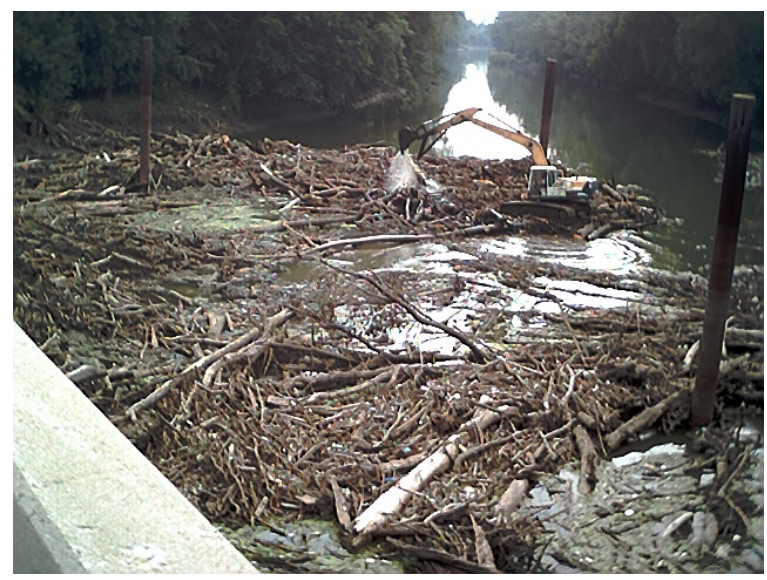

b)

Figure 4.20: Images from the SR63 sites taken in a) 9/4/2002, and b) 8/14/2003

An aerial photograph of the site, together with plan view and three cross-sections taken from the 2001 bridge report, and a photograph of the site when cleared of debris are shown in Figure 4.21. In contrast to the SR59 site, the SR63 site is located on a quite pronounced bend, that is $\approx 0.7$ miles upstream of a large river (the Wabash). As might be expected in a bend, the thalweg region runs relatively close to the outside of the bend. An island or peninsula-type feature is noted between piers 5 and 6. There is some flow expansion indicated in Figure 4.21b, though there might actually be considerably greater expansion at higher stages. As is typical of bends, a bar formation is located on the inside of the bend (clearer in the upstream fascia and 100 -ft upstream cross-sections in Figure 4.21c), which is entirely submerged at higher stages. The span between piers, $69 \mathrm{ft}$, is, like that at SR59, probably less than Diehl's design log length, though it is not clear that the extensive DA is necessarily caused by a large log spanning two piers. Bed elevations taken during the earlier 1994 inspection are also shown in Figure 4.21c, and these indicate substantial aggradation and/or a lateral instability. Three debris deflectors, identical to those at SR59, are present, and are labeled as $\mathrm{D}_{\mathrm{N}}$ (north), $\mathrm{D}_{\mathrm{S}}$ (south) and $\mathrm{D}_{\mathrm{W}}$ (west).

\subsubsection{Hydrological events}

The USGS gaging station on the Vermillion River nearest to the site is located $\approx 20$ miles upstream near Danville. As with the SR59, the distance between the site and the gaging station implies that the magnitudes, shape, and timing of the hydrograph are only approximately correct for the site. The video monitoring equipment at this site has been operational since May 2003. The previous report (Lyn et al. 2003) did not discuss observations at the site because of the rather late start of operations. Herein, results beginning in 5/1/2003 will be dealt with, although the current project did not officially start until 10/1/2003. Because of problems first with the video recorder and then also with the cameras, it was decided to suspend entirely video recording at the site after 7/14/2004. The mean daily discharges spanning the 14-month period of operation from $5 / 1 / 2003$ to $7 / 1 / 2004$ are shown in Figure 4.22. Also shown is a line indicating the median annual peak discharge of $15,400 \mathrm{cfs}$, which corresponds to a 1.4-year event, based on 83 years of data. The largest flow event over the period of operation occurred on 6/12/2004 (recall in Chapter 3 that this was true of much of Indiana) with a discharge of 20,000 cfs. This was again by no means a very large event, since its recurrence interval was estimated to be only $\approx 4$ years. The second largest event, on $9 / 2 / 2003$, a discharge of $16,700 \mathrm{cfs}$, had a recurrence interval of $\approx 2.7$ years, with several other smaller events. 


\subsubsection{The video monitoring system}

The video monitoring equipment was installed during a previous study (Lyn et al. 2003). It consisted of three video cameras, one (Camera 1) mounted on pier 7 angled partly upstream and partly towards the inner bank to provide a view of all three debris deflectors, one (Camera 2)

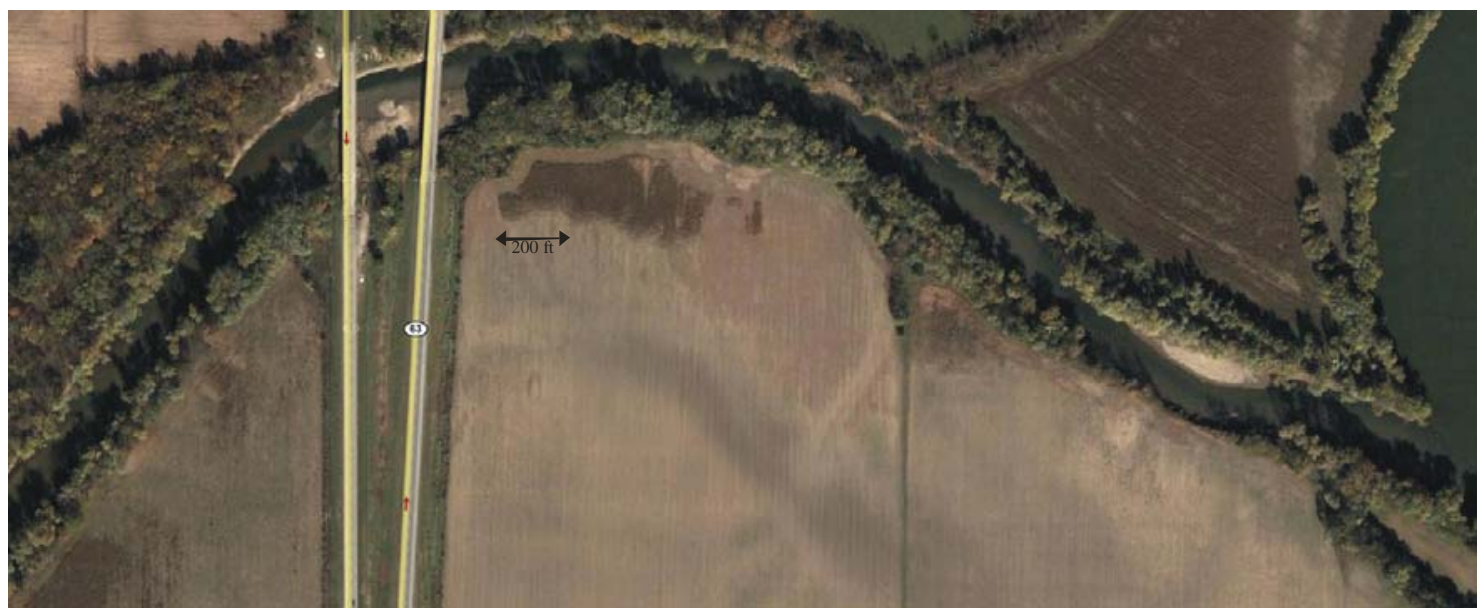

a)

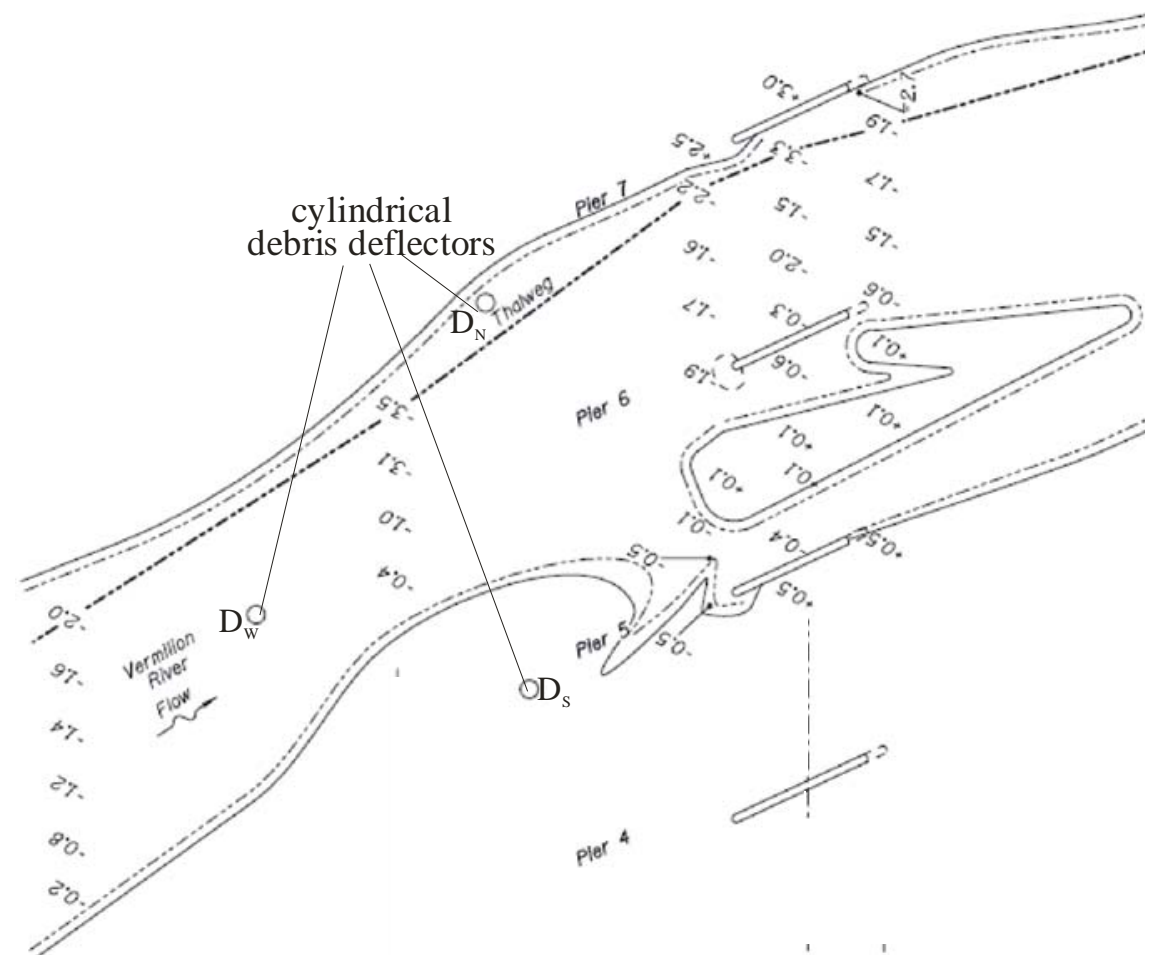

b)

Figure 4.21: SR63 site, a) aerial photograph (using GoogleMap), b) plan view, c) cross-sections from 2001 bridge inspection report, d) photograph, looking upstream, of the site when cleared of debris (note debris deflectors and point bar, i.e., sand deposit, on inside of bend) 


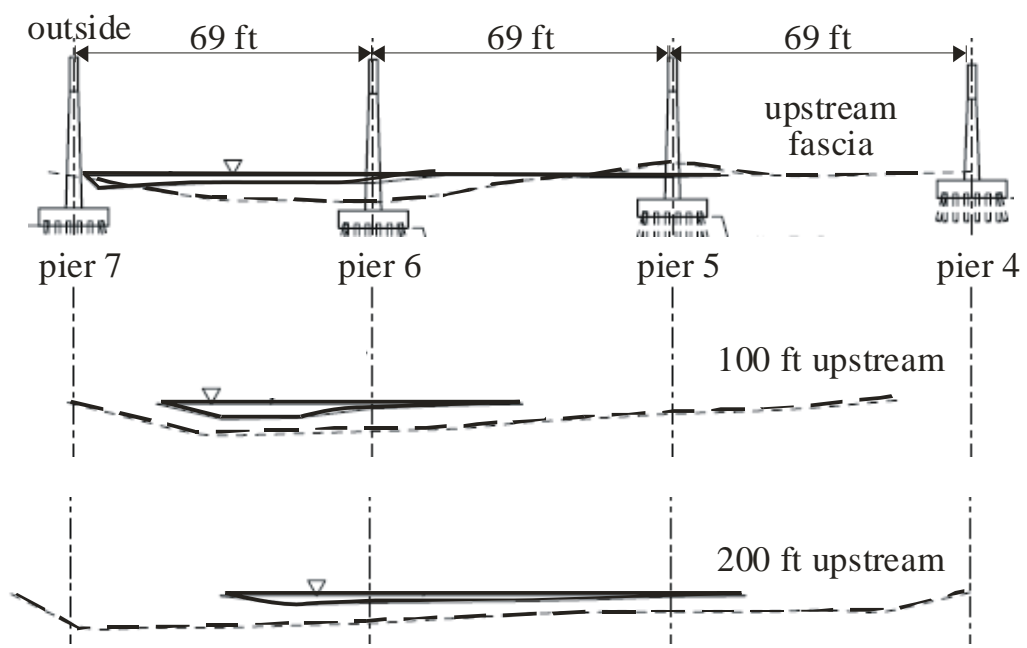

c)

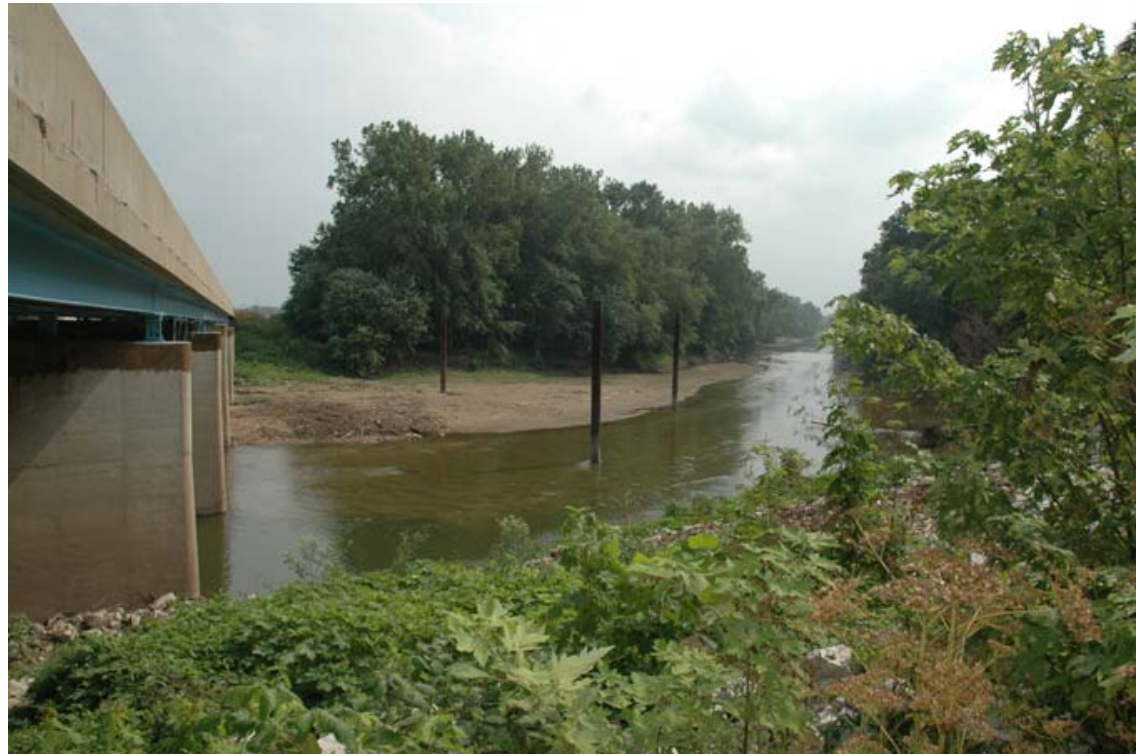

d)

Figure 4.21 SR63 site, a) aerial photograph (using GoogleMap), b) plan view, c) cross-sections from 2001 bridge inspection report, d) photograph, looking upstream (southwest), of the site when cleared of debris (note debris deflectors and extensive point bar, i.e., sand deposit, on inside of bend) cont'd.

mounted on pier 6 looking directly upstream, and the third (Camera 3) mounted on pier 4 looking across the stream towards the outer bank, with a view primarily of the pier noses. Except for the use of three cameras, the video system was operated in the same manner as the system at SR59.

\subsubsection{Events and observations}

Events before the 8/14/2003 debris clearing operation Before the 8/14/2003 clearing operation shown in Figure 4.20, four events of interest were identified. Just prior to the first event on $5 / 11$, there was already extensive DA at the site (Figure 4.23a). Even for this smaller event, the bar feature on the inside of the bend is completely submerged. During this first event, with a 
peak stage of $9.8 \mathrm{ft}$ and peak discharge of $6190 \mathrm{cfs}$, very little debris transport was observed, and as a result no noticeable increase in DA could be attributed to the event (Figure 4.23b). The subsequent event, peaking on 6/14 at a stage of $10 \mathrm{ft}$ and a discharge of $6350 \mathrm{cfs}$, was of similar magnitude and resulted in similarly little debris transport and accumulation (so no images are shown). During these events, some rearrangement of the debris was noted, but there was nothing as dramatic as that seen at the SR59 site. Another factor that may have induced some rearrangement was observed in the recorded video images, namely power boaters going up and downstream. These generated noticeable surface waves, which could induce some 'extraneous' or artificial instabilities in the existing DA. The third event, which peaked on 7/12 at 1:00 a.m., was substantially larger with a peak stage of $13.8 \mathrm{ft}$ and discharge of $10000 \mathrm{cfs}$. The combination of high stage and an already extensive DA at the site made any monitoring of transport and accumulation difficult during the event. Over forty hours before the peak, the stage was already so high (Figure 4.23c), that, with the DA blocking part of the view, the region upstream of the deflectors could barely be seen. Although large logs may be noted in the foreground, these evidently did not become trapped between events. Rather they were already present at the pier, and only came into the field of view of the camera because of the rise in stage. Near (or possibly just after) the peak of the event (Figure 4.23d), it is difficult to see any dramatic change. On the other hand, an image taken at a much lower stage (Figure 4.23e) suggests that substantial accumulation likely occurred during the event (compare with Figure 4.23b when the stage was comparable). Relatively little change was however seen in the region between the bridge and the deflectors.

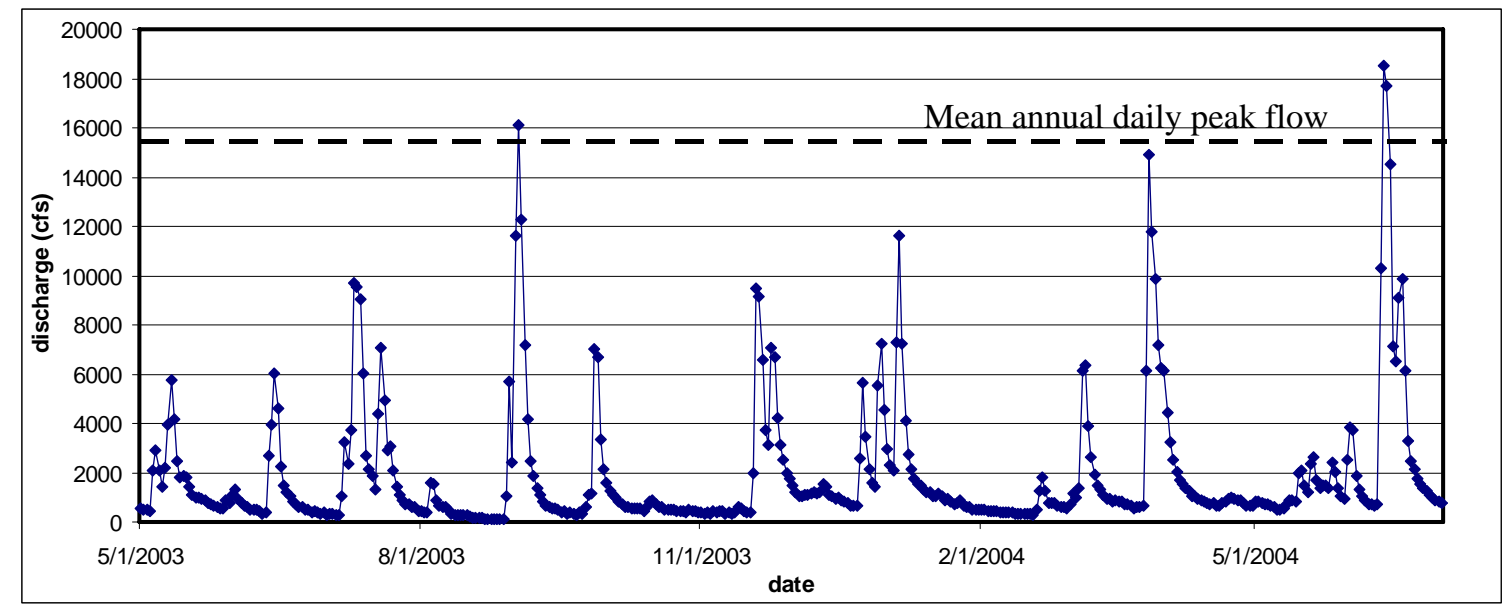

Figure 4.22: Discharge time series at the SR63 site during period of operation of video recording

The fourth event, a somewhat intermediate-magnitude event, followed closely the third event, with peak stage of $11.6 \mathrm{ft}$ and discharge of $7910 \mathrm{cfs}$ at 3:00 am on 7/19. Similar difficulties were encountered in observing transport and accumulation events upstream of the deflectors, but a sizeable instability event was recorded near or just after the flow peak. The image in Figure 4.23f is essentially identical to that taken 36 hours before (Figure 4.23e), but within five minutes, the scene is dramatically changed, with the region within the deflectors that had previously been free of debris almost completely filled in by debris that had been previously been trapped upstream of the deflectors. Some upstream debris had also escaped entirely and was swept downstream of the bridge. The image at low stage (Figure 4.23g) shows some minor rearrangement of the DA. 
Events of 8/30/2003 and 9/2/2003 The second largest event recorded at SR63 occurred on $9 / 2 / 2003$, soon after the debris clearing operation was completed (on 8/29). Immediately before it, however, was a smaller event, peaking at 8:30 a.m. at a stage of $10.6 \mathrm{ft}$ and a discharge of 6910 cfs (Figure 4.24), thus comparable to the first two events discussed above. Unlike the case with those earlier events, the site was cleared of debris so that monitoring capabilities were en-

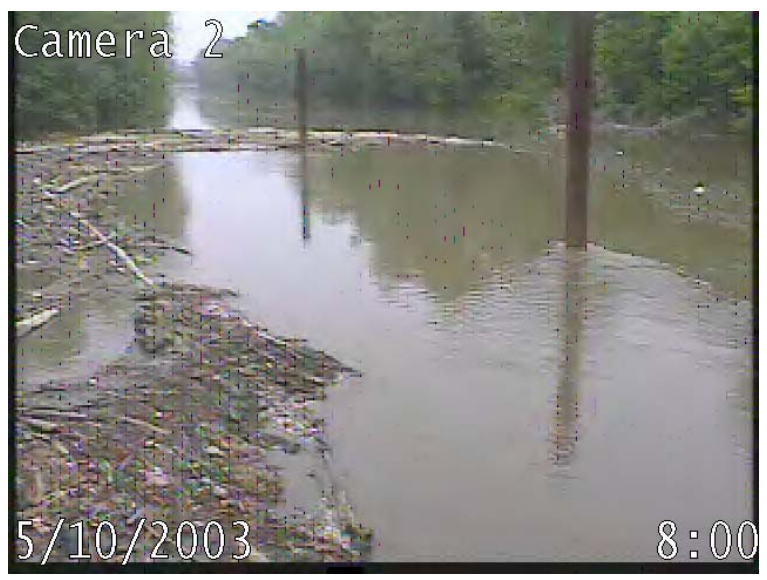

a)

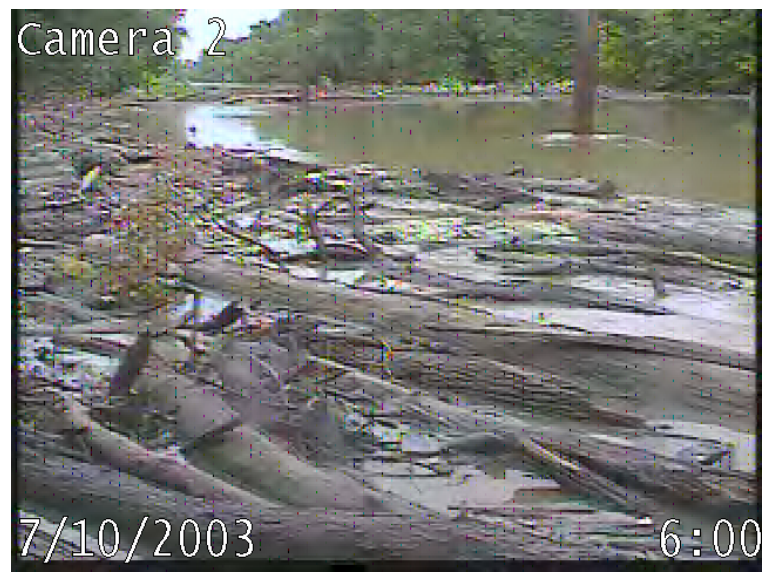

c)

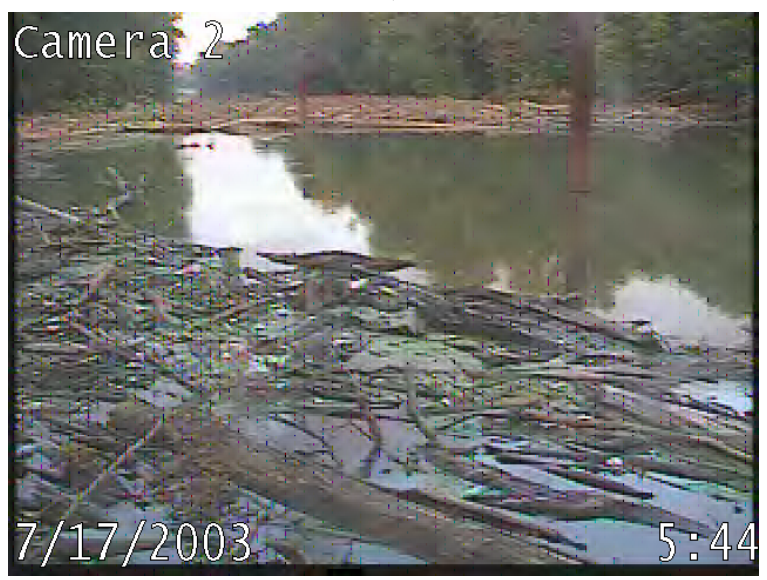

e)

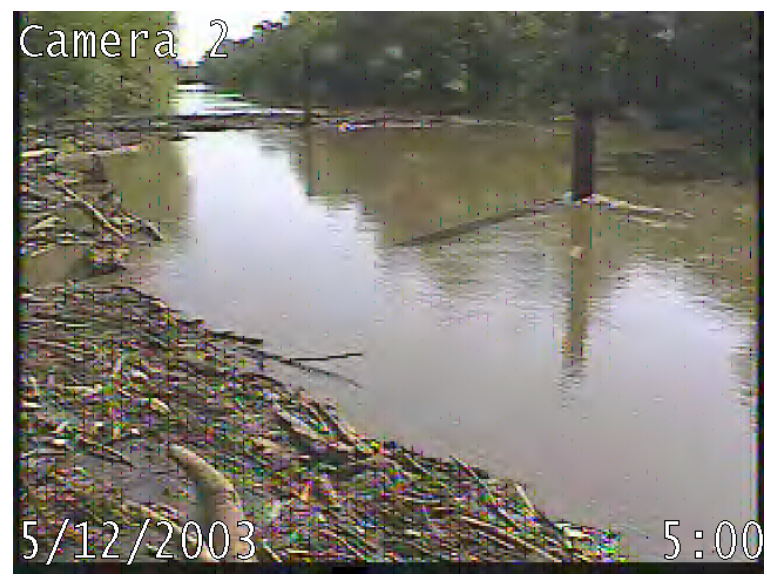

b)

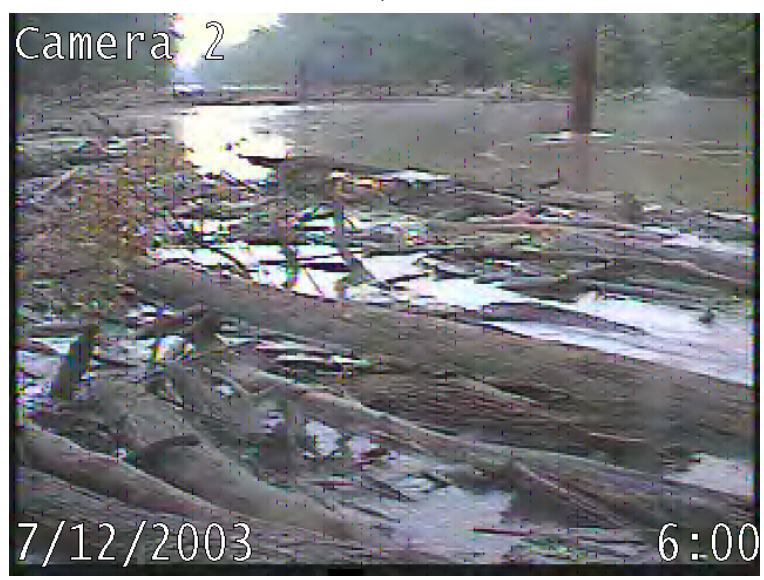

d)

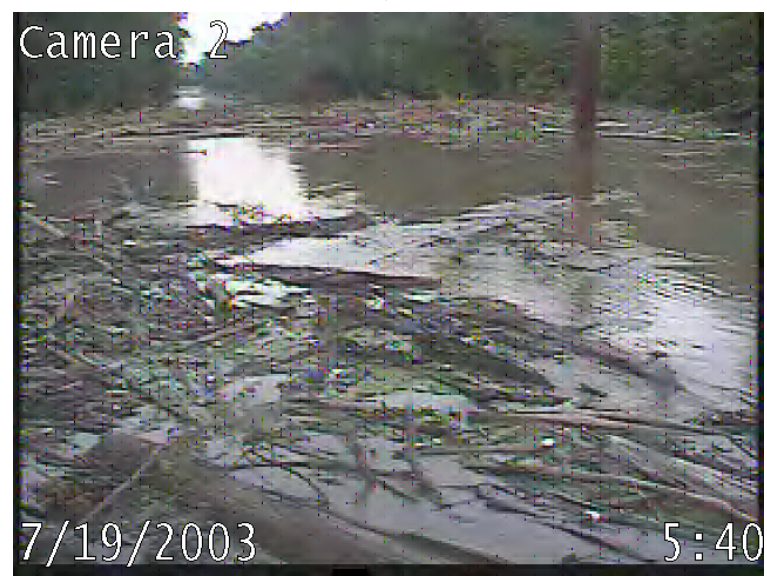

f)

Figure 4.23: Images from events before the debris clearing operation in 8/2003. 


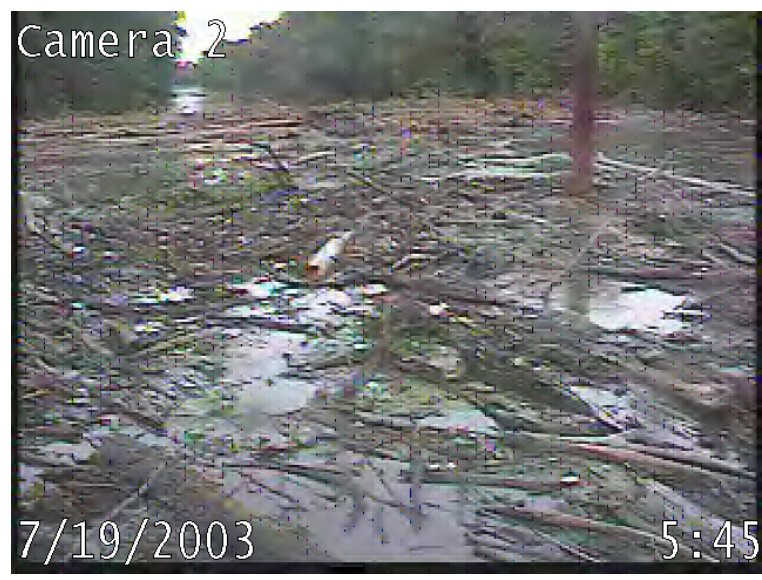

g)

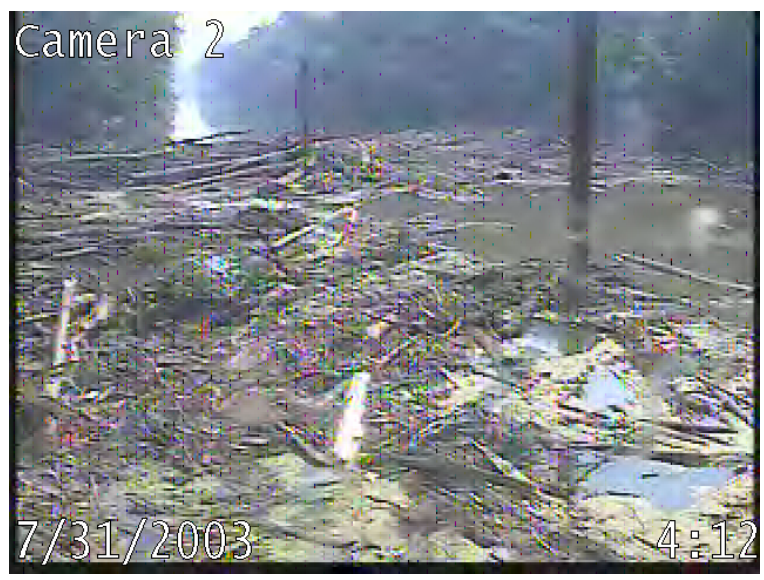

h)

Figure 4.23: Images from events before the debris clearing operation in 8/2003 (contd.).

hanced, and the influence of antecedent DA on subsequent DA during the event was minimal. The first image of a larger debris element was noted at 6:47 a.m. (Figure 4.25a) - a longer dark feature just upstream of deflector $\mathrm{D}_{\mathrm{W}}$ is a debris element, more clearly identifiable when in motion. The lack of any debris accumulation in this view compared to the images in Figure 4.23 is striking. An alternate view at the same time from the side camera is shown in Figure 4.25b, and some very minor DA may be seen at one pier. To the left, there is a larger feature that seems to be the top of an 'island'. Other isolated upstream debris transport was noted over the new few hours, including a cluster (Figure $4.25 \mathrm{c}$ ) at $\approx 12: 42 \mathrm{p} . \mathrm{m}$. After the cluster, very little transport was noted. The resulting DA at the pier, which would be considered minor to moderate, is seen somewhat more clearly at a lower stage the following day (Figure 4.25d). The 'island' feature seen to the left in Figure 4.25b is submerged in Figure 4.25d. At the same time, the deflectors were free of debris, and so are not shown.
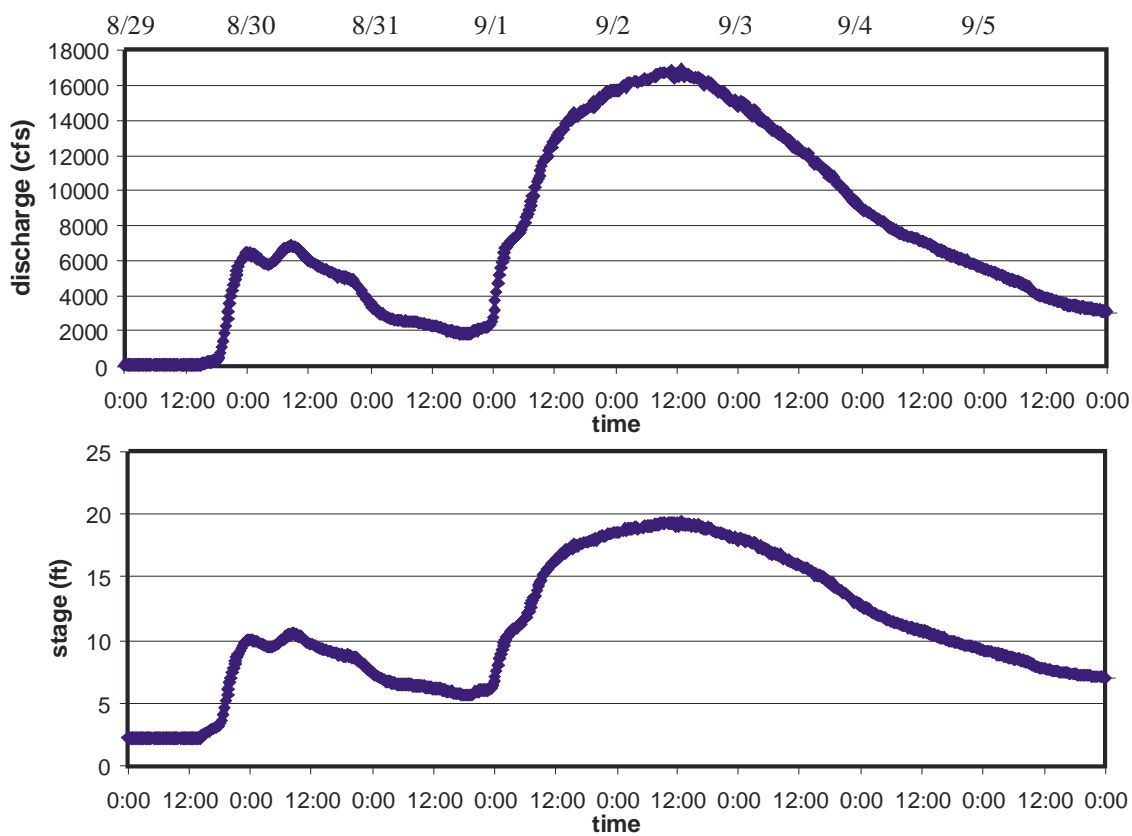

Figure 4.24: Discharge and stage time series for the events of $8 / 30$ and 9/2. 


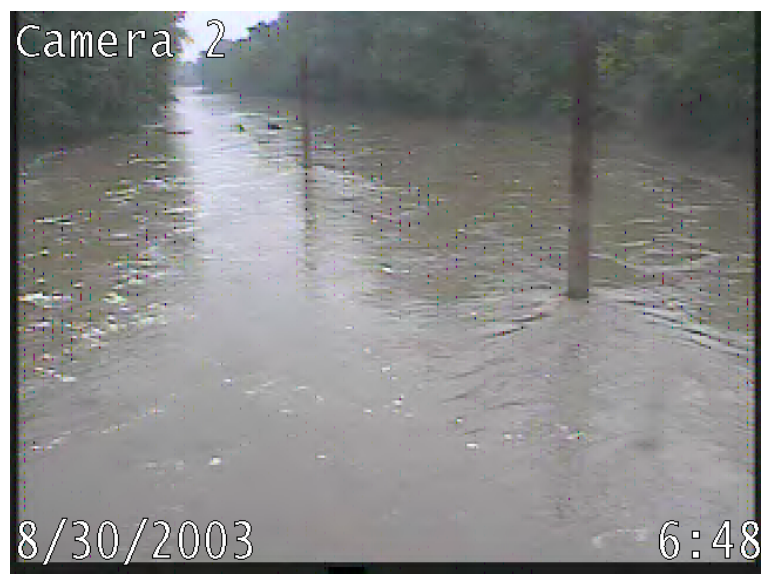

a)

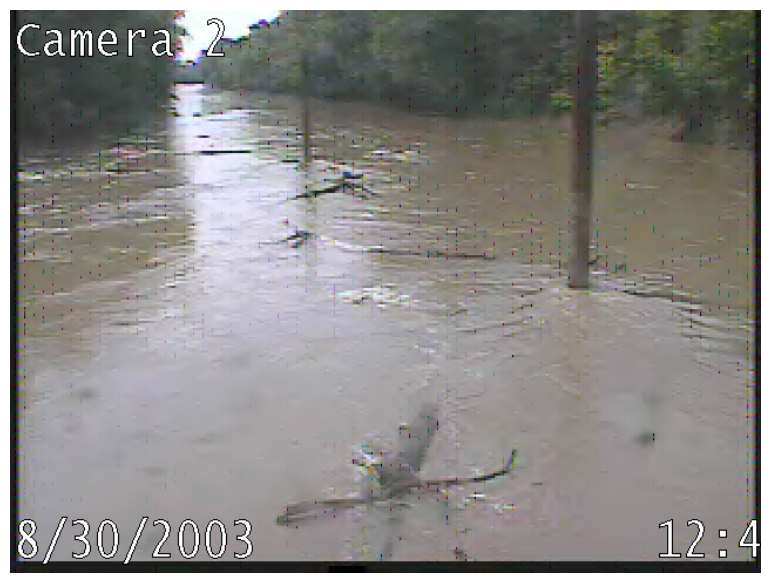

c)

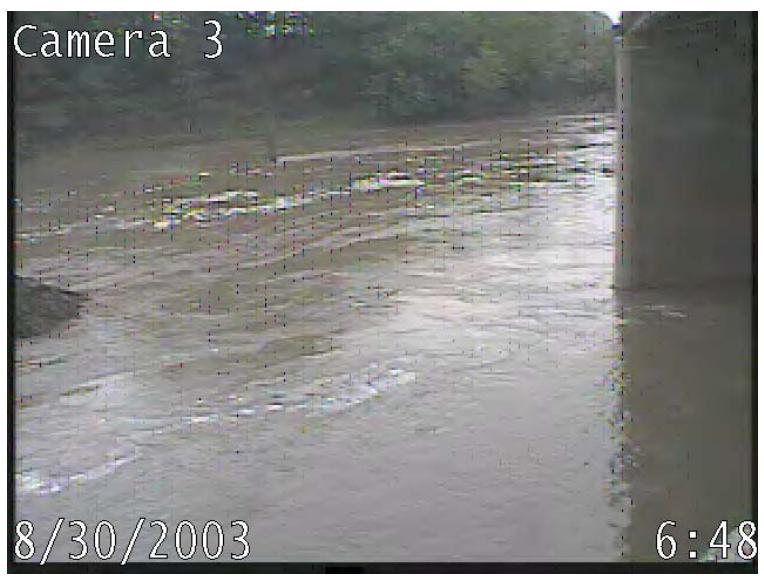

b)

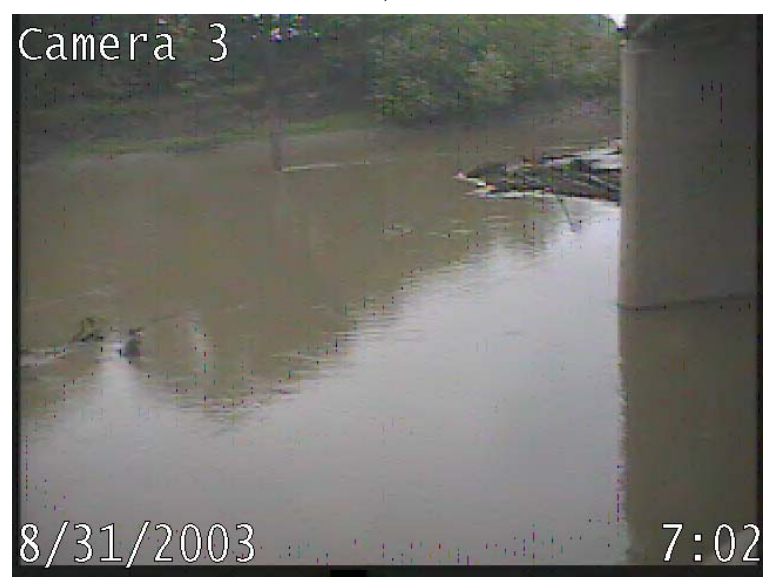

d)

Figure 4.25: Images from the 8/30 event

Transport of larger debris elements was already noted by 6:30 a.m. on 9/1 (Figure 4.26a), probably at least 30 hours before the peak discharge. At this time, the discharge (at Danville) was $8480 \mathrm{cfs}$, and so would be consistent with a minimum discharge of $\approx 7000 \mathrm{cfs}$ for mobilizing large debris elements in the Vermillion River. After 7:00 a.m., debris arrived rather continuously at the site, and it was more difficult to identify clusters at this site than at the SR59 site. During this time, the large bulk of the debris observed was not trapped permanently at either the deflectors or the piers. Beginning $\approx 12: 20 \mathrm{pm}$, transport seemed to become more intense, in what might be termed an extended cluster (Figure 4.26b), and within two hours, sizeable DA due to the flow event was seen both at the deflector (Figure 4.26c) and at the pier (Figure 4.26d compare with Figure 4.25d). The DA continued to grow throughout the day, and some growth overnight could also be seen (Figure 4.26e, f). Debris transport on 2/9 was much more sporadic, with the last notable transport observed at 12:20 p.m., near the peak of the flow event, and so the DA did not change appreciably from what is seen in Figure 4.26f, recorded in the early morning.

Other events of 2003 Several other smaller events were recorded in 2003. A debris-clearing operation was again undertaken later in September, and was completed three days before an event that peaked on 9/27 at 3:00 p.m. with a stage of $12.3 \mathrm{ft}$ and a discharge of $8610 \mathrm{cfs}$. Some transport of larger debris elements was noted, again primarily before the peak, but this was sporadic and mostly isolated, and did not lead to any significant DA. The only interest arose 
from DA instabilities at the pier. A minor-moderate DA at the pier was washed downstream (Figure 4.27a, b). Shortly afterwards, a mass of debris became trapped at the same pier (Figure $4.27 \mathrm{c}, \mathrm{d}$ ). This clearly did not originate from upstream transport, since nothing significant was observed with the camera looking upstream; debris that had previously been trapped at a debris deflector (apparently the preceding debris-clearing operation overlooked this) became unstable,

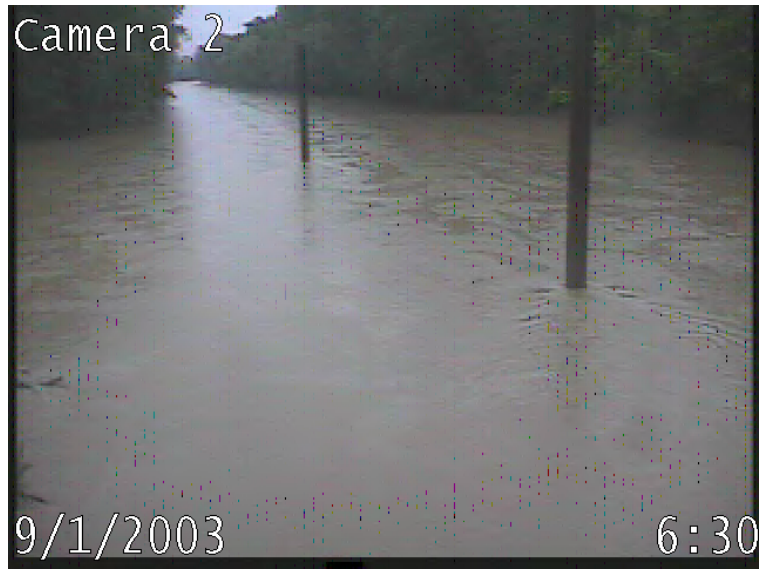

a)

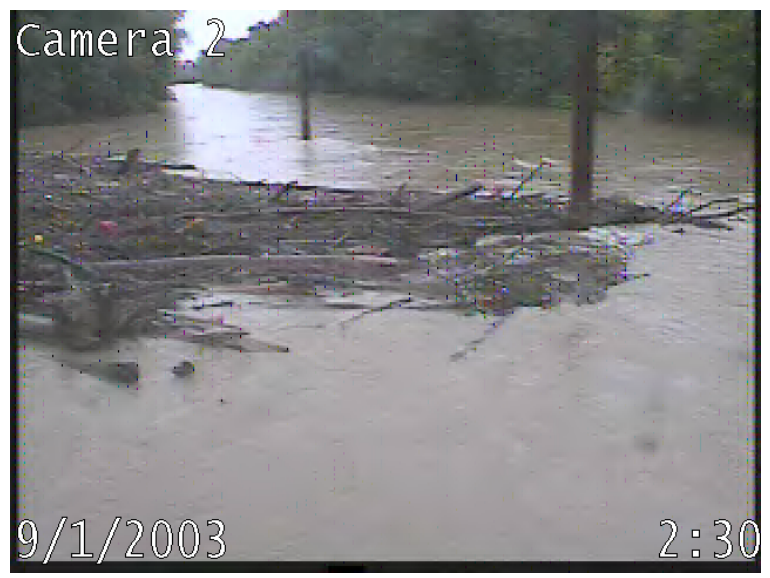

c)

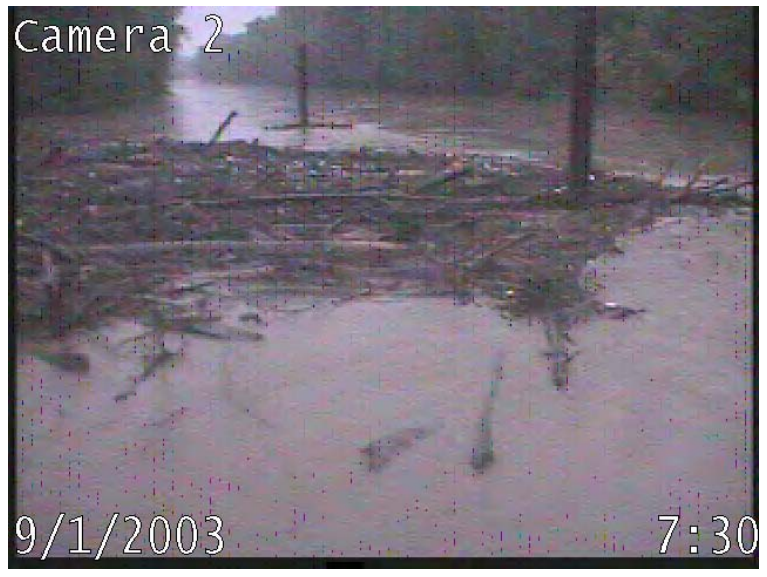

e)

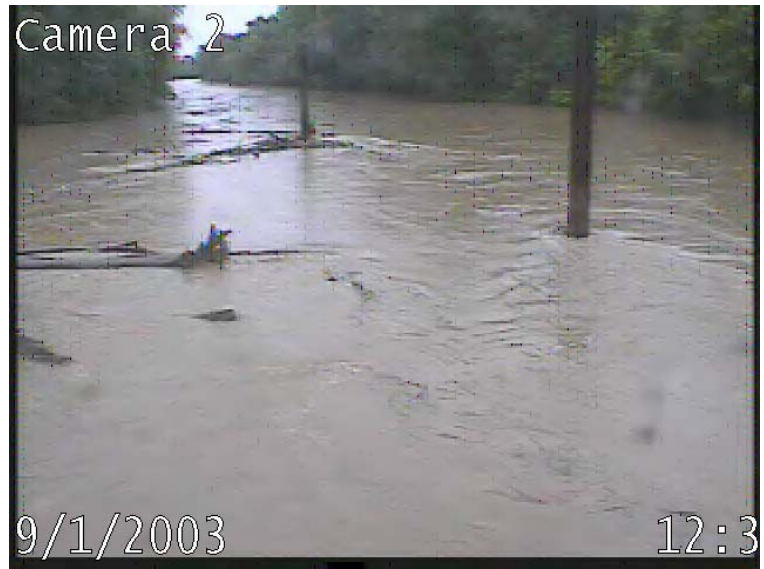

b)

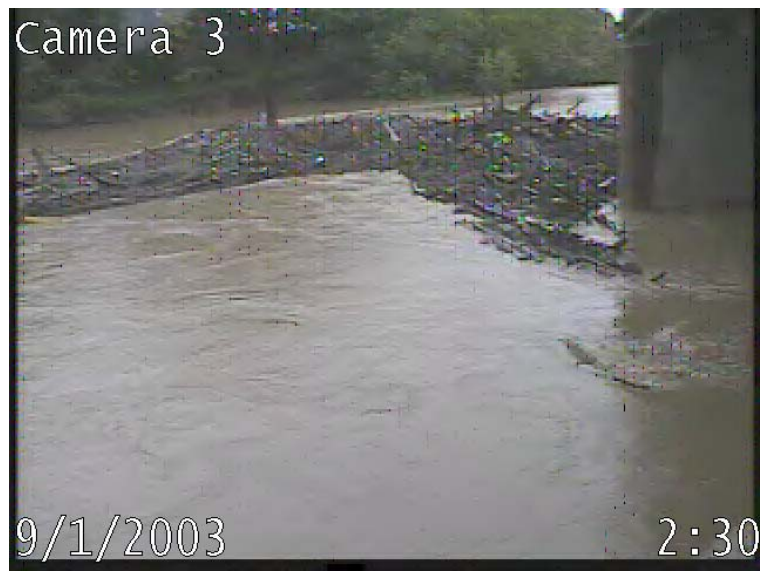

d)

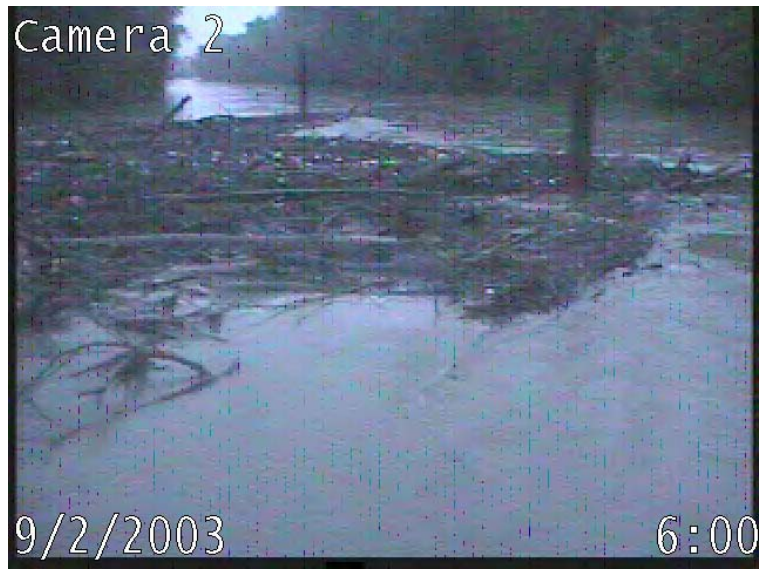

f)

Figure 4.26: Images from the event of 9/2/2003 


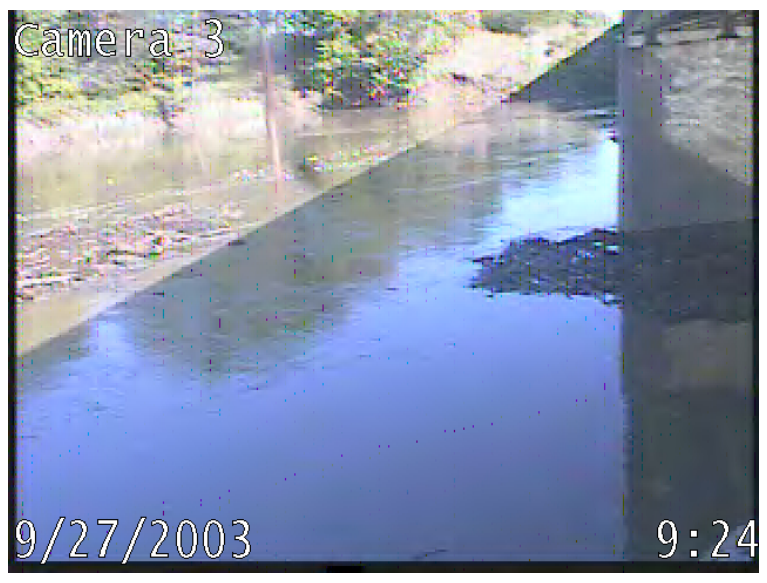

a)

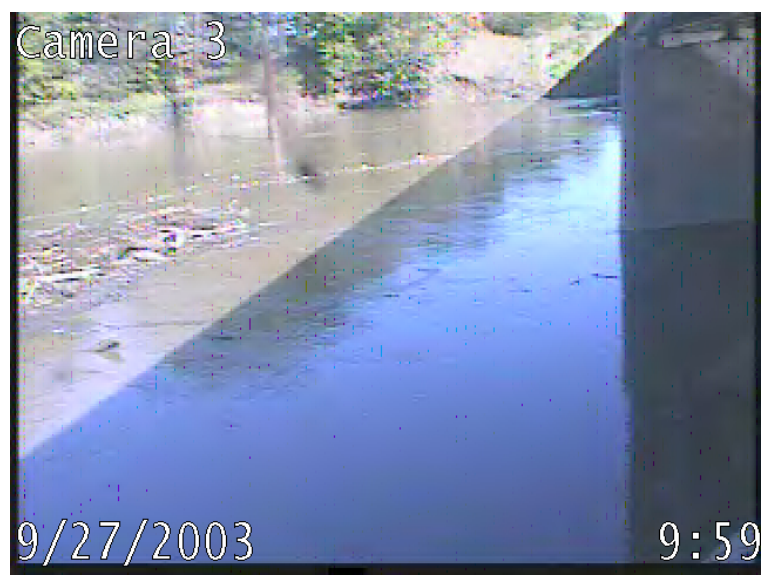

c)

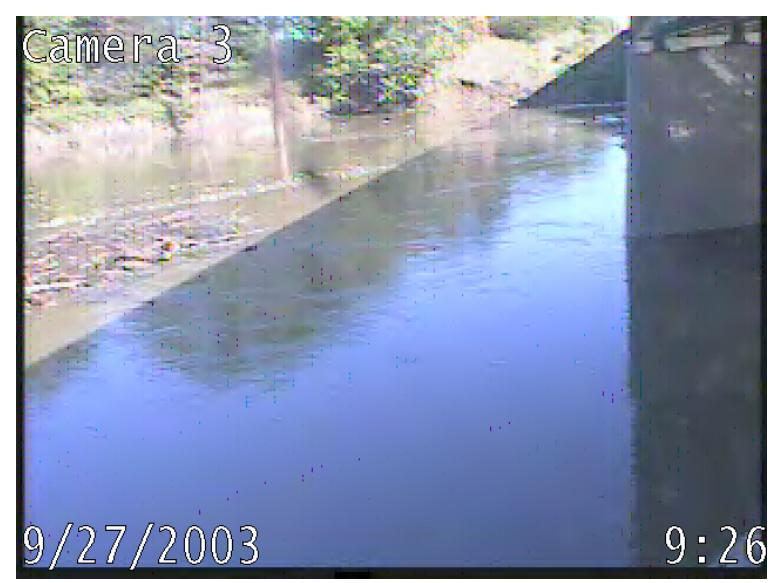

b)

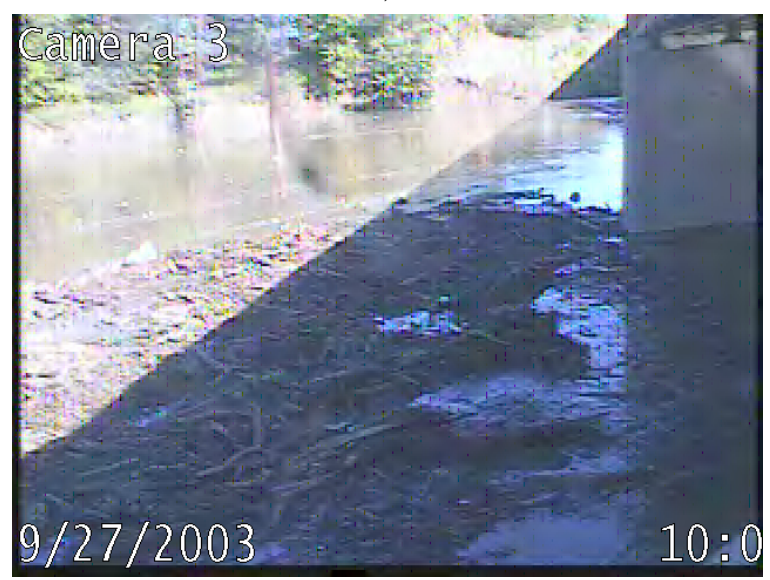

d)

Figure 4.27: Images from event of 9/27/2003

and was subsequently trapped again by the downstream pier, all within two minutes.

A slightly larger event peaked on $11 / 19$ at 2:30 p.m. with a stage of $13.7 \mathrm{ft}$ and a discharge of 9900 cfs. There was noticeably more debris transport than the 9/27 event, as might be expected from the higher discharge. As in other cases, the heaviest transport occurred before the

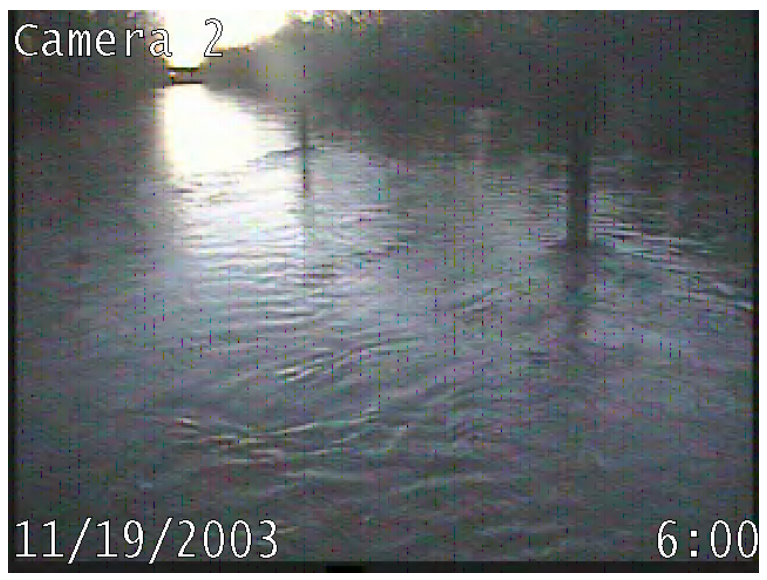

a)

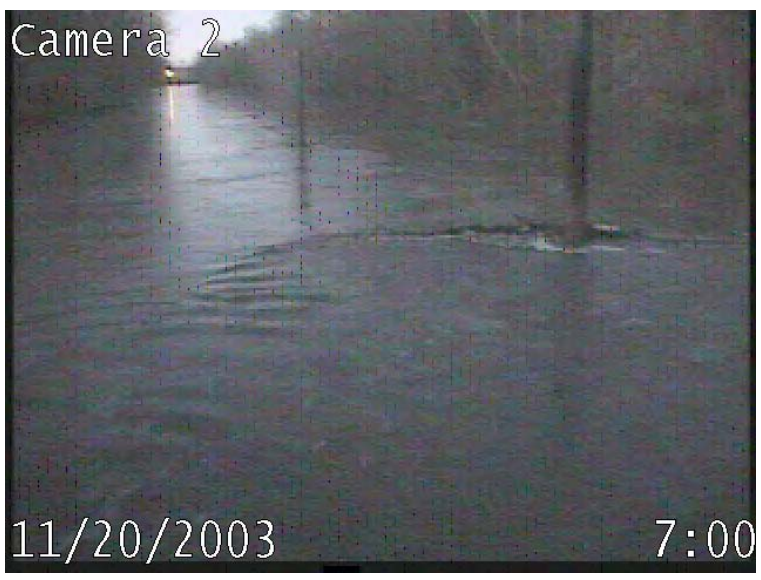

b)

Figure 4.28: Images from the 11/19/2003 event. 
peak, but no significant DA resulted, either at the deflectors or the piers. Curiously, some DA did result overnight, i.e., well past the event peak (Figure 4.28a, b), indicative of some transport may occur past the peak. A smaller event followed soon thereafter with a peak on 11/24 at 6:45 p.m. (stage of $11.7 \mathrm{ft}$ and discharge of $8030 \mathrm{cfs}$ ). Very little if any transport was noted.

Two events in December were examined: the smaller peaked on 12/24 at 5:00 p.m. with a stage of $9.8 \mathrm{ft}$ and a discharge of $6170 \mathrm{cfs}$, the larger peaked on 12/29 at $\approx 10: 00 \mathrm{p} . \mathrm{m}$. with a stage of $12.3 \mathrm{ft}$ and a discharge of $8560 \mathrm{cfs}$. Very little if any transport was observed during the smaller event, and so this discharge can be considered below that which would mobilize larger debris elements. Some sporadic isolated transport was noted during the larger event, again during the early rising part of the event. No significant DA resulted from either event.
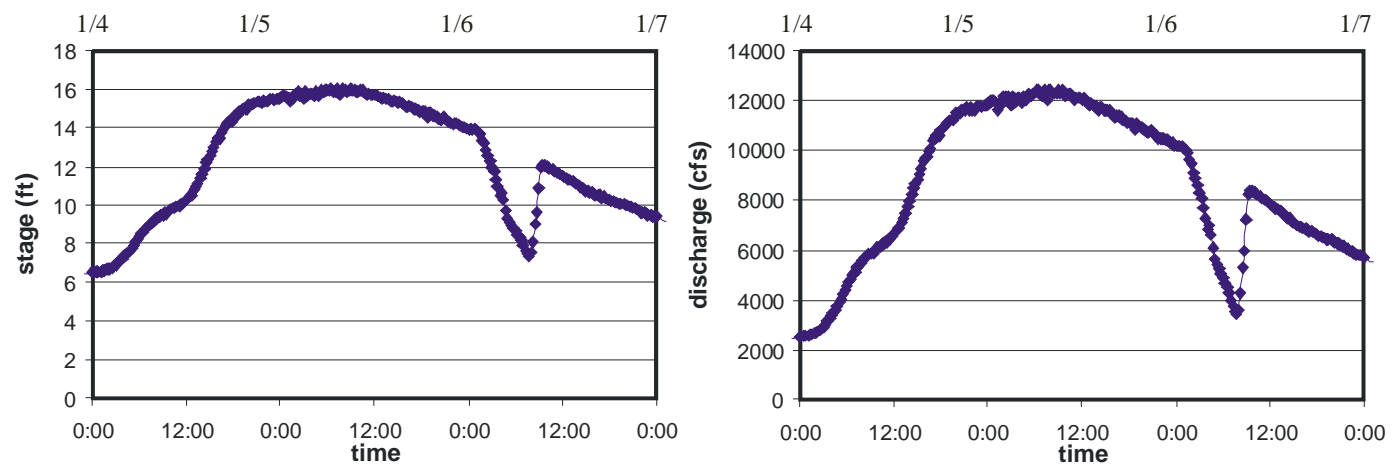

Figure 4.29: Stage and discharge time series for the $1 / 5 / 2004$ event

Event of 1/5/2004 The first event of 2004 was relatively major, peaking at $\approx 8: 00$ a.m. with a stage of $16.0 \mathrm{ft}$ and a discharge of 12,400 cfs (Figure 4.29). Although larger debris elements were observed being transported before 9:00 am on 1/4/2004 (Figure 4.30a - the small DA at the nearer deflector, $\mathrm{D}_{\mathrm{N}}$, is due to preceding events), transport was sporadic and isolated with no noticeable accumulation until the first 'cluster' arrived at 2:42 p.m (Figure 4.30b). Thereafter more intense transport was noted, including other clusters, and by the end of the (recording) day, in spite of one episode of a minor instability, a large DA had formed at $\mathrm{D}_{\mathrm{N}}$ (Figure 4.30c). This continued overnight, with debris being regularly observed before 9:00 a.m. as the DA grew (Figure 4.30d). Debris transport became much more sporadic in the late morning, though isolated debris was noted in the early afternoon. As a result, there was little change in the DA from that seen in Figure 4.30d. At the piers, only minor accumulation was observed during this event.

Event of 3/27/2004 This event was the third largest over the study period. It peaked at 7:30 a.m. with a stage of $18.7 \mathrm{ft}$ and a discharge of 15,900 cfs. The hydrograph rose quickly but had a long receding tail (Figure 4.31). The first larger debris element was observed on 3/26 at 5:03 p.m. (Figure 4.32a - note that this is just upstream of the farther deflector; the debris in the foreground is the submerged remnant of the antecedent DA). It was only after 6:00 p.m. however that transport became more intense with clusters appearing regularly (Figure 4.32b). This continued overnight, and clusters were observed (Figure 4.32c) until 9:00 a.m. the next morning. Thereafter, transport became increasingly sporadic, with only isolated debris observed infrequently. Relatively little DA at the deflectors resulted from the event (Figure 4.32d, taken well after the peak). There was some moderate-heavy accumulation at one pier (Figure 4.29e and f). The lack of any more substantial DA is somewhat surprising in comparison to the earlier and notably smaller 1/5/2004 event, where a more extensive DA did develop at a deflector, if not at a pier. 


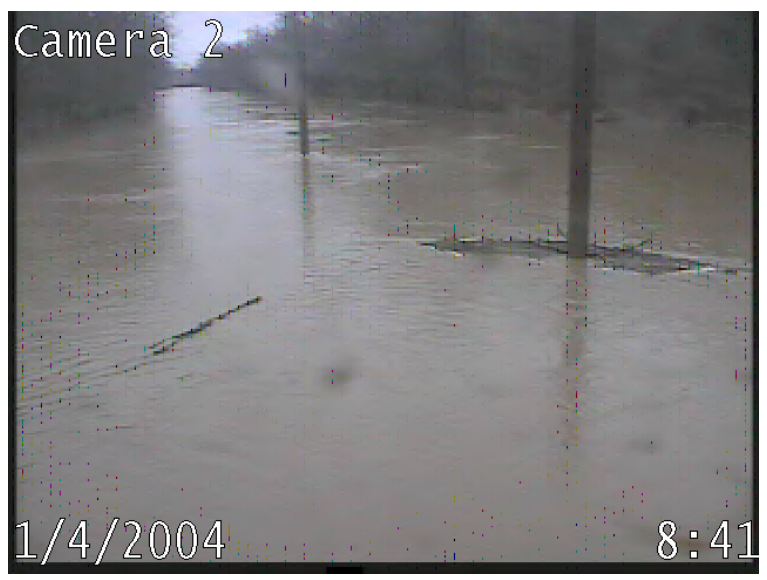

a)

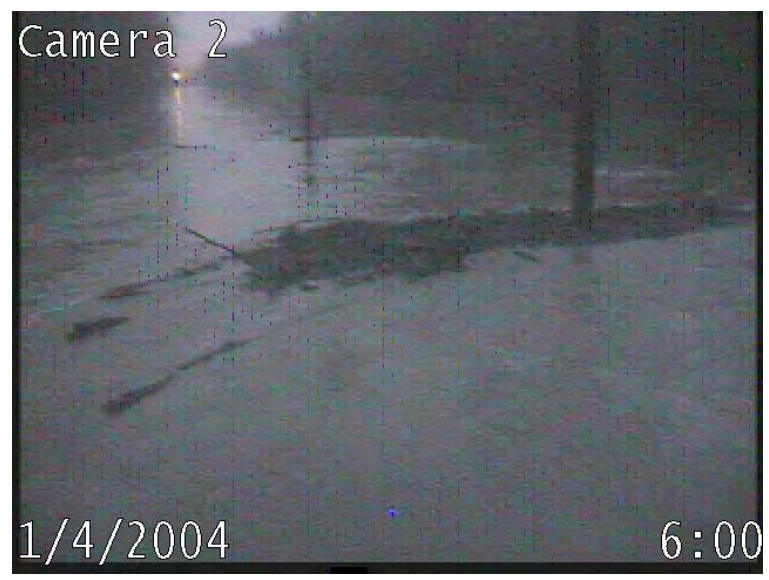

c)

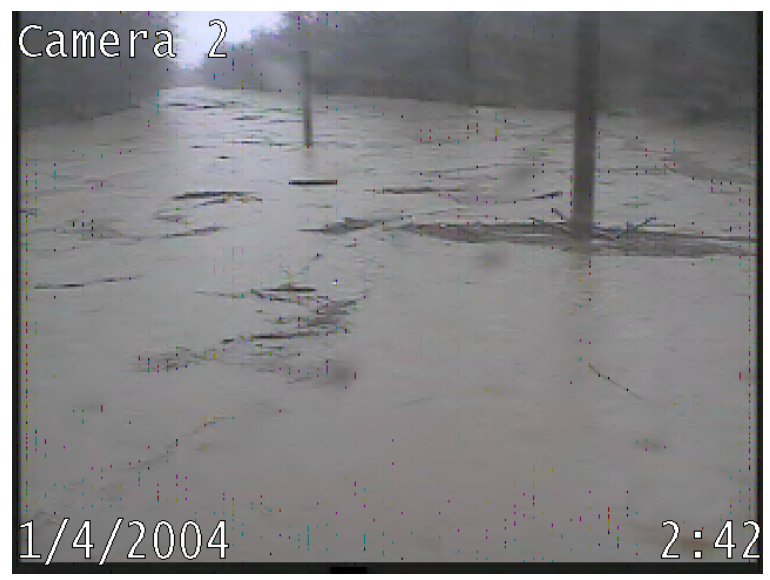

b)

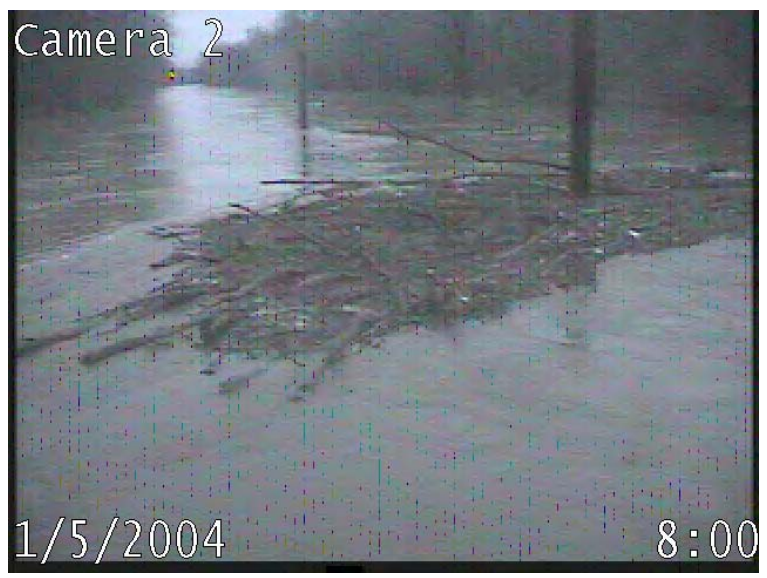

d)

Figure 4.30: Images from the 1/5/2004 event

Event of 6/12/2004 The largest event at the site during the study period peaked at $\approx 4: 00$ p.m. with a stage of $21.4 \mathrm{ft}$ and a discharge of 20,000 cfs (Figure 4.33). The initial conditions may be best seen from camera 1 (Figure 4.34a). The moderate-heavy DA at a pier and the smaller ones at the deflectors, all mainly developed during the 3/27 event, have remained. The first larger debris element was noted before 9:00 a.m. when the discharge was less than 10,000 cfs, but heavy transport in clusters was observed only after 10:30 a.m. (Figure 4.34b), when the discharge was over 11,000 cfs, still over 24 hours before the event peak. By 3:00 p.m. (Figure
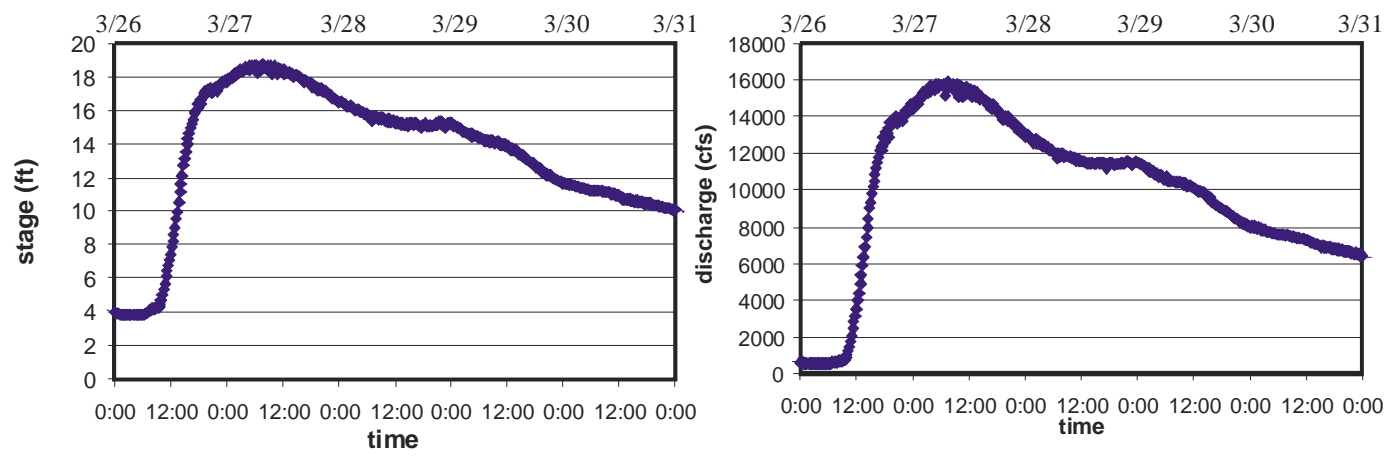

Figure 4.31: Stage and discharge time series for the 3/27/2004 event 


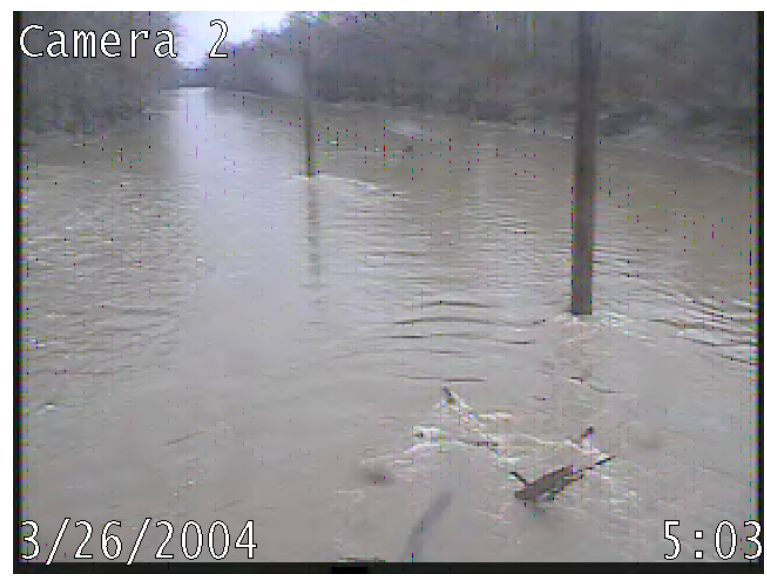

a)

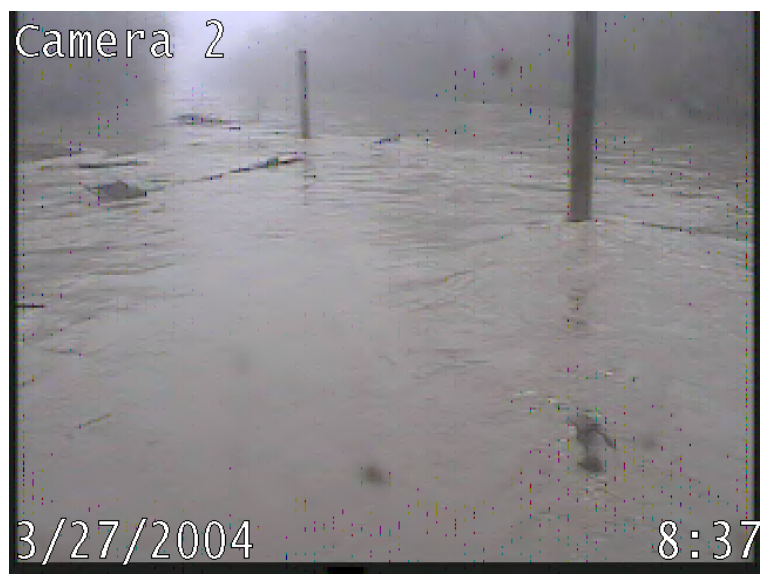

c)

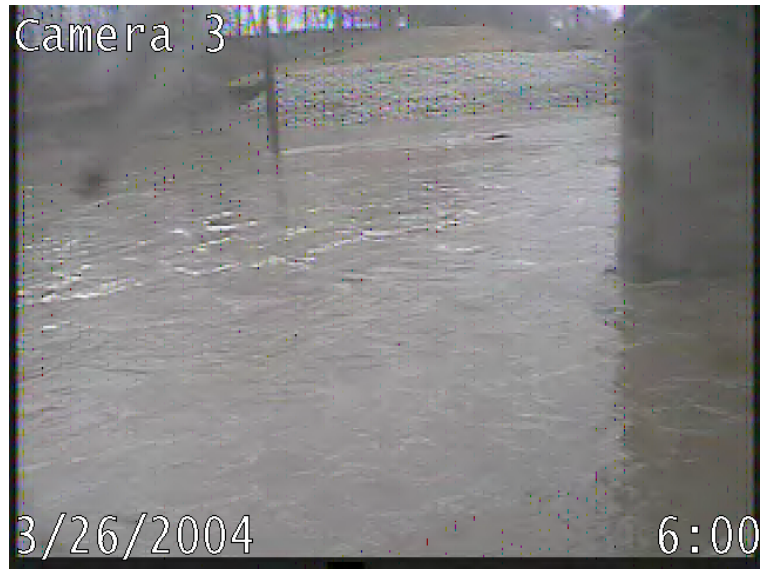

e)

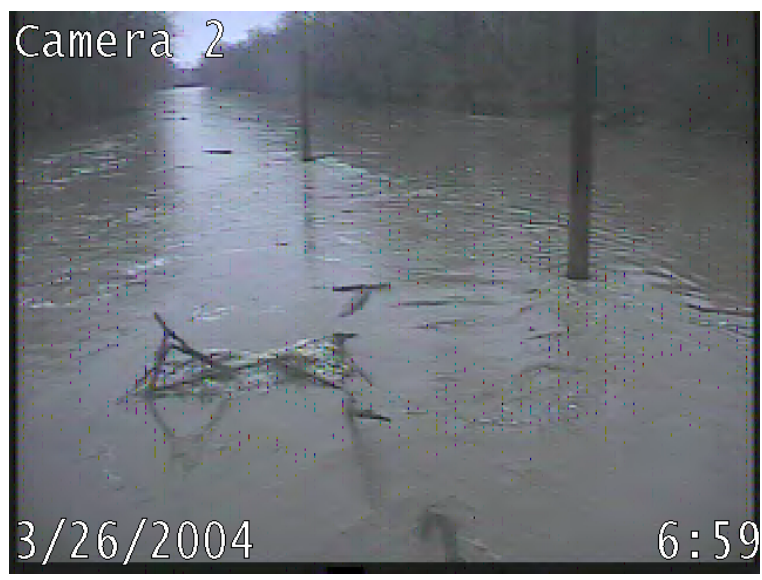

b)

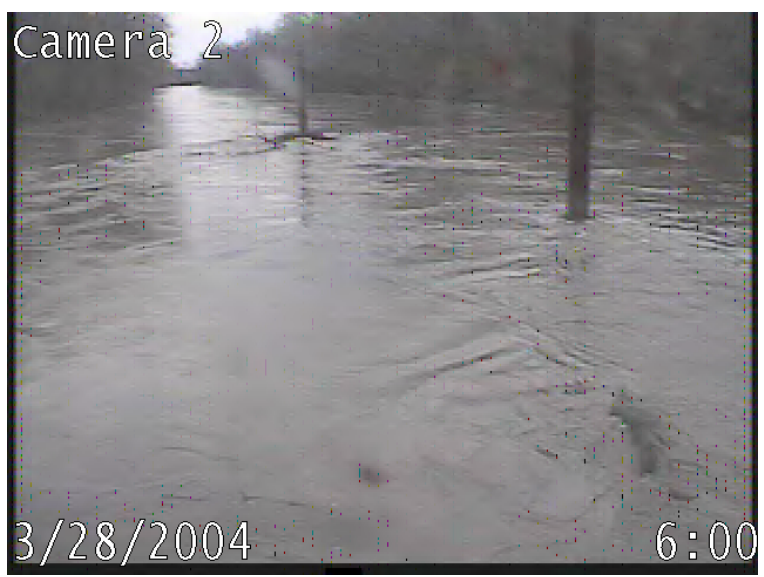

d)

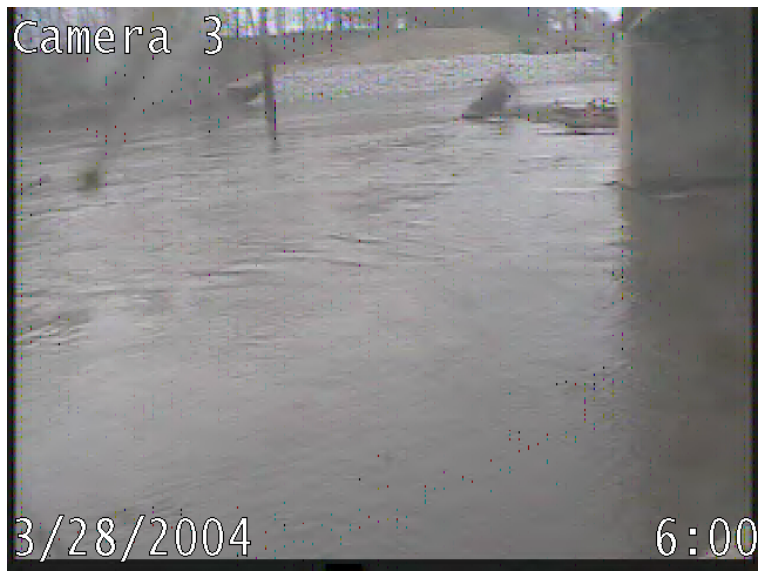

f)

Figure 4.32: Images from the $3 / 27 / 2004$ event

4.34c), the DA at the pier had grown noticeably, but the DA at the deflectors did not grow appreciably. At about 5:00 p.m., a DA started to form at the rightmost (looking upstream) deflector, and started to extend towards the left, such that by 8:00 p.m., it became linked to the growing DA at the pier (Figure 4:34d, e). The combined DA continued to grow overnight (Figure 4.34f). Upstream debris transport did decrease noticeably in intensity, becoming more 

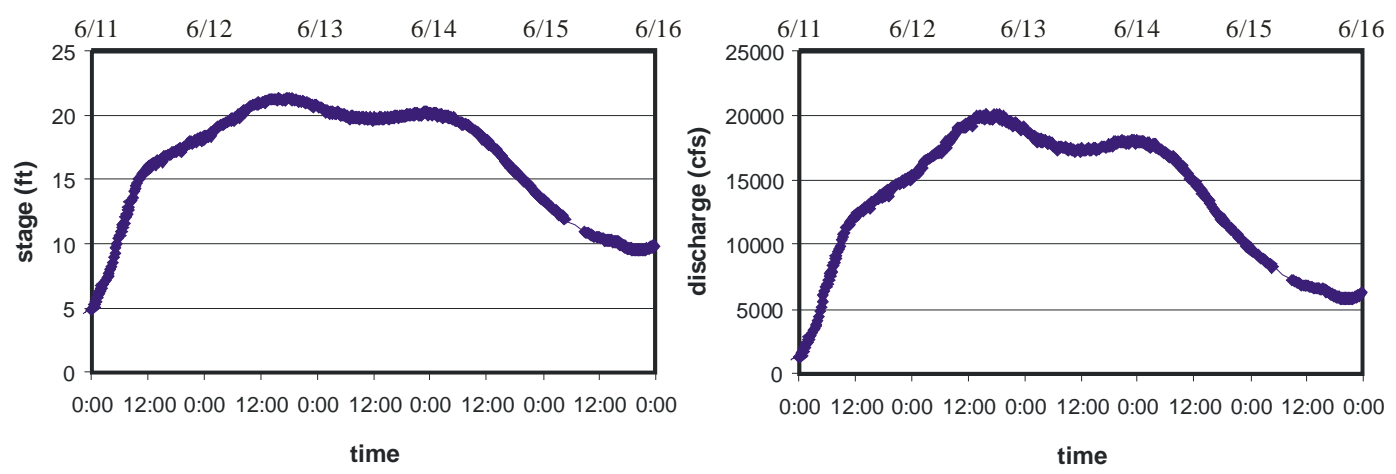

Figure 4.33: Stage and discharge time series for the 6/12/2004 event

sporadic and isolated after 9:00 a.m. Large debris elements continued to be observed however and to contribute to the DA throughout the rest of the day, such that some growth, though not dramatic, could be seen (Figure 4.34g). Some of the apparent changes between Figures 4.34f and $g$ is due to the higher stage at the later date causing the DA to appear larger. A small event peaking at $\approx 9: 00$ a.m. on 6/18 with a discharge of 10,500 cfs did not appear to contribute much to the already present DA. The full extent of the DA does become clearer at lower stage (Figure 4.34h) when some of the DA that is submerged at high stage becomes exposed.

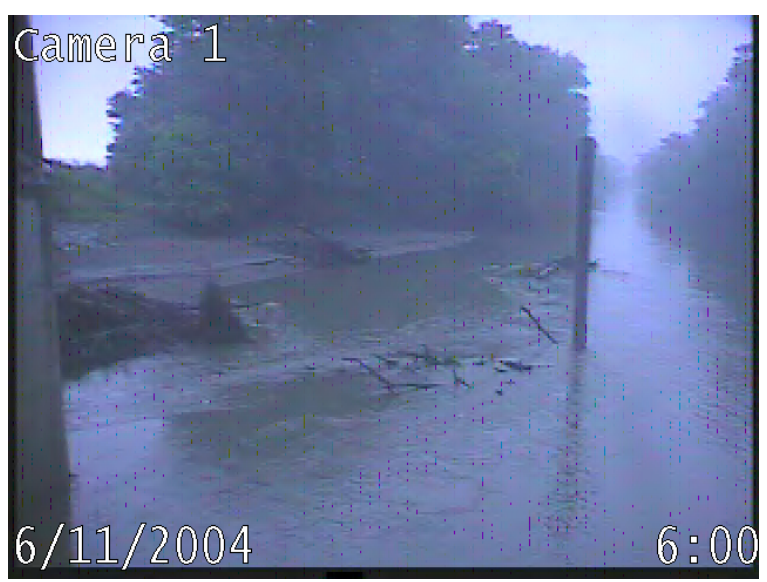

a)

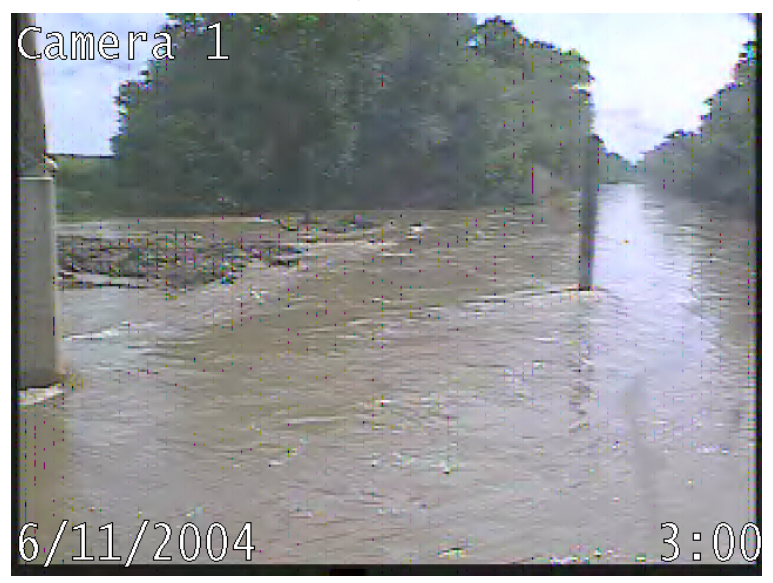

c)

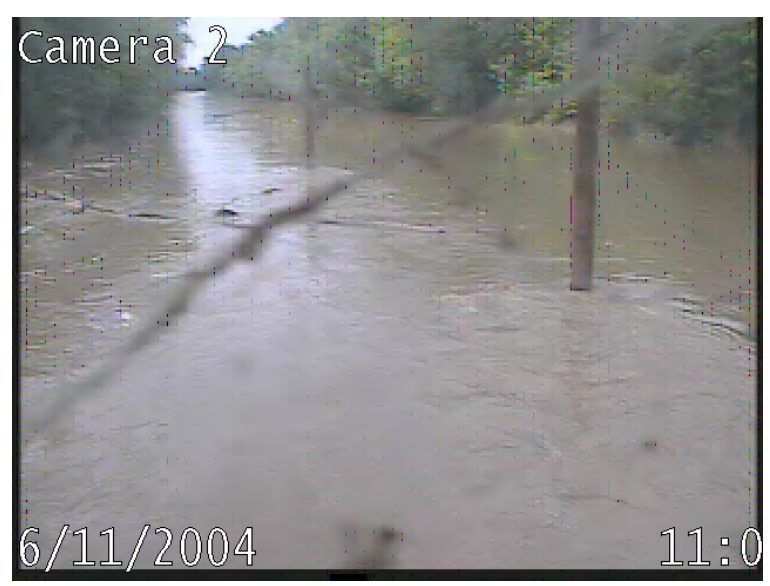

b)

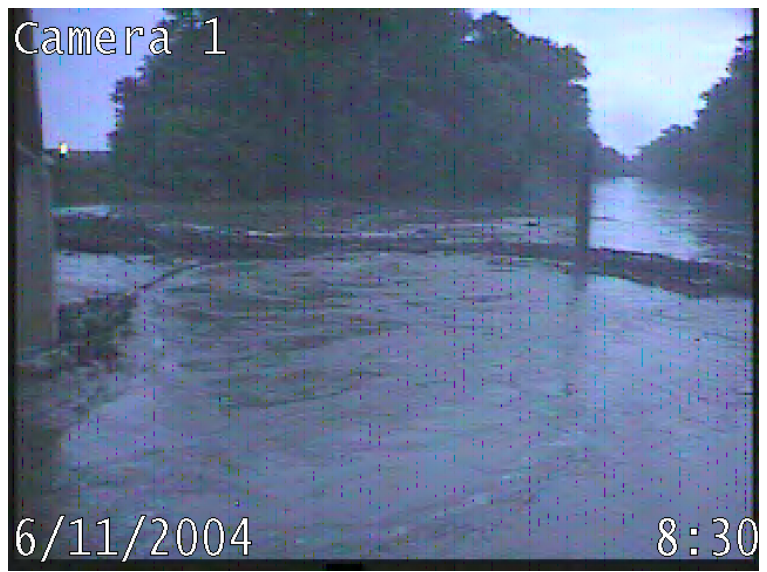

d)

Figure 4.34: Images from 6/12/2004 event 


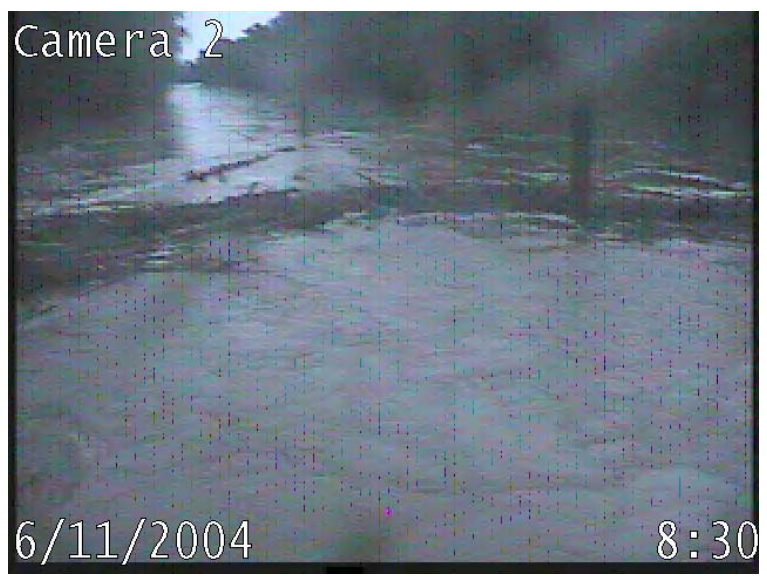

e)

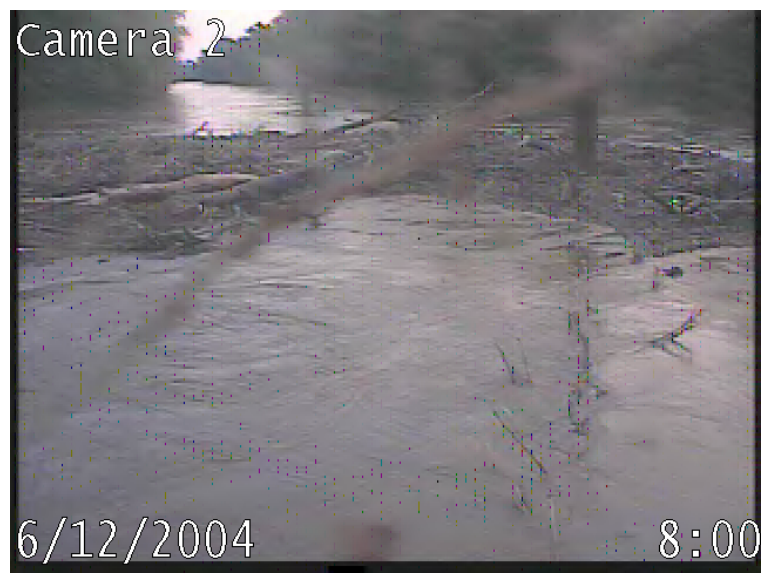

g)

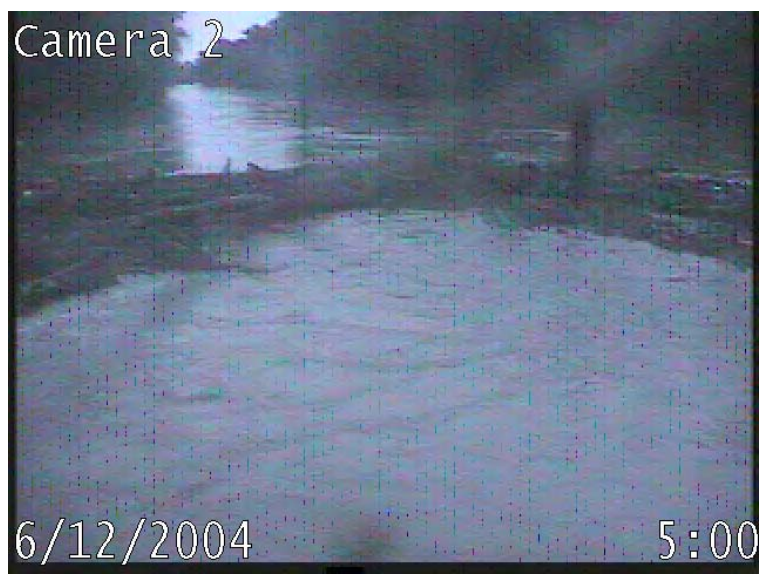

f)

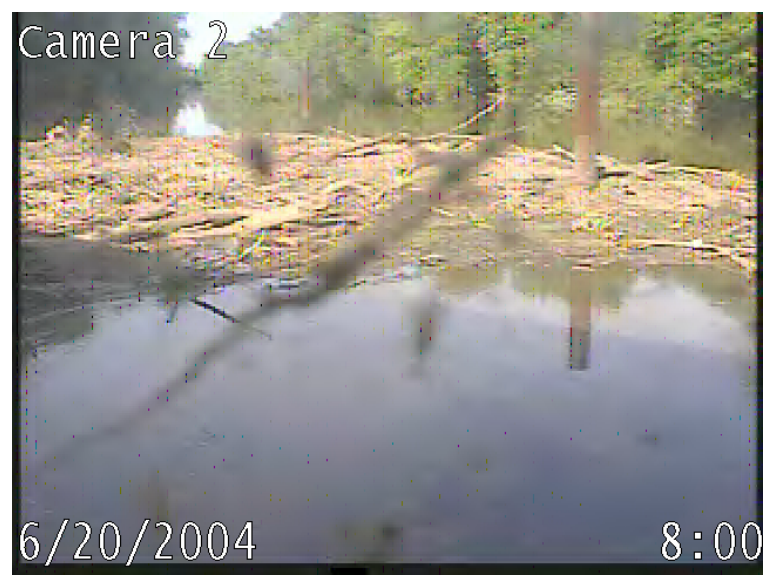

h)

Figure 4.34: Images from 6/12/2004 event (contd.)

Debris trajectories at SR63 Thus far, attention has been focused on the temporal development of debris transport and accumulation, particularly with reference to the flow hydrograph. The other main issue concerns debris trajectory, and its relationship to local bathymetry and pier location. Much, perhaps the majority, of the debris travels to the south of the upstream deflector, $\mathrm{D}_{\mathrm{W}}$ (see e.g., Figure 4.25a, c, Figure 4.26b, or Figure 4.30b). The available bathymetry information (Figure 4.21) in the vicinity of the bridge crossing shows however a thalweg that is clearly much closer to the opposite bank. In contrast to the commonly held view (e.g., see HEC9) that debris tends to travel along the thalweg, at least for straight reaches, the video evidence for this site shows that much if not most of the debris travel at some distance from the thalweg. Farther upstream, at least from the video record, debris is more likely to originate from the left half of the channel, which may partially explain the bias in the debris trajectory. Farther upstream the thalweg may be located closer to midstream, and perhaps even closer to the south bank. The video images also often show debris veering away from the thalweg, as it bypasses the upstream deflector. This behavior, which also contributes to the bias in the debris trajectory, is attributed at least partially to the flow expansion which results in surface flow being diverted towards the south bank. That heavy DA tends to occur towards the south bank is due in large part to the bias in the debris trajectory, and not only because of any stabilizing effect of the point bar towards the inside of the bend. 


\subsection{The SR157 - White River near Worthington}

\subsubsection{Site characteristics}

Like the other two other sites, the SR157 site underwent two underwater bridge inspections (in 1994 and 2002). Moderate DA was reported at pier 5 (see Figure 4.35b for the labeling of the piers) in 1994 and 2002, while heavy DA was reported at pier 4 in 2002. Like the other two sites, DA at the SR157 site was considered sufficiently serious that debris countermeasures were installed. In this case, however, a commercial device, an early version of the DebrisFree system (already seen in Chapter 1), was installed prior to the beginning of the study. One of the motivations for the choice of this site for the study had been to monitor the effectiveness of this countermeasure. Before video recording began at the site, however, one of the DebrisFree units, that was mounted on pier 5, failed, and the district declined to replace or to remove it.

An aerial photograph of the site, together with plan view and three cross-sections taken from the 2002 bridge report, are shown in Figure 4.35. In addition to the presence of the commercial debris deflectors, a number of other features make this site of interest to the study. The span between piers is much longer that at the other sites, $200-\mathrm{ft}$ between the piers 4 and 5 , the piers that are typically always in the stream, $160-\mathrm{ft}$ otherwise. This is much larger than Diehl's design log length, though the distance to the banks may then become the effective span length. The crossing also lies $\approx 0.5$ miles downstream of the confluence of the White and the Eel Rivers

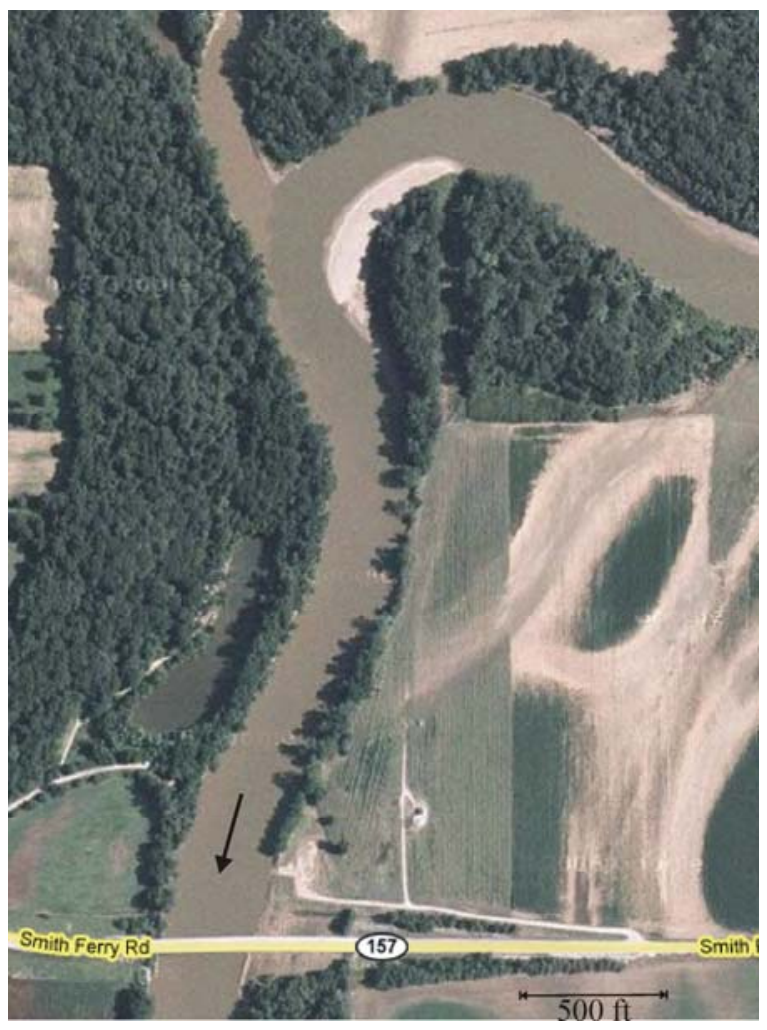

a)

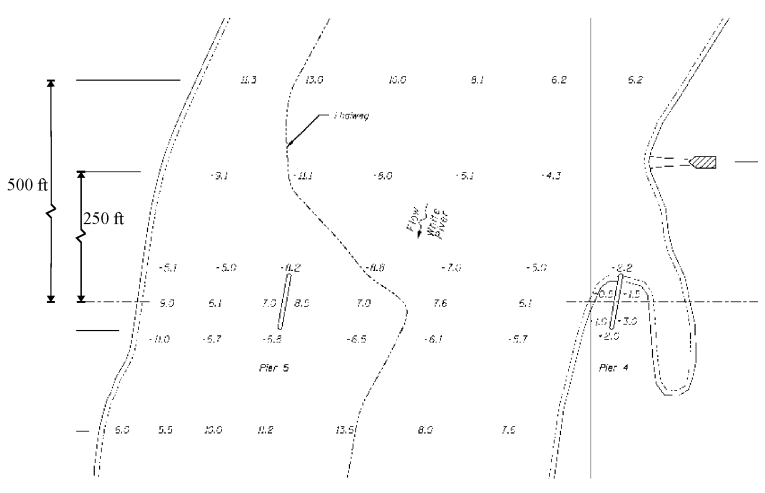

b)

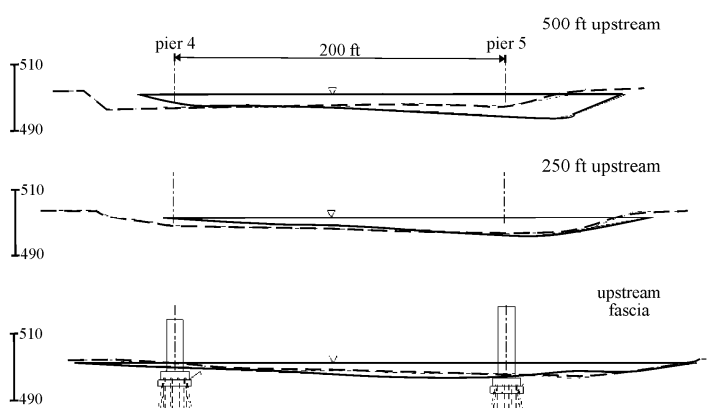

c)

Figure 4.35: SR157 site characteristics, a) aerial photograph (from GoogleMap), b) plan survey, and c) three cross-sections upstream of bridge (viewed going downstream, the last two from 2002 bridge report) 
(in fact, it is also $\approx 12$ river miles downstream of the SR59 site). Directly upstream there is a mild bend, but, farther upstream at the confluence, there is a sharp bend with an evident point bar. The channel widens somewhat at the crossing, and a peninsula feature may be seen around pier 4. The thalweg as drawn in the bridge report veers abruptly in front of pier 5, though, as with the other sites, how meaningful such a thalweg definition is for DA is unclear.

\subsubsection{Hydrological events}

The USGS gaging station upstream on the White River that is nearest to the site is located $\approx 23$ miles from the site near Spencer. Unfortunately, the Spencer gaging site records only the stage, and discharge information is not available. The daily stage time series at Spencer is shown in Figure 4.36a. Another gaging station is located near Newberry, $\approx 18$ miles downstream of the site, which does record both stage and discharge. The daily discharge time series at Newberry is shown in Figure 4.36b. As might be expected, the two correspond rather closely, with the Newberry gage lagging Spencer gage somewhat. As with the other sites, the distance between the SR157 site and the two gaging stations implies that the magnitudes, shape, and timing of the hydrograph are only approximately correct for the site. For most of the detailed comparison, the Spencer data will be used, because it was initially thought to be of greater relevance (in hindsight, this is less clear). Two large events may be identified, where the two-peak event in 1/2005 is considered to be a single event. The larger event is estimated to have a return period of $\approx 18$
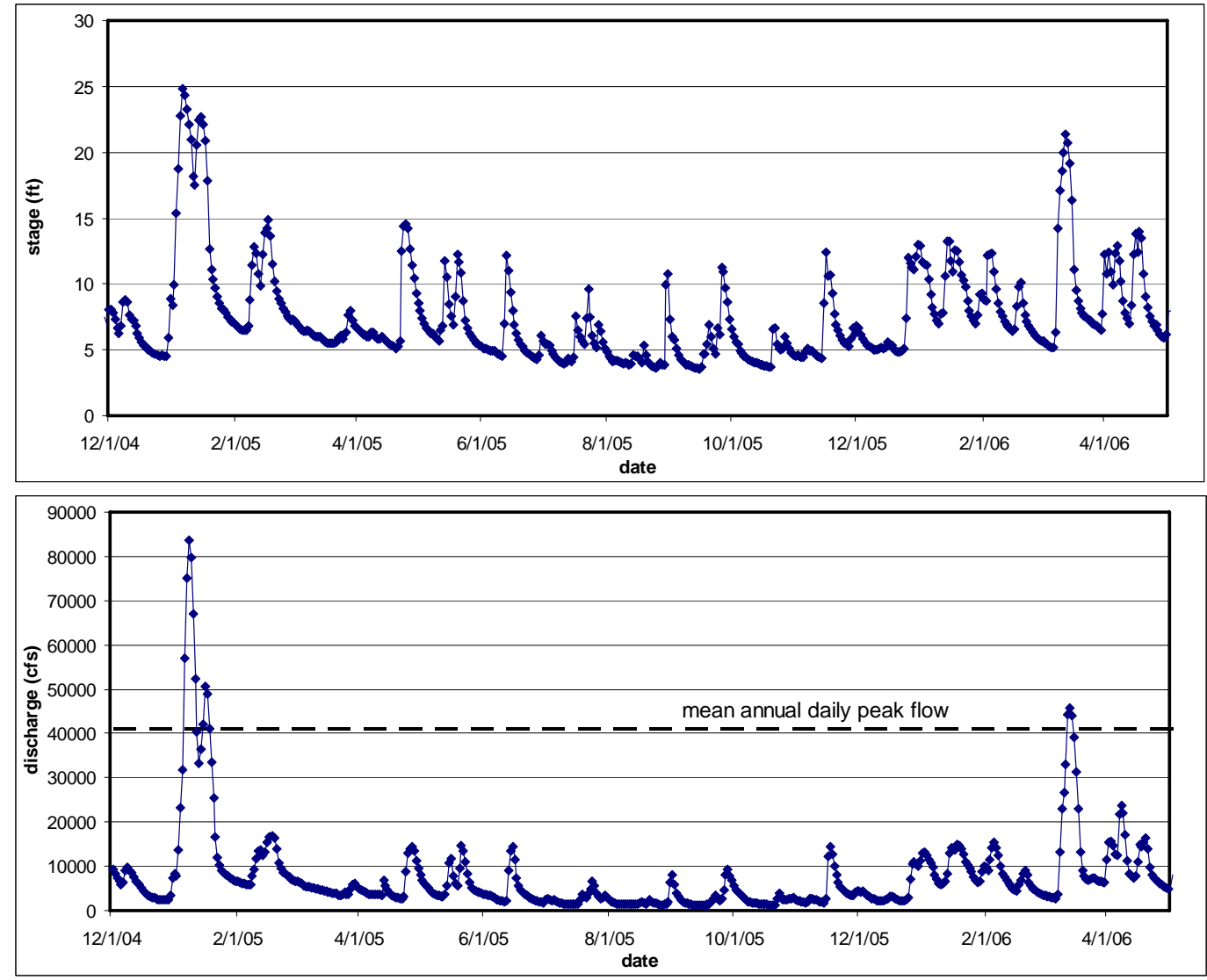

Figure 4.36: a) Stage time series at Spencer gaging station, b) Discharge time series at Newberry 
years, while the smaller event has a return period of $\approx 3$ years. The largest event at the SR59 site also approximately coincided with the largest event at the Newberry site, but the return period of the SR59 event was estimated to be much less, namely 4 years. The magnitudes of the discharges clearly show that the White River near Worthington is a much larger river than the other sites, with a mean annual peak flow more than twice that of the Vermillion River near Cayuga (which is still larger than the Eel River near Brunswick). Except for the two large events, the flows during the study were relatively small compared to the mean annual daily peak flow.

\subsubsection{The video monitoring system}

Planning and installation of the video monitoring equipment was performed during much of 2004. Installation in particular had to be coordinated with INDOT personnel because of the need for the REACH-ALL truck. The system was in almost all respects identical to the SR63 system, consisting initially of three video cameras. Camera 1 was mounted on pier 2, and was initially angled towards the piers, but included a view of the approaching flow. Camera 3 was mounted on pier 5 and had an opposing view. These were placed so that conditions at piers 4 and 5 could be observed, but a view of the approaching flow was also desired. Camera 2 was mounted on pier 4, with an upstream view. The operation of the cameras was identical to that of the other systems. Video recording was started on 12/2004, and continued until 2006, though there were intermittent periods when the system malfunctioned due to equipment failure.

\subsubsection{Events and observations}

Event of 1/7/2005 The first major flow event of 2005, which turned out to be the largest over the study period (as noted above, estimated to be an 18-year event), started on 1/4 and ended $1 / 20$, but, due to equipment malfunction, was not recorded. Images prior to and after the malfunction, taken at times with comparable relatively low stages, are shown in Figure 4.37. Both piers 5 (the nearer) and 4 may be seen, with the still operational DebrisFree device attached to pier 5, but the non-functioning DebrisFree device on pier 4 is difficult to see. The scene before and after the event is almost identical, with surprisingly little or no evidence of any debris accumulated during the event. Pier 5 was clear of debris both before and after the event. At pier 4 , some debris though possibly not vegetative may be seen before the event, and some remnants still seem to be there after the event though somewhat less noticeable.

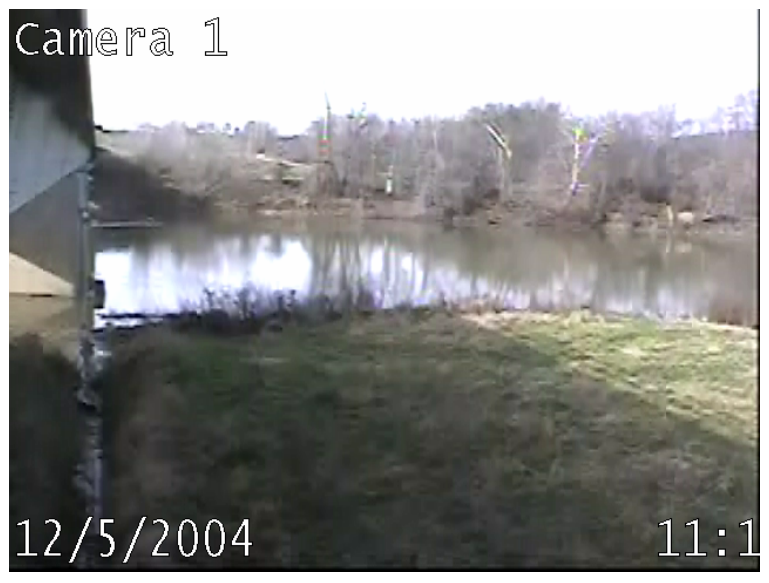

a)

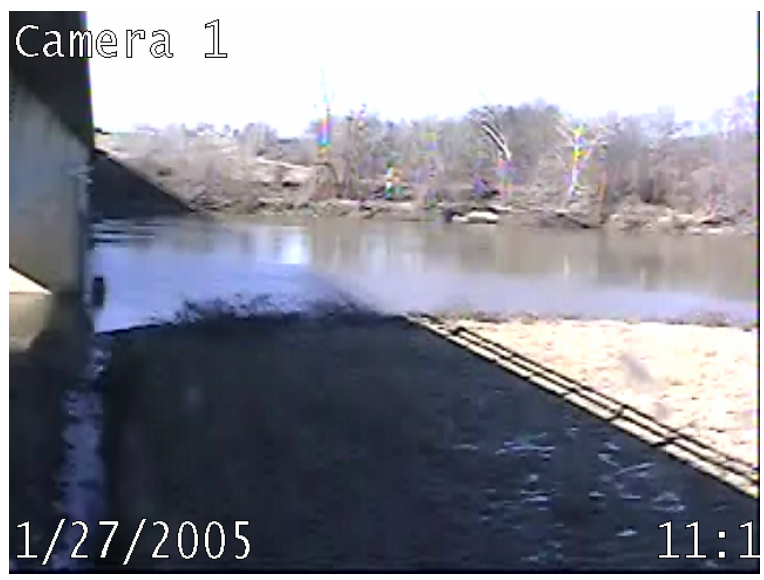

b)

Figure 4.37: Images taken before and after the large 1/2005 event 
Events between 2/1/2005 and 3/1/2006 Between the 1/2005 event and the 3/2006 event, which was the second largest during the study period, there occurred a series of much smaller events of comparable magnitude, with discharges at Newberry less than 20,000 cfs. In each of the eight events with discharges over 10,000 cfs, debris transport was quite light, compared to those seen previously at the SR59 and SR63 sites. Some transport was observed in each event, but was generally sporadic, consisting primarily of smaller debris elements. As a consequence, over the entire period of more than a year, little DA was noted.

Event of 3/14/2006 The largest recorded event at the SR157 site peaked at Spencer at 5:00 a.m. with a stage of $21.4 \mathrm{ft}$ (Figure 4.38). This compares with a stage of $25.1 \mathrm{ft}$ for the 1/7/2005 event, and stages less than $15 \mathrm{ft}$ for the preceding smaller events. Initial conditions prior to the event (3/8) are shown in Figure 4.39a and b; at this time, the stage at Spencer was recorded as $5.2 \mathrm{ft}$, i.e., over $16 \mathrm{ft}$ below the stage at flood crest. A large log or tree, which may still be directly anchored to the bank, can be seen in the upstream view. To the right, a boat ramp and bank can also be seen; at the height of the event, these will be completely submerged. Early in 2005, it was also decided to change the focus of the side camera mounted on pier 2 in order to obtain a closer view of the piers in the water (at the expense of a narrower field of view). At the low stage, a moderate-to-heavy DA is noted at pier 5, but pier 4 (with the DebrisFree device) is bare.

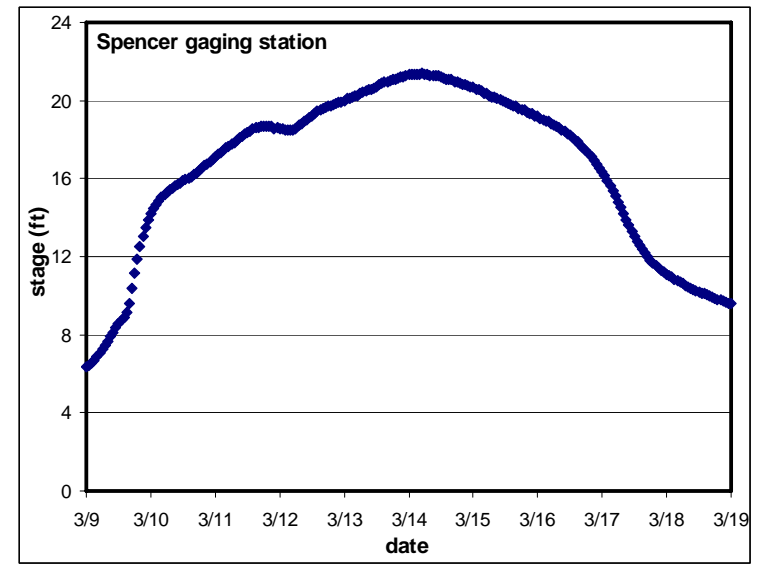

a)

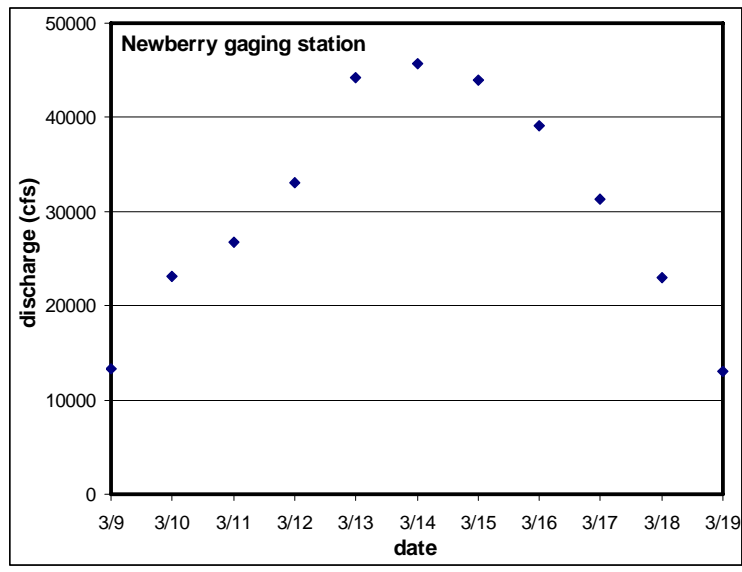

b)

Figure 4.38: a) Hourly stage time series at the Spencer gaging station, b) daily discharge time series at the Newberry gaging station

The event started on 3/9. Although smaller debris elements were observed being transported sporadically during the morning, more regular and sustained transport did not begin until the afternoon after 3:00 p.m. By 4:25 p.m (Figure 4.40a), the stage at Spencer had risen over 4 foot higher than that seen in Figure 4.36, but was still over $11 \mathrm{ft}$ less than the peak stage, which occurred over three days later. The boat ramp and bank seen in Figure 4.36 were already submerged at that time. In spite of the transport activity, there was little additional DA at the piers (Figure 4.40b) by 7:00 p.m. Transport of large debris elements was noted regularly throughout the next day (Figures 4.40c, d), but still by the following morning (3/11) at 7:00 a.m., little had changed at the piers (Figure 4.40e). There were still periods of heavy debris transport during the early morning of 3/11 (Figure 4.40f), but this was considerably reduced after 11:00 a.m. until the end of that day. Increased transport activity was noted for more than an hour during the early morning of 3/12 (Figure 4.40g). Thereafter transport became much more isolated and sporadic, but large logs could still be seen (Figure 4.40h, i) on both 3/13 and 3/14, the latter being close to 


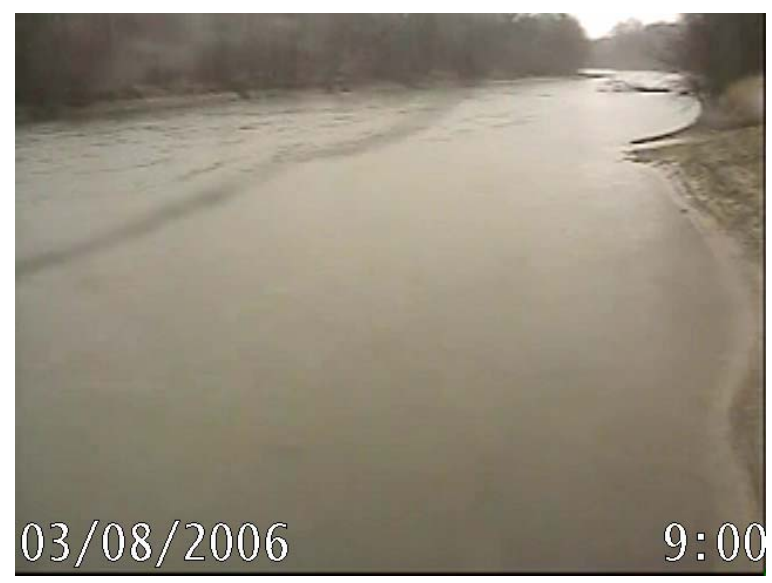

a)

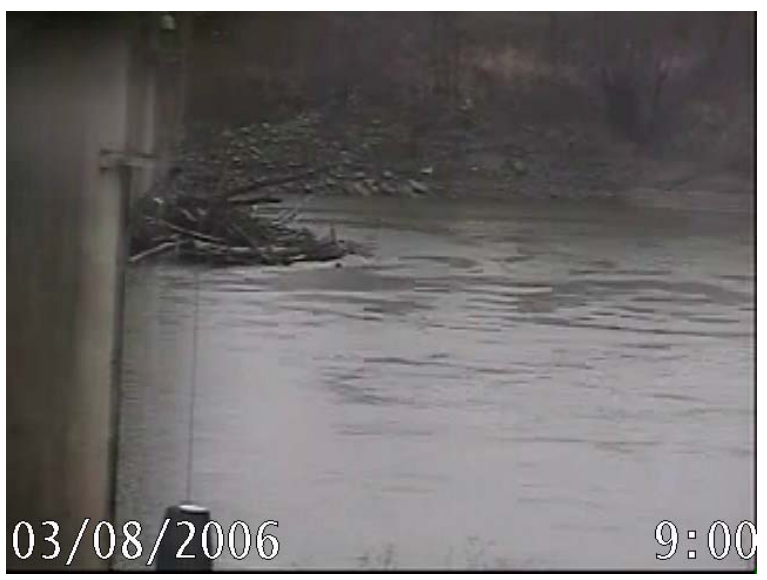

b)

Figure 4.39 Images prior to the event of 3/14/2006

the peak of the flow event. Images of the pier region near the event peak (Figure 4.40j) and well after the peak (Figure 4.40k on 3/20), with the river at low stage, indicate little noticeable change in DA, and even some possible decrease in DA at pier 5. The large log initially upstream was washed downstream during the event and is no longer seen (Figure 4.401).

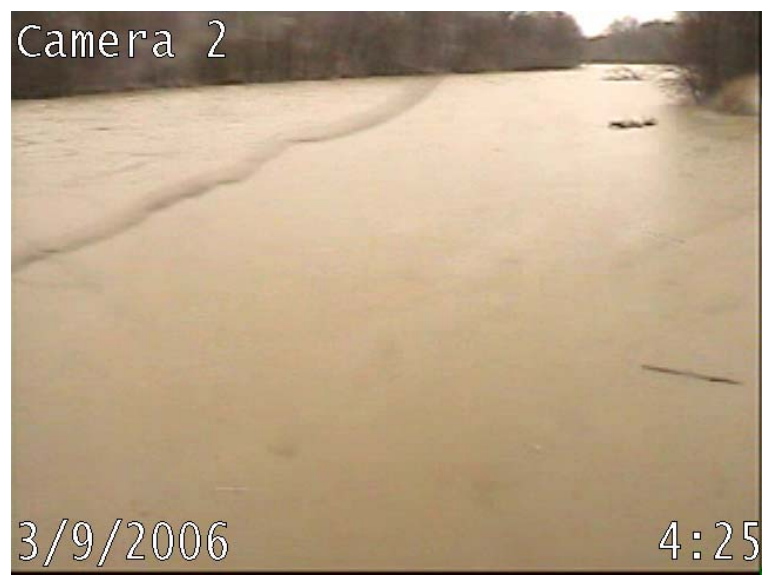

a)

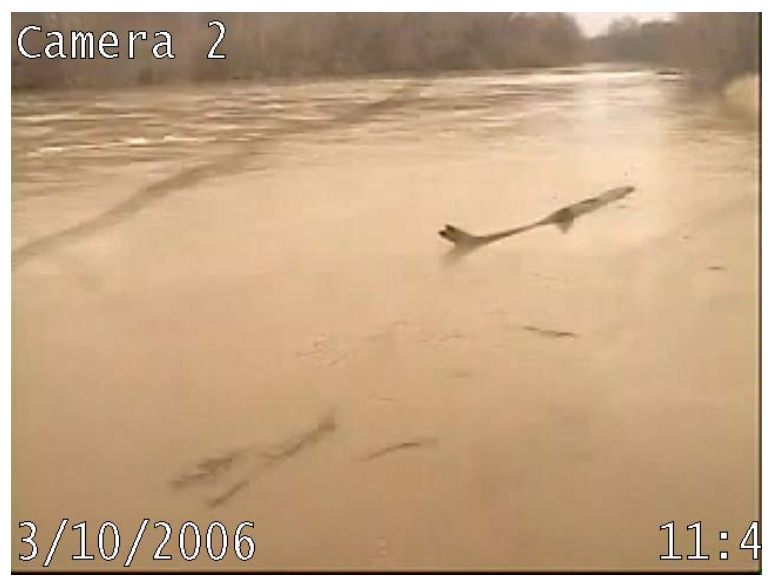

c)

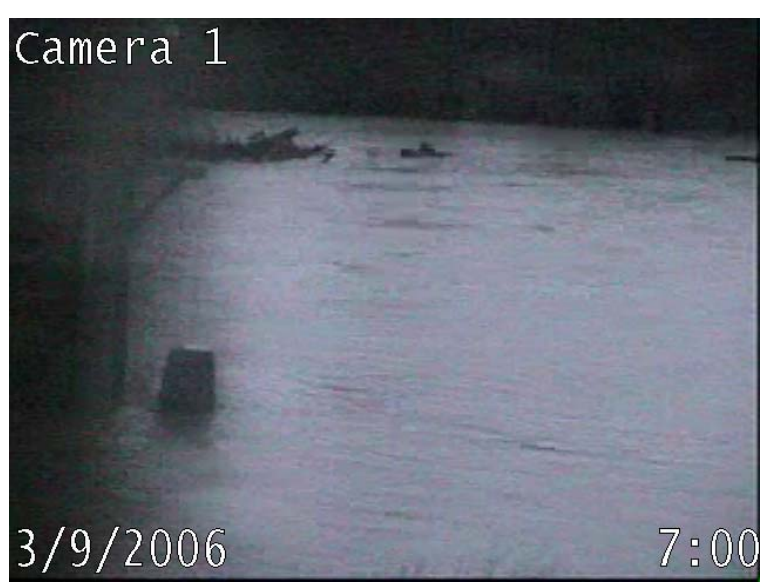

b)

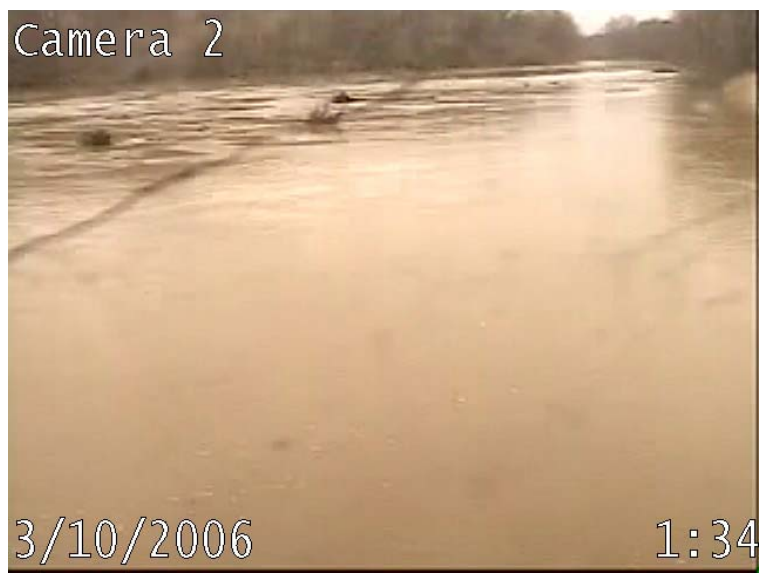

d)

Figure 4.40: Images from the 3/14/2006 event 


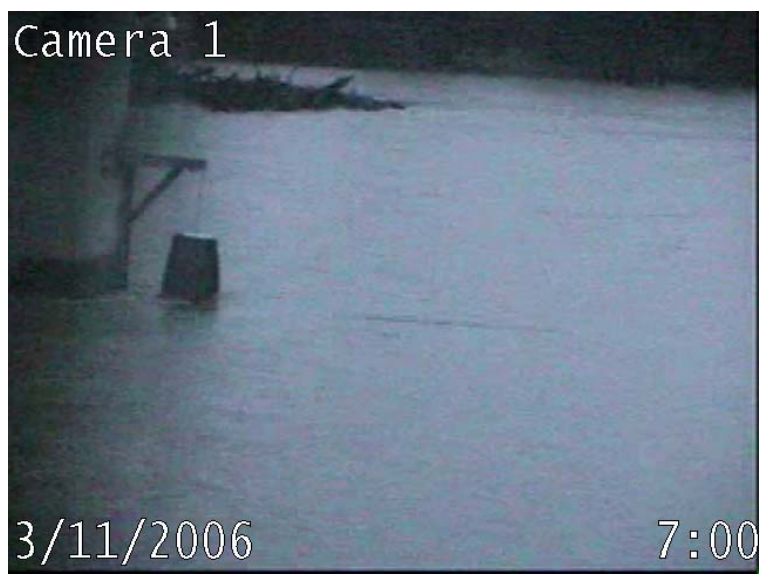

e)

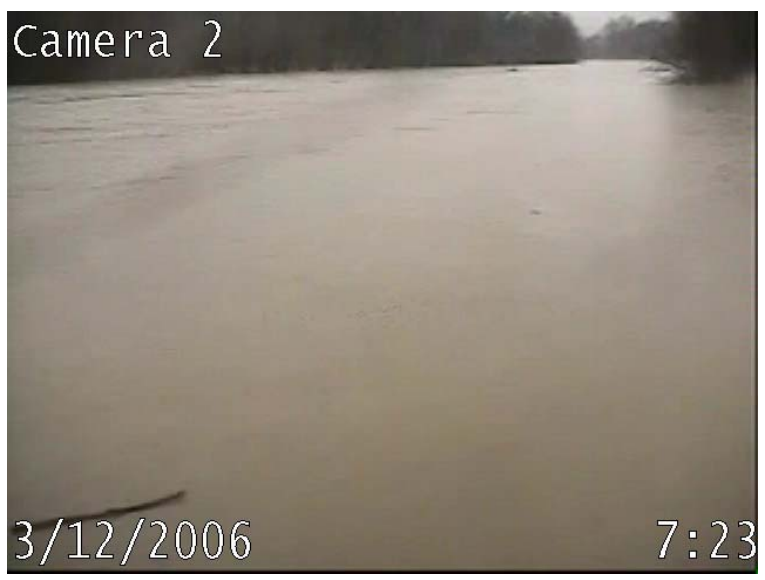

g)

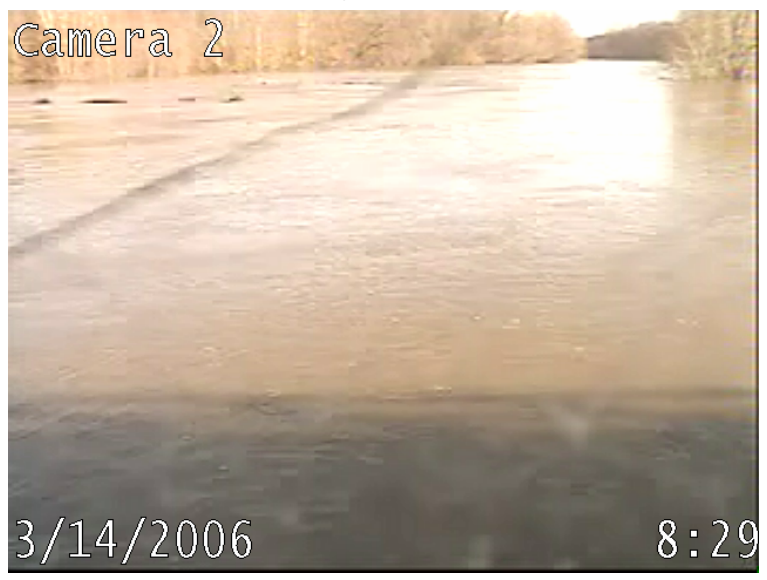

i)

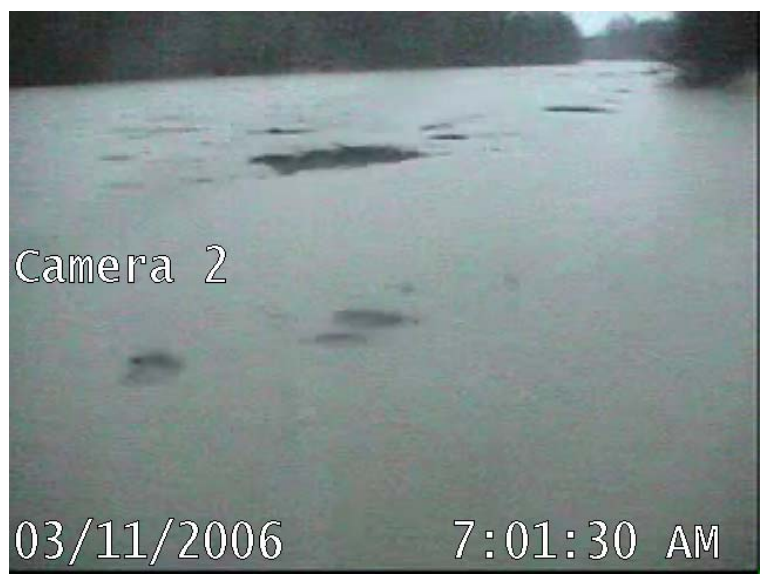

f)

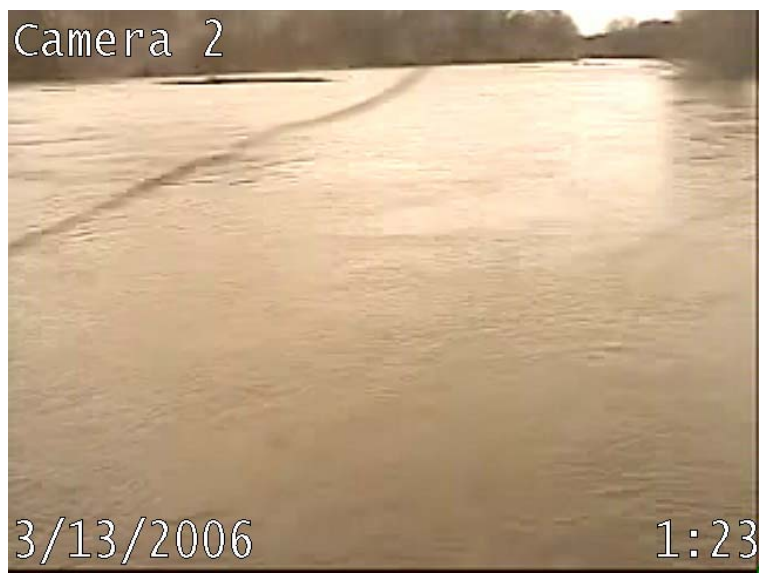

h)

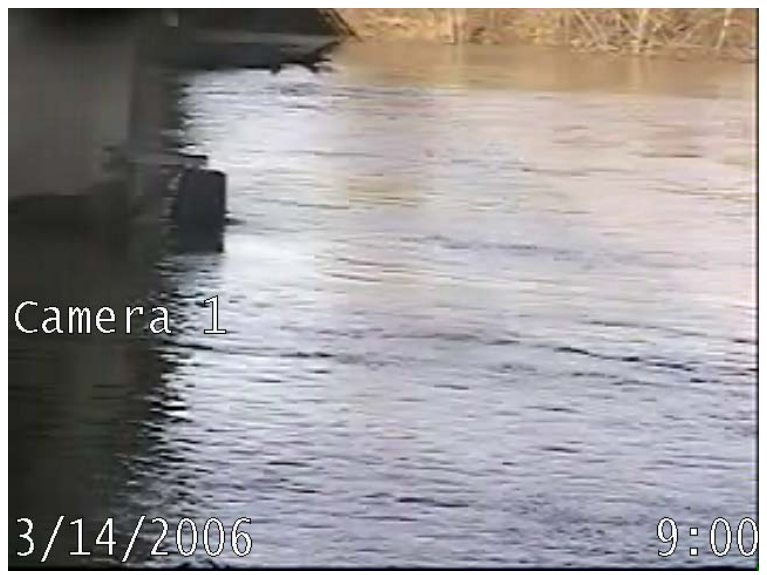

j)

Figure 4.40: Images from the 3/14/2006 event (contd.)

It would be tempting to attribute the absence of debris at pier 4 to the correct functioning of the debris deflector. In at least one respect, it functioned as designed, namely, it did rise with the stage. At the top of its travel near the event peak, it may have been entirely submerged during the earlier event of 1/5/2005 when the stage was likely to have been a few feet higher. It was was also intended to rotate under the action of the flowing water. Examination of the video images did not show any significant continuous rotation. In spite of the sometimes quite heavy 


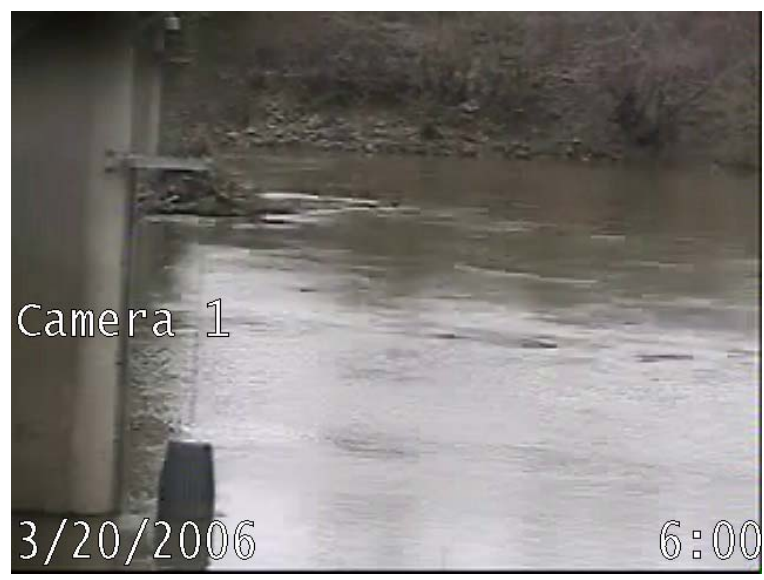

k)

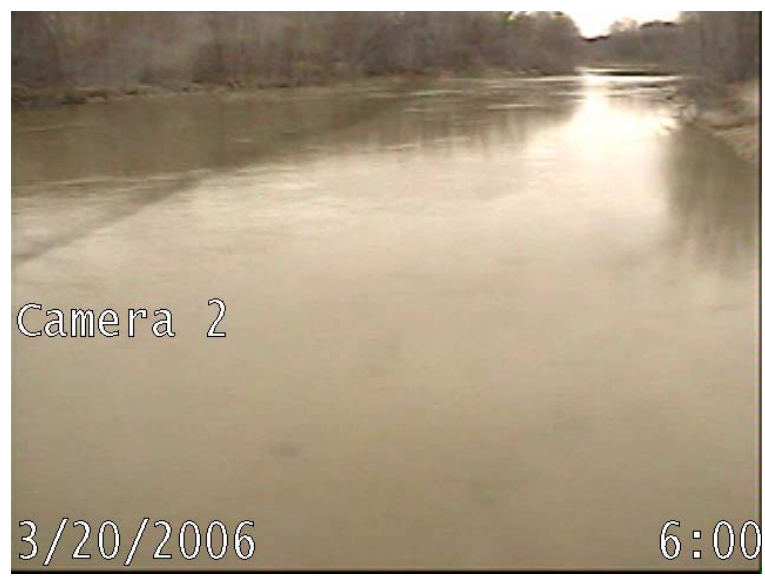

l)

Figure 4.40: Images from the 3/14/2006 event contd.

debris transport, there did not seem to be any direct hit with a larger debris element, and so whether it would have functioned as designed could not be directly verified from the recorded video images. The absence of debris at pier 4 is therefore likely due to the pier not suffering any direct hit, and not necessarily to the functioning of the DebrisFree device. This point is reinforced by the observations at pier 5, which had a non-functioning DebrisFree device installed which may even have contributed to the existing DA, but still experienced little or no additional DA.

Much of the debris passed between the two piers. Observations indicate that the debris did not make any abrupt changes in direction such as would have happened if the debris followed the thalweg drawn in Figure 4.35. Two factors may influence the debris paths: the upstream bends and the confluence with the Eel River. The sharp bend just upstream of the confluence would tend to concentrate the debris towards the right (looking downstream) side of the river. If the discharge of the Eel River were sufficiently large, however, it would have a counteracting influence, increasing mixing across the channel, and possibly even directing the debris towards the left side of the river. This would also have been reinforced by the milder bend just upstream of the bridge crossing. The end effect was then a more uniform lateral distribution of debris, with perhaps a small bias to the side closer to pier 4. As such, the long span length between piers contributed to the lack of additional DA.

Event of 4/8/2006 The last event that was examined occurred in 4/2006. An interesting aspect of the flow time series is the mismatch in peaks, pointing to possible varying influence of the Eel River (Figure 4.41). At the Spencer gaging station upstream on the White River, the highest stage was reached on $4 / 19$, while at the downstream Newberry station, the largest discharge was attained on 4/8 - the difference presumably being due to the inflow from the Eel River.

Only during the $4 / 8$ event was there any significant debris transport observed. A large log was noted in the stream late afternoon on 4/6 (Figure 4.42a), but the next morning there was mostly smaller debris was seen. An intense cluster (Figure 4.42b, c) was recorded later in the afternoon, but thereafter transport of larger debris elements became sporadic and isolated. As in the previous events, there was little or no lasting DA at the piers as seen in Figure 4.42d, taken during the immediately following low-stage period. 


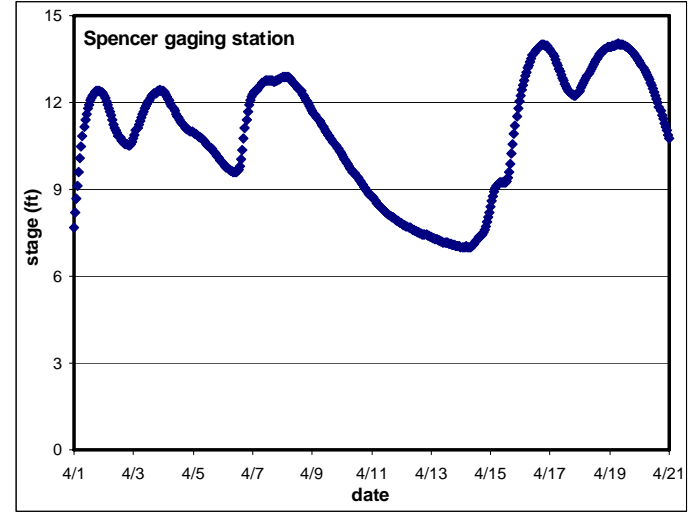

a)

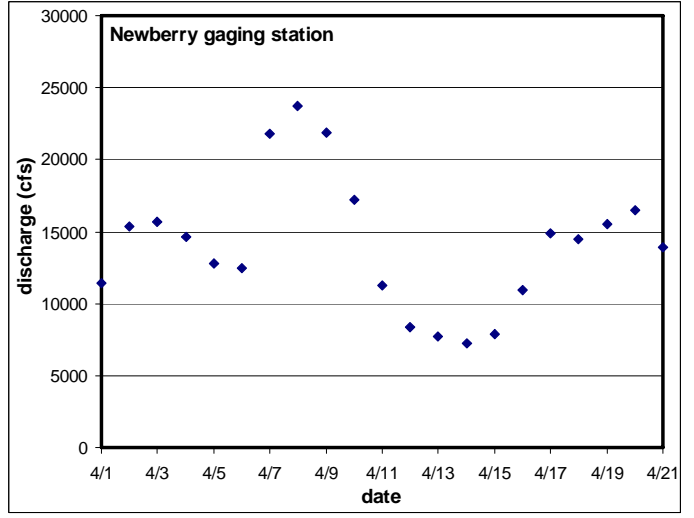

b)

Figure 4.41: a) Stage time series at Spencer, b) Discharge time series at Newberry

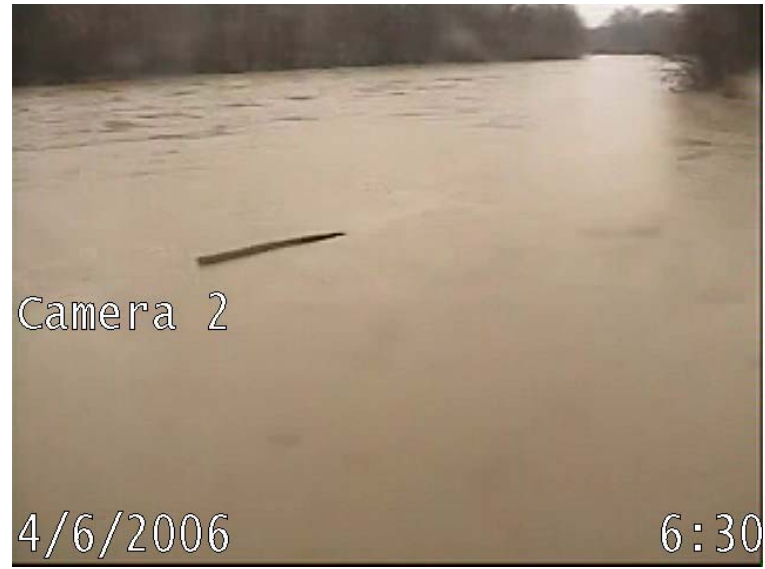

a)

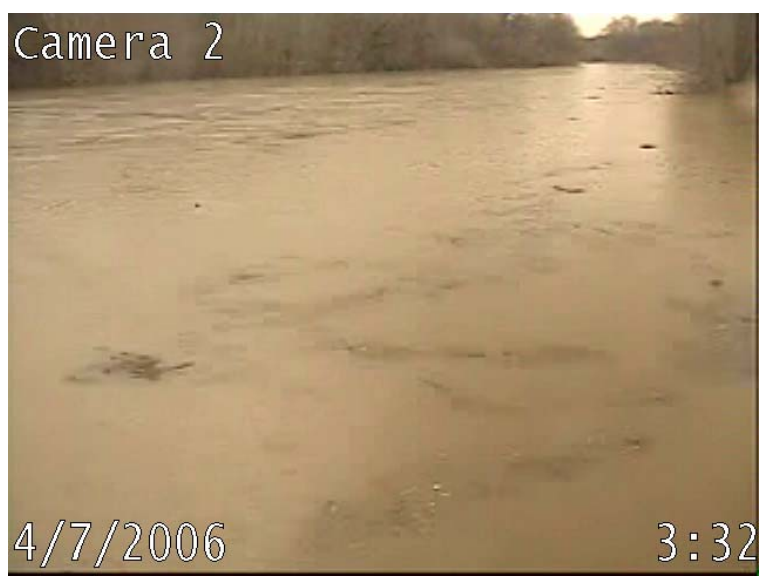

c)

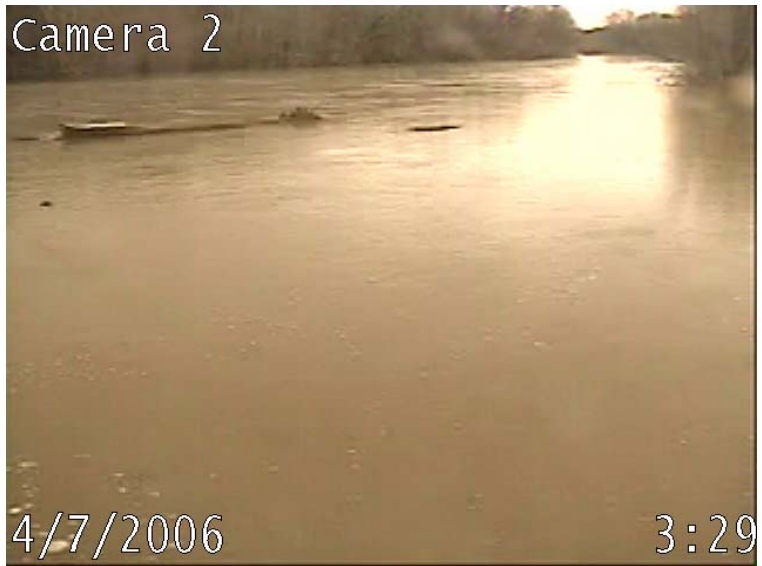

b)

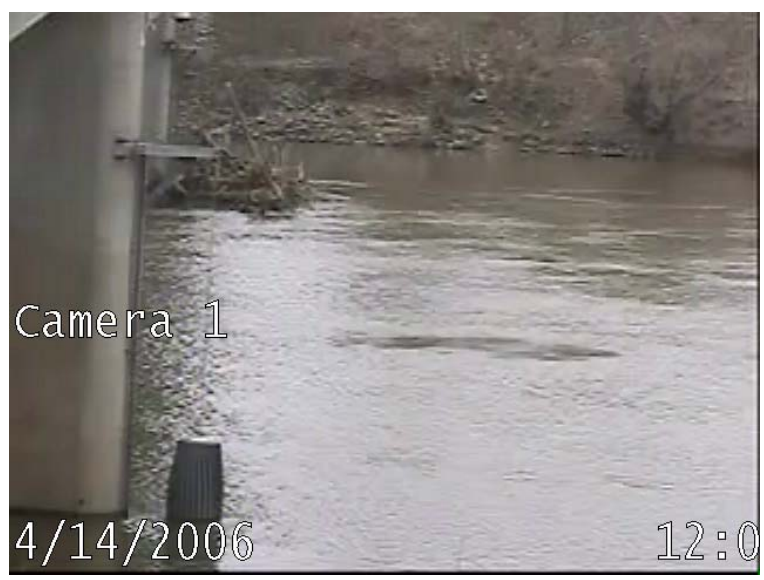

d)

Figure 4.42: Images from the 4/8/2006 event

\subsection{Further discussion}

Time development of flow and debris transport Regular sustained transport of larger debris elements can begin quite early in the flow event, well before the peak, at a discharge substant- 
ially smaller than the mean annual maximum discharge. During larger events, there may be periods of noticeably more intense transport activity, termed clusters above, which may enhance the probability of debris pile formation and accumulation. The occurrence of these clusters suggests that they may result from mobilization of upstream debris piles, possibly at upstream bridge crossings or on the banks. This is supported by the observations of spontaneous destabilization of existing DA, including particularly dramatic examples at the SR59 site, during a highflow event. For extended large events, in which the time to peak stage or discharge exceeds 24 hours, transport activity may be reduced substantially, becoming almost negligible, well before the event peak is reached. This would imply that the large bulk of the debris reaching a site originates relatively close to the site rather than from the more remote regions of the watershed which contribute to the flow but not necessarily to the debris. At more remote watershed sections, flow conditions, such as velocity and depth, being smaller, are less likely to be conducive to debris transport, and even if debris transport is initiated, there is a greater probability for the debris to be trapped at some upstream point because of the longer travel length.

The flow velocity or discharge, although it must be important in debris mobilization, by itself would not seem to be well correlated with debris transport. Flow velocities are expected to be, near the event peak, at least as high as and likely higher than during the initial period when debris transport begins. Yet debris transport has been observed to be heaviest during the first 15 - 30 hours of the event, well before the peak is attained, and can become substantially diminished thereafter. It is also observed that transport may be much heavier at the same discharge, $Q$, during a high-flow event than a small-flow event. Thus, debris transport at a given $Q$ towards the beginning of a high-flow event may be noticeably larger than transport at the same $Q$ near the peak of a smaller event. A related issue concerns the transport during two successive high-flow events, separated by a relatively short interval, e.g., less than a month. In this case, supply limitations may play a role in that the prior event transports most or all of the available debris, such that transport is substantially reduced during the subsequent event. In some situations, supply limitation will undoubtedly play an important role, but observations at SR59 and SR63 indicate that its importance may be weaker than might be otherwise thought.

Debris trajectories and channel geometry The region of the channel section where most of the debris passes is important in determining where DA may occur. The evidence from this study for the debris generally following the thalweg is rather weak, at least as far as the thalweg defined in the most recent bridge inspection reports is concerned. It may however be that debris paths may more closely correlate with the thalweg farther upstream. At the SR59 site, debris seemed to follow more of a straight-line path from far upstream to the bridge section, and as such tended to be more concentrated towards the east of the channel at the bridge section, where also significant sediment deposition also led to formation and continual growth of a mid-stream island. In contrast, at the SR63 site, debris tended to veer away from the thalweg towards the inside of the bend, in the direction of point bar or shallow regions. This difference in behavior may be due to the larger flow expansion at high stages, when the point bar becomes submerged. This could cause surface velocities to be directed to regions where the flow has expanded. It is not clear that the bend itself, such as at SR63, had any strong influence, somewhat in contradiction to what was concluded from the study of the underwater bridge inspection reports.

The shallow areas, such as the island feature at the SR59 site or the point bar at the SR63 site do not seem to have any strong direct influence on debris trajectory. If however they are active regions of significant sediment deposition, they may point to flow patterns that are rele- 
vant to the DA problem. The possible effect of an upstream confluence with a larger river was also suggested in explaining the distribution of debris at the SR157 site. Not only might the confluence enhanced lateral mixing and so lead to a more uniform lateral debris distribution, but, depending on the relative discharges in the main river and the tributary, regions of greater debris concentration could possibly change with different events.

Debris accumulation, pier placement, and debris deflectors The DA observed during the project period at the three sites differed, with two sites experiencing very heavy, possibly even 'mega' class at the SR59 site, DA, during a single debris-transport season, but the third site experiencing little or no additional DA, in spite of there occurring at least two large flow events (only one of which was however recorded). The two sites that experienced heavy DA had pierto-pier spans of less than $70 \mathrm{ft}$, while the site that experienced little noticeable additional DA had a pier-to-pier span of $200 \mathrm{ft}$ in the central part of the stream. It is interesting to speculate to what extent a much longer pier-to-pier span would have lessened the DA at the two 'heavy-DA' sites. There is no strong evidence for and much evidence against the initial DA being due to a large log spanning two piers. This suggests that much longer spans with ill-placed piers would still suffer the same fate of heavy DA, so that longer spans by themselves will not necessarily solve the problem, unless spans can be so long that piers are no longer in the stream. Unfortunately, reliable prediction of the trajectory of the bulk of the debris cannot be based on simple rules such as 'debris will generally follow the thalweg'. Detailed information regarding the channel geometry upstream of the bridge crossing will be necessary.

In both cases of heavy DA, the DA initially developed in a shallow region, either due to an island feature (SR59) or due to a point bar on a bend (SR63). Nevertheless, the third site (SR157) also had a 'peninsula' region around pier 4, which did not seem to plan any role since there was no DA at all at pier 4. Shallow regions may therefore be conducive to trapping of debris, and may stabilize already existing DA, and may even be indicative of flow features associated with DA, but are not themselves primary determinants of debris trajectory.

The debris deflectors examined, both the simple cylindrical piles as well as the commercial DebrisFree device, did little or nothing to minimize DA at the sites. In the case of the cylindrical piles, they may have arguably made the situation worse by providing additional structures in the stream at which DA could form and grow to such an extent that they could merge with DA from other structures. The poor performance of these structures was certainly due to poor positioning, but whether a better choice could have been made is difficult to assess. The DebrisFree device installed at the SR157 site may have contributed marginally to the absence of any DA at pier 4, which however is attributed primarily to the little or no larger debris elements actually hitting the device, at least in the recorded images. At the time of this writing, the DebrisFree device has already undergone changes, and the model installed at the SR157 site may no longer be marketed.

\subsection{Summary}

The third phase of the project studied debris transport and accumulation at three specific Indiana sites via continuous video monitoring, at one site for over 30 months (two debristransport seasons), and at the other sites for about 15 months (one debris-transport season). Interest was focused on three aspects: i) the time development of debris transport during a flood and its relationship to the flow hydrograph, ii) the lateral distribution of debris trajectories at 
bridge crossings, and its relationship to local geometric features of a stream, and iii) the development of debris accumulation and the effect of debris deflectors.

For more extended larger flow events, most of the debris transport occurred during the early part of the event, and relatively little was transported near and past the event peak. Debris clusters, i.e., short periods of intense transport separated by more sporadic transport, also seemed to be characteristic of events with heavy debris transport. Debris trajectories were not closely related to thalweg location in the immediate vicinity of the bridge crossing, at least as defined by the most recent bridge inspection reports. Other local factors such as the extent of flow expansion, or the presence of an important upstream confluence may exert a stronger influence. Under appropriate conditions, very heavy DA may develop during a single large-flow event, especially if there is some, even minor, residual DA at a pier that can act as a nucleus for DA growth. For extended events, DA development may be essentially complete well before the event peak. Longer pier-to-pier span lengths will undoubtedly provide more flexibility for pier placement, but pier placement will remain important in avoiding or at least minimizing DA. Debris deflectors did not play any significant positive role at any of the sites, and, in the case of the simple cylindrical piles, may have exacerbated the problem. 


\section{Summary and recommendations for implementations}

Debris accumulation at bridge crossings in Indiana was studied using three complementary approaches: i) an examination of reports of underwater bridge inspections performed between 1993 and 2003 for over 300 bridges, ii) periodic visits with visual inspection over a period of 18 months to over 20 sites, and iii) continuous video monitoring of three sites in southwestern Indiana over a period of up to 30 months. The bridge inspection reports provide the broadest sample but provide the least direct information regarding debris transport. At the other extreme, video monitoring provide the most direct information regarding debris transport but is limited to a very small sample. The periodic site visits were designed as an intermediate solution.

\subsection{Observations}

From bridge inspection reports The main results from the study of the underwater bridge inspection reports were:

1. Approximately $20 \%$ (74 out of 370 structures) of the bridges for which underwater bridge inspections were performed were observed to have had at least one occurrence of heavy DA. The heaviest DA were generally found in southwestern Indiana in the downstream reaches of the main Indiana rivers, namely the Wabash, the White, and the East Fork White River.

2. In almost all of the bridges with heavy DA, these occurred as a single-pier accumulation, though the affected pier may be the closest to one of the river banks. Four of the six 'mega' sites, i.e., those with DA over estimated debris volumes over $1000 \mathrm{cu}$. yds., had pier-to-pier spans over 100-ft, with the longest span being 160-ft. While the concept of a design log length advanced by Diehl (1997) may provide a useful design guideline, it does not provide a ready explanation of observed DA, and following such a guideline will not ensure a debrisfree site.

3. Sites at or immediately downstream or upstream of reservoirs or lakes had few DA problems.

4. In cases where heavy DA was observed more than once at a site, the pier suffering the heaviest DA was in most cases the same. This suggests that the processes determining DA are not entirely random, but may be predictable from 'local' characteristics of the channel.

5. A strong correlation between the location of the thalweg in the immediate vicinity of the crossing and the location of the pier with the heaviest DA is not evident. The effect of even a mild bend seems stronger in that the pier closest to outer bank suffered often the heaviest DA, but there were certainly examples where the heaviest DA occurred neither near the thalweg nor close to the outer bank.

6. Although there were notable exceptions, piers very close to (say $<15$-ft from) or at the lowwater banks generally suffered little DA. While it is difficult to locate precisely the lateral region within a cross-section where the debris transport is heaviest, the pattern of observed DA in the underwater bridge inspection reports suggests that debris transport is relatively light in the regions immediately adjacent to the banks.

7. Island or peninsula features immediately upstream of a pier do seem to be associated with DA, but their precise role is subtle, possibly consisting only in reducing surface velocities or stabilizing DA. On the other hand, large islands that may affect flow patterns may direct 
debris away from piers. Shallow areas, such as bars, may also be associated with DA, though the cases where these features were prominent were not as common. Instead of directly causing DA, island and bar features may act as 'symptoms', with the processes contributing to the development of these features also contributing to the development of DA.

8. Lateral channel expansion at the bridge crossing may also play an important role in contributing to DA. An analysis of the ratio of the width at the bridge section to the width of an upstream section (typically 200 -ft upstream), both widths based on low-stage top widths, indicated that sites with a ratio greater than 1.2 had an $\approx 60 \%$ probability of an incidence of heavy DA being observed. The effect of channel expansion may lie in the overall reduction of surface velocities as well as in creating flow patterns, such as flow separation, that may be conducive to the development of DA.

From periodic site visits The main results from periodic site visits were:

1. Although there were at least two large flow events over most of the region under study, heavy DA was observed to develop during the course of the study only at some bridge crossings over smaller streams with small pier-to-pier spans, such as SR164 over the Patoka, or US27 over St. Mary's. There was little dramatic development at bridge crossings over larger rivers such as the Wabash or the White Rivers. At some of the latter sites, such as SR257 over the E. Fork White or SR39 over the White River, there were pre-existing heavy, even very heavy, DA, but these did not grow substantially during the study. This suggests that the recurrence interval for very heavy DA at bridge crossings over larger rivers, which often have larger pier-to-pier spans, may be several years rather than less than the 18 months of the study.

2. The pier with the heaviest DA, whether pre-existing or developed during the study, was generally the same as that with the heaviest DA observed in the underwater bridge inspection reports. This points again to specific local features determining the location of DA at a site.

3. Due to the general lack of large changes in DA, definite conclusions regarding a relationship between the magnitude of a flow event and the likelihood of a heavy DA occurring could not be made. A large flow event, with a recurrence interval greater than 8 years, did occur in January 2005 over most of Indiana, but did not result in any very large DA at the sites that were visited before and after the event. It should be noted that visits to some sites began after this event, including sites with heavy DA that was labeled as pre-existing, but could have resulted from this early large event.

4. At one site, the SR57 crossing of the E. Fork White River, there was evidence of a spontaneous destabilization of an existing DA, and transport downstream to a nearby railroad bridge, where a new DA was established. The possibly significant effect of upstream structures or more generally upstream debris storage on DA at downstream sites was suggested.

From continuous video monitoring The main results from continuous video monitoring at three sites were:

1. Debris transport tends to be noticeably heavier during the early rising part of the flow event. For extended events with time to peak greater than 24 hours, most of the debris is observed being transported during the first $12-18$ hours, with transport becoming much more sporadic and isolated thereafter. As a result, if a DA does develop, the dramatic-growth phase occurs during this initial period, with much more incremental, if any, growth thereafter.

2. Even this initial period of heavy debris transport was often punctuated by shorter bursts of relatively more intense activity. These so-called clusters were attributed to destabilization of 
upstream DA, such that resulting debris appeared at a downstream site as a compact group, though not necessarily bound.

3. Direct evidence of, in some cases at the SR59 site very dramatic, spontaneous destabilization of DA was recorded, supporting the hypotheses that the observed clusters are the result of such destabilization, and that upstream debris storage may play an important role in the debris transport phenomena.

4. Observations of debris trajectories indicate that thalwegs, at least those based on the limited data and as defined by simple procedures as in the underwater bridge inspection reports, are poor predictors of debris trajectories. More comprehensive and more detailed surveys, including sections much farther upstream may provide more meaningful definitions of thalwegs.

5. In the one case studied with a pronounced bend (the SR63 case), the heaviest debris transport was observed to occur over the central point-bar region, more towards the inside rather than the outside of the bend. This is quite different from the conventional view, to some extent supported by the results of the bridge inspection reports, that the the pier suffering the heaviest DA tended to be located on the outside of river bends.

6. Factors such as lateral channel expansion and upstream confluences may exert a stronger influence on debris trajectories than might be otherwise thought, and should be considered when deciding on pier placement.

7. The cylindrical pile debris deflectors were at best ineffectual and at worst might have exacerbated the DA problem by providing additional structures where debris could be trapped. The limited observations of the commercial DebrisFree device at a single site, essentially for one large flow event, cannot yield any definitive evaluation of its performance. There was no DA at the pier with the functioning device, but there was also little or no additional DA at the pier with the non-functioning device.

\subsection{Recommendations for implementation}

Many bridge crossings over larger streams in Indiana, particularly towards the southwest, can be expected to be subject to debris transport and hence potentially liable to DA. From the above results, the following recommendations with the aim of minimizing DA may be given:

1. Pier-to-pier spans should be as long as economically and practically feasible, and should certainly exceed the Diehl's design log length. Though this by itself may not eliminate DA entirely (unless it can be achieved that no pier is in the stream), it will likely reduce the probability of heavy DA.

2. Unnecessary widening of the channel at the bridge crossing site should be avoided or minimized. This might also have the added benefit of avoiding sediment deposition and development of island features, but may require post-construction 'restoration'.

3. If the above recommendations have been followed, and piers must still be placed in the stream, then the difficult problem of pier positioning must be confronted. The most important part of the problem concerns the most likely debris trajectory, but other secondary issues such as the stability of a DA once formed may need to be considered.

i. The DA patterns in the bridge inspection reports, and to a more limited extent the video recording results, indicate that the regions close to (say, within 15-ft of) the banks at low stages are least exposed to debris traffic. Alternatively, if possible, avoid the central region 
of the stream. Two piers in the water, each close to one of the banks, may be less susceptible to heavy DA than one pier in midstream. Note that this is somewhat at variance with the simple interpretation of Diehl's effective span length, which would then be the distance from the pier to the bank and hence quite small.

ii. For larger channels, it may not be feasible to avoid placing a pier in the central region of the stream. It is still recommended that a pier be placed close to the outer bank. In this case, the following may serve as very crude guidelines for placing the remaining piers:

a. If the crossing is part of a mild bend, without any pronounced bar formation on the inside of the bend, the remaining piers should be placed as far as practicable towards the inside of the bend. Notable high points in the sections, especially if quite localized, i.e., island features, should be avoided

b. If a pronounced bar formation is present on the inside of the bend, then more care may be needed in placing the pier next to the pier close to the outer bank. At the SR63 site (see also the DA pattern at SR163 - Wabash R. and SR45 - E. Fork White R. sites), where such a pronounced bar was present, the heaviest transport and hence the heaviest DA were observed to occur in the region of the bar closest to the outer bank, immediately adjacent to the thalweg region. If it is not possible to avoid this region because pier-to-pier spans cannot be made longer, then the alternative of using shorter spans and moving the pier into the thalweg region might be considered. The empirical basis for this recommendation is at the moment not strong, and the recommendation should be considered very tentative. On the other hand, the empirical basis for believing this central bar region to be problematic as far as DA is concerned seems well founded.

c. Nearby upstream confluences may cause variation in patterns of debris transport and the lateral distribution of debris discharge, depending on the relative importance of the discharges. Because of this, and because such confluences are expected to increase lateral mixing, and therefore lead to a more homogeneous lateral distribution of debris discharge, local regions of especially heavy debris concentration cannot be easily designated, and so the procedure of ii a) is recommended. 


\section{References}

1. Brice, J. C., Blodgett, J. C., Carpenter, P. J., Cook, M. F., Craig, G. S., Jr., Eckardt, D. A., Hines, M. S., Lindskov, K. L., Moore, D. O., Parker, R. S., Scott, A. G., and Wilson, K. V. (1978). Countermeasures for hydraulic problems at bridges, vols. 1 and 2, Washington, D. C., FHWA-RD-78-162 and FHWA-RD-78-163.

2. Bradley, J. B., Richards, D. L., and Bahner, C. D. (2005). Debris control structures Evaluation and Countermeasures, Hydraulic Engineering Circular 9, FHWA-IF-040-016 HEC-9, $3^{\text {rd }}$ ed., U. S. Dept. of Transportation, Federal Highway Administration, Washington, D. C.

3. Chang, F. F. M. and Shen, H. W. (1979). Debris Problems in the River Environment, FHWA-RD-79-62.

4. Diehl, T. H. (1997). Potential Drift Accumulation at Bridges, FHWA-RD-97-028.

5. Diehl, T. H. and Bryant, B. A. (1993). Supply of Large Woody Debris in a Stream Channel, Hydraulic Engineering '93, Proc. 1993 ASCE National Conf., San Francisco, July 25-30, pp. 1055-1060. 